Portland State University

PDXScholar

Fall 11-19-2019

\title{
Experiences of Early Childhood Educators Working with Teaching Strategies GOLD®: A Narrative Inquiry
}

Sarah Kathryn Guyon

Portland State University

Follow this and additional works at: https://pdxscholar.library.pdx.edu/open_access_etds

Part of the Curriculum and Instruction Commons, and the Early Childhood Education Commons Let us know how access to this document benefits you.

\section{Recommended Citation}

Guyon, Sarah Kathryn, "Experiences of Early Childhood Educators Working with Teaching Strategies GOLD®: A Narrative Inquiry" (2019). Dissertations and Theses. Paper 5336.

https://doi.org/10.15760/etd.7209

This Dissertation is brought to you for free and open access. It has been accepted for inclusion in Dissertations and Theses by an authorized administrator of PDXScholar. Please contact us if we can make this document more accessible: pdxscholar@pdx.edu. 
Experiences of Early Childhood Educators Working with Teaching Strategies GOLD®:

\author{
A Narrative Inquiry \\ by \\ Sarah Kathryn Guyon \\ A dissertation submitted in partial fulfillment of the \\ requirements for the degree of \\ Doctor of Education \\ in \\ Education Leadership: Curriculum and Instruction
}

Dissertation Committee:

William Parnell, Chair

John Nimmo

Ingrid Anderson

Jana Meinhold

Portland State University

2019 
(C) 2019 Sarah Kathryn Guyon 


\begin{abstract}
Research regarding the effects of positive early childhood experiences on long term learning and success is drawing more attention to early childhood education programs than ever before. Promises on the federal and state level of better pay for early childhood educators and 'high quality' publicly funded early childhood education programs is an exciting and long-awaited vision by both families and early childhood educators. However, with federal and state funding comes the need for justification of those funds through different measurement structures. One of the widely used measurement structures is the Teaching Strategies GOLD® preformatted, portfolio style assessment system. Teaching Strategies GOLD® is an assessment system in which early childhood educators enter observations and documentation of children's work and connect them to 38 pre-established, generic learning objectives to track children's learning and development.

The implementation of assessment systems such as Teaching Strategies GOLD® follows the Department of Education's continuing aspiration of consistency and fidelity in publicly funded schools and education programs. There is considerable research that supports the use of the Teaching Strategies GOLD® assessment system as a valid and consistent way to rate young children's growth and development. Yet there is a significant absence of the voices of the early childhood educators that are required by their place of practice to use the Teaching Strategies GOLD® assessment system. In this research, I explored the experiences of self-identified constructivist early childhood educators who are required by their place of practice to use the Teaching Strategies
\end{abstract}


GOLD ${ }^{\circledR}$ assessment system through the use of narrative inquiry, by giving these early childhood educators a chance to share their experiences in working with this system.

Data and findings included a series of interactions including interviews, and reflective conversations with the three participants as well as an observation completed in their workspace. Data was interpreted using Clandinin and Connelly's (2000) three commonplaces of narrative inquiry; the temporal commonplace, the sociality commonplace and the place commonplace. Conclusions drawn from this research indicated that practicing the Teaching Strategies GOLD® assessment system in early childhood programs can have a problematic impact on some of the ways in which selfidentified constructivist early childhood educators worked with young children. These effects were most strongly noted during times in which Teaching Strategies GOLD® checkpoint dates were approaching for the educators. Additional conclusions signified that using Teaching Strategies GOLD® in early childhood programs affected the professional development opportunities offered by the programs. The professional development opportunities became centered on the use of Teaching Strategies GOLD®. Issues arose with early childhood educators' perceptions of themselves as professionals. 


\section{Acknowledgements}

This work would not have been possible without the support and guidance of many individuals along the way. I am deeply grateful to my Dissertation Chair, Dr. Will Parnell. As I walked into the forest of this research, Will let me forge my own path without letting me get caught in the bogs or fall off any cliffs. Each time I started to get lost, he gently reminded me of my true beliefs by asking simple, direct questions. He trusted my insight, encouraged my process, and helped me sharpen my machete to clear out the undergrowth and find my pathway out of the forest. Thank you Will, for your guidance and humor through this process.

I would also like to acknowledge the support of my Dissertation Committee, Dr. Ingrid Anderson, Dr. John Nimmo, and Dr. Jana Meinhold. I am grateful for their feedback during my proposal that helped me to develop a methodological system that amplified the voices of the participants. I would especially like to thank Dr. Ingrid Anderson who helped me find the right blend of research systems to support this work. Ingrid has been both a mentor and good friend as I begin my academic career. Thank you, Ingrid, for taking me under your wing, giving me access to so many new opportunities, and for being my friend.

I am grateful for the participants in this research study. Your dedication to the research process, honesty, enthusiasm, and bravery are what made the implications of this study authentic and valuable. Thank you for your time and for sharing your experiences with me. You have been heard and you are valued.

Additionally, I would like to thank my teammates in the classroom for the 
majority of completing this dissertation, Becky Huber and Emily Bennet. I am so grateful for your flexibility with your work schedules, your enthusiasm for my studies, and your willingness to grow and learn alongside me. I am honored to consider you as friends. You are both wonderful early childhood education professionals, and I became a better teacher, student, and human in the time we worked together.

I am grateful to the support I received from the families and children in my classroom as I started, designed, and completed this dissertation. Being with your children each day filled me with energy and joy. Your constant curiosity about my work and your encouragement helped me to stay focused on what was important and stay positive throughout the process.

Nobody has been more important to me in the pursuit of this project than the members of my family. I would like to thank my father for always asking how it was going and keeping my feet to the fire and thank my mother who showed me through both words and actions that you are never too old to return to school or pursue your dreams. Mom, you were and are an inspiration to me. I would like to acknowledge the support of my older brother Wade, who understood the sometimes overwhelming consequences of thinking too much and helped me keep my sense of humor. I would also like to acknowledge the influence of my late younger brother Sam, whose kindness and respect for his children helped me to see children in a different and authentic way than I had before.

Most importantly, I would like to thank my husband Matt for all of his encouragement and support. You believed in me when I barely believed in myself. You 
were always understanding in regard to my homework or research filled weekends and when I brought my laptop on our vacations. You have been my constant cheerleader, my port in the storm, and my sometimes-begrudging editor. Thank you so much for always having my back, I could not have become the person I am today without your love and support. 
Table of Contents

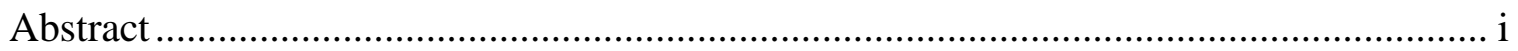

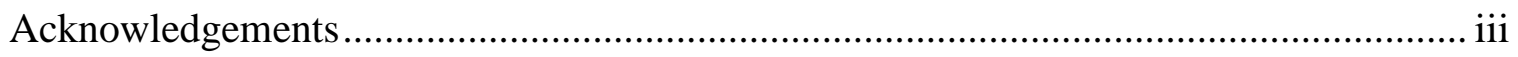

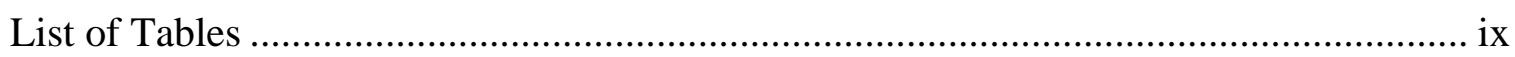

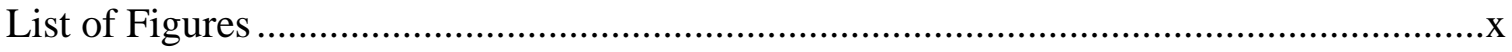

Definitions of Key Terms and Concepts......................................................................

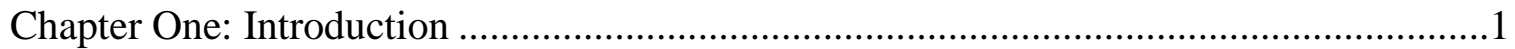

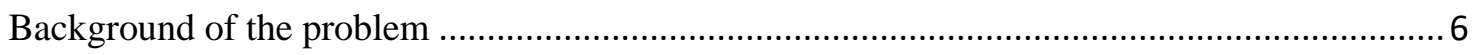

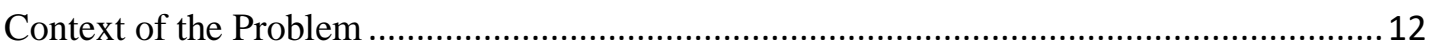

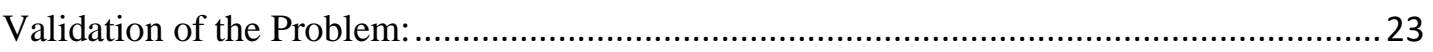

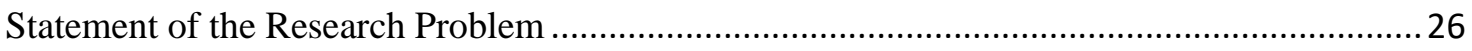

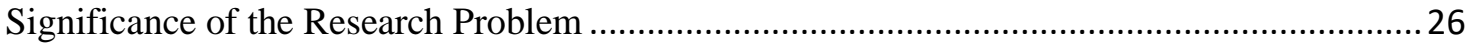

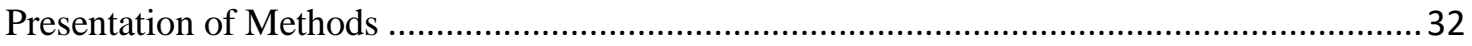

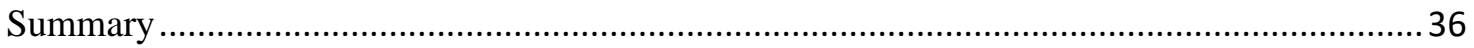

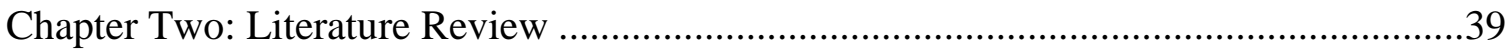

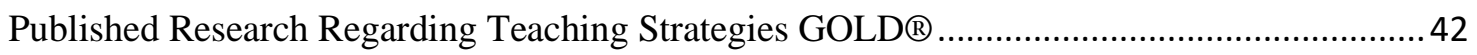

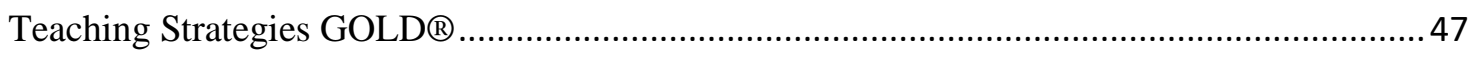

Documenting and assessing children's experiences in Teaching Strategies GOLD®_..........52

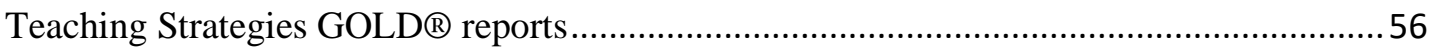

Sharing information with families through Teaching Strategies GOLD® ...........................58

Notions and Enactments of Standardization Early Childhood Education in Policy and Practice

Perceptions of early childhood educators in the midst of United States early education policy

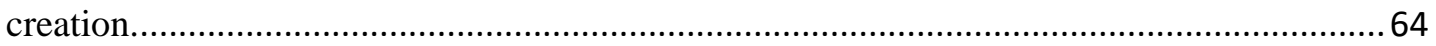

Pedagogical Documentation as a Learning Process: An Innovative Way to Assessment. ........70

Constructivism as a Teaching, Learning, and Research Theory ….......................................... 80

The self-identified constructivist early childhood educator................................................. 86

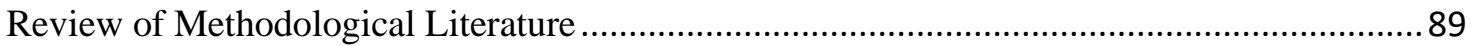

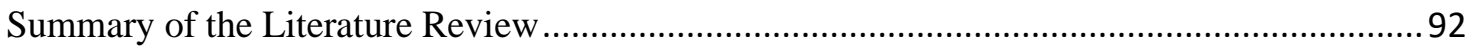

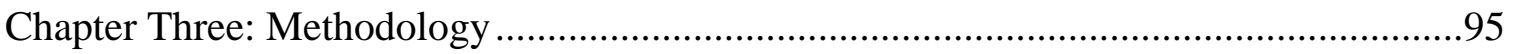

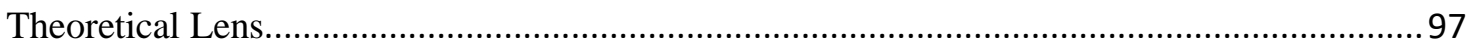




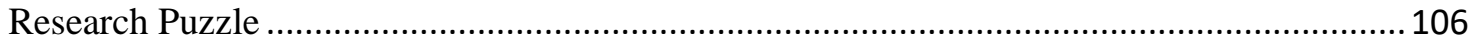

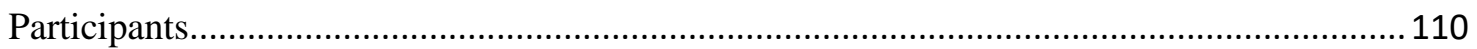

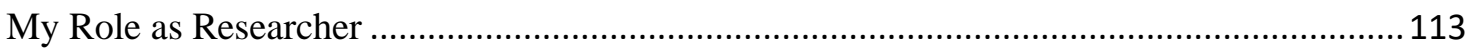

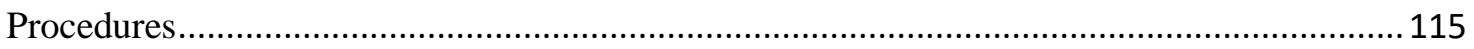

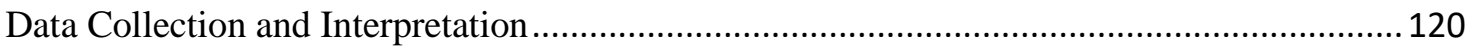

Data collection instruments and interpretations during research. ...................................128

Data interpretation at the completion of data collection: Three-dimensional narrative inquiry

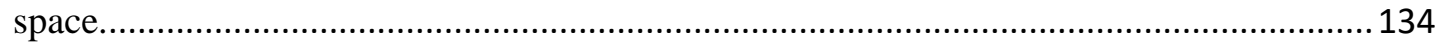

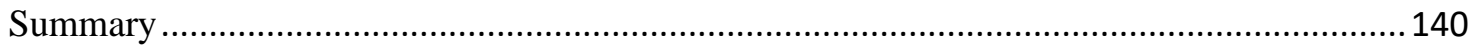

Chapter Four: Data Presentation and Interpretation ............................................. 142

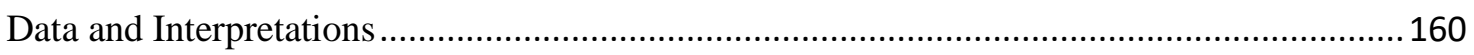

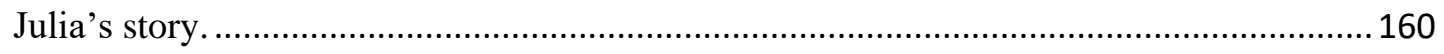

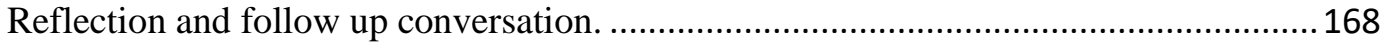

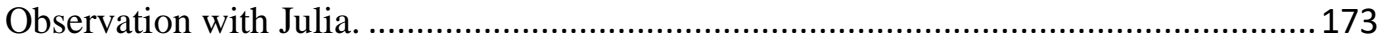

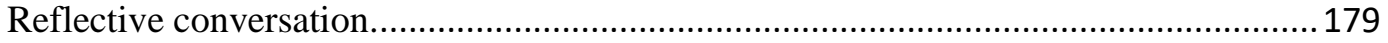

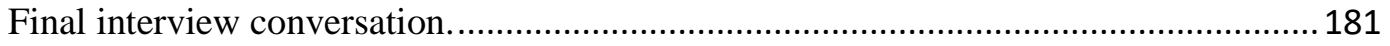

Julia - Sorting out the puzzle pieces and final reflection. .......................................... 185

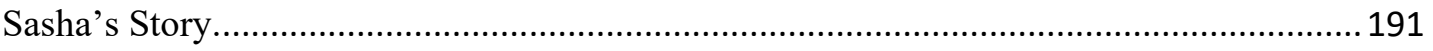

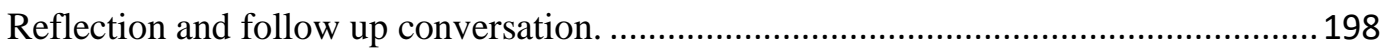

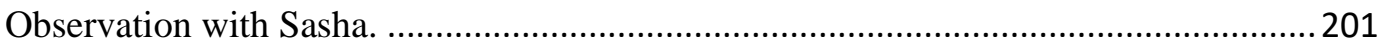

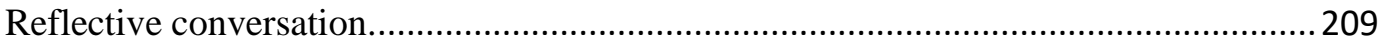

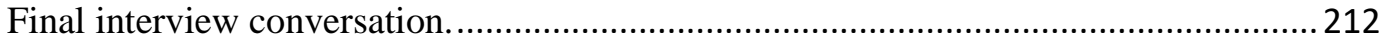

Sasha - Sorting out the puzzle pieces and final reflection............................................215

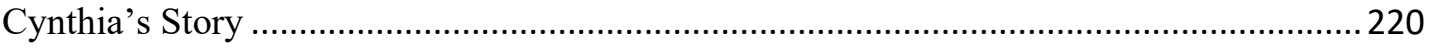

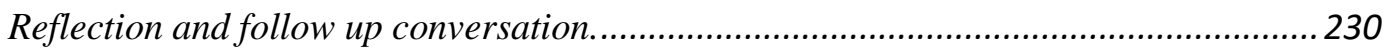

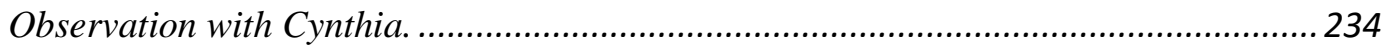

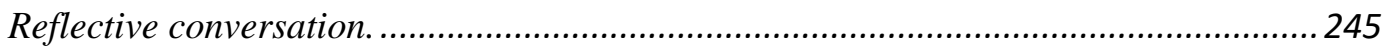

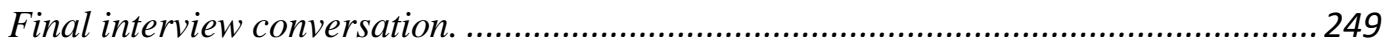

Cynthia - Sorting out the puzzle pieces and final reflection.........................................254

Interpretation of Findings: Fitting the Puzzle Pieces Together............................................ 260

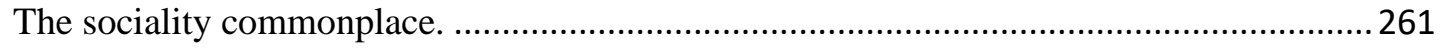

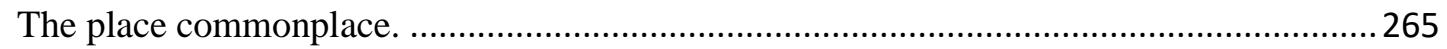


The temporal commonplace.

Reflections

Give in or get out.

The disconnection between Teaching Strategies GOLD® and the work the participants' found valuable.

Ways in which the participants found Teaching Strategies GOLD® helpful.

Chapter Five: Discussions and Conclusions

The participants work with children and what they deemed as valuable.

How working with Teaching Strategies GOLD® affected the ways in which the participants worked with children.

The effects of Teaching Strategies GOLD ${ }^{\circledR}$ on the participants' perception of their professional self.

The ways in which Teaching Strategies GOLD® supported the work of the participants. .295

Connecting the Puzzle Pieces

Rethinking a Reductionist View of Assessment in Early Childhood Education 302

Final Thoughts and Future Research Interests 309

References: .312

Appendix A: Introduction Email .329

Appendix B: Participant Screening Questions. .330

Appendix C: Congratulations Email

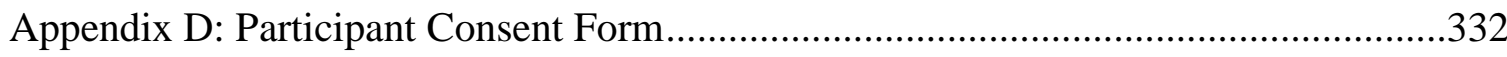

Appendix E: Participant Contact Sheet..................................................................335

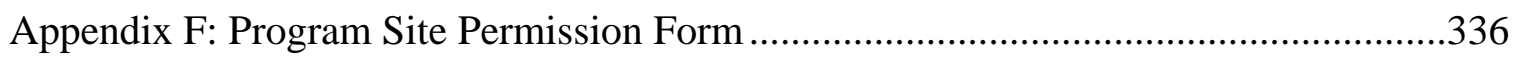

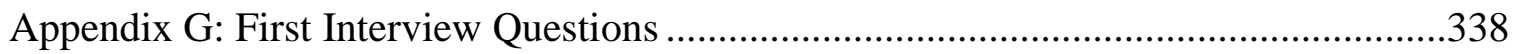

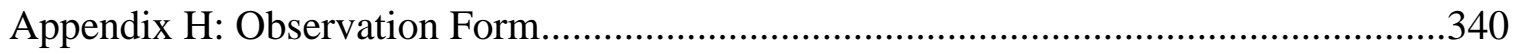

Appendix I: Sample Second Interview Questions ..................................................341

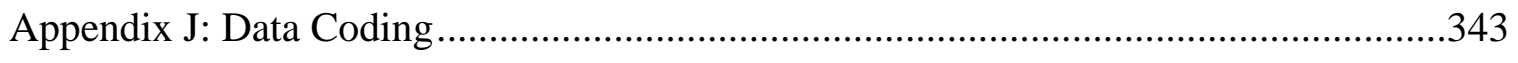

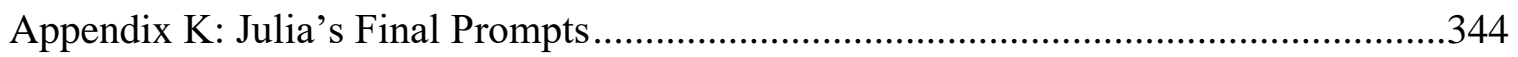

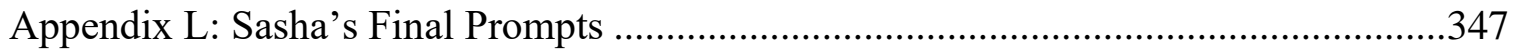

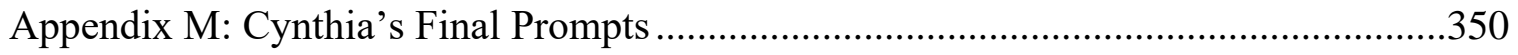




\section{List of Tables}

Table

Page

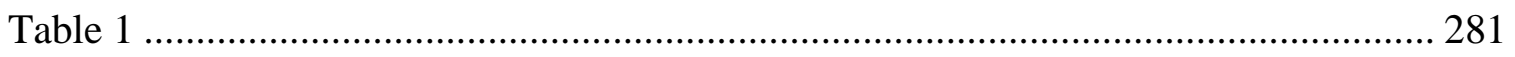




\section{List of Figures}

Figure

Page

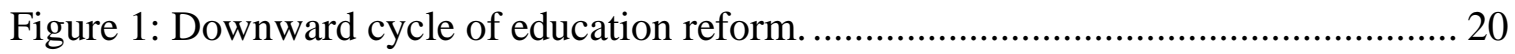

Figure 2: Guyon's cycle for collaborative narrative inquiry. ..................................... 35

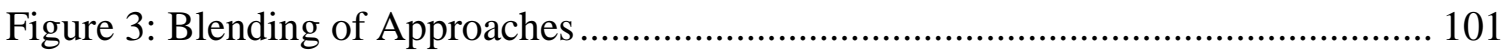

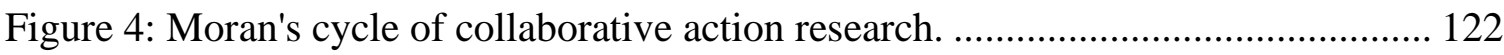

Figure 5: Guyon's cycle for collaborative narrative inquiry. .................................... 124

Figure 6: Clandinin and Connelly's Three Commonplaces. ......................................... 136

Figure 7: Guyon's cycle for collaborative narrative inquiry..................................... 142

Figure 8: Guyon's cycle for collaborative narrative inquiry, step one. ........................ 145

Figure 9: Guyon's cycle for collaborative narrative inquiry, step two........................ 147

Figure 10: Guyon's cycle for collaborative narrative inquiry, step three. ..................... 148

Figure 11: Guyon's cycle for collaborative narrative inquiry, step four ....................... 149

Figure 12: Guyon's cycle for collaborative narrative inquiry, step five....................... 150

Figure 13: Guyon's cycle for collaborative narrative inquiry, step six. ....................... 152

Figure 14: Participant 1, consistencies and inconsistencies....................................... 154

Figure 15: Participant 2, consistencies and inconsistencies......................................... 154

Figure 16: Participant 3, consistencies and inconsistencies...................................... 155

Figure 17: Guyon's cycle for collaborative narrative inquiry, final interview preparation.

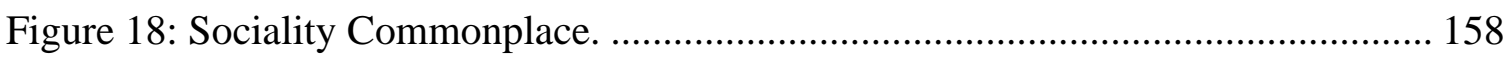

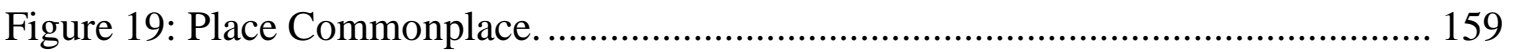

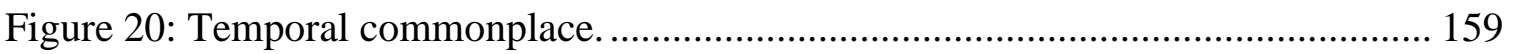

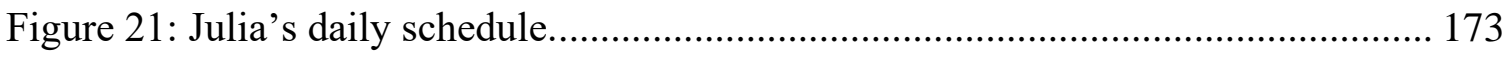

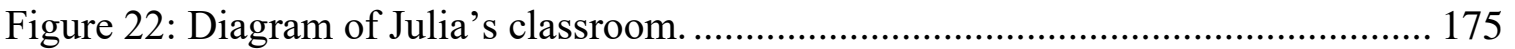

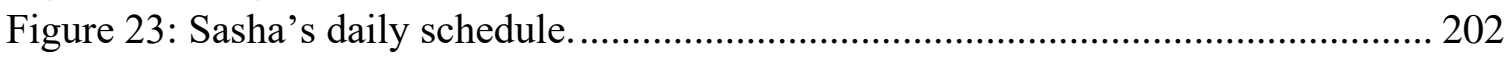

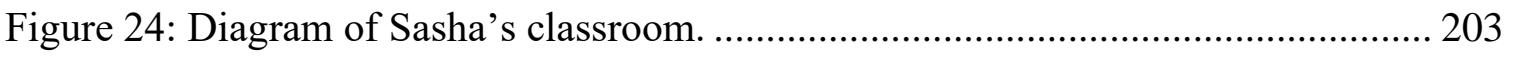

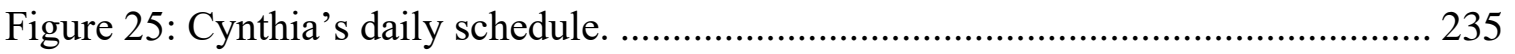

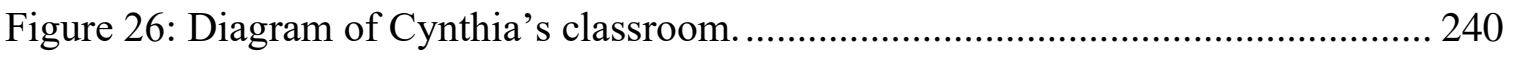

Figure 27: Cycle for completing Teaching Strategies GOLD®. ................................... 288

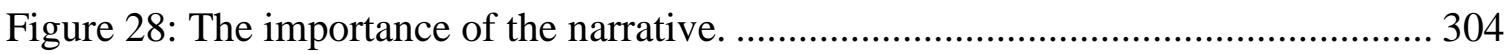




\section{Definitions of Key Terms and Concepts}

\begin{tabular}{|c|c|}
\hline $\begin{array}{l}\text { Academically based } \\
\text { curriculum }\end{array}$ & $\begin{array}{l}\text { Curriculum based on building academic skills through } \\
\text { direct instruction and rote memorization. }\end{array}$ \\
\hline A Nation at Risk & $\begin{array}{l}1983 \text { United States' Department of Education report } \\
\text { calling for education reform. }\end{array}$ \\
\hline $\begin{array}{l}\text { Child Behavior Rating } \\
\text { Scale }\end{array}$ & $\begin{array}{l}\text { Tool used to measure early childhood educator perceptions } \\
\text { of students' self-regulation and interpersonal skills as part } \\
\text { of the OKA. }\end{array}$ \\
\hline $\begin{array}{l}\text { Common Core State } \\
\text { Standards }\end{array}$ & $\begin{array}{l}\text { Standards for K-12 education that have been deemed as } \\
\text { essential for helping children become collage and career } \\
\text { ready upon graduation. Set and adopted by states } \\
\text { beginning in } 2009 \text {. }\end{array}$ \\
\hline Constructivism & $\begin{array}{l}\text { Learning theory that children are able to construct } \\
\text { knowledge about the physical and social world by } \\
\text { connecting their own ideas and understandings in different } \\
\text { interactions and experiences. }\end{array}$ \\
\hline $\begin{array}{l}\text { Early Education for All } \\
\text { Americans Act }\end{array}$ & $\begin{array}{l}\text { Federal and state partnership proposed by President } \\
\text { Obama in } 2013 \text { to provide high-quality preschools for all } \\
\text { 4-year old children of low and moderate income families. }\end{array}$ \\
\hline $\begin{array}{l}\text { Instructionally based } \\
\text { curriculum }\end{array}$ & $\begin{array}{l}\text { A curriculum based on increasing children's learning } \\
\text { through direct instruction. }\end{array}$ \\
\hline $\begin{array}{l}\text { Interrater Reliability } \\
\text { Tests }\end{array}$ & $\begin{array}{l}\text { An evaluation process created by Teaching Strategies } \\
\text { GOLD® in which educators work through a series of } \\
\text { scenarios in Teaching Strategies GOLD® to assure that } \\
\text { they are rating children correctly according to the system. }\end{array}$ \\
\hline $\begin{array}{l}\text { National Association for } \\
\text { the Education of Young } \\
\text { Children (NAEYC) }\end{array}$ & $\begin{array}{l}\text { Professional organization that is known for promoting } \\
\text { excellence in early childhood education. }\end{array}$ \\
\hline Narrative Inquiry & $\begin{array}{l}\text { Narrative inquiry a method of looking at the personal } \\
\text { reflections of other's past and present experiences for the } \\
\text { purpose of research. }\end{array}$ \\
\hline $\begin{array}{l}\text { No Child Left Behind Act } \\
\text { (NCLB) }\end{array}$ & $\begin{array}{l}\text { 2001, standards-based education reform that required all } \\
\text { students at selected grade levels to participate in } \\
\text { standardized testing with an emphasis on academic } \\
\text { progress, educator qualification and reports in direct link } \\
\text { to federal funding. }\end{array}$ \\
\hline $\begin{array}{l}\text { Oregon Kindergarten } \\
\text { Assessment (OKA) }\end{array}$ & $\begin{array}{l}\text { An assessment created to help the state of Oregon } \\
\text { determine where to invest early childhood education } \\
\text { resources by providing a "quick snapshot" of selected } \\
\text { skills of groups pf children entering Oregon kindergarten } \\
\text { classrooms }\end{array}$ \\
\hline
\end{tabular}




\begin{tabular}{|l|l|}
\hline $\begin{array}{l}\text { Oregon Preschool } \\
\text { Promise }\end{array}$ & $\begin{array}{l}\text { Oregon legislation passed in 2016 to make full time early } \\
\text { childhood education available to children age } 3 \text { and } 4 \\
\text { living in families with an income of up to 200\% of the } \\
\text { federal poverty level. }\end{array}$ \\
\hline $\begin{array}{l}\text { Pedagogical } \\
\text { Documentation }\end{array}$ & $\begin{array}{l}\text { An intentional practice for learning through the process of } \\
\text { documenting and supporting children's learning by } \\
\text { working with children to revisit past learning episodes to } \\
\text { give children and early childhood educators the } \\
\text { opportunity to reflect, remember and build in ideas. }\end{array}$ \\
\hline $\begin{array}{l}\text { Preformatted portfolio } \\
\text { style assessment (PFPSA) }\end{array}$ & $\begin{array}{l}\text { A portfolio style assessment process consisting of set } \\
\text { groups of standards in which to categorize student's } \\
\text { learning }\end{array}$ \\
\hline Portfolio style assessment & $\begin{array}{l}\text { An assessment process done through observation, } \\
\text { documentation, work samples, and reflection. }\end{array}$ \\
\hline Qualitative Research & $\begin{array}{l}\text { A method of research used to gain understanding of the } \\
\text { meanings that an individual attributes to a social or human } \\
\text { situation. }\end{array}$ \\
\hline $\begin{array}{l}\text { Self-identified } \\
\text { constructivist early } \\
\text { childhood educator }\end{array}$ & $\begin{array}{l}\text { An educator working with children age 6 and under who } \\
\text { believes that children learn best through constructivist } \\
\text { learning practices. }\end{array}$ \\
\hline Standardized assessment & $\begin{array}{l}\text { Large-scale, externally developed and mandated, } \\
\text { assessments that are uniformly administered and scored as } \\
\text { an evaluation of student learning }\end{array}$ \\
\hline $\begin{array}{l}\text { Teaching Strategies } \\
\text { SOLD® (Teaching } \\
\text { assessment system) }\end{array}$ & $\begin{array}{l}\text { An on-line, preformatted, portfolio style assessment } \\
\text { system. Renamed "My Teaching Strategies" in September } \\
\text { 2017. }\end{array}$ \\
\hline $\begin{array}{l}\text { Widely Held Expectations } \\
\text { The pre-determined developmental domains, categories, } \\
\text { and sub-categories set within the Teaching Strategies } \\
\text { GOLD® assessment system. }\end{array}$ \\
\hline
\end{tabular}




\section{Chapter One: Introduction}

The purpose of this dissertation is to collect and understand the experiences of self-identified constructivist early childhood educators who are required by their place of practice to work with the preformatted, portfolio style assessment system Teaching Strategies GOLD®. As a self-identified constructivist early childhood educator who was required by my place of practice to use the Teaching Strategies GOLD® assessment system as a means of tracking children's learning, I had long struggled with the way in which the Teaching Strategies GOLD® assessment system categorizes children's learning into pre-established, generic learning objectives. I had consoled myself by the knowledge that when meeting with parents and guardians about their child's learning and growth, I could represent their child's learning and growth in a genuine way based on my interactions, experiences, and relationship with the child.

However, as I continued to implement this strategy, I could not help but notice that even with my best intentions, my ability to holistically describe the child's learning became lost within the system. To illustrate this effect clearly, I have included a short vignette. This vignette begins with my observation of Sam $^{1}$. After recounting my observation of Sam, I walk through the process I took in recording this observation of Sam into the Teaching Strategies GOLD® assessment system and the ways in which the process breaks down Sam's learning experience into the pre-established, generic learning objectives found within Teaching Strategies GOLD®:

\footnotetext{
${ }^{1}$ Pseudonyms have been used for all children's names in this dissertation
} 
I sit on the playground, literally sitting on the ground, near the slide. It is a warm day and I can feel the sand from earlier castle building sticking to the back of my neck. Sam, age 20 months, runs to me, "Sal Lay! Sal Lay!” she calls, "Watch me!" She looks into my eyes as she speaks, breathless from her previous endeavors. Her smile is huge and she sprints from where I am sitting to the front of the slide. Sam waits at the bottom of the slide, watching her friend Justin at the top. Justin, age 15 months, screams and motions his hand. Sam moves to the side of the slide. With his path free, Justin sits and slides quickly down the slide then runs off. Sam glances over her shoulder at me and smiles big to see that I am looking at her still.

"Sal Lay! Watch! Watch me!” Sam calls, still smiling at me. "I'm watching Sam!" I call, smiling back at her. Sam climbs onto the slide. She starts to walk up it slowly. As the slope increases Sam leans forward and puts one hand on each side of the slide. She looks up to the top then turns her head down, watching her feet. She moves purposefully, moving her right hand and left foot together, getting her bearings then moving her left hand and right foot together, slowly and determinedly making her way up the slide.

I watch Sam climb. I think about the confidence she must have in herself, her strength, and her determination. I wonder what she is thinking as she climbs this slide that is two and half times taller than her. I wonder how it feels for her to use her muscles this way, to experience the pull of her arms and the push of her legs working together to slowly move her body up the slide. I marvel at how, at this moment, everything is aligning perfectly for her.

As Sam reaches the top of the slide, her progress pauses. The sides of the slide are changing, growing straighter and taller as the slope of the slide steepens just before the platform at the top. Sam looks up and studies the top of the slide. She moves her left hand and right foot. Instead of reaching her hands toward the wall of the slide, she reaches to the back of the platform, stretching her body forward as she pushes with her right foot. She grabs the back of the platform with her hand then moves her other hand and foot the same way. She pulls and pushes her body onto the platform, bringing her knees under her, then stands up. Sam turns, a triumphant smile on her face. "You see Sal Lay? I climb, I climb up the slide!" "I saw Sam!" I yell back, "You worked so hard at that, you must feel great!" Sam's smile broadens, her eyes light up and she looks around from the top of the slide. "Yeah!” she yells, "Watch! I do it again!” Then Sam sits and slides back 
down the slide, running to me to give me a hug before running back to the slide to climb again.

The observation was on a Thursday, and it is the following Monday before I had an opportunity to enter Sam's accomplishment into the Teaching Strategies GOLD ${ }^{\circledR}$ assessment system and connect it to the learning objectives that are built into that system. It was 1:30 in the afternoon, naptime. As the opening shift, it was my turn to sit with our most reluctant napper. He fell asleep 15 minutes before, and since then I finished cleaning up after lunch and set out explorations for the children who wake up before their classmates.

I sat in the dark with the iPad. Another teammate is on the computer. I logged into the Teaching Strategies GOLD® assessment system and looked around the room trying to decide where to start. The last time I was able to log any observations was the Wednesday before last and as I scanned the room, I could think of at least three things I wanted to record about each child. Next to me was an observation clipboard. It's a tool that my team and I created to quickly jot down notes to help us remember what we have noticed. I saw my post-it巴 note that says, "Sam, climbing slide" with my initials and the date. I smiled as the first image that came to mind was Sam standing at the top of the slide smiling.

I began and then sighed. I knew that I could not record my full observation. At best I had 35 minutes before the first child woke up and I had at least 15 observations that I wanted to record. I began:

Sam runs to me, "Sal Lay! Sal Lay!" she calls, "Watch me!” Her smile is huge and she sprints from where I am sitting to the front of the slide. Sam glances over her shoulder, "Sal Lay! Watch! Watch me!" Sam calls, still smiling at me. Sam 
climbs onto the slide. She starts to walk up it slowly. As the slope increases Sam leans forward and puts one hand on each side of the slide. She looks up to the top then turns her head down, watching her feet. As Sam reaches the top of the slide, her progress pauses. Sam looks up and studies the top of the slide. She reaches to the back of the platform, stretching her body forward as she pushes with her foot. She pulls and pushes her body onto the platform, bringing her knees under her then stands up. Sam turns, a triumphant smile on her face. "You see Sal Lay? I climb, I climb up the slide!"

I consider this account of Sam's work to be accurate but antiseptic. I had recorded Sam's voice but had lost my own, my thoughts of Sam have been cut out, given weight for this process, so I suddenly felt my ideas were unimportant. Instead, I scrolled down and searched for which objectives to connect. My checkpoints were due in three weeks so I glanced at the Documentation by Objective/Dimension Report attached to the observation clipboard. This is a report that lists each learning domain and each child showing me where my team and I have connected observations and what areas in which we still need to connect observations. I was required to have a minimum of one observation connected to each learning sub-category per checkpoint period. I chose three:

Objective 2a: Forms relationships with adults. Rating: 4, uses a trusted adult as a secure base from which to explore the world.

Objective 4: Demonstrates traveling skills. Rating: 5, experiments with different ways of moving.

Objective 9b: Uses language to express thoughts and needs. Rating: 4, uses some words and word-like sounds and is understood by most familiar people.

As I waited for the system to update, my mind wandered. I thought about the Individual Child Report that I was required to present to Sam's parents at her conference and what this report says about her. Basically, this report showed that Sam is in the zone or a little 
to the right of the zone of what the creators of the Teaching Strategies GOLD® assessment system have deemed as the Widely Held Expectations for a 1- to 2-year-old child. In other words, her learning and development was 'typical' for a child her age.

'Typical' is not a word I would use to describe Sam. Funny, outgoing, caring, determined, curious, brave, clever, silly, kind, and understanding are the first ten words that immediately popped into my mind. But unless someone takes the time to really read the observations, they will not know this about Sam. They will not learn how she wants to take care of her friends or how she will start laughing when she is telling you something that she finds funny. They will not learn her passion for bugs, snakes, and other small creatures. They will not understand that she thinks about the squirrel that visits our playground, wondering where it goes when we cannot see it and bringing these wonderings to her friends and early childhood educators.

Most likely, they will only look at this report. A report that tells them that Sam is in the 'safe' zone and if Sam continues to progress down this path she will enter kindergarten 'ready to learn.' In this report, Sam's voice becomes lost, her voice is not important for this process. This report tells them the only thing that they want to know about Sam; that she should not be a problem when she enters the public education system.

What I have noted is that when we use a system such as Teaching Strategies GOLD® we are made to silence the voices of children and early childhood educators. This silencing first happens as we enter observations into the system, removing our thoughts and wonderings about the child as we go. There is no room for them in this 
process. They seem unimportant. We seem unimportant. Then we take it further. We remove the child's voice by categorizing their learning into pre-established, generic definitions. Their voices too seem now to be unimportant, unnecessary to the process. Instead we place what we have seen into generic steps of progression; the relationship a child has with their early childhood educator becomes "uses a trusted adult from which to explore the world," her hypotheses and testing while she climbs is now just, "experiments with different ways of moving" (Teaching Strategies, 2014, p. 4). The silence continues when these steps lose all definition.

In the Individual Child Report the child and their experiences are no longer categorized into generic phrases, but now are just numbers within a color band. Seemingly, the child has disappeared completely. This disappearance of the child conflicts strongly against the values I hold as a self-identified constructivist early childhood educator. Yet I, like many others, am required to follow this procedure and I wonder if there is a better way. My troubling scenario left me with a lingering question that I decided to research: What are the experiences of self-identified constructivist early childhood educators who are required by their place of practice to work with the Teaching Strategies GOLD® assessment system?

\section{Background of the problem}

The process of using developing portfolios as a method of meaning-making through collaboration with other early childhood educators, children, and parents is one that is often seen when using collaborative, hand written collections of children's work, learning, and development (Feeney, 2016; Goldstein \& Flake, 2015; Kim, Lambert, \& 
Burts, 2013a). However, in the past decade there has been a push for many early childhood education programs to move away from collaborative, hand written portfolios that can make children's learning visible, to online preformatted portfolio style systems and checklists such as Teaching Strategies GOLD®, the Work Sampling System, the Child Observation Record, and the Ounce Scale (Feeney, 2016; Goldstein \& Flake, 2015; Kim, et al., 2013a). Often the claim behind this push is that preformatted portfolio style assessment (PFPSA) systems can help early childhood educators evaluate children's learning and development with less area for subjectivity, giving the evaluations more validity (Kim et al., 2013a; McClelland \& Squires, 2012). There is also the additional claim that using a standardized source to measure children's learning and growth will expose which early childhood education programs can be considered 'successful' and where more resources need to be focused (McClelland \& Squires, 2012).

PFPSA systems such as Teaching Strategies GOLD®, the Work Sampling System, the Child Observation Record, and the Ounce Scale often come with standardized assessment forms and preformatted learning objectives. The idea of standardized assessment forms and preformatted learning objectives supports the dominant educational discourses that quantitative, rubric style checklists in education are the most reliable way to demonstrate learning accountability through measurement (Goldstein \& Flake, 2015; Kim, Lambert, \& Burts, 2013a). The requirement of standardized measurement in early childhood education is a recent education policy focus and is a result of newly available federal funding through programs such as Race to the Top and the Early Education for All Americans Act 2013 (Goldstein \& Flake, 2015). 
The use of PFPSA systems run the risk of reducing a child's learning process to a series of checkpoints and learning objectives to obtain, moving the focus away from the process of the learning and looking only on the 'next step' to achieve (Feeney, 2016; Shultz, 2015). Recent research conducted by Shultz (2015) suggests that when using a PFPSA system, early childhood educators' interpretations of observations are often altered during the process of data collection and analysis to fit within the set learning areas, objectives, categories, and subcategories outlined by the system. Schultz researched the use of two different PFPSA systems, Early Excellence and Learning Stories. Conducted in 18 kindergarten groups over a period of 15 working days each, Shultz also examined "the idea of the homogeneity of the 'learning child' and the related assumption that the learning child is always observed and documented in the same way" (p. 210). After analyzing over 800 pages of data Shultz concluded that "the documented object - the children's learning - is subject to a continuous transformative reworking in a contextually bound and situationally produced interplay of documents, actors, and practices" (p. 216). Or in other words, as the documentation is transferred from the original recording by the early childhood educator to the final categorization within the assessment system, it is changed and transformed to fit within that system until it is not an accurate reflection of the child's learning "but of the child within the context of the institution" (p. 215). The assessment systems that are used in the Shultz study are what some might call a hybrid version of portfolio style assessment and standardized assessment. In this dissertation, I refer to these hybrid assessment systems as preformatted portfolio style assessment (PFPSA) systems. Although PFPSA systems fit 
the portfolio style assessment layout in that they are supported by the child's work samples, early childhood educators' anecdotal recordings of observations of the child, photographs, and other artifacts to create a comprehensive view of the child and the child's learning and development, they are also somewhat standardized in that the actual analysis of the documentation. In PFPSA systems, the analysis of children's work is done through sorting the artifacts collected into pre-established categories and subcategories in order to classify and label the child and the child's learning and development. As with standardized assessment, the learning categories and subcategories in PFPSA systems have been externally developed and mandated and are uniformly administered and scored as an evaluation of the student's learning.

In my experience as a self-identified constructivist early childhood educator, I have seen how portfolio style assessment, such as through documentation inspired by the experience of Reggio Emilia, presents a much more holistic view of the child and the child's learning than standardized assessment (Gandini, 1993; MacDonald, 2007). In the municipally funded preprimary schools and infant and toddler centers of Reggio Emilia, Italy, the processes of collaboration, documentation, discussion, and reflection happens between early childhood educators, children, and parents. They all play a role in the practice of understanding how a child learns and how they are making meaning of their experiences (Gandini, 1993). This practice, known as pedagogical documentation, can be a valuable alternative to more traditional means of standardized assessment (MacDonald, 2007). Pedagogical documentation is a process for understanding and being understood, it is an intentional practice for learning that occurs in everyday context (Gandini, 2001; 
Goldhaber, 2001; Parnell, 2011a, 2011b; Rintakorpi \& Reunamo, 2016). When practicing pedagogical documentation, early childhood educators work with children and revisit past learning episodes to give children and early childhood educators the opportunity to reflect, remember, and build on ideas (Gandini, 2001; Parnell, 2011a, 2011b). The value in pedagogical documentation is collaborating during the process of documentation, not the final product of documentation (Gandini, 2001). Pedagogical documentation can be used as an interactive process of communicating with children while making their learning and voices visible for others who do not have the privilege of working with children on a daily basis.

When reflecting on the process of evaluation using pedagogical documentation, I cannot help but revisit my earlier vignette about Sam in the atmosphere of using the Teaching Strategies GOLD® assessment system. When early childhood educators use these PFPSA systems, an atmosphere of isolation is the norm. I had witnessed the episode with Sam on a Thursday. I recorded it on the following Monday, in the dark, by myself, at naptime. Because of the time constraints placed on me by the policies of my place of practice, when analyzing Sam's episode of climbing up the slide I was completely isolated. I did not have the opportunity to share it with my teaching team or with Sam herself. I cannot help but wonder if I had revisited this episode with Sam and asked for her thoughts about it, what new insights she and I would have had about her learning and development and how we both would have connected this learning event to others in her life. 
There are many different styles of documenting and assessing children's learning and development in early childhood education programs. For the purpose of this research I chose two on which to place my focus. The first is the Teaching Strategies GOLD® assessment system. I chose this system because it was the one that I was required to use in my place of practice as well as the system that is commonly used in many publicly funded early childhood education programs. The second style of documenting children's learning used in early childhood education classrooms that I chose, is pedagogical documentation (Cadwell, 1997, 2002; Fleet, Patterson, \& Robinson, 2006; Forman \& Fyfe, 2012; Rinaldi, 2001a, 2001b, 2012; Rintakorpi \& Reunamo, 2016).

I chose pedagogical documentation because it is one that connects strongly to my values as a self-identified constructivist early childhood educator and it is a practice that I have used - although somewhat unofficially - with the children in my care. In this chapter, I will begin to map out the contrast between each of these assessment styles as well as provide a brief glimpse of the contemporary image of the early childhood educator in the United States. In chapter two, I look at each of these documentation and assessment styles in detail.

Measuring what has been considered successful educational practices through learning standards is not new in United States education policy (Parnell \& Iorio, 2018). As I stated previously, recent research in the effects of positive early childhood education experiences on long term learning and success is drawing more attention to early childhood education programs than ever before. Promises on the federal and state level of better pay for early childhood educators and 'high quality' publicly funded early 
childhood education programs for children who are currently unable to attend is an exciting and long-awaited vision by both families and early

childhood educators. However, with federal and state funding comes the need for justification of those funds through different measurement structures. In the next section, I lay the groundwork in which United States educational policy has continued to push down this convention into classrooms that serve younger and younger children.

\section{Context of the Problem}

Government officials and policymakers who are interested in Oregon's education system have long been inspired to have quality early childhood education available for all children. The Oregon Kindergarten Assessment (OKA), which was implemented in the 2013-14 school year, was developed to determine whether Oregon's school children were entering kindergarten "ready to learn” (McClelland \& Squires, 2012. p. 1). McClelland and Squires (2012) define school readiness as having a "direct measure of selfregulation" and "early reading and math skills" (p. 1). The OKA is administered to children entering kindergarten each fall within the first six weeks of the school year. In the 2017-18 school year, early reading is determined through a series of short tests that evaluate the child's English letter name and sound recognition. Early math skills are determined by short tests regarding number and operational skills. (Oregon Department of Education, Kindergarten Assessment Comprehensive Training Recording, 2015c, slide 106). The Oregon Department of Education (ODE) recommends that the Approaches to Learning checklist be completed within the last three weeks of the six-week assessment window during the beginning of the school year. 
Teaching Strategies GOLD® is an assessment system in which early childhood educators can document observations of children then assess their students' learning and development through a checkpoint system (Teaching Strategies GOLD®, 2014).

Observations are categorized by pre-determined developmental domains, categories, and sub-categories. At set times throughout the year, early childhood educators use this data to pull together an analysis report, called the Assessment Status Report, showing what level the early childhood educator has classified the children's learning and development based on the information entered and stored into the Teaching Strategies GOLD® assessment system (Teaching Strategies 2013). The Assessment Status Report lists each category and subcategory of the developmental domains, highlights the Widely Held Expectations outlined by Teaching Strategies GOLD® assessment system for the child's age, and where the early childhood educator has classified the child's learning and development at that point (Teaching Strategies 2014).

Throughout the process of creating publicly funded early childhood education policies in Oregon there have been many questions around the definitions of the terms 'high quality early learning', 'kindergarten readiness', and 'ready to learn'. There has also been much discussion about the measurement systems being implemented in order to determine the success of the policies and practices proposed. For example, Oregon's 2011 Early Childhood and Family Investment Transition Report states:

To maximize learning, all children must develop cognitive, language, sensory, motor and attention skills. But they also need to be exposed to the experiences and social interactions that are essential to encourage the underlying brain development upon which literacy, healthy relationships, and other abilities are built. This starting point, which is different than the one upon which our current 
education system is based, reflects current research and science and the consensus of leaders in the early childhood and education fields. (p. 4)

Yet, in 2012, when McClelland and Squires presented a report to then Oregon Governor Kitzhaber's office about the importance of assessing children to determine whether they are what McClelland and Squires label as 'ready to learn' when entering kindergarten, the focus was more toward children's academic readiness rather than "the experiences and social interactions that are essential to encourage the underlying brain development" (Oregon Department of Education, Early Childhood and Family Transition Report, 2011, p. 4). As stated before, McClelland and Squires (2012) defined school readiness as having a "direct measure of self-regulation" and "early reading and math skills" (Oregon Department of Education, Early Childhood and Family Investment Transition Report, 2011, p. 1). However, the majority of the focus of the OKA has been in the areas of early reading and math.

An example of this heavy focus on early reading and math skills is found in the 2015-16 Kindergarten Assessment Test Administrator Training Recording. The training module is just under eighty minutes long and goes into great detail about the ways in which children's early reading and math skills are to be assessed and the changes that have been implemented in the OKA the prior year (Oregon Department of Education, 2015-16 Kindergarten Assessment Comprehensive Training Recording, 2015c). In contrast, the area of direct measurement of self-regulation, (now called Approaches to Learning) is not addressed until the seventy-fourth minute. Even at this late juncture in the training module, the importance of completing the Approaches to Learning area of assessment was stressed because it is "based on the Child Behavior Rating Scale which 
has been demonstrated to be strongly predictive of reading and math achievement in elementary grades" (Oregon Department of Education, 2015-16 Kindergarten Assessment Comprehensive Training Recording, 2015c, slide 102).

The trend of a stronger focus on academic skills than social/emotional development in the OKA continued each year. In the 2016-17 Oregon Kindergarten Assessment Test Administrator Training PowerPoint, only three slides out of sixty-two address Approaches to Learning and that is not until the fifty-eighth slide. The 2017-18 Kindergarten Assessment Training Modules for math and literacy are separate from the training module for Approaches for Learning. The math and literacy module is 28 slides, the Approaches to Learning module is only 9. However, the 2017-18 Approaches to Learning training module is much more informative in how to complete the Approaches to Learning form than in previous years.

Children's cognitive development is strongly connected to their social/emotional development, however, when the focus of children's early learning experiences is on academics and getting the correct answer, children lack the experiences and opportunities to be reflective about their work and make meaning of their learning (Christakis, 2016). A child's ability to identify, understand, and express their own feelings and the feelings of others helps them to develop the skills of regulating their behavior, which builds their confidence in themselves to take initiative to explore and take risks (Poglitsch \& Ryan, 2008). When children take initiative, they are able to analyze their experiences and begin to form opinions about themselves and the self-concept that they will take with them as they enter into the world. These risks are not only physical and social, they are also 
cognitive risks. When early childhood educators and programs support risk taking and encourage children to think about their successes and their failures, it helps children develop self-evaluation skills about their learning and the way in which the world around them works (Fleet, et al., 2006; Rintakorpi \& Reunamo, 2016).

The focus away from social/emotional development and towards academic learning standards is recent to early childhood education but not to United States educational policy. The implementation of Teaching Strategies GOLD® assessment system and the OKA into early childhood education and kindergarten programs is similar to what has been happening in elementary and secondary schools for the past four decades. These assessments include the National Assessment of Educational Progress (NAEP) which was created in the era of No Child Left Behind, and more recently implemented along with the Common Core State Standards (CCSS), the Smarter Balance Assessment Consort (SBAC), and Oregon Assessment of Knowledge and Skills (OAKS). These assessments are similar to Teaching Strategies GOLD® and the OKA, in which discrete bits of information are tallied or tick-boxed to understand the student learning gains. The focus on isolated learning gains does not support children's right to make meaning of their learning. For example, to return to the vignette at the beginning of this dissertation, I was able to connect Sam's exploration of climbing up the slide to many different objectives. However, each of these objectives are isolated from each other and do not connect to Sam's other learning experiences. If I would have been looking at the experience in connection to Sam's other learning experiences, I would have focused on her confidence in the accomplishment of climbing up the slide and her ability to adapt her 
movement when the terrain of the slide changed. Thus, in the efforts to categorize what Sam has learned, my focus has moved away from how Sam is thinking about her own learning. Furthermore, if I were using only the Individual Child Report to consider Sam's development, I would miss Sam's confidence and problem solving completely.

Both the OKA and the Teaching Strategies GOLD® assessment system focus heavily on the child's level of development. Through the Teaching Strategies GOLD ${ }^{\circledR}$ assessment system, early childhood educators classify each area of the child's development and learning into the Widely Held Expectations color bands according to the child's age. The Widely Held Expectations outlined in the Teaching Strategies GOLD® assessment system are "connected to the Common Core State Standards, state early learning guidelines, and the Head Start Child Development and Early Learning Framework" (Teaching Strategies, 2014 p. 12). Oregon also adopted the Head Start Child Development and Early Learning Framework as the guiding document for state funded preschools in 2011 (Oregon Department of Education, Oregon's Early Learning and Kindergarten Guidelines, 2017). When Head Start released an updated framework in 2015 titled Head Start Early Learning Outcomes Framework, it became Oregon's "official early learning and development standards for all children age 3-5" (Oregon Department of Education, Oregon's Early Learning and Kindergarten Guidelines, 2017, p. 2).

Teaching Strategies GOLD® has long partnered with Head Start and has worked in connecting the 38 Widely Held Expectations to state early learning and development standards (Teaching Strategies, 2017a). However, when early childhood educators are 
asked to focus whether or not a child is meeting learning objectives and goals, we have to wonder what they might be missing about the child and the child's experiences.

Additionally, we need to consider whether the focus on children achieving learning objectives leads the early childhood educator to no longer seeing the child as an individual but only as a score on a report. In this context, learning is viewed as individual and isolated steps of achievement, not as an interacting kaleidoscope of moments that come together to form an intricate and engaging pattern of meaning.

The disconnection and isolation from the child's learning when using a PFPSA system is similar to the way that the guidelines and Common Core State Standards (CCSS) have affected elementary and secondary education classrooms, what Wolk (2007) describes as the dumbing down and sanitization of curriculum. Elementary and secondary educators who are required to follow CCSS often feel frustrated by the lack of connectivity between the students and the curriculum (Gilbert, 2014; Wang, Beckett, \& Brown, 2006; Wolk, 2007). When speaking with a colleague who teaches elementary education about the CCSS her comment was, "There are more learning objectives in the Common Core than there are school days. When I have to teach so broadly, how can I ever teach deeply?" (S. Lewis, personal communication, 2014). Gilbert (2014) describes this focus, in the context of English Language Arts, as one in which the "text is often elevated over students" (p. 28). Just as when the guidelines and CCSS were implemented into elementary education in the past, most early childhood educators who are working in early childhood education classrooms, have not had a voice in whether or not the standards being implemented into early childhood education classrooms and programs 
are appropriate for young children (Feeney, 2016; Parnell \& Iorio, 2018). This lack of representation by the individuals and communities that work with children on a daily basis, creates an inaccurate representation of how children learn, holistically, which could lead to better understandings of the child themselves.

The OKA focuses on the child's knowledge in a different way than the Teaching Strategies GOLD® assessment system. Instead of categorizing the child as an individual, the OKA is a process of labeling what the child, as a member of one or more groups, knows or does not know at a particular point in time, under a particular situation. The ODE claims that the OKA is "not designed to measure a child's readiness but instead to determine how ready our system is for the children" (Oregon Department of Education, 2015-16 Kindergarten Assessment Comprehensive Training Recording, 2015c slide 4). With the use of the word "system" the ODE is not referring to the K-12 system in Oregon but the newly emerging early childhood education policies being created for Oregon's publicly funded early childhood education classrooms. This focus of learning objectives for younger and younger children is reminiscent of the highly debated, downward spiral of academically based education reform that has plagued the United States' education system for years (Figure 1), a cycle further pushing down a system that is as alienating to students as it is to families and educators (Kohn, 2000). 


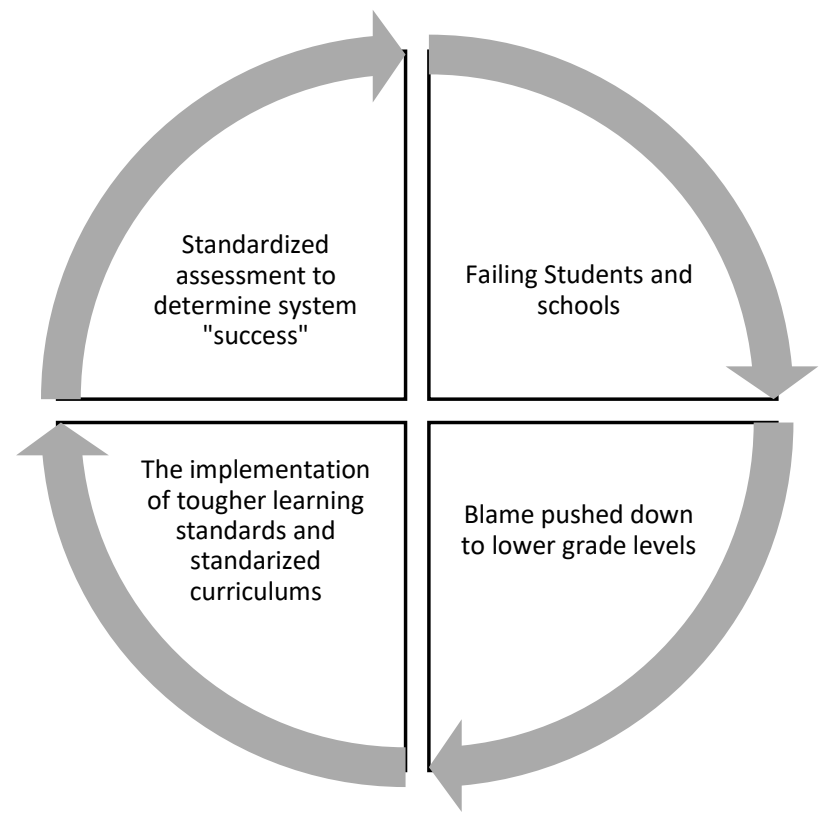

Figure 1: Downward cycle of education reform.

Apple (2009) refers to this downward spiral of restructuring as the deskilling of teaching by the implementation of technical control procedures into the curricula. That is, as we strive to teach more efficiently, we lose the quality of what is being taught, the relationships between the students and the educators, and the student's relationship with their own learning. Often with new policies and requirements comes an additional intensification in the educator's workload outside of time spent with students. The intensified focus on learning objectives and categorizing children's learning can become overwhelming to educators, leading them to conforming to practices and policies in which they do not believe. Parnell (2010) connects this phenomenon to early childhood educators through the United States' image of the early childhood education teacher by writing:

The early childhood education teacher is viewed in contemporary United States society as a babysitter, caretaker, and omniscient giver of knowledge pouring the 
right way of thinking ${ }^{2}$ into empty heads as reflected in the well-known policy of No Child Left Behind" (p. 2)

This image described by Parnell (2010) moves the focus away from children and towards the measurable accountability of early childhood educators. It is a misguided premise that implies that not only do children need to be taught the right way of thinking, but that the professionals that work with them need to be taught the right way of thinking as well (Ayers, 1989; Parnell, 2010).

The focus on measurable accountability and the institutional expectations of pushed down standards, as shown in Figure 1, can have an even larger effect on the educator's idea of what is deemed appropriate learning. When educational policies enforce learning standards that are not age appropriate, educators who are required to try and meet those standards can become so accustomed to what is being enforced, that their perception of what is appropriate learning for children at a certain age or grade level can be altered (Bassok, Latham, \& Roram, 2016; Christakis, 2016). In other words, what once was considered as advanced learning or skills at a certain age becomes the required norm. An example of this would be the expectation of a child's ability to read when leaving kindergarten. In 1998, thirty percent of kindergarten educators surveyed nationwide expected children to know how to read when leaving kindergarten, in contrast, eighty percent of kindergarten educators surveyed nationwide in 2013 had this same expectation (Bassok, et al., 2016; Christakis, 2016). Further, when the assessment of children becomes primarily academic and their social and emotional development

\footnotetext{
${ }^{2}$ Emphasis in original text.
} 
becomes secondary, the emphasis of education will not be on the child as an individual but of the industry as a whole (Feeney, 2016).

The process described by Apple (2009) of focusing on academic standards and increasing early childhood educators' workloads outside of the time they spend with students, is prevalent to the time needed to utilize Teaching Strategies GOLD®. The Teaching Strategies GOLD® assessment system can be incredibly time consuming. For children age three to six there are 38 objectives containing additional $75+$ categories and subcategories in which children's learning and development can be classified.

Early childhood educators in a classroom of fifteen students would need to enter 450 pieces of documentation for individuals per checkpoint period even if they were connecting each entry to an average of three learning categories and subcategories. In addition, early childhood educators would also need time to consolidate the information collected about each child into Checkpoint Status Reports that reflect the early childhood educator's assessment of the child's learning and growth based on the way the information put into the system was categorized when entered.

Depending on the program or school's standards, these checkpoint periods can occur up to four times a year. With so much time and energy being spent on classifying children's learning and development, it is no wonder that the early childhood educators' observations in the Schultz (2015) study were often changed and transformed to fit within that system until they were not an accurate reflection of the child's learning "but of the child within the context of the institution" (p. 215). The increasing focus on quantitative, rubric style checklists and learning standards that do not actually connect to children's 
learning is evidence of how the interest of United States educational policies is not on the child as a competent learner but on the system as a means to measure children's schooling (Eisner, 1985).

In this section I have outlined the ways in which preformatted, portfolio style assessment (PFPSA) systems can isolate the child's learning processes from the child. I have also shown how the with measurement structures being promoted by the ODE early childhood educators are at risk to manipulate the observations, either consciously or subconsciously, to fit the learning objective category or subcategory. In the next section I turn my focus towards the National Association for the Education of Young Children (NAEYC) and how the purpose of assessment in early childhood education is defined through this organization.

\section{Validation of the Problem:}

The National Association for the Education of Young Children (NAEYC) is the professional organization that is known for promoting excellence in early childhood education by connecting practice, policy and research. In the 2002 Position Statement on curriculum, assessment, and program evaluation, the NAEYC stated that:

The purposes of doing assessment are: (1) making sound decisions about teaching and learning, (2) identifying significant concerns that may require focused intervention for individual children, and (3) helping programs improve their educational and developmental interventions. (NAEYC, 2002)

In other words, assessment in early childhood education should be used as a way to reflect on children's learning to consider ways in which to expand on their connections, experiences, and interests. This belief is also reflected in the NAEYC Position Statement on early learning standards. The NAEYC has stated that standard-driven curriculum is a 
trend that could undermine the use of effective and appropriate curriculum and teaching strategies in the field of early childhood education (NAEYC, 2002). Assessment should not be used as a placement process for individual children or as a means to create a standardized curriculum to be implemented in all early childhood education classrooms (NAEYC, 2002). In addition, the NAEYC's Position Statement on early learning standards regarding using assessment in order to support children's learning and development states that:

Information gained from assessments of young children's progress with respect to standards must be used to benefit children. Assessment and accountability systems should be used to improve practices and services and should not be used to rank, sort, or penalize young children. (NAEYC, 2002)

I agree with the NAEYC's Position Statement in that assessment should be used as a tool for early childhood educators to reflect on what they see in the classroom and to gain perspective about each child as an individual and the dynamics of the classroom as a whole. This information can help early childhood educators support children in the areas that they seem to be struggling with a concept. It can also help early childhood educators to think about what learning opportunities need to be offered and consider how they respond in certain situations or to certain children, including deliberating on what may need to change about the classroom schedule or the early childhood educators' personal work schedules in order to be more available for children when they need them. In addition, assessment can help early childhood educators determine when and if they need to bring in additional help or a fresh set of eyes in consideration to a child's development. I also agree with the NAEYC on the point that assessment should not be used to rank, sort, or penalize children (NAEYC, 2002). Unfortunately, with the implementation of the 
OKA and PFPSA systems such as Teaching Strategies GOLD®, I fear that this is the path that the state of Oregon has begun to follow in creating early childhood education policies. It is a path that has complicated past United States' elementary and secondary education policies for decades.

To better understand the complicated path of past United States' education policies that the Oregon early childhood education system is beginning to follow, it is necessary to make a closer examination of the complexity of United States' academically focused education reform. In chapter two, I outline the downward spiral of United States' academically focused education reform in more detail by briefly examining United States' education policy over the last forty years. I start with the publication of A Nation at Risk in 1983 which led to the increase of the federal government's engagement into public schooling. Next, I examine the implementation of No Child Left Behind, 2001, a policy known for tying federal funding to test score increases. I complete this analysis by exploring the Common Core State Standards, 2012, which was an attempt to identify and standardize the necessary curriculum across the states that is essential for children to become college and career ready. Each of these policies have had unintended ramifications on the way educators, policy makers, and the public perceive children's learning and development. I then connect those findings to the policies and procedures being created in the wake of President Obama's Early Education for All Americans Act, 2013, which was implemented as an effort to make high quality preschool available to all children age four to five years old, and the effects that the focus on school readiness has 
had on Oregon's early childhood education policies in the areas of learning standards and assessment.

\section{Statement of the Research Problem}

The purpose of this dissertation is to understand the experiences of self-identified constructivist early childhood educators who are required by their place of practice to work with the Teaching Strategies GOLD® assessment system. I conducted this study to reflect on my own development and practices as an early childhood education professional, as well as to inspire other early childhood education professionals to consider if and how standardized assessment systems affect the way they view children's learning and development. On a larger scale, it is my desire that this study will have an influence on the policies and practices being implemented as the state of Oregon creates publicly funded early childhood education policies. I have already given an overview of tendency for United States' educational policy to focus on standardized assessment and curriculum focused on pre-established learning standards and how this focus is in disagreement with the NAEYC's position statement on assessment in early childhood education. Next, as I layout the significance of this problem, I explore the literature that demonstrates the ways in which the focus on standardized assessment and curriculum focused on pre-established learning standards is entering pervasively into early childhood education programs.

\section{Significance of the Research Problem}

Never before in the history of the United States has so much emphasis been focused on early childhood education. It seems as if the United States Department of 
Education (DOE) has decided that early childhood education is the "silver bullet" that will fix the issues plaguing our schools and society. For many early childhood education professionals, it is a time of excitement and uncertainty in early childhood education. Exciting because of the opportunities available for young children and their families that were not available previously and uncertainty due to the unknown stipulations that often arrive hand in hand with state and federal funding.

However, with so much focus on school readiness and what is deemed as academic excellence, the debate can quickly move away from what may or may not be appropriately classified as school readiness and becomes focused on who is to blame for the lack of perceived readiness (Peters, Ortiz, \& Swadener, 2015). Peters, et al., (2015) state that the blame of lack of readiness is often placed on families and early childhood education practitioners. This blame has created a hypercompetitive atmosphere between families and between early childhood education programs that is unhealthy for early childhood educators, children, and families alike (Christakis, 2016). Christakis (2016) writes about the stress these standards place on parents, stating parents feel as if "Pick the wrong preschool or ease up on phonics drills at home you're your child might not go to college" (para. 11) creating what Parnell (2010) refers to as a marketplace mentality for early childhood education programs. Parnell (2010) writes, "How parents see teachers plays a fundamental role in praxis - the connection between theory and practice" (p. 5). Meaning that from the insistence from parents, and the wider social, cultural, and political forces, schools often feel pressured to conform to instructivist and academically focused curriculum demands based on media attention and regurgitated educational buzz 
words rather than looking towards early childhood educators as researchers of children's development and a source of knowledge about the ways young children learn (Parnell, 2010). This effect on curriculum has spilled into the conversations around creating publicly funded early childhood education programs and what is considered as 'high quality early childhood education'. Further competitiveness is encouraged by and between states with the implementation of federal and state funding for early childhood education programs (Goldstein \& Flake, 2015).

Kohn (2000) writes that when incentives such as funding are tied to learning standards, we run the risk of implementing a curriculum that is not reflective of children's abilities but instead is focused on increasing tests and assessment scores. Even within the early stages of the development of the Oregon Preschool Promise there are reflections of an instructivist based curriculum entering pervasively into early into childhood education classrooms. This focus can result in early childhood education curriculums that are based on academic status and assessment scores and will continue to move the focus of early childhood education away from the child as a constructor of their own knowledge to that of a statistic to be increased (Feeney, 2016; Katz, 2000).

For example, one of the program standards for Oregon early childhood education programs to maintain funding is for the new publicly funded early childhood education classrooms to offer a full day schedule with "Instructional hours equivalent to full day kindergarten in local public schools" (Oregon Department of Education, Preschool Promise Legislative Report, 2016, p. 11). The current requirement for instructional hours 
in a full day kindergarten classroom is 900 hours per academic year. Instructional time is defined by the ODE as:

...time during which students are engaged in regularly scheduled instruction, learning activities, or learning assessments that are designed to meet Common Curriculum Goals and academic content standards required by OAR 581-0221210 , and are working under the direction and supervision of a licensed or registered educator, licensed CTE instructor, licensed practitioner, or Educational Assistant who is assigned instructionally related activities and is working under the supervision of a licensed or registered educator as required by OAR 581-0370015. (Oregon Department of Education, 581-022-0102. 2015a, para. 30 [a])

More telling is the instructional time not considered in this definition. According to the ODE instructional time does not include time at recess or times when "attendance is not required and no instructional assistance is provided" (Oregon Department of Education, 581-022-0102. 2015a, para 30 [c]). This strongly conflicts with what the NAEYC considers as learning standards befitting in early childhood education classrooms and programs. The NAEYC states that early learning standards should be based on research of the structures, processes, and outcomes of early learning and development and not scaled-back versions of standards for older children (NAEYC, 2002).

The ODE's idea of instructional time is inherently in opposition to the beliefs of constructivist learning theories. Self-identified constructivist early childhood educators believe that children are always learning and are able to construct knowledge about the physical and social world by connecting their own ideas and understandings in different interactions and experiences (Chaillé, 2008). To be able to make these connections children need time and space to put their own ideas into practice (Chaillé, 2008). It is 
essential for children to have the opportunity to create and coordinate relationships with others and objects to support their critical thinking skills (Kamii, 1991). If the ODE's definition of instructional time does not include recess or times in which "no instructional assistance is provided" (Oregon Department of Education, 581-022-0102. 2015a, para 30 [c]) we need to think about how and when children will get the time and space necessary to build on and connect their own ideas and theories. Constructivist early childhood educators know that children's learning and development can happen interchangeably (Leong \& Bordova, 2006; Vygotsky, 1978). Vygotsky (1978) believed that all mental processes began in a shared space and then move to an intellectual plane (Leong \& Bordova, 2006). This belief coordinates with Piaget's (1977) theory of cognitive development and the steps of assimilation, accommodation, equilibrium and adaption. Piaget (1977) theorized that we are first exposed to new knowledge we think about it in context to what we already know (assimilation), our thinking evolves either by accepting or challenging the new knowledge (accommodation), and our perceptions have altered as we apply new information in the future (equilibrium and adaption). Vygotsky referred to the functions of the learning process as the mental tools children utilize when using memory and problem solving (Leong \& Bordova, 2006).

Additionally, self-identified constructivist early childhood educators know the value of play in children's learning processes (Bodrova, Germeroth, \& Leong, 2013; DeVries, Zan, Hildebrant, Edmiaston, Sales, 2002; Forman \& Hill, 1984; Piaget, 1954; Vygotsky, 1978). Vygotsky (1978) wrote that when children play roles, even if the role is one they have in life, they tend to follow the rules of the role stating, "Only actions that 
fit these rules are acceptable to the play situation" (p. 95). More recently, Bodrova et al., (2013) connect this commitment to the rules of the role to a child's self-regulation skills. Play gives children the opportunity to try different ways of doing something, a chance to build and test theories and think critically about the task at hand (Forman \& Hill, 1984). Self-identified constructivist early childhood educators must find a balance of supporting, but not controlling, children's play (Chaillé, 2008; Bodrova et al., 2013; Forman \& Hill, 1984). We must be aware that when meeting learning standards becomes the focus of working with young children, early childhood educators run the risk of stifling children's natural learning abilities (Christakis, 2016).

With the implementation of the OKA and PFPSA systems such as Teaching Strategies GOLD®, early childhood educators will be asked to spend more time assessing young children and less time interacting with them. Shultz (2015) writes that because of the enormity of documented observations required by the PFPSA systems in his study, the Early Excellence and Learning Stories systems, the kindergarten educators needed to develop an observational matrix of which child would be observed and designated times for observations. Therefore, children were not observed because what they were doing was considered relevant to their learning, they were observed simply because it was their turn (Shultz, 2015). Because of the consistent nature of the most convenient times for kindergarten educators to observe and record children as they played, worked, and learned, Shultz noted that the children began to recognize when the kindergarten educators were observing them or other students. Even more telling, the children began to recognize what interactions and behavior was rewarded a favorable 
response and through these interactions learned "what the institution expects of them what it means to be a good kindergarten child" (p. 215). In other words, PFPSA systems not only affect the kindergarten educator's understanding of the child, they can also affect the child's concept of themselves.

When considering what are good practices in documenting, assessing, and supporting children's learning, we cannot just rely on the systems being created and implemented into early childhood education and kindergarten classrooms by policy creators. Instead, we must look more deeply into the ways the systems are used by early childhood educators and policy makers and the influence the systems have on the way early childhood educators perceive the child and the child's learning. We must also consider whether or not the systems are respectful to the child and the child's culture, and if so, how we can best utilize the information within the assessment system to support the child's learning and growth.

\section{Presentation of Methods}

Constructivism is a learning theory that is grounded in the idea of learning as a process of making connections through experiences with objects and others (Chaillé, 2008; DeVries, 2004; Forman \& Hill, 1984; Fosnot, 2005). Similarly, qualitative research is often used when wanting to bring light upon individual situations in context to the larger institution (Krathwohl, 2009). The research methods for this study are qualitative. The method I used for this research was narrative inquiry. Narrative inquiry is a process of story-telling and story-listening in order to build understanding (Clandinin, 2007, 2013; Clandinin \& Connelly, 2000; Kanno, 1997). I chose this path to gain insight to the 
different ways that self-identified constructivist early childhood educators work with and within the Teaching Strategies GOLD® assessment system to identify common practices that support working with children in ways that maintain constructivist values.

Further, narrative inquiry is also a method of looking at the personal reflections of other's past and present experiences for the purpose of research (Clandinin, 2007, 2013; Clandinin \& Connelly, 2000; Wells, 2011). As a self-identified constructivist early childhood educator who have used the Teaching Strategies GOLD® assessment system I have had many experiences, struggles, successes, and strategies that have shaped the way I use the system. The role of the researcher is different in narrative inquiry than in other forms of qualitative research (Clandinin, 2013; Clandinin \& Connelly, 2000). Clandinin (2013) describes narrative inquiry as a relational research methodology, guided by relational ethics. When engaging in narrative inquiry, researchers do not sit passively and gather data, instead, narrative inquiry involves the researcher "inhabiting a relational borderland space" with the participants in the study (p. 140-141). The experiences I brought with me and the position I held as a researcher in this study offered my subjectivity. In chapter three, I outline how I addressed my own subjective understandings as I moved through the research collection and interpretations.

The participants in this study were self-identified as constructivist early childhood educators who had experience working in a classroom with children age three to five years old. I chose this age range because it is the age range that the ODE recommends for the Preschool Promise classrooms. Additionally, the participants had a minimum of 5 years of classroom experience working with children age three to five years old. 
According to Katz (1972), early childhood educators working five or more years in the field are at a place where they begin to look for more meaningful insight about what it means to be an early childhood educator, their philosophical roots, and are ready to seek out the opportunities for more diverse professional development. An early childhood educator in this phase of their career, what Katz (1972) refers to as "maturity" would be open to using a critical lens when reflecting on their practice and the ways in which they use assessment (p. 9). Early childhood educators in the mature phase are also open to discussing ways in which they could improve as an individual and ways we could improve as an industry.

Further, the participants in this study had a minimum of one-year experience using the Teaching Strategies GOLD® assessment system. To help build an understanding of the complimentary ways that participants are able to maintain constructivist values when working with the Teaching Strategies GOLD® assessment system, it was important for the early childhood educators in the study to have a strong base knowledge of the way the Teaching Strategies GOLD® assessment system works as well as have had experience in building their own strategies in which to record and enter their observations of children.

Research was conducted from August 2018 through February 2019. Initial recruitment procedures began in February 2018 by sending out an interest email (Appendix A) to early childhood education programs requesting participation. The email included a brief description of the study, the months and type of research that will take place, the responsibilities of the participant, and a request for contact information to 
complete a survey to determine that the potential participant met the established criteria (Appendix B).

This research was conducted using Narrative Inquiry. Data collection and interpretation were a process of interconnections between myself and the participants. Moran (2007), Pitre, Kushner, Raine, and Hegadoren (2013), and Clandinin and Connelly (2000) informed my data collection and interpretation process. Using Moran's cycle of collaborative action research as a model, I incorporated the aspects of Clandinin and Connelly's reciprocal nature of narrative inquiry and Pitre, et al.'s hermeneutics of faith to create a process of interpretation, reflection, and verification with the participant which I refer to as the cycle for collaborative narrative inquiry (Figure 2).

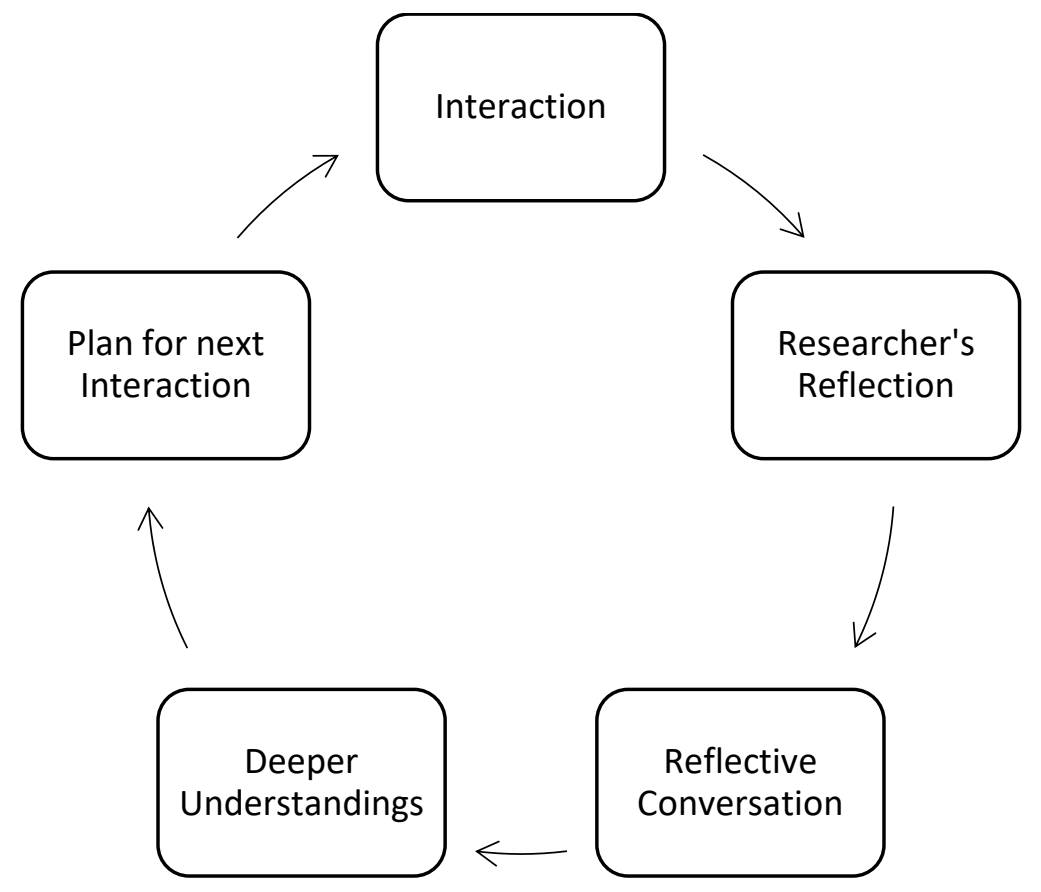

Figure 2: Guyon's cycle for collaborative narrative inquiry.

Clandinin and Connelly, (2000) and Clandinin, (2007, 2013), note that there are two potential beginning points when entering a narrative inquiry exploration. Narrative 
inquiry researchers can start by listening to the participants as they tell their stories or by living alongside the participants as they live and tell their stories. For the purpose of this research, I chose to begin by listening to the narratives of the participants as they told their stories through narrative interview and then moved into a place of living alongside the participants as they lived and told their stories through a field observation (Clandinin, 2007, 2013; Clandinin \& Connelly, 2000). Original audio files were stored on my personal laptop and on an external hard drive. In chapter three, I define how each of these methods were implemented and the reason they were chosen in detail.

\section{Summary}

In this chapter, I have articulated the frustration and challenges I had experienced as a self-identified constructivist early childhood educator who was required by my place of practice to use the Teaching Strategies GOLD® assessment system as a means of tracking children's learning. I walked through the process I took in recording the observation of Sam on the slide into the Teaching Strategies GOLD® assessment system and the ways in which the process broke down Sam's learning experience into the preestablished, generic learning objectives found within Teaching Strategies GOLD®.

I then took a brief look into the pressure being placed on many early childhood education programs to move away from traditional, collaborative, hand written portfolios that can make children's learning visible, to online preformatted portfolio style systems (Feeney, 2016; Goldstein \& Flake, 2015; Kim, Lambert, \& Burts, 2013a). Next, I outlined the empirical research done by Shultz (2015) around two PFPSA systems and the conclusions in which he suggests that when using a preformatted portfolio style 
assessment system, early childhood educators' interpretations of observations are often altered during the documentation process to fit within the set learning areas, objectives, categories, and subcategories outlined by the system.

Additionally, I briefly touched an alternative idea for assessment in early childhood education, the documentation process known as pedagogical documentation and the many ways in which pedagogical documentation supports constructivist learning theory by giving early childhood educators and children the opportunity to revisit past learning episodes providing children and early childhood educators a chance to reflect, remember, and build on ideas (Gandini, 2001; Parnell, 2011a, 2011b).

In this chapter, I concisely overviewed the policies and assessment procedures recommended by the Oregon Department of Education (ODE) for publicly funded early childhood education programs focusing specifically on the Oregon Kindergarten Assessment and the Teaching Strategies GOLD® assessment systems. I went on to scrutinize the risks of the policies and assessment procedures recommended by the Oregon Department of Education for publicly funded early childhood education programs. I then provided a compact definition of constructivism and what it means to me to be a self-identified constructivist early childhood educator. I connected these values in general to qualitative research and more specifically to the methodology of narrative inquiry.

In chapter two, I review the literature around each of these concepts. I begin by taking an in-depth look at the different reports, strategies, tools, and supports that are provided in the Teaching Strategies GOLD® assessment system. I connect aspects of 
Teaching Strategies GOLD® to the educational polices in the United States that focus on fidelity, standardized assessment, and curriculum created around pre-established learning objectives. Next, I show how these policies support an assumption of inefficiency and inadequacy about educators and the public education system in the United States that is amplified for early childhood education professionals.

As a contrast in chapter two, I next look at the municipally funded preprimary schools and infant and toddler centers of Reggio Emilia, Italy and the consideration of documentation as forms of assessment. I then connect the values attributed to the municipally funded preprimary schools and infant and toddler centers of Reggio Emilia, Italy to constructivist learning theory. Finally, I complete my literature review with an overview of the methodology in which I conducted this research study, narrative inquiry, and the methods I implemented in order to collect and understand the experiences of selfidentified early childhood educators who are required to use the Teaching Strategies GOLD® assessment system. 


\section{Chapter Two: Literature Review}

In this chapter I review literature in the areas of the Teaching Strategies GOLD® assessment system, perceptions of the early childhood educator in contemporary United States society, pedagogical documentation, and constructivist learning theory. To begin my literature review, I conducted searches in seven search engines (Worldcat, Ebsco, ERIC, Humanities and Social Science Index, Research Starters Education, Psychology and Behavioral Sciences, and Anthropology Plus) using the search tools of the exact phrase 'Teaching Strategies GOLD®' and the keywords 'empirical study, early childhood, and constructivist.' Out of seven search engines I found sixteen articles related to my research. The majority of these articles contained only a mention Teaching Strategies GOLD® as an option for assessment in early childhood classrooms with a brief explanation of the system. Five of the articles were regarding a single large-scale study conducted across all fifty states and with multiple dimensions. This large-scale study considered the validity of the Teaching Strategies GOLD® assessment system in comparison to traditional assessment systems but did not consider the experiences of early childhood educators using the system. As a self-identified constructivist early childhood educator and learner who was required by my place of practice to use the Teaching Strategies GOLD® assessment system, I felt the need to look further into the experiences of self-identified constructivist early childhood educators who are required to use the preformatted, portfolio style assessment system Teaching Strategies GOLD®. The paucity in the literature around this more precise topic is concerning. 
I begin my literature review by exploring the published research around Teaching Strategies GOLD®. I follow this by providing a history of the Teaching Strategies GOLD® assessment system, looking at the reasons for its creation, and the way it has evolved. In addition, I explore and define the structure of the documentation system within the Teaching Strategies GOLD $®$ assessment system, the different reports, strategies, tools, and supports that are provided, and the purpose of each. I present this extensive disclosure of the Teaching Strategies GOLD® assessment system to display the ways in which the system encourages early childhood educators to categorizing children's learning experiences into pre-established, generic definitions, as well as use pre-established, generic forms to share children's learning with parents, and plan for new learning experiences through pre-established, generic curriculum occurrences. One of the goals of the Teaching Strategies GOLD® assessment system is for early childhood educators to have a system of assessing young children with fidelity (B. Mack, personal communication, November 3, 2016). In other words, assessments could be completed objectively, an idea fraught with problems related to loss of teachers' subjectivity (Rinaldi, 2006). Fidelity through objectivism in education is not new and after my extensive disclosure of the Teaching Strategies GOLD® assessment system, I connect the ways in which the idea of fidelity through objectivism connects to standardized assessment and curriculum focused on pre-established learning objectives.

In United States' educational policy, the perception of the educator is that of a giver of knowledge (Apple 2009; Eisner, 1985; Freire, 2003; Parnell, 2010). In this chapter, I investigate what this media-driven description does to early childhood 
educators and how it effects the image of the child and the larger image of what school should be. I do this in order to establish a sense of the culture that surrounds educational policy creation in the United States. I then look at an innovative view regarding assessment in early childhood education, pedagogical documentation, focusing primarily on the municipally funded preprimary schools and infant and toddler centers of Reggio Emilia, Italy.

Early childhood educators and programs influenced by the municipally funded preprimary schools and infant and toddler centers of Reggio Emilia, Italy do not look at the processes of observation, documentation and assessment to figure out what a child can or cannot do (Edwards, 2012). Instead early childhood educators and programs influenced by the Reggio Emilia approach use observations and documentation to become closer to the child, to understand the child's learning in a deeper way (Rinaldi, 2012). In the Reggio approach, assessment does not seem to be about what the child has accomplished, but about what children are trying to understand and how early childhood educators can support them in this endeavor. As a linked component in this research literature, I chose to look in on this innovative style of documentation as assessment, often considered pedagogical documentation (Fleet, Patterson, \& Robinson, 2006), because it is one that connects strongly to my values as a self-identified constructivist early childhood educator and it is a practice that I have used - although somewhat unofficially - with the children in my care.

I also link some of the values attributed to pedagogical documentation to constructivist learning theory by examining the works of Piaget $(1954,1977,1979)$ and 
Vygotsky $(1962,1978)$. I then connect these theories to those of current early childhood education researchers such as Chaillé (2008), Katz (2000), DeVries (1997, 2000, 2004), Bodrova (2008), Bodrova and Leong (2005), Parnell (2010, 2011a, 2011b), Forman (2005), Forman and Hill (1984) and others to establish a definition of common constructivist practices that are found in early childhood education classrooms today.

Finally, I complete my literature review with an overview on the method in which I will conduct this research study, narrative inquiry. Narrative inquiry is a method of looking at the personal reflections of other's past and present experiences for the purpose of research (Clandinin, 2007, 2013; Clandinin \& Connelly, 2000; Wells, 2011). It is a method of story-telling and story-listening (Clandinin, 2007, 2013; Clandinin \& Connelly, 2000; Kanno, 1997; Wells, 2011). I follow this research paradigm, because I believe that it correlates well with my values as a constructivist learner and early childhood educator.

\section{Published Research Regarding Teaching Strategies GOLD®}

However, before I move to this level of work, I examine a few articles regarding the single large-scale research study considering the validity of the Teaching Strategies GOLD® assessment system across multiple dimensions. This research study, constructed from assessment data collected during the fall 2010, winter 2010, and spring 2011 checkpoint dates for 3-, 4-, and 5-year-olds, set to examine the viability of the Teaching Strategies GOLD® assessment system across subgroups of children based on their primary language and ability status (Kim, Lambert, \& Burts, 2013b). Kim et al. (2013b) "sought to address whether the items in the Teaching Strategies GOLD $®$ system 
functioned differently between (a) children with and without disabilities, (b) ELLs and non-ELLs and (c) Spanish-speaking ELLs and non-ELLs" (p. 580). The research question for this empirical study was, "When a teacher knows that children have a disability or are ELLs, do they give them the same scores for items in the Teaching Strategies GOLD® assessment system as they do children with the same ability levels who do not have a disability or are not ELLs" (p. 580)? Kim, et al. (2013b) determined that the results of the research study provided support that the Teaching Strategies GOLD® assessment system was useful and valid for children with disabilities and children whose home language is not English. However, at the completion of the first research analysis, Kim et al. write about the risk of teacher bias effecting children's ratings and proclaim that training for teachers using the system should include ways to help teachers be more aware of sociocultural background as well as including many examples of how children with a range of language experiences and abilities display competencies.

Looking at different aspects of the 2010 study, Kim, Lambert, and Burts have written a handful of papers stemming from the data collected. Each of these examinations use quantitative analysis. An area of concern for the researchers after the initial research study was the risk of teacher bias that may or may not be present when using the Teaching Strategies GOLD® assessment system (Kim et al., 2013b). To address this concern, Lambert, Kim, and Burts, (2014) applied the Rasch model to "examine the appropriateness of the rating scale structure, unidimensionality, the consistency of item difficulty hierarchy with theory, and the relationship of developmental scale scores to the 
child age" (p. 413). Or in other words, the researchers wanted to look at the data in comparison to the Rasch model in order to determine the risks of inaccuracy based on teacher bias. The researchers determined that evidence was provided, based on this study, that teachers have the ability to assess valid ratings on the development of children using the Teaching Strategies GOLD® assessment system. Lambert et al. (2014) continued to support the Teaching Strategies GOLD ${ }^{\circledR}$ assessment system as a resource for "authentic assessment" but recommend "appropriate training for teachers" in regard to how to use the system effectively (p. 416). This research supports the purpose of my study, to understand the experiences of self-identified constructivist early childhood educators who are required to use the Teaching Strategies GOLD® assessment system, by displaying the ways in which the focus of learning standards, rating scales, and checklists are heavily promoted in United States education policy creation and curriculum development and is disconnected to the work that actually happens in early childhood education classrooms. More recently, Lambert, Kim, and Burts (2015) have published an article that "explores evidence for the reliability and validity of the information provided by [Teaching Strategies] GOLD® using two national samples” (p. 49). Lambert et al., (2015) give a brief overview of many different "authentic assessment instruments" (p. 50). There is not a universal definition of the term authentic assessment, however, in early childhood education, authentic assessment is most often used to describe a type of assessment that is based on children's intellectual and real-life challenges (Fosnot, 2005; Lambert, et al., 2015). The many different assessment instruments described by Lambert, et al. include the Work Sampling System, the Ounce Scale, the Child Observation 
Record, and the Learning Through Relating Child Assets Record. The article then gives a detail account of the Teaching Strategies GOLD® assessment system, and asserts that Teaching Strategies GOLD ${ }^{\circledR}$ has "unique contributions to the validated authentic assessment measures currently used" (p. 52) including the ability to use the same system from ages birth to kindergarten as well as with children with different learning abilities, and dual language learners. In this research study, Lambert et al. revisit the original 2010 large scale empirical research study and compare results with a smaller empirical research study. The smaller, empirical research study was conducted in Tulsa, Oklahoma, and the Bracken School Readiness Assessment was used by the school district in which the research study took place as criterion measure. Lambert et al. (2015) describe the Bracken School Readiness Assessment by stating:

The Bracken is an individually administered, norm-referenced assessment, and one in which school district personnel were already familiar, the instrument is a subset of the Bracken Basic Concept Scale-Revised (BBCS_R) which has demonstrated high total test and subtest internal consistency $(r=.96-.99 ; r=.85-.98$, respectively) and generally moderate to high concurrent validity (r-.36-.80; and .69-.79) (p. 55).

Bracken assessments are about 15 minutes long and are conducted with children individually, outside of the context of the classroom (Lambert et al., 2015). Children are assessed in the areas of numbers, letters, colors, counting, size comparison, and shapes.

Lambert et al. (2015) conducted this research study to verify the reliability and validity of the Teaching Strategies GOLD® assessment system, expanding on their previous research. Evidence from this research study showed that teachers using the Teaching Strategies GOLD® assessment system tended to rate children much more one- 
dimensionally than what would be evident using direct assessment measures. However, Lambert et al. (2015) claim that:

Teachers of young children reflect about instructional strategies in terms of both their holistic and integrated properties, and as domain specific activities within the classroom daily schedule. The knowledge teachers can obtain regarding a child's level of development with respect to both specific developmental progressions and overall domains of development can provide teachers with potentially useful directions for differentiated instruction. (p. 59)

In other words, although there is a chance for bias in this style of assessment, Lambert et al. claim there are also additional benefits to teachers working within this system to determine a child's development stage in the context of overall development.

Lambert et al. (2015) highly recommend vigorous training for early childhood educators using the Teaching Strategies GOLD® assessment system prior to its implementation. In addition, the researchers recommended continuous training as early childhood educators continue to use Teaching Strategies GOLD®. The researchers concluded once again in this article that the Teaching Strategies GOLD® assessment system is a valid and reliable assessment system.

In the next section I provide a brief history of Teaching Strategies GOLD® looking at the reasons for its creation and the way it has evolved. In addition, I explore and define the structure of the documentation system and the different reports, strategies, tools, and supports that are provided in the Teaching Strategies GOLD® assessment system and the purpose of each. I complete this in-depth exploration to show the extensive amount of processes and procedures that many early childhood educators are required to access and implement in their work with young children and families. 


\section{Teaching Strategies GOLD®}

Teaching Strategies GOLD® is an assessment system in which the roots are connected to President Johnson's War on Poverty (1964) as a way in which early childhood educators can document their observations of the children in their care and then assess their students' learning and development through matching the learning they observe with a matrix of predefined developmental domains (Teaching Strategies, 2014). The Teaching Strategies GOLD® assessment system has been designed as a way to measure a child's developmental progress from age 0 to 71 months (Kim et al., 2013a; Lambert et al., 2014, 2015). The intended use of the Teaching Strategies GOLD® assessment system is with children developing typically, children with special rights, and children who are duel language learners (Kim et al., 2013a, 2013b; Lambert et al., 2014, 2015; Teaching Strategies LLC, 2014).

The Teaching Strategies GOLD® assessment system was developed over several years (Lambert et al., 2015). The current system was created in response to the growing research of "the importance of early leaning and its relationship to school and success in later life" (Teaching Strategies, 2010, p. 1). Pilot studies were conducted with a diverse population and feedback from early childhood educators, administrators, consultants, and other professionals was considered in the development of the current system (Lambert et al., 2015). The Teaching Strategies GOLD® assessment system focuses on 36 basic objectives that measure "the knowledge skills, and behaviors that are predictive or most important for school success" (p. 2) with two additional objectives focused in the area of English language acquisition (Teaching Strategies, 2010). 
Using the Teaching Strategies GOLD® assessment system, early childhood educators collect and record observations of children's work over a specified period of time (Teaching Strategies, 2012). This specified period of time is called a checkpoint period. Closing dates for checkpoint periods can be determined by the child development or preschool program using the system (Teaching Strategies, 2014). At the end of each checkpoint period, early childhood educators use the data collected and recorded to analyze and record where the child's developmental level and knowledge fall along a 10point rating scale supplied by Teaching Strategies GOLD® (Kim et al., 2013a; Lambert et al., 2014, 2015). This rating scale, labeled as Widely Held Expectations by the Teaching Strategies GOLD® assessment system, runs from zero to nine, zero being a rating of not yet and nine being beyond kindergarten expectations (Kim et al., 2013a). Indicators, which are levels that provide examples of everyday occurrences, are set at levels two, four, six, and eight. In-between levels are one, three, five, seven, and nine and are levels that indicate that the early childhood educator is seeing the child exhibit the next level of skill or knowledge some of the time but not consistently, indicating that the skill and/or knowledge is emerging.

The rating scale of Widely Held Expectations objectives include predictors that are associated with the Head Start Child Development and Early Learning Framework and state learning standards (Teaching Strategies, 2014). Within these objectives are specific categories and subcategories. The purpose of these categories and subcategories is to help "educators focus on what matters most for children's success" (Teaching Strategies, 2014, p. 3). Each of these categories and subcategories are divided into color- 
coded bands that reflect the pre-set expectations for different age groups as outlined by the Teaching Strategies GOLD® assessment system; red for children age zero -11 months, yellow for children age 12-23 months, orange for children age 24-35 months, green for children age 36-47 months, blue for children age 48-59 months, and purple for children age 60-71 months (Teaching Strategies, 2014). Information gathered about children through work samples, observations, photos, conversations with families, etc. can be applied to these categories (Kim et al., 2013a; Lambert et al., 2015). This information can be used to plan activities, consider individual and group learning experiences, monitor child progress, and determine if a more specific evaluation may be required (Lambert et al., 2015).

Objectives in the Teaching Strategies GOLD® assessment system are organized by growth and development, content learning, and English language acquisition (Kim et al., 2013a; Lambert et al., 2014, 2015; Teaching Strategies, 2010). Objectives in the area of growth and development are focused on social-emotional development, physical development, oral language, and cognitive development. Objectives in the area of content learning are focused on literacy, mathematics, science and technology, social studies, and the arts.

Under the area of growth and development, the Teaching Strategies GOLD® assessment provides three social-emotional objectives which include regulating own emotions and behaviors, establishing and sustaining positive relationships and participating cooperatively and constructively in group situations (Kim et al., 2013a; Lambert et al., 2014, 2015; Teaching Strategies, 2010, 2014). Objectives for physical 
development include traveling skills, balancing skills, gross-motor manipulative skills, and fine motor strength and coordination (Kim et al., 2013a; Lambert et al., 2014, 2015; Teaching Strategies, 2010, 2014). Oral language objectives include listening and understanding others, using language as a means to express thoughts and needs, and using appropriate conversational skills (Kim et al., 2013a; Lambert et al., 2014, 2015; Teaching Strategies, 2010, 2014). Objectives for cognitive skills include positive approaches to learning, remembering and connecting experiences, using classification skills, and using symbols and images to represent something not present (Kim et al., 2013a; Lambert et al., 2014, 2015; Teaching Strategies, 2010, 2014)

Objectives in the area of content learning are focused on literacy, mathematics, science and technology, social studies, and the arts (Kim et al., 2013a; Lambert et al., 2014, 2015; Teaching Strategies, 2010). The Teaching Strategies GOLD® assessment system has five objectives in the area of literacy. These objectives are demonstrating phonological awareness, alphabet knowledge, knowledge of print and print uses, book awareness, and emergent writing skills (Kim et al., 2013a; Lambert et al., 2014, 2015; Teaching Strategies, 2010, 2014). Objectives for mathematics include number concepts and operations, spatial relationships and shapes, comparing and measurement, and pattern knowledge.

The objectives focused on science and technology, social studies, and the arts are for children age 36-71 months (Kim et al., 2013a; Lambert et al., 2014, 2015; Teaching Strategies, 2014). There are five objectives in the area of science and technology which are using scientific inquiry skills, knowledge of the characteristics of living things, 
knowledge of the physical properties of objects and materials, knowledge of the Earth's environment, and using tools and technology to perform tasks. The area of social studies includes four objectives which are knowledge of self, an understanding of people and how they live, exploring change related to familiar people or places, and simple geographic knowledge. Objectives for the arts are exploring visual arts, exploring musical concepts and expression, exploring dance and movement concepts, and exploring drama through actions and language (Kim et al., 2013a; Lambert et al., 2014, 2015; Teaching Strategies 2010, 2014).

The objectives that analyze English language acquisition include demonstrating progress in listening to and understanding English and demonstrating progress in speaking English (Teaching Strategies 2010, 2014). There are also additional objectives in the area of Spanish language ${ }^{3}$ and literacy. In the Teaching Strategies GOLD® Tour Guide (2014) the Spanish language and literacy objectives are described as being "similar to the English language and literacy objectives but they have been adopted to reflect patterns unique to Spanish language and literacy" (p. 23). In addition, the Teaching Strategies GOLD® early childhood educator site is available in a standardized dialect of Spanish and English, and many of the reports that can be generated by the Teaching Strategies GOLD® assessment system are available in Spanish and English as well (Teaching Strategies, 2014).

Teaching Strategies GOLD® describes itself as "an authentic, ongoing observation system for assessing children from birth through kindergarten” (Teaching

\footnotetext{
${ }^{3}$ For the purpose of this dissertation Spanish language is used to represent a standard dialect of Spanish spoken in the United States.
} 
Strategies, 2014, p. 3). There is not a universal definition of the term authentic assessment, however, in early childhood education, authentic assessment is most often used to describe a type of assessment that is based on children's intellectual and real-life challenges (Fosnot, 2005; Lambert, et al., 2015). Lambert et al. (2015) describe authentic assessment as a process in which early childhood educators collect evidence about each child by documenting how the child interacts with objects, peers, and early childhood educators in different situations. This evidence can be in the form of photographs, anecdotal notes, work samples, recordings, etcetera (Teaching Strategies, 2014).

\section{Documenting and assessing children's experiences in Teaching Strategies GOLD®.}

The Teaching Strategies GOLD® assessment system offers different opportunities for early childhood educators to focus their observations, organize the information, and document facts including processes for General Documentation, using Assessment Opportunity Cards, or On-the-Spot tools (Teaching Strategies, 2014). Each of these tools can be found on the Add Documentation page in the Teaching Strategies GOLD® assessment system website. Under General Documentation early childhood educators begin by choosing a child or group of children in which the evidence is about and the date that the evidence was acquired (Teaching Strategies, 2014). After recording each of these characteristics, the early childhood educator enters notes describing the evidence (Teaching Strategies, 2014). Early childhood educators can upload additional documentation regarding the situation such as a scanned copy of the artifact, photo, video, or recording (Teaching Strategies, 2014). Once the early childhood educator has documented the evidence for assessment, they connect the documentation to the different 
learning objectives as outlined by the Teaching Strategies GOLD® assessment system on the Widely Held Expectations rating scale (Teaching Strategies, 2014). Early childhood educators select an area of development by clicking on the small plus sign to the left of the development title, exposing the different objective categories and subcategories found within this area of development (Teaching Strategies, 2014).

Once an area of development has been selected, early childhood educators can then record which objective categories and subcategories they want to apply the documentation to by clicking on the small box to the left of the objective (Teaching Strategies, 2000). A small rainbow-colored box will appear.

The early childhood educator then has the opportunity to select the preliminary level of the child's development in that particular objective by clicking on the rainbowcolored box. Once this is applied a new window opens and early childhood educators can record the level in which they assess the child's development according to the documentation on the Preliminary Level chart for that objective and sub-category. Early childhood educators have the option of applying multiple objectives to each documentation. When the early childhood educator has completed the assessment, they save the observation to the assessment system.

Two other options on the Add Documentation page are the Assessment Opportunity Card and On-the-Spot tool. Assessment Opportunity Cards include directions for curriculum-embedded classroom experiences that provide opportunities for early childhood educators to observe children's number and literacy skills (Teaching Strategies, 2014). There are multiple Assessment Opportunity Cards that explain how to 
structure opportunities for children to demonstrate their knowledge and what they can do in certain numeracy and literacy objectives (Teaching Strategies, 2016). Early childhood educators download the learning opportunity instructions from the Teaching Strategies GOLD® assessment system website, follow the directions when implementing the activity, then record the children's responses on the Add Documentation page. When assessing the activity, the early childhood educator clicks the circle to the left of Assessment Opportunity Cards then chooses the activity that was implemented. When the activity is selected, the objectives most closely related to that activity are highlighted so that the early childhood educator will have a focused observation of the activity.

The On-the-Spot tool is a premade checklist that early childhood educators can use to assess whether a child is able to accomplish a skill (Teaching Strategies, 2014). The early childhood educator starts by printing out a checklist for the domains/objectives they wish to record. As they see a child is able to meet these developmental objectives they mark a check next to each one. When adding documentation to the child's profile the early childhood educator selects the On-the-Spot option and is able to mark off what they recorded the child accomplishing in one entry (Teaching Strategies, 2012).

Early childhood educators collect data throughout each checkpoint period. Checkpoint periods are dates selected by the program and can be up to four times a year (Teaching Strategies, 2016). When ending a checkpoint period, early childhood educators complete a checkpoint period form for each child. There are multiple options for completing checkpoint period forms including entering checkpoints by area, objective, child, or by multiple children. Each of these options leads to progressive screens. Early 
childhood educators enter their evaluation of each child's behaviors, knowledge, and skills in terms of each objective category and subcategory. While working within these screens, early childhood educators are able to view the rating scale assigning numeric value to each level in terms of each objective category and subcategory, the level of progression indicators, examples of what each level of progression looks like, colorbands showing the Teaching Strategies GOLD® assessment system Widely Held Expectations by age, previous checkpoint levels for the child, and documentation and preliminary levels (if assigned) that have been recorded during the checkpoint period for that objective. Once the checkpoint levels are complete, early childhood educators and administrators can analyze the information through a number of reports.

Programs using the Teaching Strategies GOLD® system, are encouraged to have the educators using the system successfully complete the Interrater Reliability certification process. The Interrater Reliability Certification process is "An online certification process that gives you the opportunity to evaluate sample child portfolios and compare your ratings with those of Teaching Strategies' master raters" (Teaching Strategies ${ }^{\circ}$ How-To Guide for Teachers, 2018 p. 1). The Interrater Reliability Certification process was designed to coach educators on how to analyze the work they were seeing the children do fit within the Teaching Strategies GOLD® system. Although Teaching Strategies GOLD® states that the Interrater Reliability Certification process is "not designed to train you, or evaluate you as a teacher" educators need to agree $80 \%$ of the time with the "master ratings in each area of development and learning" in order to 
earn certification in each of the categories (Teaching Strategies GOLD® How to Guide for Teachers, 2018, p. 59).

\section{Teaching Strategies GOLD® reports}

In addition to multiple ways to document and assess children's learning, the Teaching Strategies GOLD® assessment system offers a plethora of tools in which to use these observations to summarize, plan, and share information with families, administrators, and other stake-holders (Teaching Strategies, 2014). The Class Profile Report, Individual Child Report, and Developmental and Learning Report can be used by both early childhood educators and administrators (Teaching Strategies, 2015a). The second three of the six reports are more strongly focused towards administrators and include the Snapshot Report, Growth Report, and Comparative Report.

The Class Profile Report can be complied for one classroom or several (Teaching Strategies, 2015a). It is a tool that can be used by early childhood educators anytime during the checkpoint period to recognize where children's knowledge and behavior skills are at along the rating scale. This information can be used to plan for group activities and can be compared to the end of the previous checkpoint to see where children have grown and where there is more opportunity for growth.

Individual Child Reports can be customized to show the progression of one child or multiple children individually (Teaching Strategies, 2015a). Using this report the early childhood educator can determine each child's growth and development to consider what further support may be necessary. This report can be generated during the checkpoint 
period to support planning or at the end of the checkpoint period to provide early childhood educators and parents an overview of the child's growth and development.

The Development and Learning Report was designed as a support tool for early childhood educators to share with parents (Teaching Strategies, 2015a). It "provides narratives that explain the child's knowledge, skills, and behaviors in relation to each objective or dimension" (p. 8). The Developmental and Learning Report uses the generic descriptions of the child's current level of development in the objective areas selected by the early childhood educator. In addition, the Development and Learning Report lists out the next developmental steps expected to be exhibited by the child. This report can also be generated to include recommended activities to support development.

Snapshot Reports present an overarching glimpse at the program or classroom performance ratings over a single checkpoint period (Teaching Strategies, 2015a). Snapshot Reports display the percentage of children whose development and learning are below, meeting, or exceeding the Widely Held Expectations as outlined on the rating scale set by the Teaching Strategies GOLD® assessment system. The Snapshot Report can also be generated by the domains of the Head Start Child Development and Early Learning Framework, or state standards (Teaching Strategies Reports, 2015).

Growth Reports show gains that are separate from Widely Held Expectations (Teaching Strategies, 2015a). "This means that children who begin with developmental or other delays can still show gains toward meeting Widely Held Expectations" (p. 14). The Growth Report is a way for early childhood educators to look for any growth that a child demonstrates over time. 
The Comparative Report is a way in which early childhood educators and administrators “can compare children's scores to either the Widely Held Expectations or a nationally representative sample of children” (Teaching Strategies, 2015a, p. 16). It allows early childhood educators or administrators to look at children's growth and development on a uniform scale. The Comparative Report offers a variety of filtering options giving administrators the ability to decrease or increase the report criteria to meet the programs specific needs (Teaching Strategies, 2015a).

\section{Sharing information with families through Teaching Strategies GOLD®}

The Teaching Strategies GOLD® assessment system has a variety of resources available that encourage partnership between parents and early childhood educators (Teaching Strategies, 2014). The first of these is named Family Central. Family Central is an online tool for communicating with families about the experiences and progress of their children. To access the Family Central portal, early childhood educators invite families to register to be able to send and receive messages with their child's early childhood educator. The early childhood educator can create online calendars to keep families aware of what is happening in the classroom as well as send resources to support families help their children's leaning and development at home.

A second resource to encourage partnership with families is the Family Conference Form. Family Conference Forms are completed by the early childhood educator and family together (Teaching Strategies, 2014). The conference form is a summary of the child's developmental progress during a checkpoint period. The early childhood educator starts the form by compiling a collection of objectives in which the 
child has progressed and selecting documentation that reflects each progression. During a conference with the family, the early childhood educator and family work together to decide next steps. The form can be shared with families electronically or printed and shared with families.

A third resource to build partnerships with families is the Development and Learning Report (Teaching Strategies, 2014). The Developmental and Learning Report creates an opportunity for early childhood educators to provide narratives that "explain the child's knowledge, skills, and behaviors in relation to each objective or dimension" (p. 29). Early childhood educators can use this report to recommend activities that children and families can do at home to provide additional support for the child's development and learning in those areas.

In this section I have provided a history of the Teaching Strategies GOLD® assessment system looking at the reasons for its creation and the way it has evolved. In addition, I explored and defined the structure of the documentation system and the different reports, strategies, tools, and supports that are provided in the Teaching Strategies GOLD® assessment system and the purpose of each. The overview I give of Teaching Strategies GOLD® is of the basic system. There is an additional 'upgrade' to this system titled $G O L D$ plus ${ }^{\circledR}$. GOLDplus ${ }^{\circledR}$ is a system that connects the assessment properties of Teaching Strategies GOLD® to the curriculum experiences of The Creative Curriculum® (Teaching Strategies, 2015b). For the purpose of this research study, I do not include the options available in GOLDplus ${ }^{\circledR}$ because it is not part of the 
measurement system used in my place of practice or part of the required use for participants in this research study.

When reviewing the structure and documentation system, reports, strategies, tools, and supports provided within Teaching Strategies GOLD®, several things stood out to me. The first is how appealing the whole system can be. It has everything you need to assess a large group of children, seemly showing a child's accomplishments through documentation and, because it is based on observations, artifacts, etc. it feels authentic. An additional item that stood out for me are ways in which the system gives the perception of saving educators time by providing ways in which to implement the documentation tools, such as the Assessment Opportunity Card to categorize multiple children in specified learning objectives at one time, or using the Family Central tool to communicate with families quickly. However, in my experience, the Teaching Strategies GOLD® assessment system is not saving time, it is replacing time. It replaces time once spent in dialogue with children, families, and other early childhood educators, time that could be used to revisit and reflect with children about their learning experiences, with time spent on a computer in isolation of children and peers.

One of the goals of the Teaching Strategies GOLD® assessment system is that teachers would have a system of assessing young children with fidelity. In other words, assessments could be completed with a small risk of teacher subjectivity. The idea of fidelity in education is not a new consideration in United States educational policy. In the next section I explore how the historical habit of United States' educational policy promotion of a focus on fidelity through standardized assessment and curriculum based 
on pre-established learning objectives is being replicated into United States early childhood education policy creation.

\section{Notions and Enactments of Standardization Early Childhood Education in Policy and Practice}

Previously, I explored and defined the structure of the Teaching Strategies GOLD® assessment system, the different documentation forms, reports, strategies, tools, and supports that are provided by Teaching Strategies GOLD® and the purpose of each. Now, I begin by showing how the Early Education for All Americans Act promotes PFPSA programs such as Teaching Strategies GOLD® by encouraging policy designs that focus on standardized learning objectives, teacher accountability, and curriculum control (Feeney, 2016; Christakis, 2016). Next, couched in Apple (2009), Ayers (1989), Christakis (2016), Eisner (1985), Feeney (2016), Kohn (2000), Parnell (2010, 2011a, 2011b), and others, I investigate the assumptions commonly held about early childhood educators in the United States and how this media driven description effects the image of the child and the larger idea of what early childhood education could be (Parnell, 2010). I do this in order to establish a sense of the culture that surrounds early childhood educational policy creation in the United States.

United States public education practices have been tightly bound to the political beliefs of those in the position to create and implement policy. These polices have often reflected their ideals about what is best for the United States and its place in the world (Cross, 2014). We have seen how this influence has affected elementary and secondary education policy and practice through programs such as the publication of A Nation at 
Risk 1983 and the No Child Left Behind Act (NCLB) 2002, displaying an increasing focus on standardized learning objectives, teacher accountability, and curriculum control (Cross, 2014; Dee \& Jacob, 2011; Hursh, 2007; Vannest, Mahadrvan, Mason, \& TempleHarvey, 2009). Now, as new research continues to surface showing the importance of children's early years and brain development, the eyes of United States education reform have turned towards early childhood education policy and practice (Christakis, 2016; Feeney, 2016).

During his 2013 State of the Union address, United States’ President Obama spoke about the relationship between quality early childhood education programs and eventual long-term school success for children, stating:

Study after study shows that the sooner a child begins learning, the better he or she does down the road ${ }^{4}$. Tonight, I propose working with states to make highquality preschool available to every child in America. Every dollar we invest in high-quality early education can save more than seven dollars later on - by boosting graduation rates, reducing teen pregnancy, even reducing violent crime. In states that make it a priority to educate our youngest children, like Georgia or Oklahoma, studies show students grow up more likely to read and do math at grade level, graduate high school, hold a job, and form more stable families of their own. So let's do what works, and make sure none of our children start the race of life already behind. Let's give our kids that chance. (President Barack Obama, State of the Union Address, 2013)

Through the United States Department of Education (DOE), President Obama pledged funding to support states so that all children would have access to "high quality" (Fact Sheet President Obama's Plan for Early Education for all Americans, 2013, para.

\footnotetext{
${ }^{4}$ For the purpose of this dissertation it is assumed that President Obama refers to "learning" in this context as "formal school-based learning".
} 
38) early childhood education programs. High quality preschools are defined as programs that meet common and consistent standards including:

- well-trained educators who are paid comparably to K-12 staff

- small class sizes, low adult to child ratios

- a rigorous curriculum ${ }^{5}$

- comprehensive health and related services

- effective evaluation and review of programs

(Fact Sheet President Obama's Plan for Early Education for All Americans, 2013, para. 10)

In addition, for states to access federal funding, they are required to meet United States federal quality benchmarks (Fact Sheet President Obama's Plan for Early Education for All Americans, 2013). These United States’ federal quality benchmarks include state level standards for learning, qualified educators in all preschool classrooms, and a plan to implement comprehensive data and assessment systems. Following the United States' historical concepts of education reform, if early childhood education programs are supported by federal funding, then metrics will be needed to justify the cost (Feeney, 2016; Oregon Department of Education, 2011; 2015c). The terms 'state level standards for learning' and 'data assessment systems' insinuate systems similar to those that have been highly debated in elementary and secondary education programs (Christakis, 2016; Feeney, 2016). When considered through an early childhood education lens, the ideas of learning standards and assessment are highly contested and difficult to define (Christakis, 2016; Feeney, 2016).

\footnotetext{
${ }^{5}$ A rigorous curriculum can be defined as one that playfully and intentionally focuses on children's cognitive, social-emotional, and physical development (What is a 'rigorous' preschool curriculum?).
} 
There are many similarities between President Obama's plan for early childhood education and President Bush's NCLB Act. In both cases, the proposals offer financial incentives for states that demonstrate the success of their students as determined by standardized learning objectives, better qualified educators in the classroom, and more choices for parents regarding their child's education (Christakis, 2106; Dee \& Jacob, 2011; Feeney, 2016; Hursh, 2007). United States education policies have a historical focus on teaching with fidelity, meaning that each child should receive the same content exposure and have the same learning opportunities no matter what the circumstances (Fact Sheet President Obama's Plan for Early Education for all Americans, 2013; Vannest et al., 2009). This idea of teaching with fidelity should make us question the perception policy makers have regarding early childhood educators and the role of early childhood education as all children come to school having already learned, with different experiences and knowledge to share (Christakis, 2016).

\section{Perceptions of early childhood educators in the midst of United States early education policy creation.}

Recently, as policies such as the Common Core for elementary and secondary education have been under scrutiny, early childhood education has been caught in the spotlight of educational policy creation and reformation (Christakis, 2016; Feeney, 2016). The explanations for the lack of traction of the Common Core have been many, attributed on one side to a lack of alignment in materials and training for teachers to "teach to the standards effectively" (Hess \& McShane, 2013, p. 63) and on the other side as expanding the opportunity gap by making "no actual effort to connect concepts to [students'] prior 
knowledge" (Brown, 2016, p. 56). Perhaps this idea of children needing a homogeneous education is why, as Christakis (2016) states, "policy makers and educators began to recast preschool from a playful social experience to a more narrow educational opportunity focused on so-called cognitive or academic skills to the exclusion of broader learning goals" (p. 7). As I have stated before, it seems as if the DOE has deemed early childhood education as the 'silver bullet' that will fix the United States educational system and society as a whole. The conflicting attitudes regarding the value of positive early childhood education experiences and the devaluing of early childhood educators has created an ambiance that leaves early childhood educators on the outside of the circle of policy creation for early childhood education programs (Ayers, 1989; Parnell, 2010). It is a precarious attitude that insinuates a perception that early childhood educators are "unworthy of serious attention" (Ayers, 1989, p. 3) and that those who create education policy know how children learn better than those who work with young children daily. It is a disposition that has been executed repeatedly in the creation of United States educational policies and seems to be spiraling uncontrollably towards early childhood education programs (Ayers, 1989; Christakis, 2016; Parnell, 2010).

In this section I use the word 'perception' to help describe the undefined and underdefined role of the early childhood educator in the United States. The field of early childhood education is one that is complex and complicated (Ayers,1989; Bodrova \& Leong, 2005; Christakis, 2016; Edwards, 2012; Parnell, 2010, 2011b). Yet it is in this complexity that we find the beauty of working with young children (Christakis, 2016; Parnell, 2011b). Edwards (2012) has described the role of the early childhood educator in 
typical United States classrooms is that of curriculum planner, environment preparer, guidance provider, observer, parent educator, and communicator to outside audiences. Yet even this description does not fully or clearly describe the complexity of our work. However, describing the role of the early childhood educator is different than the perception of the early childhood educator, and it is the commonly held perception that has alienated early childhood educators from policy creation and professional recognition (Ayers, 1989; Christakis, 2016; Parnell, 2010).

Ayers, (1989) describes the attitude towards early childhood educators as one that makes us become invisible inside our own worlds, writing that to the outside world, "Preschool teachers appear to be glorified babysitters whose working lives are un-related to the lives of other teachers, a subject of teachers generally without exceptional and important characteristics of their own" (p. 3). In other words, even within the field of education, early childhood educators are seen as 'less than' elementary teachers. For example, even though there is an increasing amount of evidence to the importance of positive early childhood education experiences to long term learning success, the annual average salary for an Oregon early childhood educator with a master's degree in their field is less than half of what a kindergarten teacher with the same education level will make (Retrieved from: http://www.preschoolteacher.org/oregon/oregon-salary).

In the United States, it is commonly believed that the educator is seen as a giver of knowledge (Apple 2009; Eisner, 1985; Freire, 2003; Parnell, 2010). This perception has influenced United States educational policy for decades, yet at the same time it is a perception that is often articulated with a wink and a nod. Yes, the public educational 
policies that have been implemented into United States schools place the educator in the role as a giver of knowledge, however these polices also demonstrate a belief that educators need to be told what knowledge to bestow and how to bestow that knowledge to students (Apple, 2009; Eisner, 1985; Freire, 2003; Hess \& McShane, 2013; Kohn, 2000). Eisner (1985) outlines this process as the belief from policy creators of school being a place where common goals must be stated, much like a business. The tasks of politicians and administrators is to define and articulate those goals, breaking them down into units and creating procedures to help teachers achieve the goals. To make sure teachers follow these procedures, monitoring systems, such as standardized testing, need to be implemented. This process of controlling the curriculum and how it is implemented not only controls teachers, but also controls the children in their classrooms.

More recently, Apple (2009) has remarked on the process of controlling the work of educators, stating that with United States public education policies, an educator's professionalism is gaged by their ability to conform to the procedures that have been implemented to meet the goals set by administrators and politicians. Apple (2009) writes:

Becoming adept at grading all those tests and worksheets quickly, deciding on which specific skill group to put a student in, learning how to 'efficiently manage' the many different groups based on the tests, and more, all became important skills. As responsibility for designing one's own curricula and one's own teaching decreased, responsibility over technical and management concerns came to the fore. (p. 206)

Apple further states that this restructuring of the field, the de-skilling of the act of teaching, and intensification of work that is not with students, is now "misrecognized as a symbol of professionalism" (p. 206) and is causing many teachers to leave the field. 
Although the writings of Apple (2009), Eisner (1989), and Kohn (2000) are centralized mostly on elementary and secondary education, we can see the ways in which similar attitudes are fueling the undefined and underdefined perception of the early childhood educator in the United States (Christakis, 2016). The sudden and intense political and public focus on early childhood education has created an atmosphere of tension and urgency in professionalizing early childhood education and defining what early childhood education programs should be (Christakis, 2016; Parnell, 2010). It is an atmosphere full of contradictions that forces early childhood educators, parents, and programs into an environment of blame placing and accountability (Christakis, 2016). This environment has created a hyper-competitive milieu where political criticism and a marketplace mentality drive public opinion and policy creation (Christakis, 2016; Parnell, 2010). In the interest of a quick fix, early childhood education policy and programs are turning towards standardized learning objectives, teacher accountability, and curriculum control.

This pattern of education reform, the turn towards standardized learning objectives, teacher accountability, and curriculum control, can be seen in the ways in which the Teaching Strategies GOLD® assessment system promotes fidelity as objectivity in early childhood education. At the 2016 NAEYC National Conference I attended a session titled, "Helping teachers implement curriculum with fidelity by individualizing professional development and mentoring”" (NAEYC, 2016, p. 87). The session was led by Clarissa Martinez, Content Development Associate for Teaching Strategies GOLD®, and Breeyn Mack, Content and Community Manager at Teaching 
Strategies GOLD®. This session addressed the doctrine of how supervisors and mentor teachers can determine to what degree teachers were implementing curriculum the way the developer intended and how accurately and consistently teachers are delivering content (C. Martinez, personal communication, November 3, 2016). It also included coaching strategies in which supervisors and mentor teachers could support teachers to see what 'right' looks like and define the gaps in implementing curriculum with fidelity as objectivity (B. Mack, personal communication, November 3. 2016). According to Mack, these gaps could be addressed through the use of the Interrater Reliability certification process, training and staff development, and individualized instruction for teachers (B. Mack, personal communication, November 3. 2016).

When training and educational opportunities are focused on conforming to the policies and implementation procedures of PFPSA systems and boxed curriculum sets, early childhood educators lose out on the opportunities to develop teaching skills and professional development (Parnell, 2010). They do not get to choose areas in which they would like to gain new insight or support but instead are forced to follow along, increasing the image that the early childhood educator is not good enough, smart enough, intuitive enough, or professional enough to understand how to work with young children. This perceived powerlessness is enough to dampen the spirits of many early childhood educators, leaving us overwhelmed by the intensification of work that does not follow our passion (Apple, 2009; Christakis, 2016; Parnell, 2010).

In this section I have explored some of the perceptions of early childhood educators in the midst of United States early childhood education policy creation in order 
to further connect the focus of United States early childhood education policy creation to the structure and format of the Teaching Strategies GOLD® assessment system. I did this in order to demonstrate the ways in which these polices continue to encourage an atmosphere that promotes fidelity and control, leaving early childhood educators feeling overwhelmed and underappreciated. However, there is another way. The municipally funded preprimary schools and infant and toddler centers of Reggio Emilia, Italy demonstrate an innovative approach to early childhood education (Dahlberg, 2012; Delrio, 2012; Edwards, 2012; Gandini, 1993, 2001, 2012; Goldhaber, 2001; Parnell, 2011a; Rinaldi, 2006; Vecchi, 2010; and others). In order to understand the practices inside of the Reggio and Reggio-inspired documentation processes, I needed to survey the literature and situate these understandings inside the more broadly scoped approaches conceptualized and used in Reggio Emilia, Italy's municipally funded preprimary schools and infant and toddler centers. In the next section I touch briefly on the culture that surrounds the municipally funded preprimary schools and infant and toddler centers of Reggio Emilia, Italy and take an in-depth exploration of pedagogical documentation; since that particular aspect of the Reggio approach is central to this research project's aims.

\section{Pedagogical Documentation as a Learning Process: An Innovative Way to}

\section{Assessment.}

In this section, I focus on pedagogical documentation as a learning process and as an innovated way to assess children's learning. My reasons for focusing on pedagogical documentation are the connections that I see with the constructivist learning theory 
paradigm and the methodology that I have chosen for this study, narrative inquiry. As a self-identified constructivist early childhood educator and learner, I believe that children, as well as adults, learn best through a series of meaning making and connections (Bodrova, 2008; Chaillé, 2008; Piaget, 1979; Vygotsky, 1978). In my practice, I know that my team and I were at our strongest, that is, were most connected to each other and the children in our care, when we had the opportunity to revisit, reflect, consider, and make meaning of the experiences and interactions that were happening in our classroom. The opportunity to be in dialogue with each other, to discuss the magical moments, conversations, wonderings, questions, and frustrations we were each experiencing helped us to learn more about the children in our care, each other, ourselves, and the larger world around us.

This same sort of dialogue, the process of remembering, reflecting, questioning, commenting, debating, and wondering helps children learn from their experiences as well. It empowers children to see themselves and be seen by others as constructors of their own knowledge and as an important part of a learning community (Cadwell, 1997, 2002; Delrio, 2012; Parnell, 2011a; Rinaldi, 2001a, 2001b, 2012; Rintakorpi \& Reunamo, 2016). In the municipally funded preprimary schools and infant and toddler centers of Reggio Emilia, Italy and inspired schools, these conversations happen between children, educators, parents, and the community through the process and with the support of pedagogical documentation (Cadwell, 1997, 2002; Forman \& Fyfe, 2012; Parnell, 2011a; Rinaldi, 2001a, 2001b, 2012). Pedagogical documentation is the process of creating, revisiting, reflecting and making meaning of experiences with children as an ongoing 
process of learning (Cadwell, 1997, 2002; Forman \& Fyfe, 2012; Fleet et al., 2006;

Rinaldi, 2001a, 2001b, 2012; Rintakorpi \& Reunamo, 2016). Through pedagogical documentation, children are encouraged to question, wonder, and experiment, working with each other, early childhood educators, parents, and other community members to develop their own theories about life and the world around them.

Based in northern Italy, Reggio Emilia is a city in which the constructivist learning perspective has been a key element in the development of the what is commonly known in early childhood education circles as the Reggio Approach to early childhood education (Morrison, 2007). This city has a long history of the making of the schools for young children with origins that lie with the end of the second world war (Gandini, 2012; Thornton \& Burton, 2015). For many self-identified, constructivist early childhood educators like myself, the municipally funded preprimary schools and infant and toddler centers of Reggio Emilia, Italy, in fact the city of Reggio Emilia, Italy itself, can be an intimidating inspiration. Visiting the city and the schools is like meeting a long-lost sibling you never knew you had but always missed. It is a place where you see your dreams in action, where there is a culture of respect for young children, a love for learning, and a desire to discover. It is a learning city and a learning society, that grows and evolves with its citizens (D. Margini, personal communication, March 23, 2015). When you leave, you are inspired, telling yourself, 'It can be done!' and when you return to your home program (in my case to a large corporate child development program in Oregon) to a culture of regulations, learning standards, and fidelity, it can seem like there is so much work to do. 
The role of the early childhood educator in the municipally funded preprimary schools and infant and toddler centers of Reggio Emilia, Italy is not as one who bestows knowledge, but a partner in learning (Cadwell, 1997, 2002; Edwards, 2012; Gandini, 2012; Rinaldi, 2012). Coinciding with how Chaillé (2008) described the constructivist early childhood educator, the early childhood educators in municipally funded preprimary schools and infant and toddler centers of Reggio Emilia, Italy listen with full attentiveness to children (Edwards, 2012). Rinaldi (2012) describes this pedagogy of listening by stating:

One of the first questions we ask ourselves as educators is: 'How can we help children find meaning in what they do, what they encounter, and what they experience? And how will we do this for ourselves?' In the search for meaning we must ask: 'Why?', 'How?', and 'What?' These are the key questions that children constantly ask, both in and out of school. (p. 234)

Young children have the quality of the human mind to listen reciprocally and it is a quality that early childhood educators must embrace in themselves (Rinaldi, 2012). Reciprocal listening is a quality of being open to other's points of view and interpretations, being open to doubts, uncertainty, and accepting frustrations (Rinaldi, 2012). Rinaldi describes it as an "attitude for life" in which you open yourself to be in a place of crises and change (p. 235). Listening, however, is not enough alone. Early childhood educators must also observe and document what children are doing (Edwards, 2012). Strozzi (2015) describes observation not of being apart from children but as being part of children (P. Strozzi, personal communication, March 23, 2015). This information is later shared with children, parents, and other early childhood educators for making decisions about where to support the next steps of exploration (Edwards, 2012). 
The partnership with children, parents, and other early childhood educators is a key aspect to the pedagogy of the early childhood centers in Reggio Emilia (Gandini, 2012). Early childhood educators do not work alone or in a hierarchal structured teaching team as is often the norm in the United States' classrooms (P. Cagliarri, personal communication, March 23, 2015). Instead early childhood educators spend hours each week meeting with others, looking together at the work unfolding with the children and the documentation collected (P. Cagliarri, personal communication, March 23, 2015).

The history of the municipally funded preprimary schools and infant and toddler centers of Reggio Emilia, Italy is so rich that to attempt to fully represent it in detail would, and has, filled multiple books and dissertations such as The Hundred Languages of Children (2012), Making Learning Visible (2001), and Bambini (2001). Instead of taking on this huge attempt, I choose to focus on the role of documentation as assessment, a process often found in schools that are inspired by the municipally funded preprimary schools and infant and toddler centers of Reggio Emilia, Italy (Edwards, 2012; Fleet et al., 2006). The role of documentation in municipally funded preprimary schools and infant and toddler centers of Reggio Emilia, Italy is different than what we commonly see in traditional United States' early childhood classrooms (Edwards, 2012). Often referred to as pedagogical documentation, it is a daily part of life and serves many purposes (Rinaldi, 2012).

The phrase 'pedagogical documentation' has been attributed to Gunilla Dahlberg (Fleet, et al., 2006). Fleet, et al., (2006) state that "The process of documenting pedagogically can highlight a narrowing of focus in the way an experience with children 
transpires" (p. 11). It is both process and content (Dahlberg, Moss, \& Pence, 1999; Fleet et al., 2006). Rather than just being a simple narrative of what transpired, the importance of pedagogical documentation is the analysis of the process for both the early childhood educators and children (Fleet, et al., 2006).

In the municipally funded preprimary schools and infant and toddler centers of Reggio Emilia, Italy, pedagogical documentation is seen as a living record of educational practice (Dahlberg, 2012; Rinaldi, 2012). It can be used to revisit and review earlier experiences and events (Dahlberg, 2012). Dahlberg writes:

Through documentation, we can more easily study and ask questions about our practice. What image of the child do we hold? Which discourses of teaching and learning have we bought into? What voice, rights, and respect to children receive in our early childhood programs? Do we merely talk about the 'competent child', 'creativity', 'participation', and 'reflective practice' or do these ideas actually permeate what we practice? (p. 228)

Documentation in Reggio Emilia is seen as a way for children and early childhood educators to learn about and from their values and leaning processes (Dahlberg, 2012; Rinaldi, 2012).

Rintakorpi and Reunamo (2016) describe pedagogical documentation as happening when the documents are used to study and develop pedagogy. It requires diverse interpretations to be discussed and explored from children and early childhood educators and a meaning-making process to achieve a reliable, ethical, and valid approach (Dahlberg, 2012; Fleet, et al., 2006; Rinaldi, 2012; Rintakorpi \& Reunamo, 2016). In a recent study, Rintakorpi and Reunamo (2016) discovered that the use of pedagogical documentation in early childhood education classrooms led to features that are considered to reflect high quality in early childhood education including, positive 
emotions, less structured time, a high level of involvement in the activity, and children attending to one another.

Pedagogical documentation is a way to maintain relationships and experiences with children and colleagues (Dahlberg, 2012; Fleet, et al., 2006; Rinaldi, 2012;

Rintakorpi \& Reunamo, 2016). It is not done at the end of the project but is explored and expanded during the course of the work, "a process for making work visible and subject to dialogue, interpretation, consideration, and transformation" (Dahlberg, 2012, p. 225). Pedagogical documentation is a means of visible listening that can help early childhood educators and children reflect on their questions, wonderings, and research (Dahlberg, 2012; Fleet, et al., 2006; Rinaldi, 2012; Rintakorpi \& Reunamo, 2016). It abets early childhood educators in understanding children and childhood in a way that is different than just classifying children's abilities and skill sets (Parnell, 2011a, 2011b).

As a self-identified constructivist early childhood educator and learner, I see the value of using pedagogical documentation as an instrument to support learning. Through the process of exploring documentation with children, children notice what early childhood educators find valuable and begin to understand their own processes for learning (Dahlberg, 2012; Fleet, et al., 2006; Rinaldi, 2012; Rintakorpi \& Reunamo, 2016). When early childhood educators share documentation with children, they are demonstrating to the children that there is value in what the children do and say (Rinaldi, 2012). Pedagogical documentation starts with listening beyond the idea of either/or dichotomies (Dahlberg, 2012). It is subjective, a base for encouraging and nurturing negotiation, that changes and evolves along with the explorations. "Pedagogical 
documentation promotes the idea of the school as a place of democratic political practice" (Dahlberg, 2012, p. 226). It is a way for early childhood educators to learn how to work with children from their interactions with them and with others (Parnell, 2011a, 2011b).

I have used pedagogical documentation in my work with children - although somewhat unofficially - and have witnessed how sharing documentation of children's experiences with children give them the opportunity to be an active participant in the assessment of their own learning (Fyfe, 2012; Parnell, 2001a, 2011b). My workmates and I noticed that when we brought our observations back to the children, when we shared photos, videos, or our reflections with them to revisit, rethink, or gain clarification, we were often surprised by how differently they may remember the experience than we do. The use of pedagogical documentation in the classroom helps early childhood educators to uncover children's memories of experiences and find the streams of memory that connect into a larger river of meaning (Fleet et al., 2006; Parnell, 2011b; Rintakorpi \& Reunamo, 2016; Rinaldi, 2001a, 2001b, 2012). By listening with the intention of learning what the children are wondering, rather than looking for what we should do to meet the next learning objective, or assuming we know what we should be teaching them, we discover that their learning may go much deeper than we originally considered, our interactions and research together becomes deeply rich and meaningful (Cadwell, 1997, 2002; Delrio, 2012; Fleet, et al., 2006; Forman \& Fyfe, 2012; Parnell, 2011a; Rinaldi, 2001a, 2001b, 2012; Rintakorpi \& Reunamo, 2016). Pedagogical documentation unveils the twist and turns of children's learning, helping early childhood educators discover 
possibilities for future research and encouraging children to notice and discuss their own learning strategies (Cadwell, 1997, 2002; Delrio, 2012; Fleet, et al., 2006; Forman \& Fyfe, 2012; Parnell, 2011b; Rinaldi, 2001a, 2001b, 2012; Rintakorpi \& Reunamo, 2016). The use of pedagogical documentation embraces the prospect of an innovated perspective of what school can be, rather than the redundant regurgitation of current United States educational policies addressed earlier in this chapter.

In the municipally funded preprimary schools and infant and toddler centers of Reggio Emilia, Italy, documentation and assessment cannot be separated (Rinaldi, 2012). On this idea, Rinaldi (2012) writes, "It is impossible to observe without interpreting because observation is subjective. It is impossible to document without interpreting, and it is impossible to interpret without reflecting and observing" (p. 241-242).

Documentation and assessment in the municipally funded preprimary schools and infant and toddler centers of Reggio Emilia, Italy work together and feed each other (Rinaldi, 2012). Assessment is not done with the concept of what a child can or cannot do but instead is considered part of the learning paths that children are taking and the process they use as they search for meaning (Fyfe, 2012). "Thus, documentation, from a Reggio perspective, cannot be used interchangeably with the term measurement." (Fyfe, 2012, p. 274). In other words, documentation is not just a step in the assessment process, it is a living part of the school.

Pedagogical documentation can also help to build community (Dahlberg, 2012; Fleet, et al., 2006; Parnell, 2011a, 2011b; Rinaldi, 2012). It is a collaborative process that provides opportunities for early childhood educators to learn more about themselves and 
their work with young children (Dahlberg, 2012; Fleet, et al., 2006; Rinaldi, 2012; Parnell, 2011a, 2011b; Rintakorpi \& Reunamo, 2016). Parnell (2011b) writes that "through collaboration we grow as educators and become better able to help children flourish in our community context" (para. 11). Gandini (2001) describes one of the many roles of pedagogical documentation by stating that the "intention [of documentation] is to construct a shared understanding of children's ways of interacting with the environment, of entering relationships with adults and other children and of contracting knowledge" (p. 125). It is a process that supports early childhood educators in understanding their development as learners and educators, to "learn how to teach from children and the community" (Parnell, 2011b, para 14). That is, pedagogical documentation is not just a process of documenting, but also a process in which early childhood educators assess themselves and the children they work with in order to grow and develop their own practice with young children (Dahlberg, 2012; Fleet, et al., 2006; Parnell 2011a, 2011b; Rinaldi, 2012; Rintakorpi \& Reunamo, 2016).

It is in this spirit of collaboration and growth that I consider the process of pedagogical documentation in this dissertation. Through pedagogical documentation, early childhood educators collaborate to gain common meaning making through dialogue with each other, with children, parents, and the wider community (Dahlberg, 2012; Fleet, et al., 2006; Gandini, 2001; Parnell, 2011a, 2011b; Rinaldi, 2012; Rintakorpi \& Reunamo, 2016). Participating in this type of inter-subjectivity, the exchange, interaction, and growth that exists between and among people, in order to build upon and develop new knowledge, is similar to the values found in the constructivist learning theory. 
In this section I have articulated how through the process of pedagogical documentation, early childhood educators, children and others can deepen their knowledge about themselves, each other and the world around them. In the next section I present a detailed appraisal of the constructivist learning theory and qualities that are often exhibited by self-identified constructivist early childhood educators to understand how the research and theory literature have shaped theory to current practices.

\section{Constructivism as a Teaching, Learning, and Research Theory}

Constructivism is the learning theory that is grounded in the idea that learning is a process of making connections through experiences with objects and others, reflecting on those experiences, theory building, and theory testing (DeVries, 2000). It is as much about the ways in which we learn to know as it is about knowing (Fosnot, 2005). The core of constructivism in early childhood education is the value that children are competent, confident, curious young theory builders (Chaillé, 2008). The pursuit of the student's questions, interest and ideas are acknowledged and valued (Chaillé, 2008, Fosnot, 2005). The idea of knowledge itself is one of viable constructed explanations, instead of a truth to be discovered (Fosnot, 2005).

The constructivist learning theory is built upon the works of Jean Piaget and Lev Vygotsky. To inquire more deeply into these foundationary ideas, I focused on Piaget's works The Construction of Reality in the Child (1954) and The Development of Thought (1977), and Vygotsky's Thought and Language (1962) and Mind in Society (1978). Each of these fundamental texts gave me a strong foundation in which to build the framework of this section. 
The works of Piaget and Vygotsky have been debated and discussed for many years among many education researchers. As a genetic epistemologist, Piaget was interested in how children learn developmentally. In the 1977 documentary Piaget on Piaget, he states, "Human knowledge comes from what we do with objects..." (Piaget, 1979, 1:44). His theory of cognitive development was based on the belief that children learn through experiences, not externally manipulated instruction (Piaget, 1979).

Vygotsky theorized that children's knowledge was constructed through experiences and play (Mooney, 2000; Bodrova \& Leong, 2005). Vygotsky believed that personal and social experiences could not be separated from learning (Vygotsky, 1962; Bodrova, 2008; Bodrova, Germeroth, \& Leong, 2013). He theorized that to authentically understand young children's development, we need to understand the importance of the social context, of early childhood educators and peers interacting to increase knowledge (Vygotsky, 1978). This is one of the key ideas that contrasts strongly with using a PFPSA system such as Teaching Strategies GOLD® that focuses on rating scales and preestablished, generic learning objectives and the product of learning experiences rather than the interconnectivity of a child's learning and development.

Vygotsky is known for the idea that cognitive development is socially mediated and influenced by past and present interactions, whereas Piaget is more well-known for his theory of cognitive development occurring mostly through interaction with objects (DeVries, 1997). However, Piaget's later works centered on social constructivist philosophies as well. DeVries outlines the parallels in Piaget's theory of social moral and cognitive development which I examine later in this section. 
The key concepts behind Piaget's Theory of Cognitive Development are assimilation, accommodation, equilibrium and adaptation, and schemata (Singer \& Revenson, 1997; Fosnot, 2005; DeVries, 1997; Piaget, 1979). Assimilation is the process in which we take in new information and apply it to what we already know.

Accommodation is the process of adjusting what we already know to support the new information. Equilibrium and Adaptation is the process of adjusting of internal thought and external reality in order to find a balance in which to use new concepts and ideas in the future. Schemata is the mental representation of a connected set of perceptions when applying new information in the future (Singer \& Revenson, 1997; Fosnot, 2005;

DeVries, 1997; Piaget, 1977).

Piaget (1979) believed that we repeat these steps throughout our whole lifetime as we continue to take in new ideas and beliefs. He and those who subscribe to his theory have done countless studies, in many parts of the world, and within many different cultures. Through this research, Piaget (1979) found that "the stages are always the same" (12:30); we have existing knowledge that we believe to be factual, we learn something new that challenges the existing knowledge and, whether or not we decide to accept the new knowledge, our ideas have been altered, creating a new belief in which to view the world. Fosnot (2005) describes this process not as being linear, but as "a dance" (p. 20). That is, although the process can look the same, we do not move through each of the concepts as if walking up a flight of stairs, instead we move in and out of our acceptance of new ideas, challenging our old ideas and beliefs as well as challenging the new ideas being presented. Fosnot's (2005) description of Piaget's Theory of Cognitive 
Development as "a dance" (p. 20) connects strongly with my work with children.

Children's understandings change and evolve as they experience similar situations with different partners or alone and, as I continue to work with them, my understandings change and evolve as well.

Many critics of Piaget believe that he focused too heavily on cognitive development in reference to working with objects and did not consider the social aspects of cognitive development enough (DeVries, 1997). DeVries, however contradicts this criticism by outlining parallels in Piaget's theory of social-moral and cognitive development, beginning by stating that Piaget believed that knowledge is constructed by the child and that thought is changed through interactions. Just as Piaget perceived that cognitive thought was changed with the child's interaction with objects, DeVries writes that Piaget also perceived similar connections between the child's social thought and social interactions in his later work.

DeVries highlights another parallel between Piaget's cognitive and social developmental theories in the area of moral development and Piaget's idea of conservation, writing that for children to develop a sense of what the socio-moral norms are within a society, be it the society within the classroom or the larger society outside of the classroom, they must have a connection to the common values or beliefs of that society (Piaget, 1954). Children must go through a process of conservation in which they do not follow rules because they are told to follow rules but that through the exchanges they have with others they come to believe those rules as values that they hold as important internally (DeVries, 1997). 
Piaget believed that cognitive and social development processes happened interchangeably, supporting and contradicting the child's existing state of knowledge in order for the child to make stronger connections to the world in which they live. The idea of learning in community with others through interactions and stories connected with me as I conducted this research and placed myself in a spirit of unknowing, 'dancing' with other self-identified constructivist early childhood educators who are required by their place of practice to use the Teaching Strategies GOLD® assessment system.

Vygotsky is well-known for the theory of the Zone of Proximal Development (Mooney, 2000). Vygotsky (1962) describes the Zone of Proximal Development (ZPD) as the distance between a child's knowledge and the knowledge a child can achieve with the help of an early childhood educator or peer. When considering the ZPD in the context of play, it is a Vygotskian idea that "in play the child becomes a head taller than himself" (Vygotsky, 1962, p. 16). That is, when engaged in play with an older peer or sibling, a child is often able to extend his cognitive and social knowledge to something beyond what they would have been able to do on their own (Bodrova, et al., 2013).

Bodrova et al. interprets this idea by writing that in pretend play children choose to follow the rules of the role rather than to act on their own impulses in order to stay involved in the play (Vygotksy,1978; Bodrova et al., 2013). This idea of finding the internal value of the social rules of play is similar to how DeVries (1997) describes Piaget's idea of conversion in play. In other words, the rule has changed from something they are required to do by others to something they want to do in order to stay engaged in 
play with others (DeVries, 1997; Bodrova, 2005, Bordova, et al., 2013). Recognizing the value of learning with others is a key aspect of constructivist learning theory.

Piaget theorized that development followed learning whereas Vygotsky saw learning and development as having a complex and nonlinear relationship (Bodrova \& Leong, 2005). Meaning, learning has as much of an impact on development that development has on learning (Bodrova \& Leong, 2005). For Vygotsky, learning and development happened through a balance of working with objects as well as the influence of others interacting with the objects and with the child (Leong \& Bodrova, 2012).

Vygotsky focused heavily on the use of language to help children learn together and from one another, but this same concept of collaborative learning can be applied to all children regardless of their language development (Gilbert, 2001). During the 1920s and 1930s, Vygotsky (1978) and his colleagues, Luria and Leontiev, formulated the Cultural-Historical Theory of Activity or more commonly known as Activity Theory (Vygotsky, 1978). Vygotsky (1978) believed that cultural means, tools, and designs, including language, affect the way an individual reacts to an environment. It is not just the people, but also the tools within an environment that fosters children's learning (Bordova, 2008; Leong \& Bordova, 2012).

In summary, constructivism is the learning theory that is grounded in the idea that learning is a process of making connections through experiences with objects and others (Chaillé, 2008; DeVries, 2004; DeVries, et al., 2002; Forman \& Hill, 1984; Fosnot, 2005; Piaget, 1954, 1977, 1979; Singer et al., 1997; and others). The connections of the constructivist learning theory and pedagogical documentation parallel in that each places 
value in revisiting and reflecting on learning and experiences with others, materials, and the natural world in order to gain insight and knowledge. In the next section I explore beliefs, values and perceptions that are held by many self-identified constructivist early childhood educators.

\section{The self-identified constructivist early childhood educator.}

Earlier in this chapter, I explored the United States' perception of the educator in the United States as a giver of knowledge (Apple 2009; Eisner, 1985; Freire, 2003; Parnell, 2011b). In addition, I explored Ayers'(1989) and Parnell's (2010) appraisal of what this media-driven description does to early childhood educators and how it effects the image of the child and the larger image of what school should be in order to establish a sense of the culture that surrounds educational policy creation in the United States. In this section I clarify my definition of what it means to be a self-identified constructivist early childhood educator using the works of Bodrova and Leong (2005), Chaillé (2008), Forman and Hill (1984), Forsot (2005), Parnell (2010, 2011b), and others as reference points.

Forsot (2005) states, "Constructivism is a theory of learning, not a description of teaching” (p. 33). Self-identified constructivist early childhood educators believe that learning is a social construct and children learn best when given time, space, and support to make connections between different experiences (Chaillé, 2008). They believe that children are learning no matter what is going on in the classroom (Chaillé, 2008). Bodrova and Leong (2005) identify the constructivist educator's role as supporting children on their path to independence. The self-identified constructivist early childhood 
educator sees themselves as learning alongside the child rather than bestowing knowledge on the child (Chaillé, 2008; Parnell, 2010). They must work to identify what the child's concept is instead of giving the child the concept (Bodrova \& Leong, 2005).

The self-identified constructivist early childhood educator works with children in the role of a teacher-as-researcher, someone who is not only doing research with children but considers their work as doing research about children in order to support children's development as an individual and as part of a larger group (Parnell, 2010). They must always be aware of how their interactions and words can affect the child's perception of their learning experience (Bodrova \& Leong, 2005).

Constructivist early childhood education classrooms are places in which children's ideas lead the experiences and curriculum (Chaillé, 2008). Learning in a constructivist early childhood education classroom is non-linear and knowledge is seen as ever changing and dynamic (Fosnot, 2005). Bodrova and Leong (2005) write that when commenting on materials, the focus of what the adult chooses to comment on influences the way the child interacts with the materials. For example, if a child is focusing on creating a pattern of blue and green blocks by stacking them on top of each other and the adult comments on how tall the tower is rather than the pattern the child's is creating, the child's focus is influenced by the adult's comment about the height of the tower.

Chaillé (2008) writes about the importance of early childhood educators not assuming what a child is doing, stating that constructivist early childhood educators must practice a pedagogy of listening by "being totally present and open to seeing, hearing, and feeling what children are doing" (p. 7). This idea is reflective of a key aspect of 
Vygotsky's ideas that the early childhood educator must work to determine what the child's concept of an object is, not give the child the concept of the object (Bodrova \& Leong, 2005). In other words, self-identified constructivist early childhood educators do not set out to teach children the 'right' answer, but instead set out to discover the ways in which children go about discovering the world around them and their place within that world.

Constructivist early childhood educators must be committed to understanding and valuing how each individual child learns in order to truly support her in her learning and development (Bodrova \& Leong, 2005; Chaillé, 2008; Fosnot, 2005; Forman \& Hill, 1984; Parnell, 2010). By using a constructivist lens and focusing on how the whole child learns, we are focusing on the process of learning instead of looking at the product of the learning (Bodrova \& Leong, 2005; Chaillé, 2008; Fosnot, 2005; Parnell, 2011b). Early childhood educators who ascribe to constructivist learning theory consider the child as an individual, a human being with unlimited potential (Bodrova \& Leong, 2005; Chaillé, 2007; Forsot, 2005; Kamii, 1991). Focusing on how a child learns helps the child develop a sense of autonomy and fosters critical thinking skills (Kamii, 1991). This is a different perspective of children's learning than what we typically see in United States' classrooms that are focused on learning standards and standardized testing (Kamii, 1991; Kohn, 2000).

Pedagogical documentation is supportive of this perception of children's learning as it is a process of early childhood educators revisiting experiences with children in order to learn more about what, how, and the ways in which children think about the 
experience (Fleet, et al., 2006; Rinaldi, 2012; Rintakorpi \& Reunamo, 2016). It is in line with to the constructivist learning theory in that early childhood educators enter into this dialogue with children from a place unknowing and of wanting to know more.

In this section, I have explored the constructivist learning theory, as a selfidentified, constructivist early childhood educator, I understand that learning with others is essential for children's learning. Through conducting this research, I realized that it is essential for my learning as well. This awareness inspired me to seek out research methods in which I could collaborate with other self-identified early childhood educators who are required to use the Teaching Strategies GOLD® assessment system. In the next section, I discuss the methodology I have chosen narrative inquiry, and the different methods in which I chose to conduct this research.

\section{Review of Methodological Literature}

As explored previously, constructivism is a learning theory that is grounded in the idea that learning is a process of reflecting on and making connections through experiences with objects and others. Self-identified constructivist early childhood educators know the value of listening to children in order to have a better understanding of how children learn. Similarly, qualitative research is often used when wanting to bring light upon individual situations in context and making connections to the larger institution (Creswell, 2008, 2013; Krathwohl, 2009). The type of research I did for this study was qualitative. The paradigm in which I formatted this research was constructivism and the methodology I selected for this research was narrative inquiry as described and attended to thoroughly in chapter three. 
Qualitative research is conducted when the researcher's goal is to gain an understanding of the meanings that an individual or group attributes to a social or human situation (Creswell, 2008, 2013). Glesne (2016) writes, “Qualitative researchers seek to make sense of actions and narratives, and of the ways in which they intersect” (p. 1). Under the umbrella of qualitative research, I focused on the paradigm of constructivism (Creswell, 2013; Glesne, 2016; Guba \& Lincoln, 2005). The central research purpose of the constructivist paradigm is to gain a sense of understanding (Creswell, 2013; Glense, 2016; Guba \& Lincoln, 2005).

For the purpose of this research, I set out to understand the experiences selfidentified constructivist early childhood educators who are required by their place of practice to use the Teaching Strategies GOLD® assessment system through the methodology of narrative inquiry. Narrative inquiry is a method of looking at the personal reflections of other's past and present experiences for the purpose of research (Creswell, 2008, Clandinin \& Connelly, 2000; Wells, 2011). It is a method of storytelling and story-listening (Clandinin \& Connelly, 2000; Kanno, 1997; Wells, 2011).

When conducting narrative analysis, the researcher is encouraged to remove themselves from a place of authority, to be open to what is said in a context larger than what they are considering (Clandinin \& Connelly, 2000; Wells, 2011). "Narrative analysis takes the stories as its primary source of data and examines the content, structure, performance, or context of such considerations as a whole" (Wells, 2011, p. 7). It is a method of listening to other's experiences in a way to make sense of the world in the context of culture (Creswell, 2008, 2014; Clandinin \& Connelly, 2000; Wells, 2011). 
In chapter three, I describe in detail the procedures I used to conduct my study for sample recruitment, informed consent, and maintaining data. Working with self-identified early childhood educators who are required to use the assessment system Teaching Strategies GOLD® as participants, I used a combination of narrative interviews, observation, and reflective conversations to understand their experiences. In chapter three I also describe each of these data collection instruments and the rational for their use.

The role of the researcher in qualitative research cannot be considered without addressing the researcher's bias (Creswell, 2008, 2014; Krathwohl, 2009). As a selfidentified constructivist early childhood educator who was required by my place of practice to use the Teaching Strategies GOLD ${ }^{\circledR}$ assessment system, the opinions and thoughts I brought to this study were many, for if they were not there, I would not have done this research. In chapter three, I identify each of these biases in turn and provide compelling explanations of the procedures I used to acknowledge these biases in conducting this research.

In the spirit of pedagogical documentation, data analysis happened throughout the research process. Observation notes, interview transcripts, reflective conversation transcripts and personal reflections were continually revisited, reflected about, and discussed as a way to identify the larger themes, inconsistencies, and/or relative patterns of the experiences of the participants. In chapter three, I expand on how these experiences will be documented and explored. 


\section{Summary of the Literature Review}

In this chapter, I began my literature review by examining some of the articles in regard to the single large-scale research study that considered the validity of the Teaching Strategies GOLD® assessment system. Next, I provided a history of the Teaching Strategies GOLD® assessment system, the reasons for its creation and the way it has evolved over the years. defining the structure of the documentation system within Teaching Strategies GOLD® including the different reports, strategies, tools, and supports that are provided within the system and the purpose of each to display the ways in which the system encourages early childhood educators to categorize children's learning experiences in to pre-established, generic definitions as well as use preestablished, generic forms to share children's learning with parents, and plan for new learning experiences through pre-established, generic curriculum occurrences. I concluded the section on the Teaching Strategies GOLD assessment system by articulating the concerns the research exposed to me; these being the perceived simplicity of the system to rate children's learning, the replacement of time spent interacting and learning with children with time spent on a computer in isolation analyzing children, and the focus on teaching with fidelity.

Continuing on this idea of teaching with fidelity, I connected similarities of the programs, No Child Left Behind Act 2002 to the Early Education for All Americans Act and the ways in which both programs encourage the same content exposure and the same learning opportunities for all children regardless of the circumstances. I completed this 
section by examining closely the perception United States' educational policy makers have in regard to early childhood educators and the role of early childhood education.

I then connected the idea of teaching with fidelity and the ways in which the Teaching Strategies GOLD® assessment system and the encouragement of the administrators of Teaching Strategies GOLD® by creating coaching strategies for early childhood education mentor teachers and supervisors to work with the early childhood educators in their programs implement the program the ways in which the developers of Teaching Strategies GOLD® intended (C. Martinez, personal communication, November 3, 2016). Finally, I disclosed how, when training and educational opportunities are focused on conforming to policies and procedures, early childhood educators can be exposed to a perception of powerlessness in which many chose to escape by leaving the field entirely (Apple, 2009; Christakis, 2016; Parnell, 2010).

I introduced and gave a very brief description of the municipally funded preprimary schools and infant and toddler centers of Reggio Emilia, Italy, focusing primarily on the role of pedagogical documentation and the ways in which pedagogical documentation is used as a living record of educational practice (Dahlberg, 2012).

In the section on constructivist learning theory, I linked some of the values attributed to pedagogical documentation to constructivist learning theory. Connecting the works of Vygotsky and Piaget to those of current early childhood education researchers such as Bodrova (2008), Chaillé (2008), DeVreis (1997, 2000, 2004), Forman (2005), Katz (2000), Parnell (2010, 2011a, 2011b), and others to establish a definition of common constructivist practices that are found in early childhood education classrooms 
today. I completed this section by connecting the constructivist learning theory to pedagogical documentation.

I have concluded chapter two by introducing the methodical approach in which I will conduct my research, narrative inquiry. I presented the methods in which I propose to conduct my research, interviews, observations, and reflective conversations, addressing the potential for bias in my research and outlined that each of these areas will be expanded upon in chapter three. 


\section{Chapter Three: Methodology}

The purpose of this research was to collect and understand the experiences of selfidentified constructivist early childhood educators who are required by their place of practice to work with the Teaching Strategies GOLD® assessment system. As I remarked earlier, the field of early childhood education is complex and varied. From outside of the tangled web of home based, commercial, corporate, and publicly funded early childhood education and care programs, it can seem chaotic, but it is within this complexity that we find the uniqueness of early childhood education. Not every early childhood education program works for every family in all communities. Many early childhood education programs offer unique aspects that support the children and families they serve, focusing on the ever-changing needs and rights of the community around them. This thoughtful and insightful work of focusing on the needs and rights of the community is different than the contemporary goals of public education policy and practice of focusing on 'school readiness' and 'quality' and can be difficult for those outside of the field of early childhood education to understand (Parnell \& Iorio, 2018). As I have demonstrated in chapters one and two of this study, it is the ideals of 'readiness' and ever-allusive definition of 'quality' that have driven the formation of public education policy and research for decades and are now being pushed into early childhood education classrooms and programs (Apple, 2009; Christakis, 2016; Eisner, 1985; Feeney, 2016; Kohn, 2000; Parnell, 2010, Parnell \& Iorio, 2018; Peters et al., 2015).

Parnell and Iorio (2018) write, “The easily measurable phenomena of quality came about due to a reductionist view of the nature of the field and related research; 
research that is constructed to make smaller and smaller units of analysis so that we can quantify our existence, making the world simpler to understand" (p. 2). The reductionist view of educational research has had a ripple effect that is flooding into early childhood education programs and classrooms, and drowning the uniqueness of programs, educators, and children alike. Parnell \& Iorio (2018) state "often-times the voices, ideas, and values of the people in early childhood are ignored, removed and not allowed in the decision making about how they live, work and learn together" (p. 1). It is partially the exclusion of the voices of early childhood educators that led me to this research.

In chapter one and two I demonstrated my concerns regarding the ways that the use of preformatted portfolio style assessment programs such as Teaching Strategies GOLD® contributes to the loss of the voices of early childhood educators and the children and families they serve. These concerns encouraged me to pursue both an academic as well as a personal interest in this research. In doing this research, I sought to find an understanding of the experiences of early childhood educators who are caught between believing in the value of constructivist learning and meeting requirements of the Teaching Strategies GOLD® assessment system. In addition, this research gives a platform for self-identified constructivist early childhood educators who are required by their place of practice to use the Teaching Strategies GOLD® assessment system voices to be heard and their situations to be noticed and acknowledged.

In order to offer this platform in the mindful way deserved, I engaged qualitative research using narrative inquiry methodology. Qualitative research is conducted when the researcher's goal is to gain an understanding of the meanings that an individual or group 
attributes to a social or human situation (Creswell, 2008, 2014). Narrative inquiry is a method of qualitative research that studies experience as a story (Clandinin, 2007, 2013; Clandinin \& Connelly, 2000; Creswell, 2008, 2014; Wells, 2011). It is a methodology of the constructivist paradigm of qualitative research that is based on story-telling and storylistening (Clandinin, 2007, 2013; Clandinin \& Connelly, 2000; Wells, 2011). Narrative inquiry is situated in the paradigm of postmodernism with an emphasis on social constructionism (Josselson, 2006). Postmodernism is based on the idea that there is no one truth, and that knowledge is contextual (Jennings \& Graham, 1996). Social constructionism absolves the idea of absolute truth, instead questioning the assumed ways in which we view ourselves and the world (Burr, 2015). In conducting this research, under the umbrella of social constructionism, I engaged aspects of the collaborative, constructivist, critical, and feminist approaches for engaging narrative inquiry.

\section{Theoretical Lens}

Qualitative research is conducted when the researcher's goal is to gain an understanding of the meanings that an individual or group attributes to a social or human situation (Creswell, 2008, 2014; Glesne, 2016). Glesne (2016) writes, “Qualitative researchers seek to make sense of actions and narratives, and of the ways in which they intersect" (p. 1). Qualitative research is a process of emerging questions and proceedings (Creswell, 2008, 2014; Glesne, 2016; Maxwell, 2013). It is a form of research that involves listening to others, immersing oneself into the participants' being, and focusing on both the individual and collective meanings to find the reoccurring and collective 
themes of a particular circumstance or phenomenon (Creswell, 2008, 2013; Glesne, 2016; Guba \& Lincoln, 2005; Maxwell, 2013).

The methodology I selected for this study was narrative inquiry. Clandinin (2013) describes narrative inquiry as "both a methodology and a way of understanding experience narratively" (p. 9). Narrative inquiry is the study of experience as a story, it is based on story-telling and story-listening (Clandinin, 2007, 2013; Clandinin \& Connelly, 2000; Wells, 2011). Clandinin (2013) writes that narrative inquiry began as a way "to give an account of teachers' experiences” (p. 9) and is influenced by Dewey's (1938) "two criteria of experience, continuity and interaction" (p. 21). Experience in narrative inquiry encompasses more than what is happening in the here and now, it is focused also on the social, cultural, and institutional narratives that surround, shape, and influence the individual's experiences.

Narrative inquiry is about understanding experience from both a personal and social viewpoint (Clandinin, 2007, 2013; Clandinin \& Connelly, 2000; Josselson, 2006; McMullen \& Braithwaite, 2013; Pitre, Kushner, Raine, \& Hegadoren, 2013; SpectorMersel, 2010; Wells, 2010). The way an individual interprets, reacts, or responds in an experience grows out of past experiences. Experiences build upon each other and can lead to future endeavors. Individuals are never fully 'in the moment', the ways in which we think and reflect about the past, affects how we respond in the present. The consequences of our responses and how we consider the consequences will have an impact on how we respond to similar experiences in the future. 
Clandinin (2013) describes the process of gaining understanding in narrative inquiry as the living, telling, reliving, and retelling of stories. It is a collaboration between the researcher and the participants to "seek ways of enriching and transforming that experience for themselves and others" (Clandinin, 2013, p. 18). Narrative inquiry is used in many social sciences including anthropology, psychology, and psychotherapy (Clandinin \& Connelly, 2000).

The field of anthropology focuses heavily on the idea of understanding change, both in the individual and societal aspects through narrative inquiry (Geertz, 1995). This focus includes change in the participant, change in the researcher, change in the place the inquiry happens, as well as larger influences. Coles (1989), in the field of psychiatry, sees the building of understanding through the sharing of stories as a process of unwrapping a lived life, and of coming together over the shared narratives. Coles includes the narratives of the researcher's lived experiences as part of the understanding process. Geertz (1995) and Coles (1989), as well as many other narrative inquiry researchers, place significance on the importance of understanding the experience in context of time, history, and place when engaging in narrative research.

Narrative inquiry has roots situated in postmodernism with an emphasis on social constructionism (Josselson, 2006). Postmodernism looks at the grand narratives often claimed in traditional research methods and examines the assumption of truth (Etherington, 2013; Jennings \& Graham, 1996; Zeeman, Poggenpoel, Myburgh, and Van der Linde, 2002). "In postmodern thought there are no universal ideas for truth and claims to knowledge are always contextual" (Jennings \& Graham, 1996, p. 269). 
Postmodernism can be traced back to just after the end of the second World War, but its development is attributed as a cultural movement that began in the 1960s, gained ground in the 1970s, grew in popularity during the 1980s, and became recognized academically in the 1990s (Alvesson \& Skoldberg, 2009; Wilterdink, 2002). Wilterdink writes:

Postmodernism established itself in parts of the humanities and the social sciences where knowledge is uncertain, disagreements abound, and theoretical progress is problematic. The criticism of being 'nonscientific' to which this situation may give cause is met by postmodernists who state that all human knowledge, including the scientific knowledge of nature, is socially constructed, culturebound, perspectivist, discourse-dependent and therefore not in any sense an objective reflection of reality. (p. 210)

Postmodernism, in the field of social science research, disregards the idea of objectivism in research, instead focusing on critical reflexivity, epistemological relativism, and social and cultural constructionism.

Social constructionism absolves the idea of absolute truth (Burr, 2015). Burr writes, "Social constructionism insists that we take a critical stance toward our taken-forgranted ways of understanding the world and ourselves" (p. 2). From a social constructionist viewpoint, knowledge is constructed between individuals, has relevance between participants and researchers, and can be transforming for both. Social constructionism embraces the idea that knowledge is culturally and historically specific, and that through interaction and collaboration with others, new knowledge can be created.

Under the umbrella of social constructionism, there are many different approaches to narrative inquiry as a qualitative research methodology including constructivism, feminism, collaborative, and critical (Etherington, 2013). I was drawn to different aspects 
of these approaches and saw ways in which each could support my research process, but before making these connections, I provide a brief overview of each, pointing to literature that more thoroughly examines each approach (Figure 3).

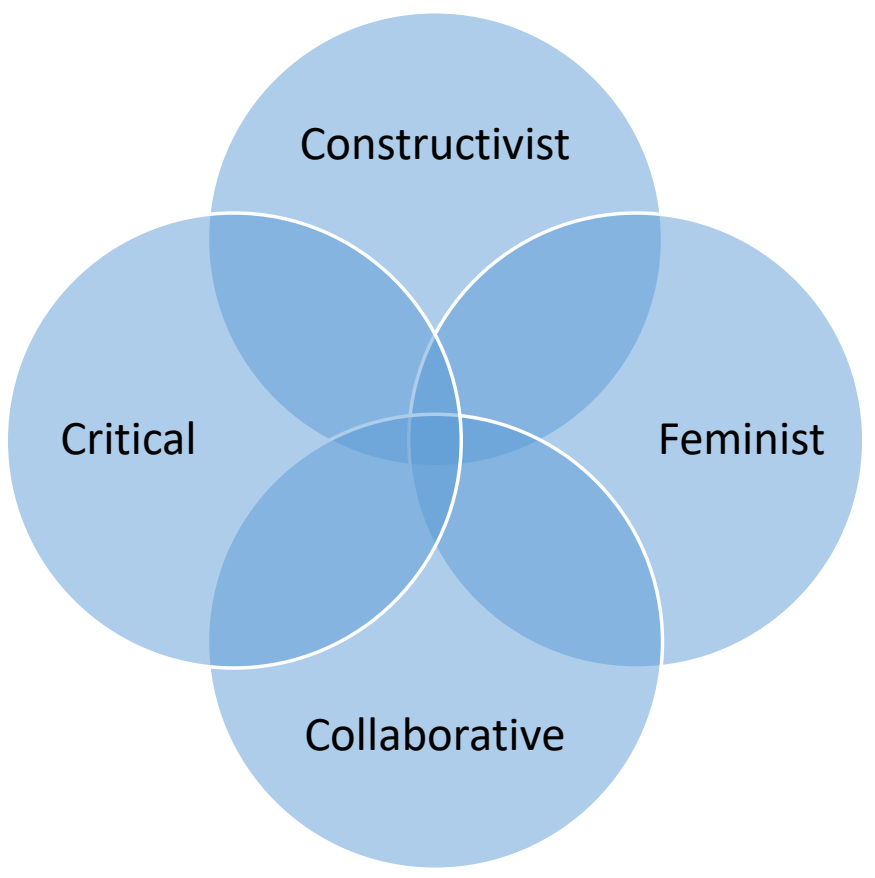

Figure 3: Blending of Approaches

Narrative inquiry roots are grounded strongly in Vygotsky's (1978) theory of learning (Clandinin, 2007). Vygotsky's (1978) theory of learning is positioned in the belief that knowledge is socially constructed through shared understandings. In the constructivist approach to narrative inquiry, the power is shared between the participants and the researcher in effort to understand how the participant has constructed meaning of the world and their experiences through their personal belief systems (Etherington, 2013). When conducting narrative inquiry research through the constructivist approach, researchers consider the identity of the participant and how the narratives shared are socially constructed. "From a constructivist perspective...there is much less separation 
between the researcher and the narrator" (Clandinin, 2007, p. 151). The participants' intentions and interpretations are a crucial part of the research. It was not my story I set out to tell, but theirs.

Looking at research through a feminist perspective can encompass a multitude of layers (Alvesson \& Sköldberg, 2006). Alvesson and Sköldberg (2006) and Clandinin (2007) write that doing research through a feminist approach means seeing the phenomena being studied in the context of power relationships in social, institutional, political, historical, and holistic orientations based on preconceived ideologies around gender. Narrative inquiry and feminist research have an entwined history, Clandinin (2007) writes that throughout the 1970s and 1980s, narrative inquiry was particularly advanced through feminist researchers writing that feminist researchers, "made narrative research crucial to the idea of giving voice to those excluded from mainstream psychological research” (p. 614), recognizing Maxine Greene (1978), Carol Gilligan (1982), and Nel Noddings (1984) among others.

The feminist approach considers the ways in which gendered relations can cause an individual's self-identity to be constrained (Pitre, et al., 2013). The feminist approach is focused on the individual to benefit the individual, with an understanding that experiences are socially located and not all identical. "Through feminist research, a space is purposefully created for their experiences to validated, for individual and social consciousness to be raised, and for the person to become critical" (p. 122). The feminist approach to narrative inquiry is an examination of how patriarchal influences can 
constrain our individual and collective agency and helps to create a sense of power for the participants.

A collaborative approach to narrative inquiry is supported by the assumption that there are many ways of knowing and that gaining knowledge is a reciprocal process of education each other (Etherington, 2013). "Collaborative inquiry is shown to be cyclical and relational in nature" (Mealman \& Lawrence, 2002, p. 3). There is a strong focus on the substance of the relationships between the participants and the researcher as they shape and create knowledge.

There are many articles describing collaborative inquiry in action research and a very few articles describing collaborative narrative inquiry. The majority of the latter are about researchers collaborating on the results of a narrative inquiry study. However, when reviewing collaborative inquiry in action research, I saw many components that could easily transition into narrative inquiry research. When writing about a collaborative action research project, Moran (2007), describes collaborative action research as forming partnerships between the preservice teachers and teacher educators in the study. Moran addresses four elements of collaborative action research; that it is collaborative in nature, that the focus is on practical problems, that there is an emphasis on professional development, and that there is a structure that provides participants with time and support for open communication with recursive cycles of planning, reflecting, and revising.

Schulz, Schroeder, and Brody (1997) use similar elements when conducting a collaborative narrative inquiry study. Shultz et al., write "Collaborative narrative research actually reconsiders the stoical relations among the participants, the place of disclosure 
for the researcher, and the place that selectivity and silence hold for the text contained" (p. 474). Clandinin and Connelly (2000) echo this perspective in their description of 'voice' in engaging in narrative inquiry. Clandinin and Connelly pronounce that 'voice' in narrative inquiry belongs to the participants, researcher, and other participants and researchers that connect to the text. When engaging in collaborative inquiry, participants and researchers work through a process of revisiting narratives to understand the complexities of realities. Taking a collaborative approach to research is as much about the processes of obtaining outcomes as it is about the outcomes themselves.

The critical approach to narrative inquiry examines the historical patterns of behavior that allow for compositions of power to perpetuate (Pitre, et al., 2013). As Pitre et al. states, this approach looks at the social collective to expose what (or who) determines privilege, domination, marginalization, and oppression. The origins for the critical approach to narrative inquiry are situated within critical theory. "Critical theory is characterized by an interpreted approach combined with a pronounced interest in critically disputing actual social realities" (Alvesson \& Sköldberg, 2009, p. 144). Critical theory is an emancipatory form of research which views social phenomena in historical context. The roots of critical theory are established through the Frankfort school established in 1920s Germany.

Habermas (as cited in Alvesson \& Sköldberg, 2006), set the trend for the second generation of the Frankfort school and critical theory, believing the crucial elements of control are power and money and that science and technology function as ideology. "Habermas claims that expertise and social engineering, supported by a narrow positivist 
view of science, have been handed the task of solving an increasing number of societal problems, while political and ethical debates and reflections are less evident” (p. 148). Critical theorists believe that we must be aware so that the that systems, procedures, goals, ideas, and control will not be taken for granted as truth but instead reflected upon and considered as a means to promote freedom from stagnate ideological and political patterns. Or in other words, using the critical approach helps individuals to recognize the ways in which the larger systems of power inhibit their responses in a particular situation (Pitre et al., 2013).

Critical narrative analysis is a process that supports individuals (the participants and the researcher) to make sense of the narratives they share (Souto-Manning, 2014). Critical narrative analysis looks at the historical patterns of behavior that influence societal norms that can inhibit an individual's responses and/or reactions to certain situations (Pitre et al., 2013). "CNA [critical narrative analysis] allows us to learn how people create their own selves in constant social interactions at both personal and institutional levels, and how institutional discourses influence and are influenced by personal everyday narratives" (Souto-Manning, 2014, p. 162-163). When individuals reflect upon of their narratives using critical narrative analysis, they intersect both personal and institutional influences.

When conducting research through a critical approach using critical narrative analysis, Souto-Manning (2014) states that the researcher should pose questions that allow the participants to not accept everything because it already exists. Pitre et al. (2013) coincides this idea by stating that the process of narrating stories helps individuals to 
reflect on all dimensions of the situated self, the personal, historical, symbolic, social, structural, and ideological, noticing areas of conflict and areas that correspond. Or in other words, critical narrative analysis can uncover the larger discourses that frame personal narratives.

I was enticed by various aspects of each of the narrative inquiry approaches that I have described under the umbrella of social constructionism. There were common threads that appealed to me in relation to this research study. These included the high regard for the participant's voice, the consideration, in collaboration with the participant, of the internal and external contexts that influence the participant's voice, and belief that we all, including the researcher, bring a certain amount of knowledge and a perception of the situation to the table when conducting research. Later I this chapter I show how I informed my research study with various components of these approaches as part of my research puzzle metaphor, explored and explained more next.

\section{Research Puzzle}

Engaging in narrative inquiry is not an objective process in which the researcher sets out to prove or disprove a stagnate problem or question (Clandinin, 2007, 2013; Clandinin \& Connelly, 2000; Wells, 2011). Rather, narrative inquiry looks outside of the realm of facts and the principals of certainty. When using narrative inquiry as a research method, the researcher frames a "research puzzle" (Clandinin, 2013, p. 42), rather than a research question. Clandinin states:

Narrative inquiries are always composed around a particular wonder, a research puzzle. This is usually called the research problem or the research question. However, this language and wording tend to misrepresent what we believe is at work with narrative inquires. Problems carry with them the qualities of clear 
definability and the expectation of solutions, but narrative inquiry carries more of a sense of search, a 're-search,' a searching again. Narrative inquiry carries more of a sense of continual reformulation of an inquiry than it does a sense of problem definition and solution. (p. 124)

Stories are multivocal (Pitre et al., 2013). Our histories, cultures, current circumstances, and audience all play a role in what we chose to share and how we chose to share it (Clandinin \& Connelly, 2000). Narrative inquiry is a reciprocal process of sharing and learning between the participants and the researcher.

As an early childhood educator who had been using Teaching Strategies GOLD® for ten years, I had conflicting feelings about the system. Each of my teammates entered observations into the system, so when I was completing my checkpoint assessments, I got to see two or three (depending on the age of the children) perspectives besides my own about each child. I read each of their observations before attaching the sum of all the observations about the child in a specific category to the achievement rating scale, and there is a level of value to these multiple perspectives. However, the system has an achievement rating scale, and I found this notion of generalizing a child's thoughts, interactions, explorations, personality, comfort level, etcetera, into a rating scale disrespectful, alienating, and cold. For me, it was a procedure that silenced my voice and the voice of the child, making the process of the child's learning and development invisible in pursuit of an end product that is seen by others as a representation of 'quality' in our child development program.

I had often wondered if part of these conflicting feelings is a result of the very limited team planning time (30 minutes per week, assuming everyone is asleep at the same time) that was built into the weekly schedule dictated by the program in which I 
worked. The time allotted for entering observations into Teaching Strategies GOLD® was even less and most often involved a teammate removing themselves from the classroom. Given the allotted time, the sheer number of requirements for each checkpoint could be overwhelming. To combat this, I had developed the habit of using multiple group observations just to get all my checkpoints completed, further generalizing each child's work. I am not alone in this process and had heard many of my work colleagues make similar comments. Or, perhaps my conflicting feelings came from the outside need to justify our work by rating young children's learning experiences in a way that seemed so unauthentic to me.

To emulate that this was the only perspective about Teaching Strategies GOLD® at my place of practice would be false. Many of my colleagues believed the system had been beneficial to their work, stating that it gave them more authority, a sense of professionalism, and confirmation in the ways in which they assessed children's learning and shared that assessment with parents. A work colleague whom I admire, stated, "I like GOLD®. It helps me to organize my thoughts and it gives me a structure in which to show parents what their child is accomplishing by connecting the observations to the objectives" (personal communication, February 7, 2017). Other colleagues had made similar statements, expressing that using Teaching Strategies GOLD® had supported them to show parents that the assessment provided about the child's growth and development wasn't just their personal opinion. These early childhood educators claimed that using the Individual Child Report, which displays the child's placement on the Widely Held Expectations rating scale created by Teaching Strategies GOLD®, gave the 
parents a perspective of authenticity, and an objectiveness in the early childhood educator's evaluation of the child's learning and growth that was not there before.

There are many different types of early childhood centers that use the Teaching Strategies GOLD® assessment system and I was curious about the way in which the system is integrated into these programs, if there is a better way than what we did at my program. I wondered what the matrix of time looked like and what tactics had been implemented by other programs and by other early childhood educators. I wondered too if other self-identified constructivist early childhood educators struggled with same issues in using the Teaching Strategies GOLD® assessment system as I did; the silencing of the voices of children and early childhood educators, the removal of our thoughts and wonderings, the disconnection of the meaning-making that happens in order to display the progress of the child's development and learning, the reduction of childhood into preestablished generic learning objectives, and the time spent in isolation on a computer instead of in collaboration with others. I was curious about the compromises that other self-identified constructivist early childhood educators who are required to work with Teaching Strategies GOLD® had made in their practice. Perhaps they, like me, had sacrificed the quality of the information they record in the system in order to meet the required quantity, knowing that when they meet with the family face to face they would have the opportunity to discuss the details and magic of the child's development and learning in person. I found myself questioning what this process does to the perception that early childhood educators had of themselves and their colleagues. 
These were the wonderings that led me to this research puzzle. As I imagined the research process, I pictured assembling a collection of experiences. As I viewed, listened, and considered each of the participants' experiences, I'd discover that there were pieces that reflected similar motifs, or experiences, in their collections that connected and begin to form a collective understanding. Or perhaps, the piece selected doesn't fit the way I anticipated, bringing about additional considerations.

I have described my personal experiences of the tension between practicing constructivist learning values and being required by my place of practice to use the Teaching Strategies GOLD® assessment in early childhood education. In doing this research, I sought to find an understanding of the experiences of early childhood educators who were caught between believing in the value of constructivist learning and meeting the requirements of the Teaching Strategies GOLD® assessment system. In addition, this research gives platform for self-identified constructivist early childhood educators who are required by their place of practice to use Teaching Strategies GOLD® voices to be heard and their situations to be noticed and acknowledged.

\section{Participants}

For the purpose of this research, the phrase 'self-identified constructivist early childhood educator' represented an educator working with children the age of zero to 72 months who, through their education and/or experience, believed that learning is a process of making connections through experiences with objects and others, reflecting on those experiences, theory building, and theory testing (DeVries, 2000). Participants had a minimum of five years of classroom experience working with children age zero to 72 
months. An early childhood educator in this phase of their career, what Katz (1972) refers to as "maturity" (p. 9), would be open to using a critical lens when reflecting on their practice and the ways in which they use assessment. According to Katz (1972), early childhood educators working five or more years in the field are at a place where they begin to look for more meaningful insight about their work with young children. They begin to reevaluate their definition of what it means to be an early childhood educator. This reevaluation may include questioning their philosophical roots, or questioning the requirements of their practice. Early childhood educators in the mature phase are often looking for opportunities to seek out more diverse professional development opportunities than what is commonly offered through workshops and conferences and are open to discussing ways in which they can improve as an individual and ways in which they can help improve as an industry.

Additionally, participants were required by their place of practice to use the Teaching Strategies GOLD® assessment system. They had a minimum of oneyear experience using the Teaching Strategies GOLD® assessment system. I placed the criteria of having experience working with the Teaching Strategies GOLD® assessment system because I believed that it was important for this research that the early childhood educators in the study to have a strong base knowledge of how the Teaching Strategies GOLD® assessment system works and to have built their own strategies for recording and entering their observations of children.

As co-researchers, participants took an active role in the interpretation of the stories they shared as part of the research process. By joining this research study, 
participants were asked to share their experiences, reflect on their work with young children and using the Teaching Strategies GOLD® assessment system, and revisit the conversations with me to help build a better understanding of their experiences.

Embracing this role as co-researcher meant that the participants agreed to assume partial responsibility in the construction of reality that comes from sharing and reflecting about the meanings of their experiences with me.

It was extremely difficult to find participants for this study. The center where I worked did not give me permission to recruit participants, and many interested individuals did not meet the criteria outlined. Eventually, with the support of my chair, three participants were found that met all of the criteria. The participants had a variety of backgrounds in their education and experience. Julia holds a Master's degree in Educational Leadership and was completing a second Master's in Early Childhood Education, Sasha was currently pursuing her Bachelor's degree in Early Childhood Education. Cynthia had started working towards her Associate's degree in Early Childhood Education years ago, she had not completed the degree but had finished all of our ECE courses.

Their work experience varied as well. Julia had worked at several different early childhood settings and was working her second year at the center. Sasha had just left a center that she had been working in for five years and was starting at a new program when we started research. Cynthia had been at her center for over 15 years. These variations held differing levels of significance in their experiences with Teaching 
Strategies GOLD®, although the majority of their experiences were similar as you will read in chapter four and five.

\section{My Role as Researcher}

The role of the researcher is different in narrative inquiry than in other forms of qualitative research (Clandinin, 2007, 2013; Clandinin \& Connelly, 2000). Clandinin (2013) describes narrative inquiry as a relational research methodology, guided by relational ethics. Narrative inquiry researchers start from a place of understanding that participants are the experts of their own lives (Clandinin, 2007, 2013; Clandinin \& Connelly, 2000; Pitre, et al., 2013). From the beginning of the relationship between the researcher and the participants, there is an understanding of trust. The researcher trusts that what the participant is sharing is true, in turn, the participants trust that the researcher will represent, or re-present, the stories they tell as authentically as possible.

I was drawn to Pitre et al.’s, (2013) use of hermeneutics of faith when interpreting the narratives with the participants. In using hermeneutics of faith, participants are considered to be experts in their experiences (Josselson, 2004; Pitre, et al., 2013). The researcher's role is to represent, or 're-present' the narrative as faithfully as possible, highlighting the stories of success and challenges. Josselson (2004) writes, "Taking people at their word through the hermeneutics of faith (restoration) produces a rich field for potential interpretive work, both in terms of personal and social meanings" (p. 8). When using hermeneutics of faith as part of the research and interpretation process, researchers hold the belief of what is being said is true and of value (Pitre, et al., 2013). 
When we share stories, we choose which facts, events, and players to include and which facts, events, and players not to include (Spector-Mersel, 2011). We do this for many reasons, to convey a certain identity about ourselves, to get to the point of the message we want to share, and/or to make a connection with the audience listening to our story. Spector-Mersel writes, "If a sense of identity is attained through the stories we tell ourselves and others, not only as identity expressed in narrative, but also importantly, it is also constructed by it" (p. 173). Through narratives, a certain personal-social identity is being declared (Mishler, 1986; Spector-Mersel, 2011) and the participant expects the researcher to honor that identity.

In narrative inquiry research, the researcher and the participants are social actors that live within the phenomena of the study (Clandinin, 2007, 2013; Clandinin \& Connelly, 2000; Pitre, et al., 2013). Earlier in this chapter, I expressed some of my own experiences of being a self-identified constructivist early childhood educator who was required by my place of practice to work with the Teaching Strategies GOLD® assessment system. These experiences have left me with my own ideas, feelings, and thoughts about the process of using Teaching Strategies GOLD® and time necessary in order to utilize this system. I have expressed my concerns about the deconstruction of children's learning experiences into pre-existing generic categories. I have also expressed my concerns about the effect that the reductionism of educational learning objectives has on the perceptions that early childhood educators have about the work they do with young children and their perception of themselves. 
In narrative research, my own subjectivity about the phenomena being studied is not seen as a determent or flaw as in traditional, quantitative research methodologies (Clandinin, 2007, 2013; Clandinin \& Connelly, 2000; Josselson, 2006; Pitre, et al., 2013; Shultz, et al., 1997; Spector-Mersel, 2010, 2011). Instead my subjectivity became an essential part of the research process. Regarding pedagogical documentation, Rinaldi (2006) writes, "Observation cannot be objective, point of view is always subjective - it is a strength" (p. 128). This same idea can be applied to the narrative inquiry process. Reflecting on, sharing, and discussing the ways my experiences were similar or dissimilar to those of the participants, with the participants, assumed a level of responsibility for the research being done. I connected this to how Pitre and Kushner (2015), describe feminist narrative inquiry, stating that:

Core intentions within feminist intersectional research further include a commitment to avoid essentialist views of experiences, and to highlight the impact of social location on knowledge claims (Olesen, 2000; Samuels \& RossSheriff, 2008). In addition, feminist intersectional researchers reflexively question personal and social understandings of power, location, position, representation, and oppressions for their influence on the research process and the experiences of participants. (Allen, 2000; Few-Demo, 2014, p. 286).

My experiences effect how I interpret theirs, by sharing these experiences, I showed the participants what I believed to be of value and in return clarified what the participants saw to be of value as well.

\section{Procedures}

When engaging in narrative inquiry, researchers seek to understand rather than to prove or disprove (Clandinin, 2007, 2013; Clandinin \& Connelly, 2000; Creswell, 2008; Wells, 2011). For this purpose, narrative inquiry is not a methodology in which I 
gathered ample amounts of data to later analyze disjointedly from the participants (Clandinin, 2007, 2013; Clandinin \& Connelly, 2000). Instead, narrative inquiry is a process in which I came alongside the participates, in collaboration, as a way to celebrate experience as a source of understanding and knowledge (Clandinin, 2007, 2013, Clandinin \& Connelly, 2000; Creswell, 2008; Wells, 2011). Clandinin (2007, 2013), and Clandinin and Connelly (2000) describe this process as stepping in the midst of the participants' experiences as they enter into the midst of mine. It is a focus on the individuals' experiences and also the cultural, social, and institutional narratives in which individuals' experiences are composed, formed, expressed, and executed. Through the living, telling, reliving, and retelling of experiences with others I sought to gain new insight and understandings, which is similar to the understandings that often come when using pedagogical documentation with young children.

In chapter two, I detailed the devaluation of early childhood educators in the midst of United States early education policy creation. This devaluation is a perception that is pushing those whom work in early childhood education out of the loop when it comes to the process of policy creation (Ayers, 1989; Parnell, 2010; Parnell \& Iorio, 2018). It was my frustration of the silencing of the voices of early childhood educators and the reductionist value of focusing on the neo-liberal ideals such as 'readiness' and 'quality' in early childhood education (Parnell \& Iorio, 2018) that inspired me to pursue my education doctorate. My purpose for working in narrative inquiry went beyond just my curiosities and wonderings about the experiences of other self-identified constructivist early childhood educators and the tension between practicing constructivist 
learning values and being required to use the Teaching Strategies GOLD® assessment system. It also came from a desire to create a platform where the voices of the selfidentified constructivist early childhood educators could be heard. In describing narrative methods of research, Creswell (2008) writes, "For participants in a study, sharing their stories may make them feel that their stories are important, and they are heard" (p.512). It is my intention that participating in this study gave the participants an opportunity to express, understand, and connect over topics that they may not have other venues in which to explore (Creswell, 2008; Egan \& McEwan, 1995; Mishler, 1986).

Research was conducted from August 2018 through February 2019. Initial recruitment procedures consisted of identifying perspective participants that met the parameters as specified in the participants section by networking through the Portland State University Curriculum and Instruction department and the Child and Family Studies department. Once potential participants were identified, I sent out an opening recruitment e-mail (Appendix A). This e-mail began with a brief explanation of the study and concluded with an invitation to join the study, requesting a date, time, and phone number in which to conduct a short screening questionnaire. The ideal number of participants was three with two alternates. After receiving emails from interested participants with a phone number and a convenient time to call, I called interested contacts and asked a short series of qualifying questions (Appendix B). Accepted participants were notified immediately and were sent an invitation to participate email (Appendix C), the consent form (Appendix D), contact information sheet (Appendix E), and site permission form (Appendix F). 
About the researcher and participant relationship Clandinin (2007) writes, The essence of the narrative research approach, what gives it its meaning and value, is that the researcher endeavors to obtain 'data' from a deeply human, genuine, empathetic, and respectful relationship to the participant about significant and meaningful aspects of the participant's life. (p. 539)

I included three participants in this study because I felt that I could develop and maintain deep and respectful relationships with three participants while obtaining a sufficient amount of information to support the study.

Participants engaged in two narrative interviews and one field observation. Clandinin, (2007, 2013), and Clandinin and Connelly, (2000), note that there are two potential beginning points when entering into a narrative inquiry exploration. Narrative inquiry researchers can start by listening to the participants as they tell their stories or by learning and listening alongside the participants as they live and tell their stories. Additionally, throughout the data collection and interpretation process, I used the hermeneutics of faith process of analysis that requires that researchers find multiple interactions with participants' stories from multiple perspectives (Pitre et. al., 2013). For the purpose of this research, I chose to begin by listening to the narratives of the participants as they told their stories through narrative interview and then moved into a place of learning and listening alongside the participants as they lived and told their stories through a field observation.

I use the term narrative interview instead of interview because it implies a deeper connection between the participant and the researcher than a traditional back and forth, question and answer interview (Mishler, 1986). Mishler (1986) writes that conducting traditional style interviews is a behavioral approach to seeking information by having an 
intentional purpose and a specialized pattern toward obtaining information. In traditional interviews, the researcher responds to the interviewee's answers in either positive or negative way depending on how well the answer fits the researcher's desired outcome of the research. However, when conducting narrative interviews, there is an agreement of collaboration between myself as the researcher and the participant (Clandinin, 2007, 2013; Clandinin and Connelly, 2000; Mishler, 1986). This agreement of collaboration empowered the participants to share what was important to them rather than what seemed to be important to me (Creswell, 2008; Egan \& McEwan, 1995; Mishler, 1986).

Each interaction took place about eight to ten weeks apart in order to give me enough time to interpret the first interaction, speak with the participant for the reflective conversation, and write reflectively about each interaction. The first of the narrative interviews took place in August and September of 2018. Observations were held in late October and early November 2018 at each of the participant's places of practice at the participant's convenience. A second narrative interview took place during January and early February 2019. The first narrative interview was followed approximately four weeks later by a reflective conversation with the participant about what I saw, heard, and connected to during the interaction. The observation was followed by a reflective conversation on the same day. After each interaction, I wrote my considerations about the interaction and reflective conversation, contemplating on how my understandings have been deepened or changed through the data collection and interpretation. 


\section{Data Collection and Interpretation}

As I have stated at the beginning of this chapter, narrative inquiry is a

collaboration between the researcher and participants (Clandinin, 2007, 2013; Clandinin \& Connelly, 2000; Creswell, 2008). It was important to me personally to accurately represent the participants' narratives and allow the participants the opportunity to collaborate with me in the interpretation of their stories. For this purpose, data collection and interpretation were not two separate aspects but a process of interconnections between myself and the participants as we moved through the processes of living, telling, reliving, and retelling experiences through narrative together (Clandinin, 2007, 2013; Clandinin \& Connelly, 2000; Creswell, 2008; Mishler, 1986). This collaboration allowed the participants to become co-researchers in the study giving them the power in which to reflectively think and discuss their experiences working with Teaching Strategies GOLD®, something that was not offered through their places of practice (Clandinin, 2007, 2013; Clandinin \& Connelly, 2000; Creswell, 2008; Mishler, 1986).

In chapter two, I discussed the ways in which using pedagogical documentation with my class of 2-3-year-olds had made our relationships with the children stronger, deeper, and more equal (Cadwell, 1997, 2002; Delrio, 2012; Fleet, et al., 2006; Forman \& Fyfe, 2012; Parnell, 2011b; Rinaldi, 2001a, 2001b, 2012; Rintakorpi \& Reunamo, 2016). I detailed how it had been empowering for the children to have the opportunity to revisit and reflect on their work, see and hear what we were seeing and hearing, correct us when our interpretations were inaccurate, and help steer the path of their explorations. It was in the spirit of pedagogical documentation that I conducted this research. Participants were 
co-researchers and through the process of data collection I continually brought back my interpretations to the participants, empowering them to revisit and reflect, see and hear what I am seeing and hearing, correct me when my interpretations are inaccurate, and help steer the path of our interactions together.

When reading different research studies, I was strongly drawn to Moran's (2007) work with pre-service teachers and teacher-educators using collaborative action research which offered me many elements that could easily transition to narrative inquiry. Moran names four elements that are imperative to collaborative action research. The first element is that the research is collaborative in nature, meaning that researchers and participants become partners (or in the case of narrative inquiry, co-researchers) in the research process. A second element is that there is a focus on practical problems, or in other words, what is being studied is a viable issue in the field. The third element is a focus on professional development, meaning that the participant and researcher will have the opportunity to deepen their understanding about the issue and their work as a professional through participating in the study. The final element is that there is a structure that provides time and support for open communication with recursive cycles of planning, reflecting and revising (Figure 4). 


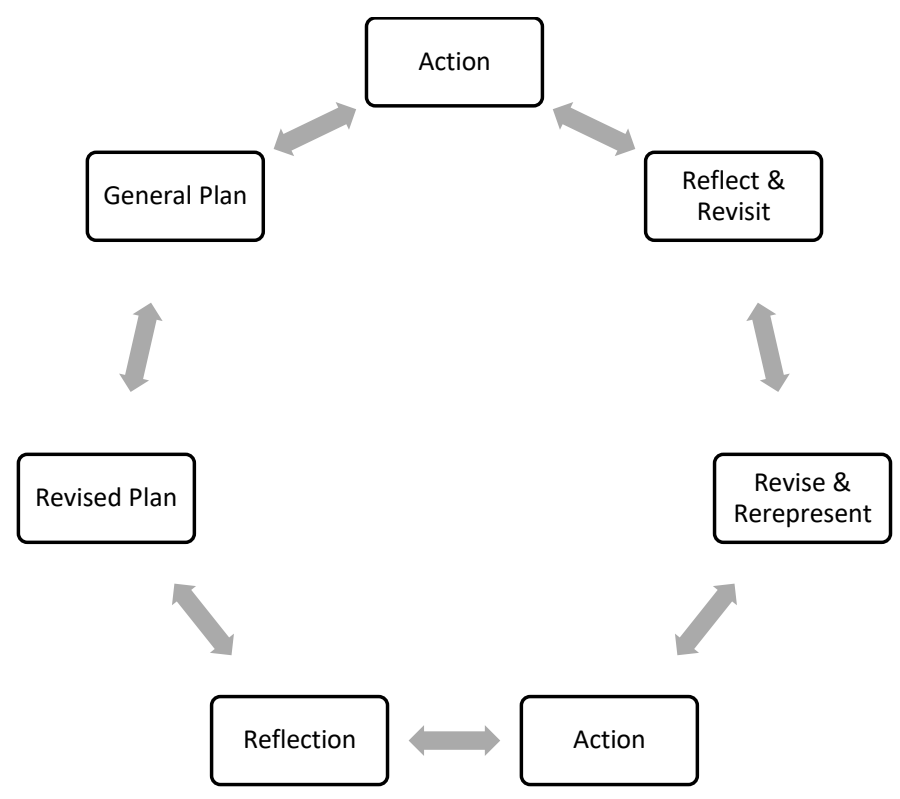

Figure 4: Moran's cycle of collaborative action research.

These four elements transition smoothly into narrative inquiry research. Narrative inquiry is collaborative in nature where the participants are considered co-researchers (Clandinin, 2007, 2013; Clandinin \& Connelly, 2000; Creswell, 2008) or as Moran (2007) states, partners, in the research process. Narrative inquiry research has a focus on seeking to understand experiences of individuals behind the taken-for-granted common beliefs of larger narratives, a deeper way of looking at practical problems. In my literature review I demonstrated the lack of empirical research conducted in regard to the experiences of early childhood educators required to use the Teaching Strategies GOLD® assessments system. Instead, the majority of research has been centered on Teachings Strategies GOLD $®$ as a valid way to document children's development and learning. In this research study, I wanted to look beyond the grand narrative supported by current published research on Teaching Strategies GOLD® that insinuates attaching children's development and learning to a rating scale of predetermined, generic learning objectives 
is an authentic way to assess young children, and discover the experiences of the early childhood educators working within the system.

Offering the participants a platform to share these experiences and a place to revisit and reflect on these experiences provided an emphasis on professional development. In the municipally funded preprimary schools and infant and toddler centers in Reggio Emilia, Italy, professional development is more than just attending conferences and workshops. Edwards (2012) writes that self-examination along with analysis and feedback from others is an important aspect of the role of the teacher. The process helps early childhood educators to pose important questions about the work they do with young children.

Further, the recursive cycle as described by Moran (2007) was easily be adapted to support this narrative inquiry research study (Figure 5). In conducting this research, the participants and I continually revisited and reflected about the stories that they shared and the parts of their narratives that connected with mine. Each interaction and reflection fed the next as we gained understanding and insight about our experiences. 


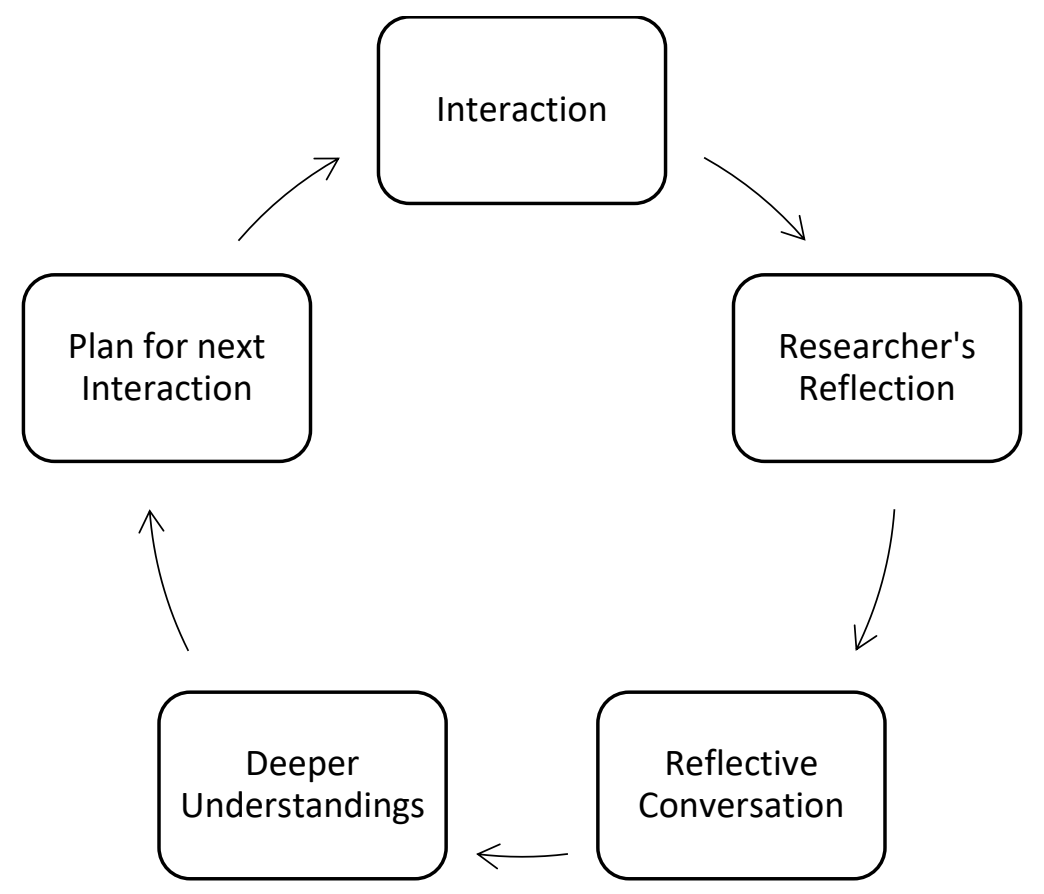

Figure 5: Guyon's cycle for collaborative narrative inquiry.

While considering respectful ways in which to follow this cycle I was drawn to Pitre et al., (2013) use of hermeneutics of faith when interpreting the narratives with the participants. In using hermeneutics of faith, participants are considered to be experts in their experiences (Josselson, 2004; Pitre, et al., 2013). The researcher's role is to represent, or 're-present' the narrative as faithfully as possible, highlighting the stories of success and challenges. Josselson (2004) writes, "Taking people at their word through the hermeneutics of faith (restoration) produces a rich field for potential interpretive work, both in terms of personal and social meanings" (p. 8). When using hermeneutics of faith as part of the research and interpretation process, researchers hold the belief of what is being said is true and of value.

Pitre et al. (2013), write that doing narrative analysis can require multiple revisiting of the narrative from a variety of vantage points. Pitre et al. recommend 
following a process of three readings using the hermeneutics of faith approach when interpreting the narratives with the participants. For this research, this process included visiting the narratives on my own, revisiting the narratives in a reflective conversation with the participants, and considering the ways that the reflective conversation has deepened my understandings.

I completed the first reading of the narrative after transcribing the narrative interview. During the first reading, I revisited the narrative in effort to identify the narrative threads that highlighted the participants conceptual understandings about their experiences with Teaching Strategies GOLD®. While completing the first reading I attempted to pull out what seemed valuable to the participant during the interview and what I connected to through my own experiences.

The second revisiting of the narrative was done in collaboration with the participant and was not an actual re-reading of the interaction but instead was an opportunity for me as the researcher to share the things that stuck out to me when revisiting the conversation. (Pitre, et al., 2013). The intent of this step as described by Pitre, et al is to, 'gain an understanding of storytellers' agency, identity, voice, and reflexivity given constant as well as evolving patterns of behavior, choices, and decisions" (p. 127). For me, it offered the opportunity to clarify my understandings with the participants by showing 'this is what I hear, what I saw, how I see it connect to my experiences' and to ask, 'is this how you see yourself, is this where you place value?'. It was similar to the process followed when conducting pedagogical documentation in that it gave me the opportunity to collaborate with the participant in attempt to construct a 
deeper understanding or knowledge about what the participant thinks about their experiences.

For the third reading I revisited the original narrative and the reflective conversation as a process of reflecting about the deeper meanings of what had been shared. I then retold the story of the participant's narrative through reflective writing. This reflective writing included my subjectivity as part of the interpretation process. Coles (1989) writes that the stories participants share tell the researcher what the participant wants the researcher to think about them and how the researcher interprets the story tells the researcher what they think about themselves. Regarding this balancing act Clandinin and Connelly (2000) write,

One of the researcher's dilemmas in the composing of research texts is captured by the analogy of living on the edge, trying to maintain one's balance, as one struggles to express one's own voice in the midst of an inquiry designed to tell of participants' storied experiences and to respect their voices, all the while attempting to create a research text that will speak to, and reflect on, the audience's voices. (p. 147)

In this reflective writing, I also considered the questions or understandings that I would like to explore further with the participant.

Up to this point, I have described the multiple venues for reflection and the clarification processes that were done in collaboration with the participants during the research process. However, once I had completed these processes with the participants, there was still additional work for me to do. When considering how to interpret the work completed with the participants at the end of the research process, I was enticed by Clandinin and Connelly's commonplaces of the three-dimensional narrative inquiry 
space. As narrative inquiry researchers begin to retell stories, they do not see stories and fixed entities but instead "work within a three-dimensional narrative inquiry space to 'unpack' the lived stories" (Clandinin, 2013, p. 34). Clandinin (2007, 2013) and Clandinin and Connelly (2000) highlight three commonplaces of the threedimensional narrative inquiry space.

The first of these is the temporal commonplace. The temporal commonplace is a perspective through the lens of time; the past, the present, and the future of the people, events, things, and places of the study. In this commonplace of interpretation, the researcher focuses on the ways in which past experiences have affected the way in which the participant responds to certain situations in the present and the ways in which past and present situations affect the participant's considerations about the future.

The second commonplace is the sociality commonplace. By the term 'sociality' Clandinin $(2007,2013)$ and Clandinin and Connelly (2000) include the social and personal aspects that influence the narrative. In the sociality commonplace of interpretation, the researcher considers the outer (social) and inner (personal) contexts that influence the participants responses.

The third commonplace is place. Place represents the actual physical setting or settings where the events and inquiry happen. Through the lens of the place commonplace, researchers consider how the different strategies and structures utilized by the place in which the participant is situated affects how they respond to their experiences. 
In this section I have presented a summation of the procedures that I followed while collecting and interpreting data with participants and, as a revisited the retellings once again, on my own. In the next two sections I demonstrate the steps I took while utilizing these procedures and working in collaboration with the participants, and the steps I took as I went through the final interpretation process on my own.

\section{Data collection instruments and interpretations during research.}

The first narrative interviews were conducted during August and September 2018. The first narrative interviews lasted approximately 60 minutes with each of the three participants. They were audio recorded on my personal device. The recording and electronic copies of the transcription have been stored on my personal laptop, and on an external hard drive.

In conducting the first narrative interview, I hoped to gain a better understanding of the participants' perspectives of what it meant to them to be a self-identified constructivist early childhood educator through the stories that they told about their work with young children. The first narrative interview was an opportunity for me to 'live' with the participants through the telling of their stories of the experiences that led them to choose a career in early childhood education, the experiences that brought them to selfidentify as constructivist early childhood educators and the experiences that the participants have had using the Teaching Strategies GOLD® assessment system. (Clandinin 2007, 2013; Clandinin and Connelly, 2000). Participants were provided with a list of potential leading questions prior to the narrative interview in order to give the participants the opportunity to reflect on their experiences (Appendix G). These questions 
included asking the participant to share the story of how they chose a career in early childhood education and share a story of a time the participant saw their beliefs about how children learn in action.

The first narrative interview was also an opportunity for me to establish a foundation from which to build a relationship between myself and the participants (Clandinin, 2013). Clandinin writes that in engaging in narrative inquiry, researchers and participant lives "come together in an inquiring relationship" (p. 43) that will continue beyond the research project. It was also my goal that the first narrative interview would give me a base of knowledge about the participant and their experiences in which to consider during the field observation. It was an opportunity to dig deeper into the answers that the participant provided during the screening phone call, such as understanding their ideas around what it meant to be a constructivist early childhood educator and their experiences around using Teaching Strategies GOLD(R). A list of questions that were asked during the first narrative interview can be found in Appendix G.

I transcribed the audio recording of the first narrative interview, filtering out the pauses and distractions in a way that authentically clarified the participant's' meanings of the stories. After completing the transcription, I revisited the first narrative interview in attempt to uncover the snippets that, in my perception, seemed to have value to the participant. As part of the interpretation process following Pitre et al.'s (2013) outline of using a hermeneutics of faith approach, I then spoke with the participant over the phone to have a reflective conversation, identifying what I connected with or did not connect with and taking it back to the participant to get their own opinions, feelings, and thoughts 
about the conversation in effort to deepen the meaning through the narrative process. The follow up questions varied slightly between the participants and generic conversation points can be found in Appendix I. The reflective conversation was audio recorded for and transcribed and stored in the same way as the first interview. After each reflective conversation, I wrote a retelling of the narrative the participant has shared, with a focus on the ways in which the reflective conversation deepened or changed our understandings of the first narrative interview.

Field observations took place in October and November of 2018 at the participants' places of practice and at the participants' convenience. The purpose of the field observations was to deepen my understanding of the participants and the participants' work with young children (Clandinin, 2007, 2013; Clandinin \& Connelly, 2000; Creswell, 2008). The field observations were an opportunity for me to 'listen in' on the participants' work world for a day and observe the participant as they moved throughout the day (Clandinin, 2007, 2013; Clandinin \& Connelly, 2000). A sample of the form that was used during the observations can be found in Appendix $\mathrm{H}$.

Through doing field observations, I gained the opportunity to experience the understandings I formulated during the first narrative interview and reflective conversation (Clandinin, 2013; Clandinin \& Connelly, 2000). The field observations also helped to build my relationship with each participant. By spending the day with each participant, I was able to show that my interest in the work they do went beyond the superficial, that I wanted to understand their experiences in a mindful way. 
I conducted the field observation in two-hour chunks, taking 45 minutes between each chunk to reflect and write a retelling of what I observed during the observation time. During the field observation, I took notes regarding the physical environment and the interactions between the participant and other individuals in the classroom. These notes were recorded on the observation sheets developed specifically for this research study (Appendix H). Creswell (2014) recommends using an observation protocol to separate information recorded while observing, such as using a line down the center of the page to separate reflective notes and descriptive notes. For the purpose of this research, reflective notes included my personal considerations, wonderings, and assumptions (Creswell, 2014). Descriptive notes included a description of the physical environment, participants, events, and activities (Creswell, 2014).

On the same day, at the conclusion of the field observation, I met with the participant to have a reflective conversation about the day. I selected to have the reflective conversation about the field observation with the participant the same day as the observation because I know, from my own experiences as an early childhood educator, how the events of each day can blend in together, and how quickly children grow and change. Events and interactions that can seem astronomical one day can quietly disappear as the next day's excitement unfolds.

The purpose of the reflective conversation after the field observation was to give the participant the opportunity to reflect on the day and share those reflections with me. Starting from a place wanting to know the participant's reflections about the day instead of starting from a place of what I saw in the participants' day, helped to turn the 
conversation to what was important to the participant instead of what I may or may not wanted to find out (Clandinin, 2007, 2013; Clandinin \& Connelly, 2000, Mishler, 1986). The reflective conversation after the field observation offered the opportunity to retell and relive the experiences in the classroom during the field observation with the participant, using my notes to contribute or expand on the narrative of the participant by taking it back to them and getting their own opinions, feelings, and thoughts about the day in effort to deepen the meaning through the narrative process.

Each of the post observation reflective conversations were held during times in which the participant could be away from the children. In this place of retelling and reliving, the participant and I had the opportunity to reflect and wonder about the ways the experiences shared during the field observation connected to the features and wonderings considered during the first narrative interview process (Clandinin, 2007, 2013; Clandinin \& Connelly, 2000).

The reflective conversation was audio recorded, transcribed, and stored the same way as our past interactions. As with the first narrative interview, after the field observation and reflective conversation I wrote a retelling about the day and ways in which I connected to the experiences of the participant with a focus on the ways in which the reflective conversation deepened or changed our understandings of the first narrative interview.

Second narrative interviews took place during January and early February 2019. The second narrative interviews lasted approximately 60 minutes. Each of the prompting questions for the second narrative interview were specific to the participant and can be 
found in Appendices K-M. The purpose of the second narrative interview was for the participants to have an opportunity to share additional stories about their work and expand on ideas that they shared before. It was also be an opportunity for us to share any new opinions, feelings, or thoughts that have surfaced while doing this research.

I transcribed and retold the stories shared by the participant during the second interview, filtering out the pauses and distractions in a way that authentically clarifies the participant's' meanings of the stories. At this point during the research process, I reviewed the transcriptions from each of the participants and wrote a narration of their individual stories based on the retellings of the two narrative interviews and the field observation. Through my retelling of each of the participants' narratives my focus was on what seemed important to the participant in the descriptions of their experiences, while being attuned to the emerging patterns that connect and define the participants' experiences.

During this process there was a probability that my own experiences of being a self-identified constructivist early childhood educator required by my place of practice to use the Teaching Strategies GOLD® assessment system may have similar patterns to the experiences the participants have shared with me that may influence my interpretation of their narratives. As part of my process I interpreted my own opinions, feelings, and thoughts alongside the interpretations of the participants in order to make connections with the participants' experiences. 


\section{Data interpretation at the completion of data collection: Three-dimensional}

\section{narrative inquiry space.}

Clandinin (2013) writes that narrative inquiry researchers begin with a "research puzzle" (p. 42) instead of a research question. My research puzzle was positioned in my wonderings about the experiences of self-identified constructivist early childhood educators who are required by their place of practice to use the Teaching Strategies GOLD® assessment system. When assembling a puzzle, it is a useful strategy to begin by sorting the pieces by the common features of each piece. Perhaps one sorts the pieces by shape, seeking out the corners and straight pieces to be examined first, finding the patterns and curves of each that connect to make out the hinterlands of the provided image. Or perhaps the pieces get sorted by the patterns or colors that define each piece, grouping the pieces that show blue water together in one space and the ones showing green leaves in another space in effort to define the larger features of the image before discovering the ways in which each feature connects to the others. No matter the preferred strategy, when assembling a puzzle, much like when interpreting research data, you must start somewhere and I chose to use Clandinin and Connelly’s (2000) commonplaces of three-dimensional narrative inquiry space in which to begin the process of interpreting the narratives of the participants in this study.

Narrative inquiry is a collaboration between the researcher and participants (Clandinin, 2007, 2013; Clandinin \& Connelly, 2000; Creswell, 2008). Creswell (2008) writes, "after individuals tell a story about their experiences, narrative researchers retell (or restory, or remap) the story in their own words" (p. 519). As narrative inquiry 
researchers begin to retell stories, they do not see stories and fixed entities but instead "work within a three-dimensional narrative inquiry space to 'unpack' the lived stories" (Clandinin, 2013, p. 34). During the process of retelling and inquiring into stories, narrative inquiry researchers have the opportunity to experience the reliving of the retold stories, highlighting the shifting and changing personal and social nature of what is being studied. (Clandinin, 2007, 2013). Clandinin (2007, 2013), Clandinin and Connelly (2000), and Creswell (2008) describe the process of the three-dimensional narrative inquiry space in analogous yet slightly different ways.

Clandinin (2007, 2013) and Clandinin and Connelly (2000) highlight three commonplaces of the three-dimensional narrative inquiry space; the temporal, the societal, and place (Figure 6). After each interpretation process for each participant, I reread through their story and made post it notes to pull out the highlights in three different categories. I attached the post it notes to three $2 \times 4$ foot pieces of foam board, each representing one of the commonplaces. I used different colored post-it notes for each participant because although I wanted to see some of the similarities under each commonplace, I did not want to blend the participants' individual thoughts or experiences during the beginning of the interpretation process. In addition, I coded each post-it note as described in the following paragraphs. After completing all three stories, I revisited each in turn and wrote a few paragraphs reflecting on our conversation and considering where more clarification was needed. 


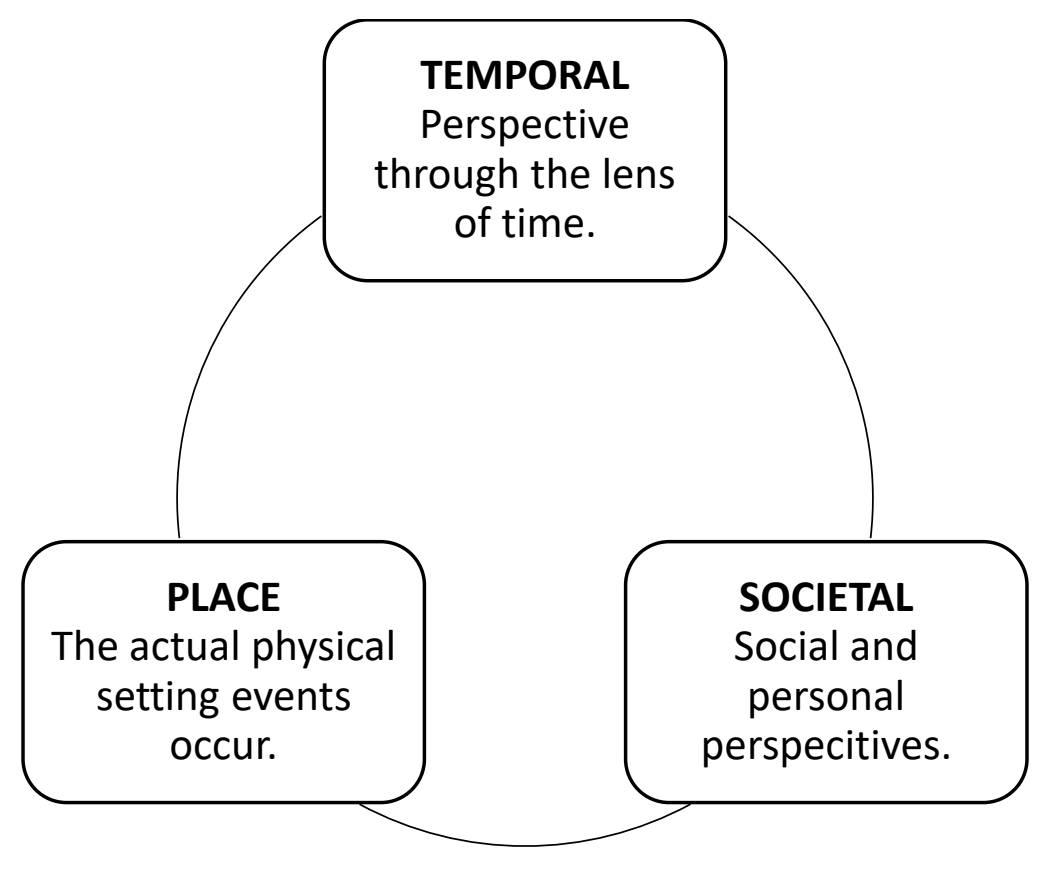

Figure 6: Clandinin and Connelly's Three Commonplaces.

The first of these is the temporal commonplace (Clandinin, 2007, 2013; Clandinin \& Connelly, 2000). The temporal commonplace is a perspective through the lens of time; the past, the present, and the future of the people, events, things, and places of the study (Clandinin, 2007 2013; Clandinin \& Connelly, 2000). The focus of the temporal is important because narrative inquiry researchers, like constructivist educators, believe that our past experiences effect the way in which we interpret present interactions and think about the future (Clandinin, 2007, 2013; Clandinin \& Connelly, 2000). As we move through experiences, our perception can go through a metamorphosis as it adjusts to new experiences, knowledge, and interactions (Clandinin, 2007, 2013; Clandinin \& Connelly, 2000; Creswell, 2008). Creswell (2008) labels this part as “continuity" (p. 521). In this space of interpretation, the past represents the remembered stories and experiences, the present represents the current stories and experiences that relate to the event, and the 
future represents a look forward, the implied or possible future experiences (Creswell, 2008).

To sort through the pieces provided by the participants' narratives using the temporal commonplace, I made marks to note whether the experience shared happened in the past, present, or is a consideration of the participant's future. One of my initial wonderings positioned in my research puzzle was the impact that being required to use Teaching Strategies GOLD® has had on the early childhood educators' perception of themselves. By marking the participants' narratives using the temporal commonplace, I was able to see the story of the participants' journeys as early childhood educators and gain an understanding of the effects that being required to work with Teaching Strategies GOLD® has had on their perception of themselves.

I marked the participants' narratives using the temporal commonplace by marking past experiences with a capital $T$ followed by a lowercase $p s$ to represent 'Temporal, past'. Similarly, present experiences were marked with a Tpr to represent 'Temporal, present', and aspects for future considerations will be marked with $T f c$ to represent 'Temporal, future considerations'. For the purpose of this research, the past referred to situations or experiences that the participant is no longer in the midst of, the present referred to situations or experiences that the participant is currently negotiating through, and future considerations referred to the upcoming situations or experiences that the participant believes may happen. A full list of note abbreviations can be found in Appendix J. 
An additional wondering positioned in my research puzzle was my own struggle with ways in which using Teaching Strategies GOLD® silenced the voices of myself and the children, moving away from the value of the child's experience as a lived experience and focusing only on the result of the child's experience as a goal to be achieved. I have preoccupied myself with how this shift in focus would affect the new policies and requirements for publicly funded early childhood education programs. This preoccupation led me to a second commonplace described by Clandinin, (2007, 2013), and Clandinin and Connelly (2000) called the sociality commonplace. By the term 'sociality' Clandinin (2007, 2013) and Clandinin and Connelly (2000) include the social and personal aspects that influence the narrative. The social aspects include the institutional, familial, and cultural narratives that are imbedded in the contexts, times, and places of each individual's experience (Clandinin, 2007, 2013; Clandinin \& Connelly, 2000). The personal aspects are the participants' inward and outward viewpoints on the situation (Clandinin, 2007, 2013; Clandinin \& Connelly, 2000). The inward viewpoint focuses on the emotions, moral responses, and aesthetic reactions to the situation (Clandinin, 2007, 2013; Clandinin \& Connelly, 2000). The outward viewpoint focuses on the people and events in the experience, including the interactions and relationship between the participants with each other and with the researcher (Clandinin, 2007, 2013; Clandinin \& Connelly, 2000). Creswell (2008) labels this commonplace as "interactions" (p. 521) and also ascribes too the focus on both the personal and social aspects that influence the narrative. 
To sort through the pieces provided by the participants' narratives using the commonplace of sociality, I marked each by the capital letter $S$ to represent 'Sociality' followed by either the lowercase letter $s$ to represent 'social' or the lowercase $p$ to represent 'personal'. Areas marked with $S s$ representing 'Sociality, social' were also be marked with either a lowercase $i$ to represent 'institutional', a lowercase $c$ to represent 'cultural', or a lowercase $f$ to represent 'familial'. Areas marked with $S p$ representing 'Sociality, personal' were marked by a lowercase $n$ representing 'inward' or a lowercase $o$ representing 'outward'. By marking the participants' narratives using the sociality commonplace, I was able to attain an understanding of the participants' struggles and/or concerns with the reduction of children's learning experiences into generic learning objectives. A full list of note abbreviations can be found in Appendix J.

The third commonplace as described by Clandinin $(2007,2013)$ and Clandinin and Connelly (2000) is place. Place represents the actual physical setting or settings where the events and inquiry happen (Clandinin, 2007, 2013; Clandinin \& Connelly, 2000). Creswell (2008) labels this commonplace as "situation" (p. 512) and describes the aspects of it in coherence with Clandinin (2007, 2013) and Clandinin and Connelly (2000). Another wondering positioned in my research puzzle has been about the time built into the program where I work. I have wondered if part of my struggle with using Teaching Strategies GOLD® was the large amount of time needed and small amount of time available to effectively utilize the Teaching Strategies GOLD® assessment system and that maybe other places had a better logistical process. By marking the participants' narrative using the commonplace of place, I gained an understanding of the different 
strategies and structures utilized by early childhood programs using Teaching Strategies GOLD®. To mark the areas that refer to the physical setting or settings where the events and inquiry happen, I used the capital letters $P L$ to represent 'Place'. A full list of note abbreviations can be found in Appendix $\mathrm{J}$.

Much like when working with a puzzle, once I had initially sorted the pieces that represent the commonplaces of three-dimensional narrative inquiry space, my next step was to discover the emerging patterns that shaped the ways in which the pieces fit together. My search for the emerging patterns in which the participants' experiences were similar began by arranging and rearranging the pieces in effort to discover the larger features of the image provided by the participants. Once the larger features were assembled, I then focused on the places where they did and did not connect with each other to find the emerging patterns between the participants' narratives.

\section{Summary}

As I began this research study, it was important to me personally to accurately represent the participants' narratives and allow the participants the opportunity to collaborate with me in the interpretation of their stories. For this purpose, data collection and interpretation was not two separate aspects but instead was a process of interconnections between myself and the participants. In this chapter, I have defined the data collection instruments I used when conducting this research and the ways in which I will verify with the participants that I have interpreted the narratives of their experiences during the research process authentically, building off the work of Moran (2007), Pitre, et al., (2013) and Clandinin \& Connelly (2000). 
Further, I have clearly described the procedures of the data interpretation after the research collection using Clandinin and Connelly's (2000) commonplaces of threedimensional narrative inquiry space in which to begin the process of interpreting the narratives of the participants in this study. These commonplaces include the temporal commonplace, sociality commonplace, and place commonplace. I have illustrated the ways in which, using an initialing system, I made marks to note the specific aspects of each commonplace as I sorted through the narratives of the experiences provided by the participants. Additionally, I have connected the commonplaces of three-dimensional narrative inquiry space with the wonderings positioned in my research puzzle that have led me to conduct this study.

The purpose of this research was to understand the experiences of self-identified constructivist early childhood educators that are required by their place of practice to use the Teaching Strategies GOLD® assessment system. In this chapter, I have disclosed many of my own experiences and struggles in using the Teaching Strategies GOLD® assessment system and articulated the curiosities and wonderings in which my research puzzle is positioned. In this research, the emerging patterns of the participants' experiences provided me insight to the use of preformatted portfolio assessment systems in early childhood education classrooms. In chapter four I share the stories of the participants' and my journeys together through the process of the data collection and interpretation. 


\section{Chapter Four: Data Presentation and Interpretation}

The purpose of this research study was to collect and understand the experiences of self-identified constructivist early childhood educators who are required by their place of practice to use the Teaching Strategies GOLD® assessment system. This research was conducted using Narrative Inquiry. Data collection and interpretation were a process of interconnections between myself and the participants. Moran (2007), Pitre, Kushner, Raine, and Hegadoren (2013), and Clandinin and Connelly (2000) informed my data collection and interpretation process. Using Moran's cycle of collaborative action research as a model, I incorporated the aspects of Clandinin and Connelly's reciprocal nature of narrative inquiry and Pitre, et al.'s hermeneutics of faith to create a process of interpretation, reflection, and verification with the participant which I refer to as the cycle for collaborative narrative inquiry (Figure 7).

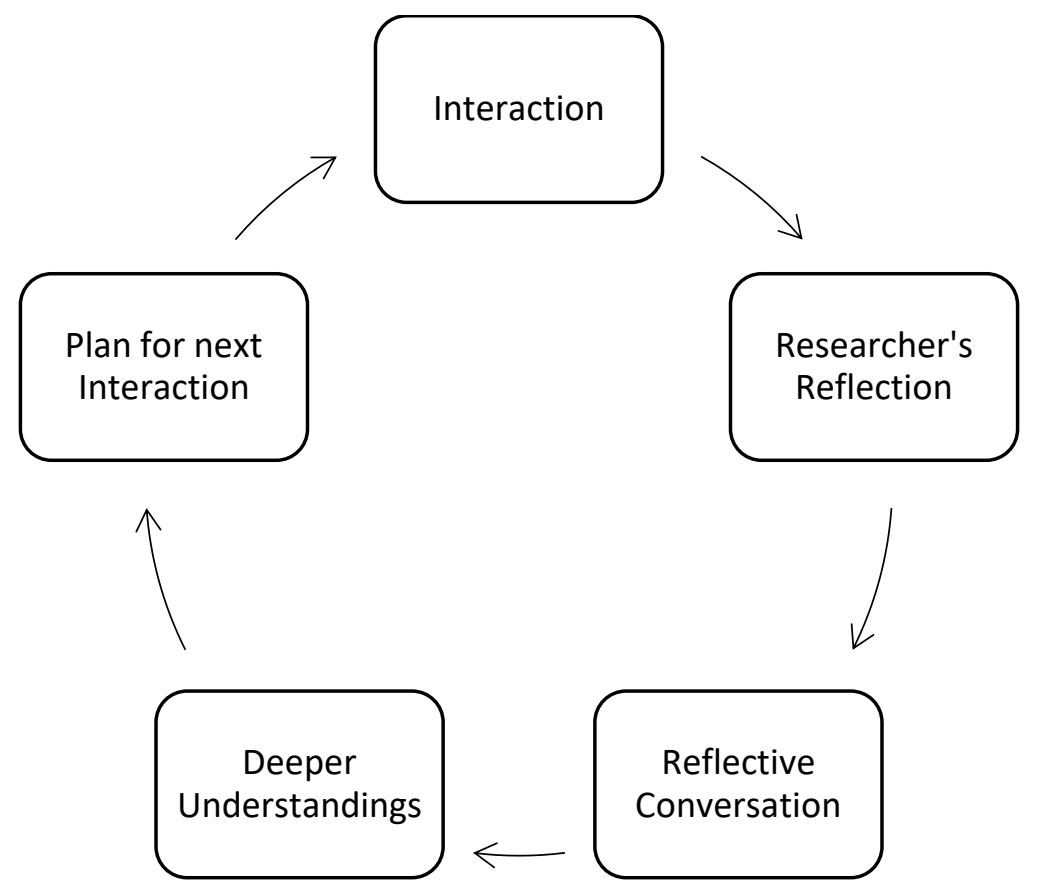

Figure 7: Guyon's cycle for collaborative narrative inquiry. 
To begin this research, I screened each participant over the phone using ten screening questions (Appendix B). The initial phone screenings started in February and ended in July 2018. The first four individuals interested in participating in the research did not meet the criteria for participants as defined in chapter three. The final three individuals intent on participating in this research met the criteria for participants. Each of these three went through the screening process in July 2018.

In August 2018, I met with the first participant, whom I will call Julia (pseudonym was used for privacy in all cases). Julia and I met at the Portland State University (PSU) library Faculty Room. We began our meeting with me thanking Julia for her time and for joining the research study. I then reviewed the IRB and Participant Consent form (Appendix D), clarifying any questions and reviewing the confidentiality aspect in great detail. Julia and I signed two copies of the IRB and Participant Consent form, one for her records and one for mine, then began the interview.

In September 2018, I met with the second participant, whom I will call Sasha (pseudonym was used for privacy in all cases). Sasha and I met at her place of practice and conducted our interview in my car. Since Sasha was not local to Portland, we could not meet at the PSU library, but my car afforded the same quiet and private space as a room at the PSU library. I began our meeting the same way in which I began my meeting with Julia, by reviewing the IRB and Participant Consent form (Appendix D), clarifying the confidentiality aspect in great detail, and having both of us sign two copies of the IRB and Participant Consent form for our records. 
In September 2018 I also met with the third participant whom I will call Cynthia (pseudonym was used for privacy in all cases). Cynthia was also not local to Portland and we met in a conference room at her place of practice. This room afforded the same quiet and private space as a room at the PSU library. My meeting with Cynthia began the same way as my meetings with Julia and Sasha; by reviewing the IRB and Participant Consent form (Appendix D), clarifying the confidentiality aspect in great detail, and having both of us sign two copies of the IRB and Participant Consent form for our records.

The interviews were recorded using my personal recording device. During the interview I asked each of the participants a list of leading questions (Appendix G). A few times I followed up on these questions for clarification or to extend the line of our conversation. This interview was the first step in following my adapted version of Moran's (2007) cycle of collaborative research, my cycle for collaborative narrative inquiry (Figure 8). 


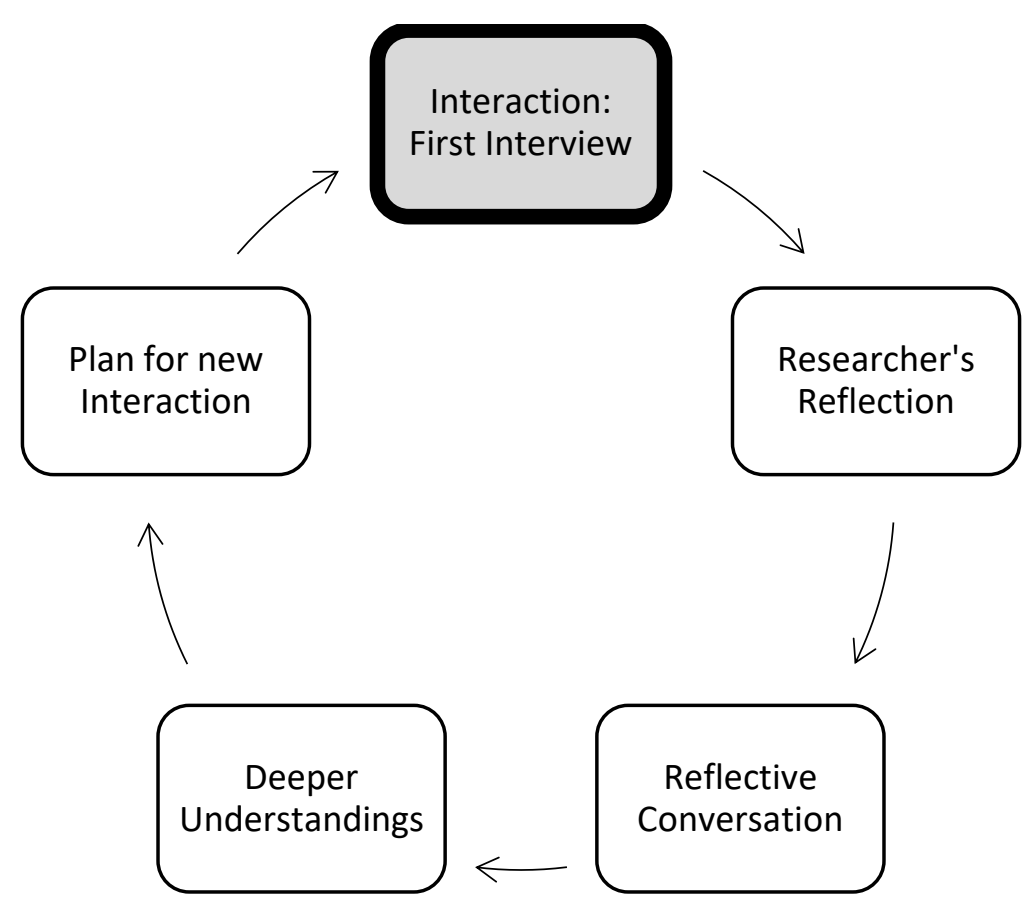

Figure 8: Guyon's cycle for collaborative narrative inquiry, step one.

Once each interview was collected, I uploaded the audio file to my personal computer and transcribed the conversation using the YouTube tool to add in timelines. I chose to do the transcribing myself rather than having an outside source do it because of the personal nature of the interviews. Once the transcription was complete, I printed a copy of the transcription for the next step in my interpretation.

I focused on each participant individually, as outlined in my methodology section. I began with Julia. First, I listened to the audio of the interview while reading the transcription. As I read and listened, I highlighted any of Julia's comments that stood out to me. Next, I went through the highlighted transcription and wrote out each comment, numbering them as I went. I chose to handwrite the comments, rather than use the computer to cut and paste the comments into a new word document, because of my past successes of retaining information this way. After completing the collection of 
comments, I read through the entire document and made turquoise post it notes to pull out the highlights in three different categories. These categories were the commonplaces outlined by Clandinin, (2007, 2013), Clandinin and Connelly (2000) three-dimensional narrative inquiry space and detailed in chapter three; the temporal, the societal, and place. I attached the post it notes to three $2 \times 4$ foot pieces of foam board, each representing one of the commonplaces.

My next step was to write a short story about Julia using the transcripts, handwritten quotes, and post it notes as a guide. I went through each of these steps in their continuation for Julia before starting with Sasha, and completed each of these steps for Sasha (using red post-it notes) before starting with the Cynthia (using yellow post-it notes). I used different color post-it notes because although I wanted to see some of the similarities under each commonplace, I did not want to blend the participants' individual thoughts or experiences at this time of the interpretation process. After completing all three stories, I revisited each in turn and wrote a few paragraphs reflecting on our conversation and considering where more clarification was needed. My interpretation and reflection on the first narrative interview continued to follow my cycle for collaborative narrative inquiry (Figure 9). 


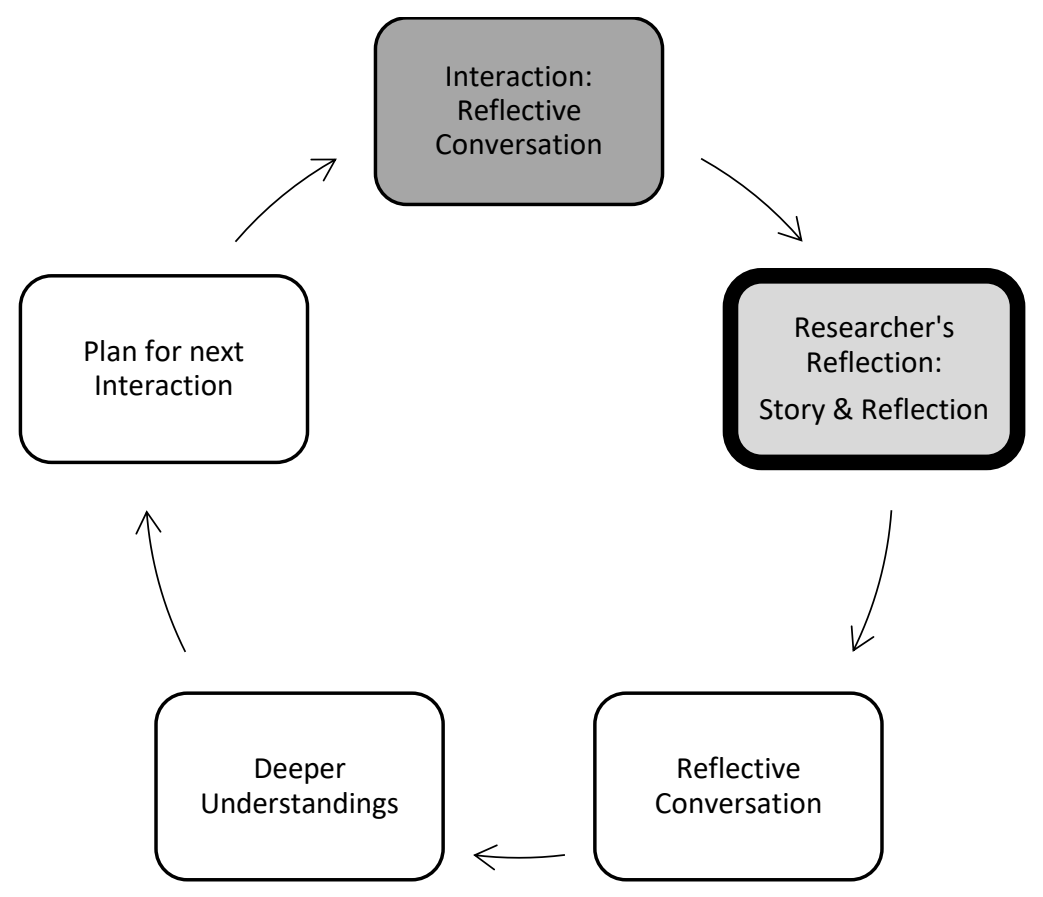

Figure 9: Guyon's cycle for collaborative narrative inquiry, step two.

Follow up conversations took place over the phone in October and November

2018. I chose to conduct these conversations over the phone because they were to be short, informal conversations in which I would share my thoughts about what the participant had shared in the interview and offer the participant to clarify their thoughts. Follow up conversations were recorded using my personal recording device. Rather than sharing the entire story with the participant, I only shared the reflection with them. The purpose of this conversation was to clarify my understandings with the participant by showing 'this is what I hear, what I saw, how I see it connect to my experiences' and to ask, 'is this how you see yourself, is this where you place value'? Each of the follow up conversations were as unique as the participants themselves. Julia wanted to expand on our initial conversation and include things she had been reflecting about since we met. Sasha was flattered and impressed by the accuracy of my reflection about our initial 
conversation. Cynthia did not agree fully with part of my interpretation and appreciated the opportunity to refine her thoughts. Cynthia also wanted to expand on our initial conversation and update me about her most recent experiences in working with the Teaching Strategies GOLD® assessment system. The follow up conversations, a revisiting to what we had discussed earlier, continued to follow my cycle of collaborative narrative inquiry (Figure 10).

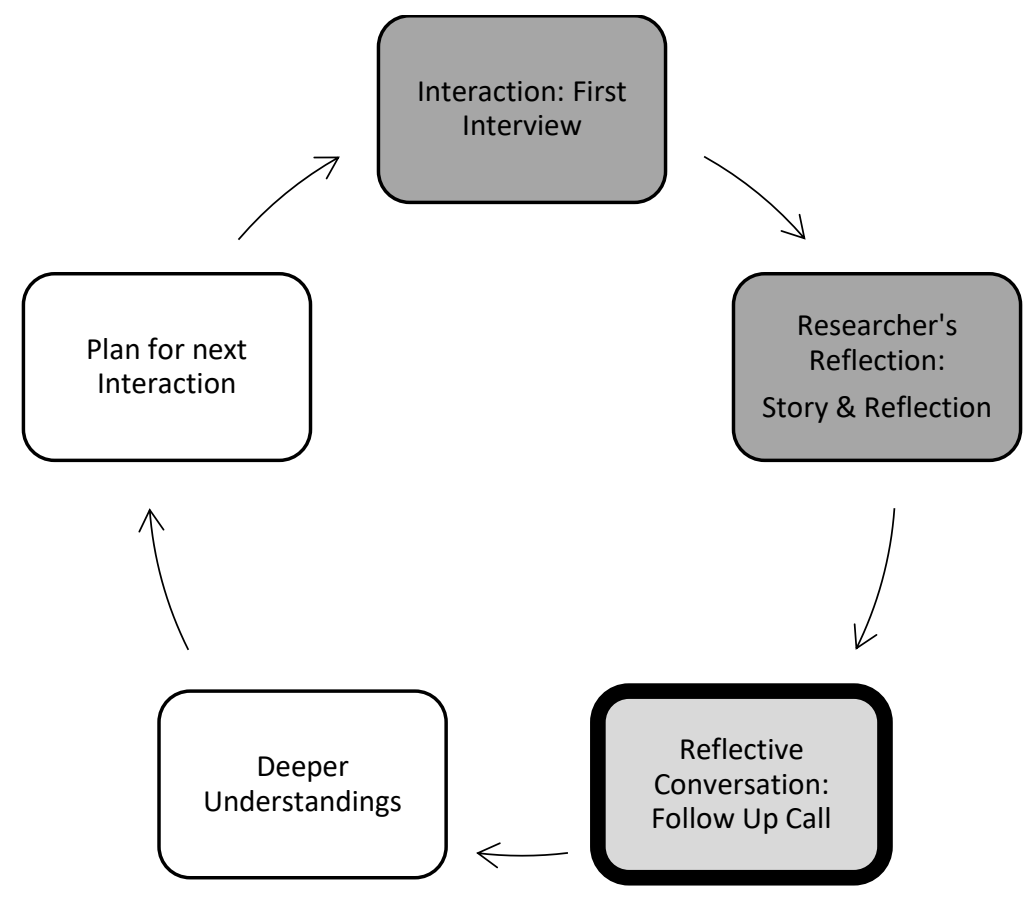

Figure 10: Guyon's cycle for collaborative narrative inquiry, step three.

Originally, I did not plan on transcribing these follow up conversations, but I was pleased with the image of each participant I was able to gather using the process of interpretation for the first interviews and I decided to use this same process for the follow up conversations as well. First, I transcribed the conversation using the YouTube tool to add in timelines. Then, I listened to the audio of the follow up conversation while reading the transcriptions, highlighting the comments that stood out to me. Next, I went through 
the highlighted transcription and wrote out each comment, numbering them as I went.

Finally, I went back through my first reflection, adapting and evolving the documents to represent the participants as faithfully as possible in order to build a deeper understanding of the participants' individual experiences (Figure 11).

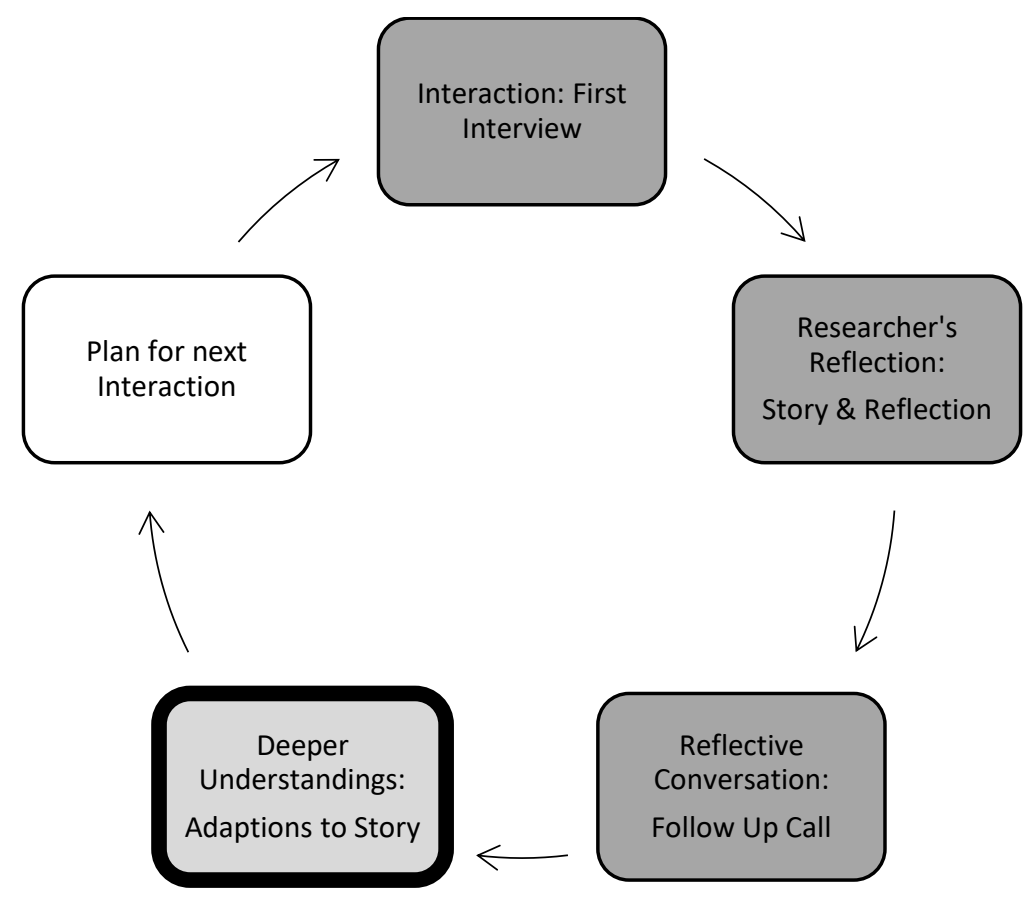

Figure 11: Guyon's cycle for collaborative narrative inquiry, step four

During the process of transcribing the follow up phone calls and following the same process as I followed for the first narrative interviews, I considered the questions and understandings that I wanted to explore more deeply through the field observation. I made notes of these areas and scheduled the observations to occur late October and early November 2018. The process of using my reflection, and the reflections of what I brought back to the participants in order to plan for our next interaction brought me to the fifth step in my cycle for collaborative narrative inquiry (Figure 12). 


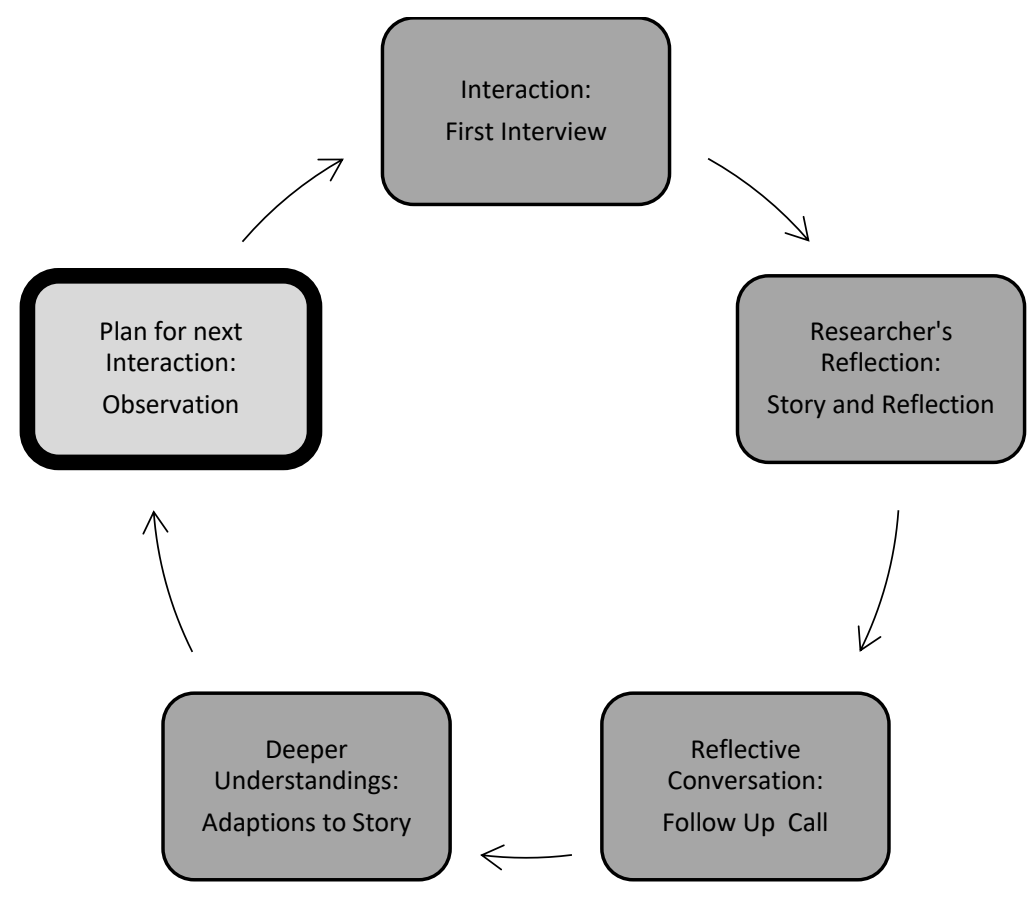

Figure 12: Guyon's cycle for collaborative narrative inquiry, step five.

Field observations took place during late October and November 2018. The purpose of the field observations was to deepen my understanding of the participant and the participant's work with young children (Clandinin, 2007, 2013; Clandinin \& Connelly, 2000; Creswell, 2008). The field observation gave me the opportunity to experience the understandings I formulated during the first narrative interview and reflective conversation, or in other words, to see how the participant moved through the day. Before completing the field observation, I reread the story and reflection I wrote about the participant from our first interview and follow up conversations in order to refresh my thoughts about the participant and recall the areas of importance to the participant in their work with young children.

During the field observation, I took notes using an observation protocol to separate the information I was recording (Appendix H). I took 20-30-minute breaks 
throughout the day to record my reflections about what I was seeing. When I would wonder about a specific interaction, I would write down my question at the bottom right corner of the observation sheet to bring up to the participant during our reflective conversation. At the end of the day, when it was convenient for the participant, I met with the participant to have a reflective conversation about the day. These conversations were recorded on my personal recording device.

The field observations, reflections, and follow up conversations provided ample information to revisit before continuing to engage the story of the participant. The process I used to interpret the gathered data was similar to how I processed the information from the initial interview conversations. First, I transcribed the reflective conversation and printed one copy for my review. Next, I reread my observation notes, the reflections I had recorded during the observation time, and the transcript of the reflective observation conversation highlighting the areas that stood out to me. I specifically revisited the information in this order to follow the natural progression of my thoughts as I went through the day with the participant.

I used all this information to add to the participants' stories. In each story I recalled the interactions I saw throughout the day and included parts of the reflective conversation I had at the end of the day with the participant. Subsequent to the process, I followed with the initial interview and following my cycle for collaborative narrative inquiry, I complete this section of the participant's story with a reflection (Figure 13). 


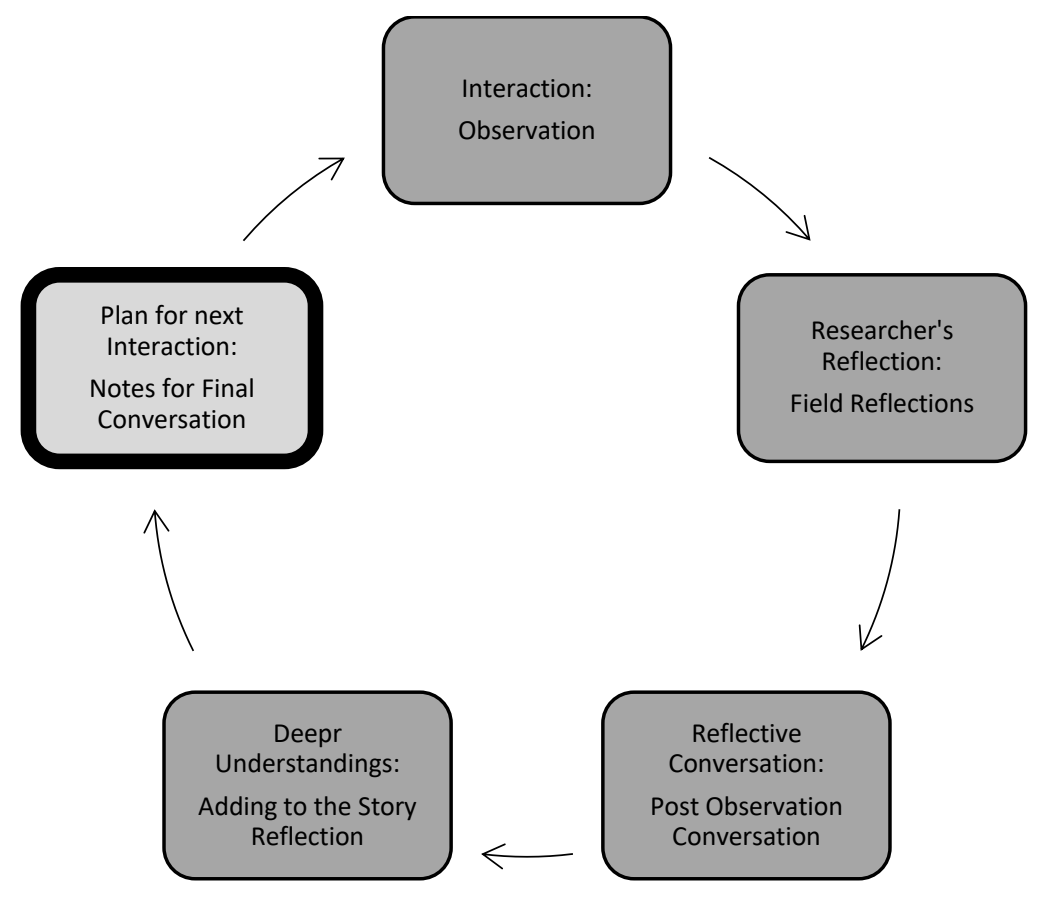

Figure 13: Guyon's cycle for collaborative narrative inquiry, step six.

When this section was completed, I reread this section of the participants'

reflections pulling out the commonplaces outlined by Clandinin, (2007, 2013), Clandinin and Connelly (2000) three-dimensional narrative inquiry space and detailed in chapter three; the temporal, the societal, and place. I attached the post it notes to three $2 \times 4$ foot pieces of foam board, each representing one of the commonplaces.

I went through each of these steps in their continuation for Julia (using turquoise post-it notes) before starting with Sasha and completed each of these steps for Sasha (using red post-it notes) before starting with the Cynthia (using yellow post-it notes). I used different color post-it notes because although I wanted to see some of the similarities under each commonplace, I did not want to blend the participants' individual thoughts or experiences at this time of the interpretation process, and marked each post-it 
with a small ' $\mathrm{O}$ ' in the bottom right corner to note it was from the observation and follow up conversation.

The next process of data collection was a third and final interview conversation. To prepare for this conversation I reread each participant's story. While rereading each story, I highlighted comments, quotes, and interactions that stood out to me. Next, I wrote each of these highlighted areas out by hand. I then sorted each area, following the possible conversation prompts for the final interview conversation as outlined in Appendix K-M: the areas of consistency that I noticed between our initial interview, the field observation, and our follow up conversations, the areas of inconsistency that I noticed between our initial interview, the field observation, and our follow up conversations, and the participant's thoughts about the way they used Teaching Strategies GOLD®. To organize my reflection about each participant, I used pink post it notes to record areas of consistency and blue post it notes to record areas of inconsistency. These post it notes were then attached to separate 2' $\mathrm{x} 4$ ' pieces of foam board, one representing each participant (Figures 14-16). 


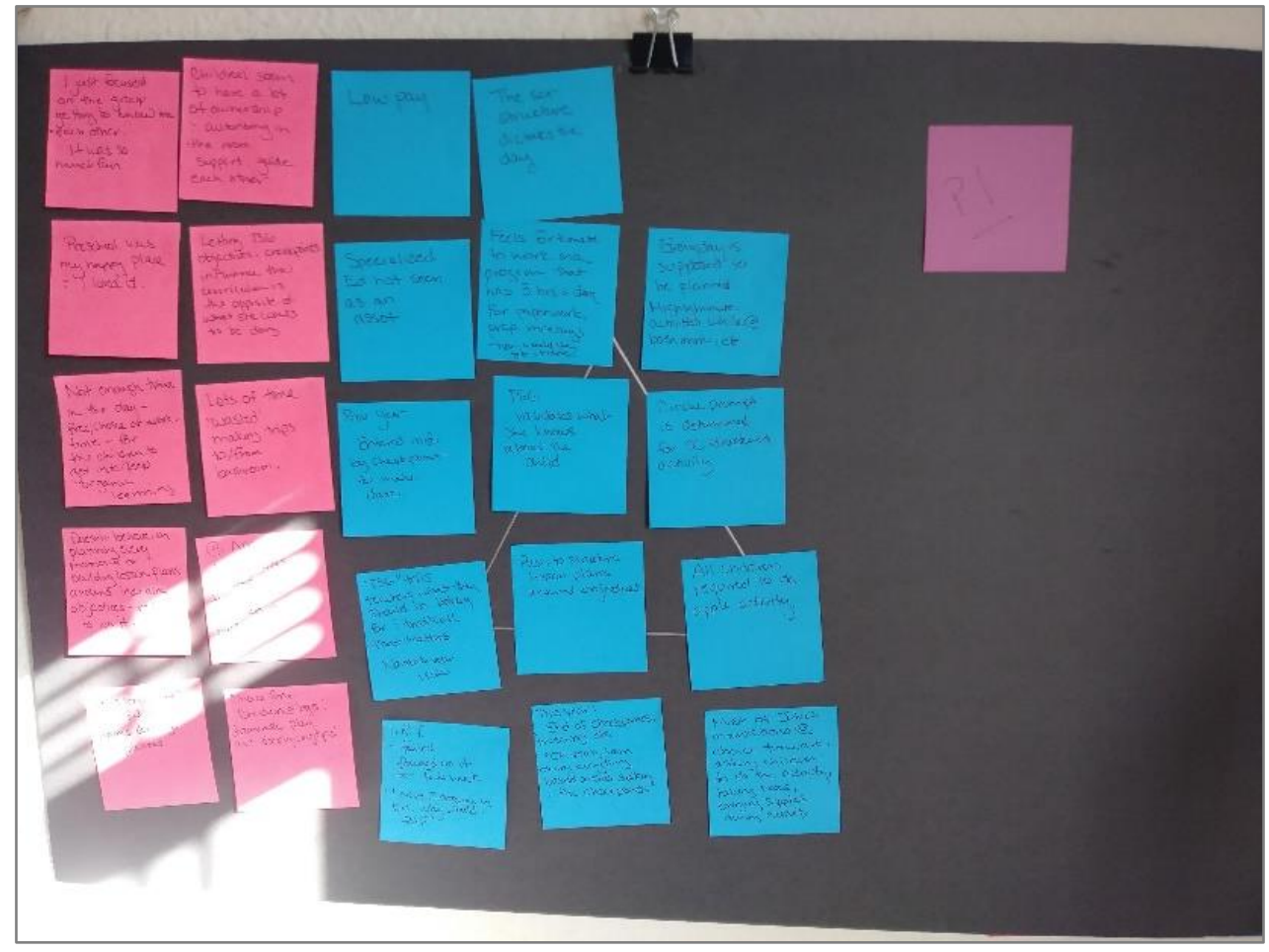

Figure 14: Participant 1, consistencies and inconsistencies.

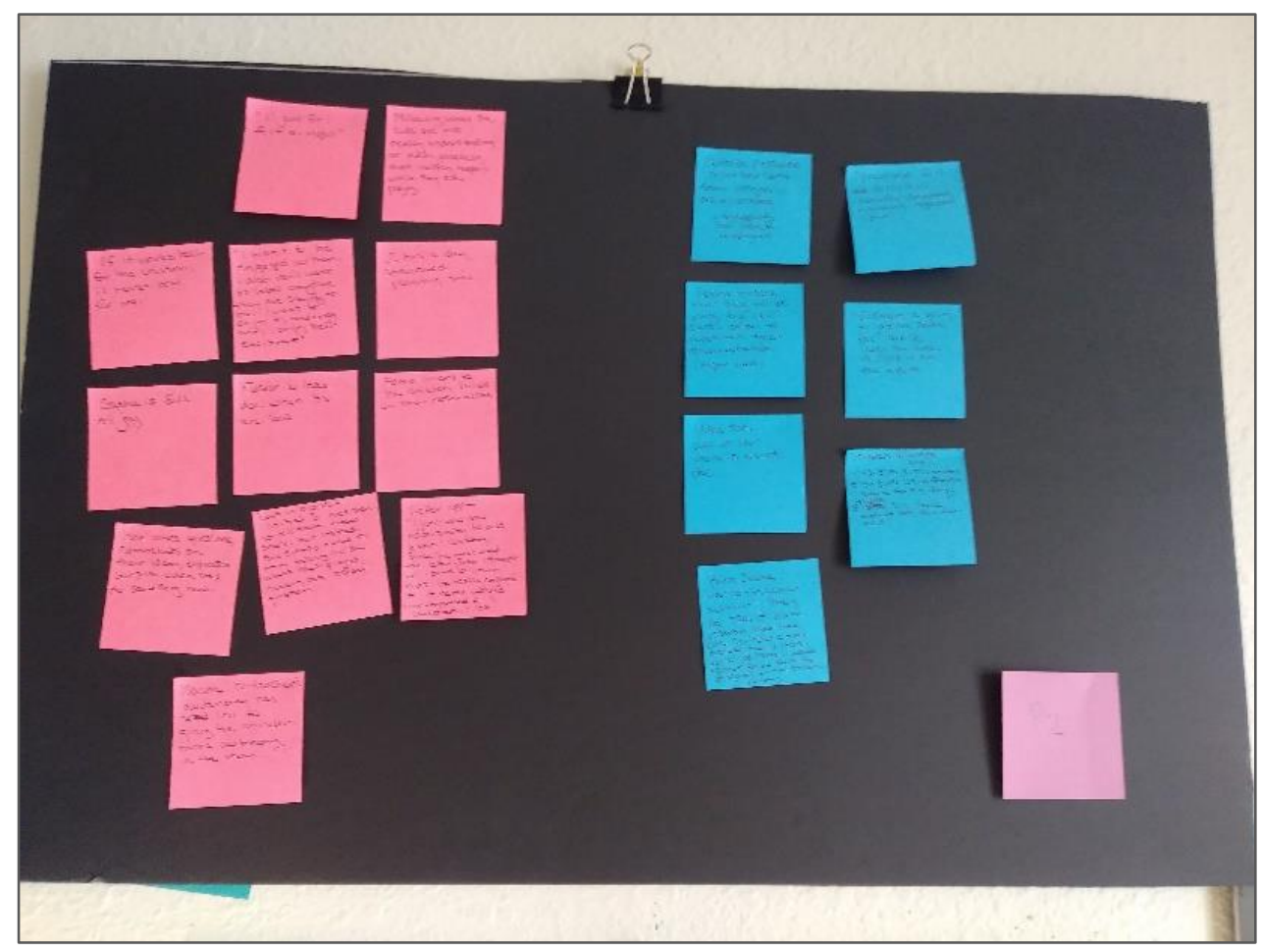

Figure 15: Participant 2, consistencies and inconsistencies. 


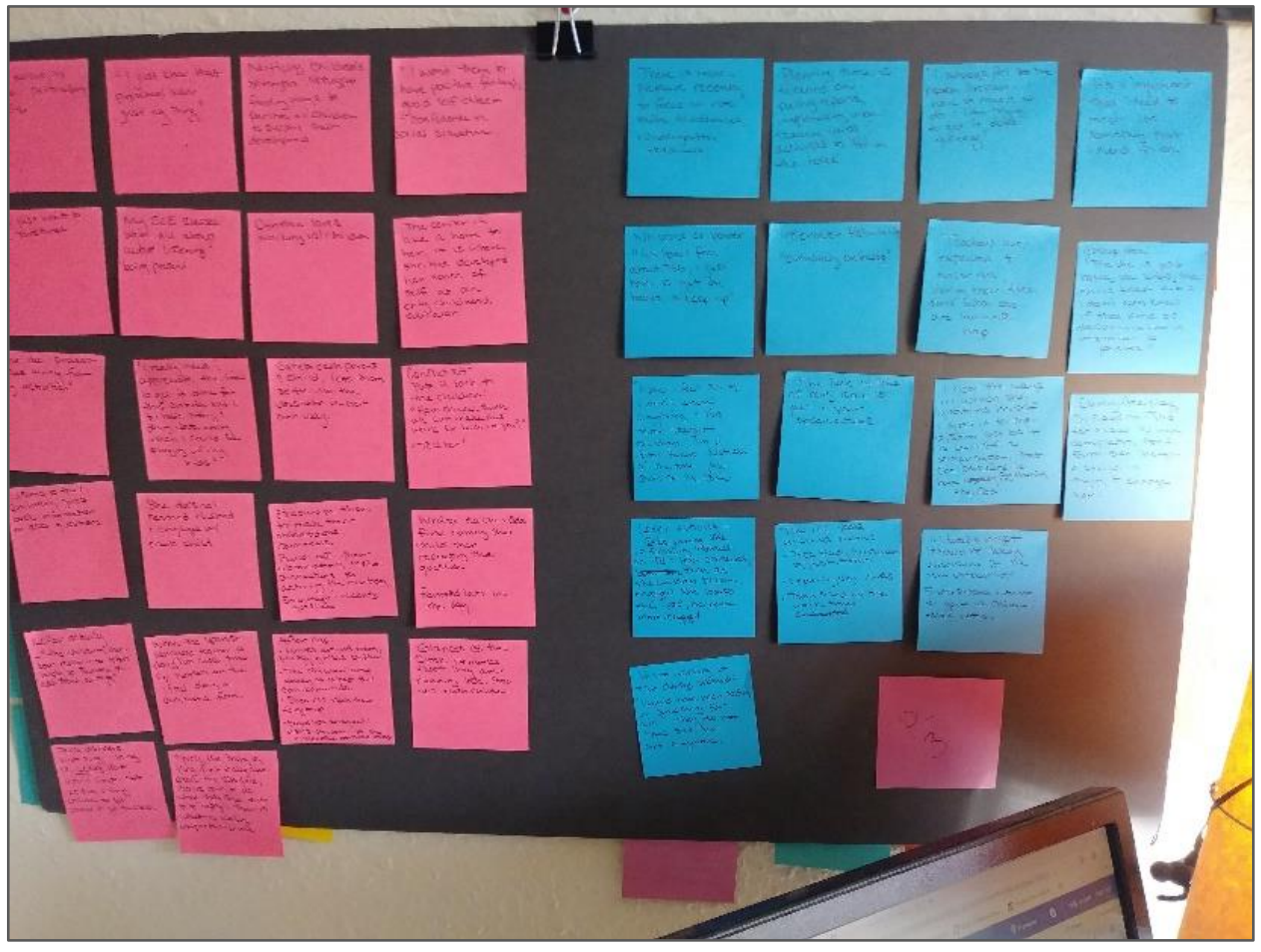

Figure 16: Participant 3, consistencies and inconsistencies.

Using these diagrams as a map, I wrote a short reflection about my thoughts and what I wanted to ask each participant during the final interview conversation, including giving the participant an opportunity to contribute anything else they wanted to share with me (Figure 17). 


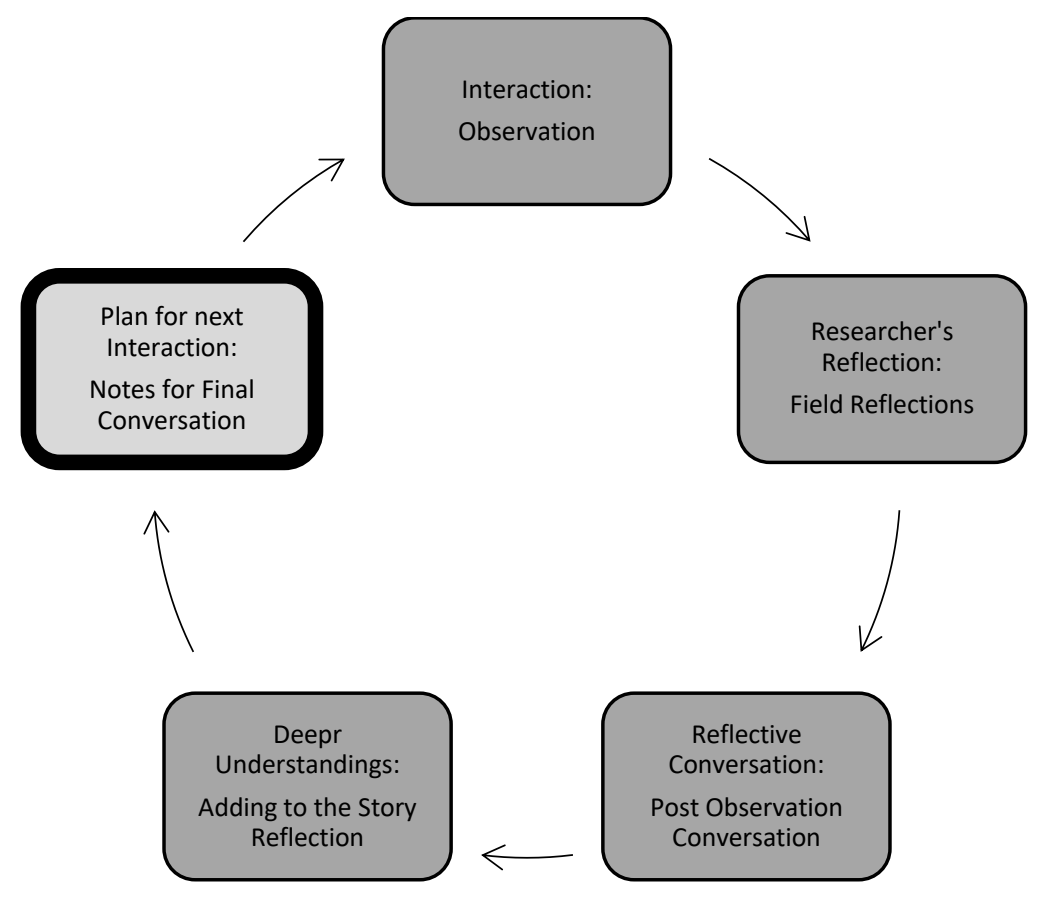

Figure 17: Guyon's cycle for collaborative narrative inquiry, final interview preparation.

As I prepared for the final interview conversations, I reminded myself of the hermeneutics of faith as described by Pitre et al. (2013) and Josselson (2004). When using hermeneutics of faith as part of the research and interpretation process, researchers hold the belief of what is being said is true and of value. As I looked for the consistencies and inconsistencies between how they described themselves as early childhood educators and what I saw in the classroom, I did so with the lens that what they had told me was true and of value. I looked for the moments that I was seeing the participant be what I interpreted as their true self as an early childhood educator, and the moments that they did not.

Final interviews were conducted in late January and early February of 2019. For each of the interviews I had prepared a short reflection about each participant and connected it to the final interview questions I had outlined in chapter three (Appendices 
K-M). Final interviews were recorded using my personal recording device then transcribed and interpreted using the same process I used for each of my conversations with the participants. First, I transcribed the conversation using the YouTube tool to add in timelines. Then, I listened to the audio of the follow up conversation while reading the transcriptions, highlighting the comments that stood out to me. Next, I went through the highlighted transcription and wrote out each comment, numbering them as I went. Using the questions I had prepared for each participant, the transcription of our final interview conversation, and the numbered comments as a guide, I adapted my final preparation notes to create final reflection about each participant. When this section was completed, I reread the final reflection pulling out the commonplaces outlined by Clandinin, (2007, 2013), Clandinin and Connelly (2000) three-dimensional narrative inquiry space and detailed in chapter three; the temporal, the societal, and place.

I went through each of these steps in their continuation for Julia (using turquoise post-it notes) before starting with Sasha and completed each of these steps for Sasha (using red post-it notes) before starting with the Cynthia (using yellow post-it notes). I used different color post-it notes because although I wanted to see some of the similarities under each commonplace, I did not want to blend the participants' individual thoughts or experiences at this time of the interpretation process and marked each post-it with a small ' $\mathrm{F}$ ' in the bottom right corner to note it was from the final interview. I attached the post it notes to three $2 \times 4$ foot pieces of foam board, each representing one of the commonplaces. 
It was now time to start sorting out the puzzle pieces of each participant's story. I wanted complete the individual stories by pulling out the themes that had developed throughout our interactions and conversations together and show the connection each theme had to the three commonplaces. To bring out these themes, I started with the image of each participant as an early childhood educator. I then considered the consistencies and inconsistencies that the participant I and spoke about in the final interview conversations and the participants' relationships with Teaching Strategies GOLD®. Using these themes as a guide, I revisited the three commonplace foam boards and the post it notes I had used for each participant (Figures 18-20). At this point of the data interpretation I was still focusing on the participants' individual stories and used these themes to complete each of the individual stories. I went through all three of the commonplaces for Julia before starting Sasha, and all three of the commonplaces for Sasha before starting Cynthia.

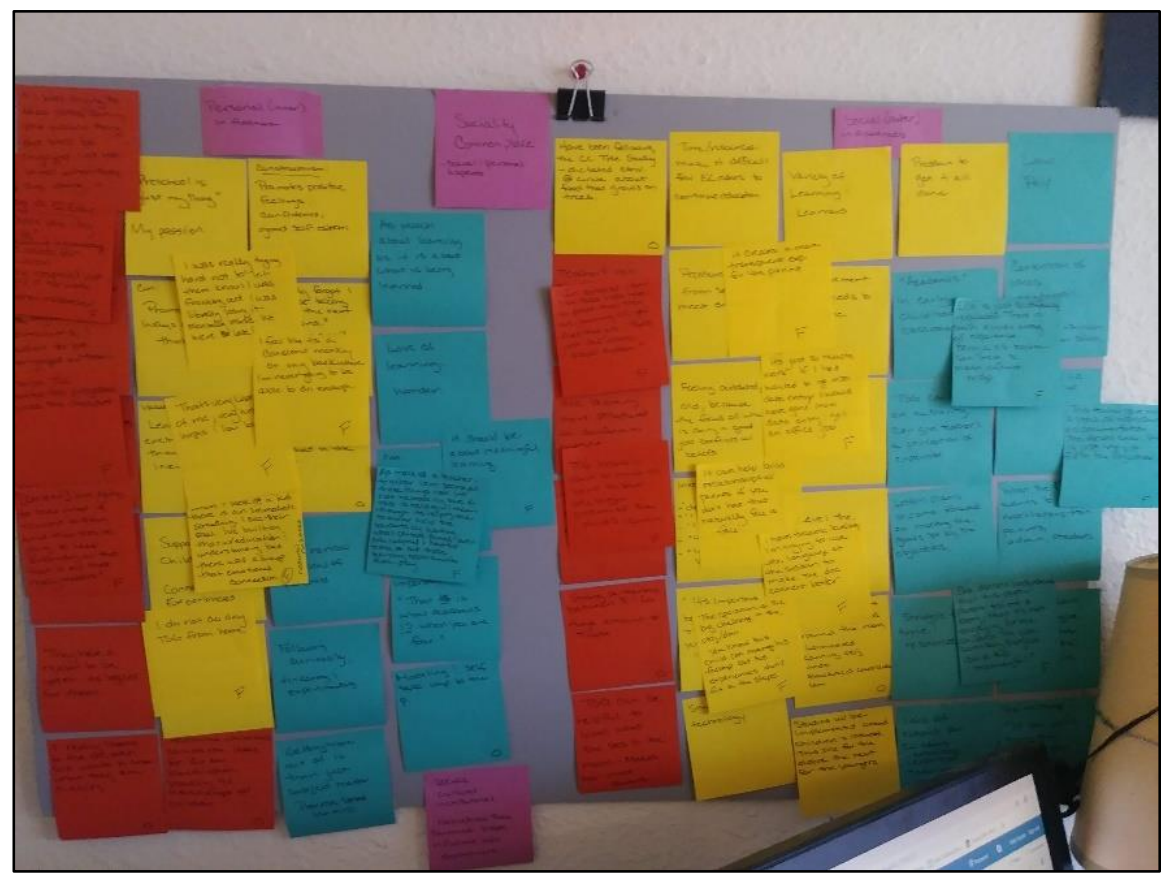

Figure 18: Sociality Commonplace. 


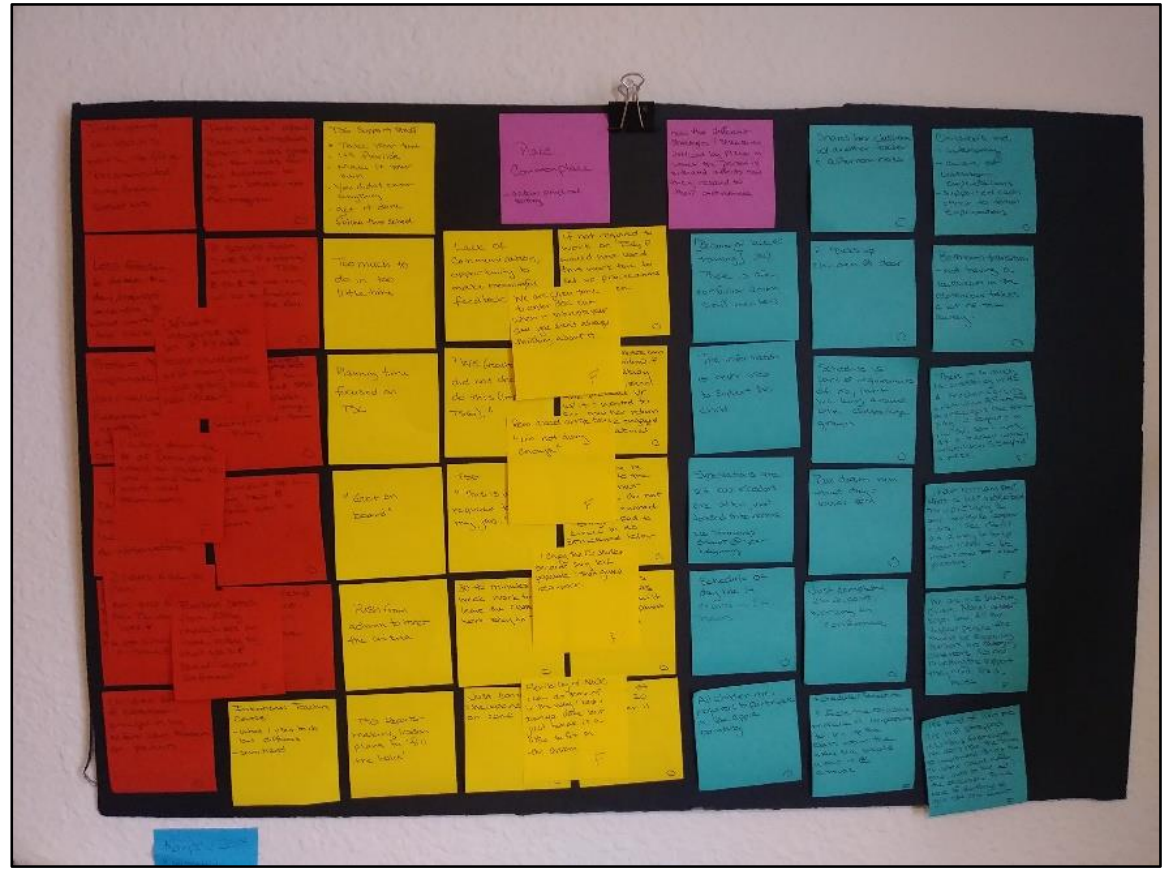

Figure 19: Place Commonplace.

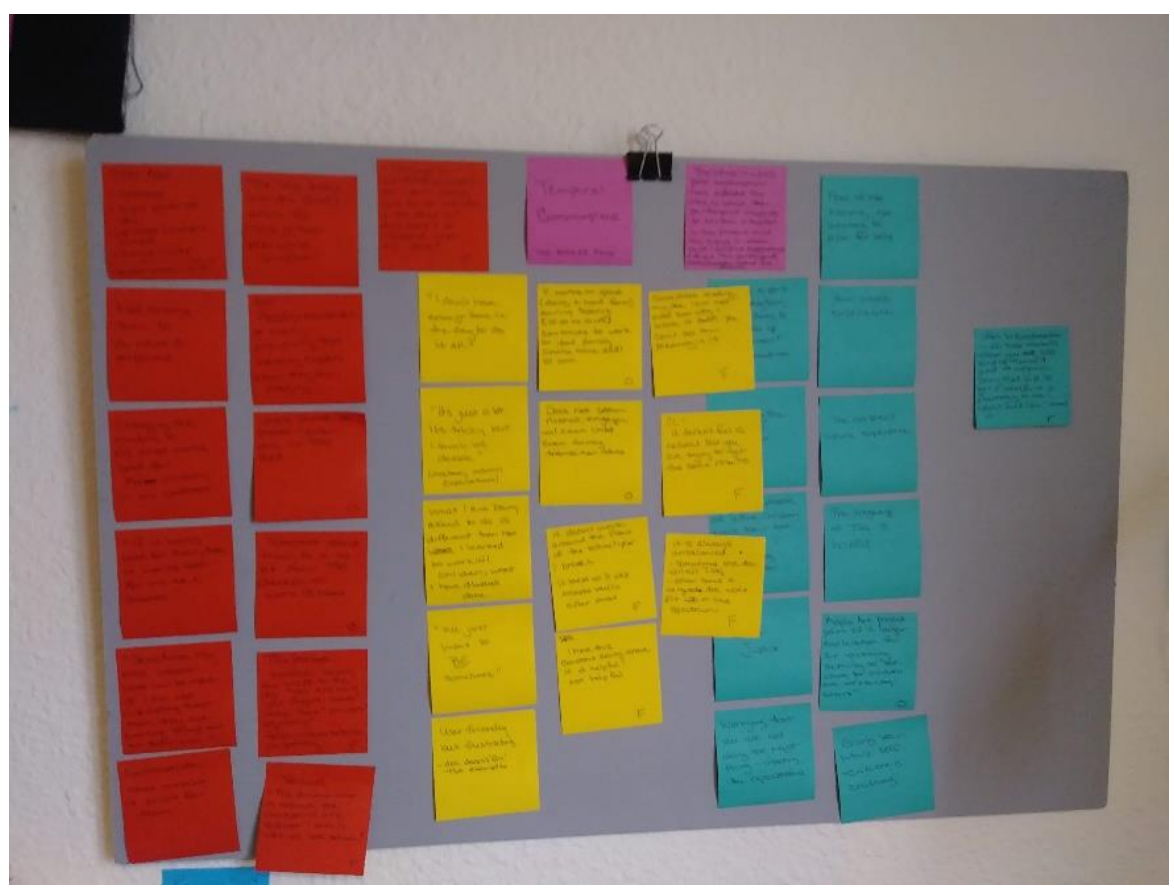

Figure 20: Temporal commonplace.

Finally, after completing the individual stories, it was time to pull together the larger narrative. I began by looking at the commonplace of sociality with all three 
participants and connecting the pieces of their individual stories before moving on to the commonplaces of place and temporality. Each of these ideas are detailed in the final section of this chapter. As I worked through each commonplace, I reflected on the initial wonderings I had about the experiences of self-identified constructivist early childhood educators required to use the Teaching Strategies GOLD® assessment system to build the larger narrative.

In this section, I have outlined my research process for collecting and understanding the experiences of self-identified constructivist early childhood educators required by their place of practice to use the Teaching Strategies GOLD® assessment system. In the next section, I present each of the participants' stories individually before moving on to the larger narrative.

\section{Data and Interpretations}

When conducting a narrative inquiry research study, the traditional roles of the participants and the researcher become blended. Throughout the data collection and interpretation period, I was continually seeking clarification from the participants about my interpretations of their stories through the processes described in the previous section of this chapter. Data collection and interpretation were a reciprocal cycle of verification and deeper understanding that are emulated throughout each of the participant's stories.

\section{Julia's story.}

I met Julia outside of the Portland State University library. She seemed nervous to meet with me, perhaps because she was a student in one of my classes the previous 
spring. I told her how much I appreciated her joining this study, and that I admired her work in our class. We proceeded to the faculty room and began our discussion.

Julia has been working in early childhood education for almost six years. She has previous experience working with teenagers, at-risk youth, and school aged children. She earned her undergraduate degree at Evergreen College. Julia recalled that before attending Evergreen she hated school but loved learning. She describes her experience at Evergreen stating, “It's all about community-based learning and driving your own education, student centered education. There is a lot of collaboration. A lot of student driven learning there" and attributes her time at Evergreen with building the core of her constructivist beliefs.

Julia's constructivist beliefs continued to be validated through her work experiences. She shared a story about working for an Outdoor School program:

When I taught Outdoor School, we had teams, but I was finally by myself. I had this group of middle schoolers that I would have all week and doing all these different classes that had been set up for us. I remember I was so anxious about knowing the actual information. I was so stressed out that I did not focus on the team building which was the first part of it. Then I was on edge that they weren't doing the right thing. I didn't bond with my group because I was so worried about getting all the curriculum out. It totally ruined the week and it was horrible. I didn't build those relationships and we just didn't have a good time. I was just so worried about knowing the right answer. After that week I just focused on the group getting to know me and each other. It was so much fun and that is when I realized it doesn't matter if I know the answer, it's that I'm willing to help you figure it out and we can figure it out together. That was a game changer for me.

In addition, Julia worked with a program that went into juvenile detention centers to do teaching workshops. The workshops were all based around subjects that the youths in the program had requested to learn about. She recalled that since she wasn't an expert 
in the subjects, she and the students learned together and remembers that through the experience, they all learned about much more than just the subject matter.

After working with a children's advocacy program and with teenagers in a crisis intervention center, Julia wanted to do something different and took a position as an assistant teacher at a private preschool. She was instantly hooked, describing the experience by saying "I realized that [preschool] was just my happy place and I loved it." At that time Julia was completing a Master's program in educational leadership and policy. She completed that program and began to work towards her second Master's degree in early childhood education.

In preschool classrooms, Julia sees community-based learning personified the most, saying, "There's this sense of wonder that everyone talks about and that's so real at the preschool age." I asked Julia to tell me a story about seeing her constructivist beliefs in action. She recalled a story from the previous year where two children, who happened to be cousins, were arguing over the grapes and raisins they had brought for snack. She wondered what would happen if they saved the grapes and set them in the window, could they become raisins too? She and the children placed the grapes into the window sill. Over the next few weeks, they observed the grapes turning into raisins, visiting the window each day and talking about the process. "It was spur of the moment, and this whole exciting thing. The experience was part of the story of our class where it was woven into the other things we did." Julia smiled and laughed as she reflected about this experience with the children. 
Julia admitted there can be a lot of struggles in being an early childhood educator. Since beginning at the first preschool she has worked at a few different programs. She talked about the struggle of trying to balance the expectations of parents and administrators with her own beliefs about early childhood education. Recalling one experience Julia stated, "A lot of parents felt very entitled to having me do whatever they wanted me to do. I really had a hard time sticking up for myself as a teacher and what I believed what I was doing." She reflected that it was hard not to take the confrontations with parents personally, "We all know being burnt out as a teacher is so real and intense because it is your whole self. It is so personal, so crushing when people [treat you] like you don't know what you are doing." I asked Julia why she believes parents felt they had the right to treat her this way. Julia spoke about how, in the greater society (in the United States), early childhood education isn't valued. She told me that she commutes across the city to work at the program she is at because the ones that are closer to her home are run by a different agency that requires a Step 10 rating on the Oregon Registry (Julia is a Step 11) and pays $\$ 13 /$ hour. Another program in her neighborhood requires an elementary teaching license for the position of Lead Teacher. Julia expressed her frustration that as she is about to have two Master's degrees, one specializing in early childhood, yet she does not qualify for this position because she isn't licensed to teach in elementary education.

Another challenge Julia spoke about is the lack of time and resources often found in early childhood education programs. She feels fortunate to work a program where the children leave in the early afternoon and she has a few hours in each day to do 
paperwork, enter observations, meet with paraprofessionals and other service providers, plan new encounters for children, and gather materials. She expressed that she could not imagine having to do the same amount of paperwork in a program in which children are present full time.

Julia began working at her current center nine months before our meeting. She works at a federal and state funded, early childhood education program located in the Pacific Northwest. One of the requirements for the program's funding is to use a standardized assessment system. The one used by the agency that Julia works for is Teaching Strategies GOLD ${ }^{\circledR}$. Through Teaching Strategies GOLD ${ }^{\circledR}$ Julia's program has four checkpoints throughout the year although one is scheduled over the summer when children are on summer break and does not require any entries. The other three checkpoints are scheduled during the school year. The first and the third (fall and spring) coincide with parent/teacher conferences. The program recommends that teachers have at least two observations per learning objective per checkpoint, per child, and that teachers use the parent/teacher conference forms built within the Teaching Strategies GOLD® system.

Julia started at her current early childhood education program in the middle of the school year and did not receive any sort of professional development or support to use Teaching Strategies GOLD® before she started. Julia remarked that she was the third teacher to be in the classroom and entering information into the system:

Every child in my class had three different teachers writing at certain times over the year. I was doing my checkpoints without knowing what I was supposed to have looked for in the first place because I did not receive any training on it. What the first teacher and I did were very similar, but the person in the middle rated 
things very differently. Even though [Teaching Strategies] GOLD® is very cut and dry, it can be interpreted very differently based on what you think.

Julia was able to incorporate the help of other teachers at her program as she learned to use the Teaching Strategies GOLD® system but "They were all confused. My family advocate said that she hadn't looked at [Teaching Strategies] GOLD ${ }^{\circledR}$ for years.” Julia recalled that it wasn't until she was entering information into the Teaching Strategies GOLD® system herself that she understood what it was about. At first Julia entered her observations by student, writing narrative observations then entering them into the system each day and connecting the observations to the learning objectives. When her checkpoint deadline was looming, Julia was concerned that she would not have everything completed on time. Other teachers who had experience using the Teaching Strategies GOLD® system showed her how she could enter information by checkpoint instead of by student, making the process more efficient.

Before her final conference with parents, Julia set up activities to watch and see where children were falling on the Teaching Strategies GOLD® rating scale for specific learning objectives. The learning objectives she focused on reflected solid skills that she wanted to talk about during the parent conference. I was curious about how this differed or was similar to what she had done before or what she might have done if she was not required to use Teaching Strategies GOLD®, Julia, replied:

It was different than what I've done before. Coming in so late I didn't feel like I knew the children well enough. You need time to be able to observe all [the learning objectives] and to reflect on them. That's hard in this program because it's only three hours a day. 
My meeting with Julia was a few weeks before the beginning of the new school year and she mentioned that she would have two weeks of professional development before starting the year. "It's required, I feel like that must mean that teachers that have been there for years have to go back and do the basic training over anyway. Or maybe it is because there are updates." I wondered how an administrator at her program would describe the ways in which the teachers use Teaching Strategies GOLD®. Julia that she felt the administrators at her program would tell me that the teachers use Teaching Strategies GOLD® as a guide to show a child's development and growth throughout the year, as well as a tool to help plan their lessons.

Throughout our conversation, Julia commented on different ways that she struggled with using the Teaching Strategies GOLD® assessment system as well as different ways in which she found the system helpful. One of the aspects she finds helpful is that Teaching Strategies GOLD® validates what she knows about a child. She recalled her experience with difficult parents at one of the early childhood education programs where she had been employed in the past saying, "It would have been helpful to me if I could use the language of that kind of system to explain what we were doing." Julia then quickly added, “But I don’t need that kind of system to do that. It is just helpful sometimes and can be an authority." I nodded my understanding.

As we went on with our conversation, Julia continued to contemplate about Teaching Strategies GOLD®. At the program where Julia currently works there is a large focus on supporting teachers that are new to the field to learn how to be early childhood educators. Many employees begin without any experience working in a classroom. Julia 
expressed concern for placing such importance on Teaching Strategies GOLD® in her program. She stated, "It kind of is telling teachers what they should be looking for and that's all that matters. That can really narrow your view." Julia said that there is an expectation at her program to use the learning objectives in Teaching Strategies GOLD® to create lesson plans. She admitted that she has been lax in this area and doesn't care to structure her day that way. In addition, Julia commented, "Structuring lesson plans around [Teaching Strategies GOLD®] objectives can mean that you are focusing on some weird rote skills sometimes." She connected this thought back to her Outdoor School experience she reflected about earlier in our discussion saying:

If you build your lesson plan along the learning objectives and you really feel like sticking to it then you are worried things will go off the rails and in a different direction. Which is actually really important and can be very powerful, but if you are worried about sticking to the plan you won't let that happen.

She continued and compared this to the experience of watching children without preset expectations:

When you don't know what you are looking for, that is when you really notice all this stuff. Once you start noticing then you are able to tell this whole other story. You are really watching to see what you can learn from them and what they are learning without any preconceived notions.

I was curious if Julia had any ideas about why some teachers use Teaching Strategies GOLD® as a support to think about children and other teachers see it as a tool to develop lesson plans. Julia stated, "I think it's more of a fear of not knowing and worrying that you are not doing the right thing. If you can't trust in the process, you can

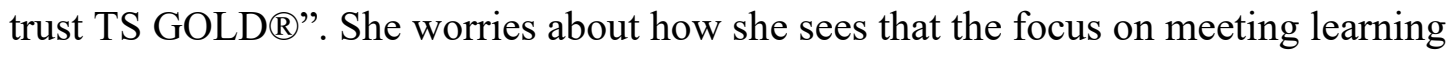


objectives takes away from focusing on children's social/emotional development. Julia completed our interview by saying;

Having a social/emotional foundation and focus is very important. That is how you set a lot of students up for success in academics, because that is what academics is when you are four. You have to trust the process and the rest will happen.

Julia and I end our conversation and I walk her to the elevators to say good-bye.

\section{Reflection and follow up conversation.}

Julia was nervous when first meeting with me and admitted in our conversation that she kept wanting to skew her answers as if she were interviewing for a job. As she became more relaxed, her comments became more focused. She is very confident in herself as a constructivist and as an early childhood educator. She values being a constructivist because it is not only the way she sees children learn best, it is how she learns best. Julia can see some value in using the Teaching Strategies GOLD® assessment system but considers it more as a way to organize the documentation about what she sees going on in the classroom rather than a way to direct children's learning or plan for children's experiences. She expressed concern that there could be an inclination for teachers to see it as the only way to plan experiences for children's learning.

When I met with Julia, it was mid-August. During our conversation she mentioned that she would have two weeks of professional development before returning to the classroom in early September. We were both curious to see how much of this professional development would be centered around Teaching Strategies GOLD®. Since Julia began at this school in the middle of the previous school year, she learned most of what she did with Teaching Strategies GOLD® as she used it. I was intrigued to discover 
what she thought of the tools and reports that she was unaware of during the previous year.

Julia and I had our follow up conversation in late October. I called Julia from my phone at a preset time and date. I was at home alone, in my office. The call was conducted over the speaker phone option and recorded using my personal recording device.

I began the conversation by reminding Julia that the purpose of this conversation was for Julia to have a chance to hear and approve of the way I was representing her in this research study. Next, I read Julia the reflection I wrote of our conversation and the areas I was wondering about after revisiting our first interview conversation. These areas included what sort of professional development Julia received when she returned to work, and how much was focused on Teaching Strategies GOLD®. I was also interested in seeing how she was using Teaching Strategies GOLD® in her planning and in the classroom. Had she continued to use it as a way to organize her thoughts to represent how she sees the children learning, or had she started to integrate Teaching Strategies GOLD® further into her work? Additionally, as a returning teacher, I was curious if she would be under more scrutiny about using the learning objectives in her lesson planning than she was last year as a new teacher. Would she be under additional pressure to integrate the objectives and dimensions into her lesson plans, and if so, would she stick with it or let things 'go off the rails'?

After reading the reflection and the areas that I had been thinking about to Julia, she affirmed that she was comfortable with the way I had portrayed her. She had been 
thinking about our initial interview and wanted to clarify what she found challenging as an early childhood educator. Julia clarified:

When I was talking about [early childhood educator] challenges it was more about not having the time to really sink into the process like you want and also having the ability to communicate what you are doing.

This message had been clear to me from Julia's initial interview. I reiterated her point, letting her know that the message I had got from her was that the challenges teachers have in general are a lack of resources; meaning time, authority, and autonomy and that it is all tied back to these external pressures that lead to these areas in which early childhood educators are deprived. Julia agreed with my interpretation and this subject was revisited later in our conversation.

We discussed the professional development she was provided with at the beginning of the school year. Most of the sessions were about different aspects of working for the agency that employed her, these aspects revolved around different procedures and policies for the flow of a typical day and required paperwork. Julia told me that she was required to attend a special professional development about Teaching Strategies GOLD® Interrater Reliability certification tests, "Which was really funny because last year I did a whole quarter of checkpoints." Julia reminded me of how when she did the year-end checkpoints the children in her classroom had three different teachers completing each checkpoint data and that the mid-year teacher had rated the children completely differently than Julia and the beginning of the year teacher. She reflected saying, "I assumed that the mid-year teacher never had done the Interrater 
Reliability testing." What Julia found interesting about the Interrater Reliability tests is that she failed the social/emotional test four times:

I feel like I really know my stuff. I have two degrees in education, but I was not succeeding in [the tests]. My co-teacher failed every single category the first time she took it. We spent our entire week trying to pass the tests. Then deadlines (for checkpoints) came down and we had to turn in everything. I was just like 'Oh yeah, I am doing everything based around this system and the checkpoints', that business is running my class right now. That feels really weird, it is just the opposite of what I want to be doing, especially at the beginning of the year.

Failing the Interrater Reliability tests is a comment I had heard from other participants and I asked Julia how it made her feel when she kept failing. Julia reflected that it made her feel confused. She was looking at the examples provided by Teaching Strategies GOLD® in the testing and they were similar to what she would enter into the system, but she was not able to pass. "It is just tedious and detrimental." Julia also told me that she had learned that many of the teachers had not passed the tests the year before.

During our first conversation Julia had mentioned that the agency she worked for encouraged teachers to include the Teaching Strategies GOLD® objectives in their lesson planning and I was curious if Julia was doing her lesson plans this way this year. Julia said she was still not integrating the objectives into her lesson planning and that she tried not to let the objectives influence what she is planning unless it is close to the end of the checkpoint date and she needs the data. I asked her if she is able to get the data required by creating lesson plans the way she had done in the past and with an emergent curriculum. Julia responded that due to the short day (3.5 hours) and the structure requirements of the day that it just wasn't possible: 
In 3.5 hours we are having two meals, recess and a circle, so it's maybe 30 minutes of work time. You have so many things going on that it's not like there's really any time to see that organic learning.

She also mentioned that since her classroom is placed within an elementary school and does not have a bathroom attached to the room that they spend a lot of time going as a group to the bathroom. This time waiting for children to finish washing hands is required to be built into the lesson plan as well:

We are supposed to [create our lesson plans to fit the objectives]. Honestly, I don't do that because I feel like it is a waste of time. The education component I am asked to use is a huge 8-page template. I'm so against it. For every activity they want you to write down what kinds of questions you're going to ask. I think in some ways if you are just learning how to be a teacher it's good to be intentional but it's also like as teacher, I don't know what questions I am going to ask because it depends on what happens with these provocations.

Julia continued to tell me that she is expected to plan each moment of the day to connect to an objective, even while the children are waiting in line to use the restroom or go outside. She reflected that the agency she worked for has many first-time teachers and planning out each moment of the day is a way they are learning how to become a teacher. Julia understands the idea of it, but, "Then it becomes weird to me, like a chain-store style of education." I understood and told Julia that I liked her analogy.

Julia and I finished our conversation by confirming the details of my observation time that the next week. Julia let me know that she would have a teacher shadowing her during the observation because Julia was taking a supervisor position at a different location. I was intrigued by this new position and wondered how Julia's philosophy about children would fit into a new role where she is expected to invoke the requirements of the agency to the teachers she would be overseeing. 


\section{Observation with Julia.}

I arrived on one of the first really cold fall days in the Pacific Northwest to Julia's school. The school is an elementary school set in the suburbs. It was built in 2006 . The agency that Julia worked for rents some of the classrooms. On the day of our observation, the bus that brings the majority of the children to Julia's classroom was not running. Parents were left to transport their children to and from school on their own that day. Because of the bus not running, Julia had less children at school than usual, just 11 instead of the usual 17. In addition, Julia's replacement, a sort of 'buffer' teacher who will support the classroom and children until the teacher position is filled permanently, was shadowing Julia and getting to know the children. My plan of the day was just to sit to the side as inconspicuously as possible and take notes.

Julia provided me with a typical schedule of her day (Figure 21):

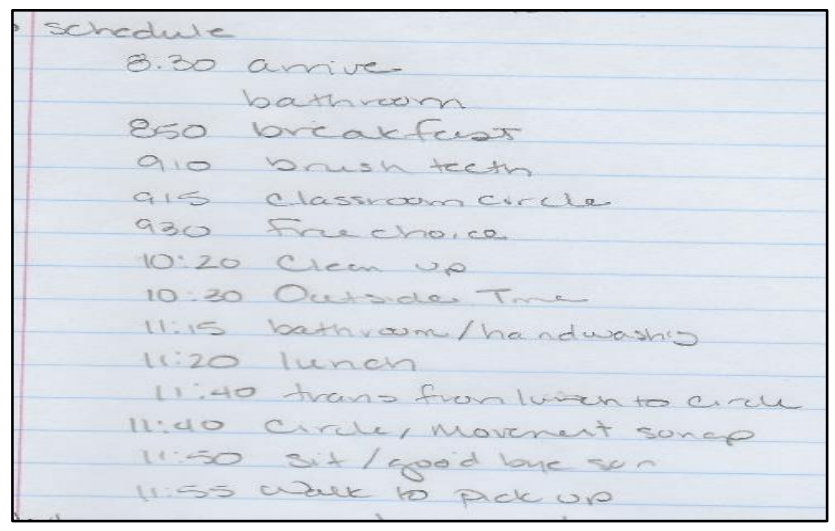

Figure 21: Julia's daily schedule.

I walked with Julia and her teammates to meet the children at the front door. As each child arrived Julia greeted the child and parent. The children stood along the wall while they waited for their friends to arrive. Julia's assistant teacher implemented songs as they waited. When Julia decided that they would probably not get any more children, 
she double checked her clipboard that everyone was accounted for, and the children walked down the hall in a line to the bathrooms to use the toilet and wash hands. After everyone was done in the bathroom (about 7 minutes later) the class and teachers proceeded into the lunchroom where a morning snack of French toast, plums, and milk was provided. The mood around the table was relaxed. As I watched I was curious about the relationships that Julia had with the children writing in my notes, "Did J. have any of these children last year?" (S. Guyon, field observation notes, October 30, 2018). Julia moved from area to area at the table, greeting the children and asking questions. She laughed with them about the stories they told and returned hugs when offered.

As the children seemed to be finishing up their morning snack, Julia directed them to put their items away and line up to move to the classroom. Two of the children had been presented small clipboards with sticker charts on them. They had been awarded stickers for their behavior at arrival, and during the bathroom routines. One of the children with a clipboard threw it while everyone was lining up after morning snack. Julia asked the child to go and pick up the clipboard which landed under one of the tables. He walked over to the table and sat under the table next to the clipboard but did not pick it up. Julia asked her assistant teacher to see if the child needed help while she and the teacher aide began to walk the children to the classroom. The assistant teacher sat with the child and asked him to pick up the clipboard so they could join their friends in class. He looked at her and she waited. After less than 20 seconds he picked up the clipboard and stood up. He reached for the assistant teacher's hand. She smiled at him as he took her hand and they walked down the hall together. 
In the classroom, the children put their jackets in their cubbies, brushed their teeth, washed their hands, and joined Julia in the circle area. The room was big with large windows overlooking the playground area. It had most of the typical features you find in an early childhood classroom including an area for art, large rug for circle time, tables, blocks, a quiet area, and a dramatic play area that had been converted into a hospital (Figure 22).

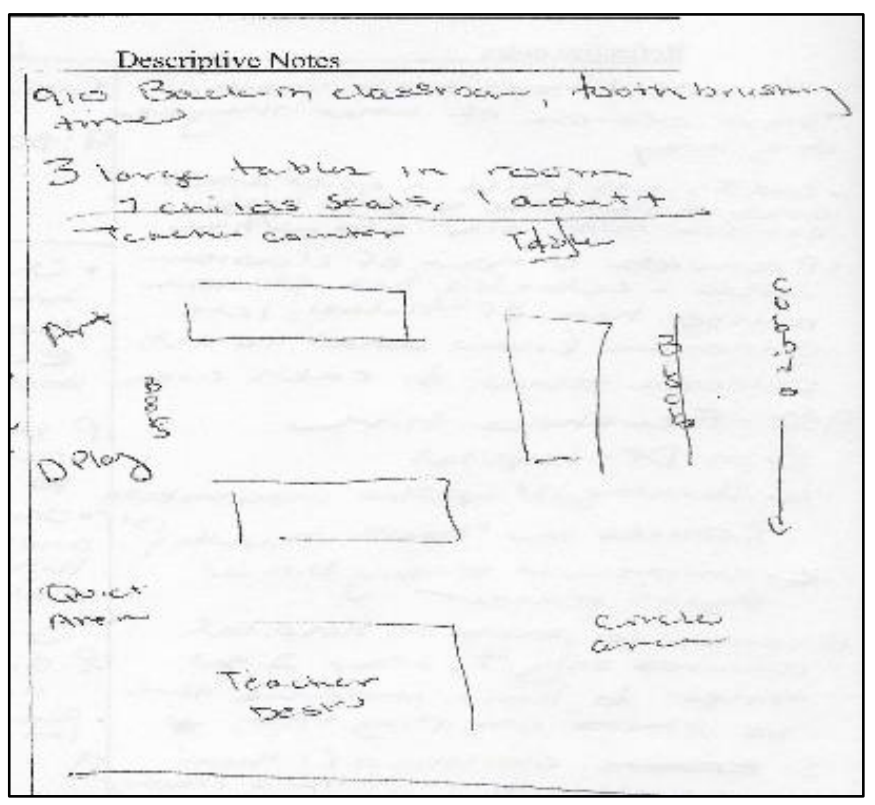

Figure 22: Diagram of Julia's classroom.

As the children were doing their tasks, a final child arrived. He was crying. His mom apologized for being late and for needing to hurry out of the door. Julia told her not to worry about it and the mother left. Julia continued to corral the children to the circle area. The assistant teacher stayed with the new child, speaking to him softly. The child continued to cry, and Julia suggested from across the room that he may want to be held. The assistant teacher asked if she could give him a hug. The child hugged her and calmed down immediately. The assistant teacher asked the child if he would like to go to the 
quiet area before joining his friends at circle. The child moved himself to the quiet area and sat on a pillow.

The other children joined Julia on the carpet in the circle area. They did a movement greeting song and Julia asked the children to sit down. There were two chairs on the carpet. Although Julia asked the children to sit on the carpet, some sat in the chairs and some lay on the floor. Julia didn't stop what she was doing to correct the children. Julia showed the children some apples and asked the children to tell her what they noticed about the apples. The children shared their ideas, some raising hands and others just calling out. Julia listened to each of them and only reminded the ones who called out their answer without raising their hand to please remember to raise their hand next time. The child in the quiet area joined circle and Julia greeted him good morning. She then told the children that they would be looking at and the using the apples during choice time. She told the children which areas would be open and then asked each child where they will be going as she released them into the room one by one.

During choice time, Julia set up an apple printing activity with sliced apples and paint at one of the tables. She invited children to come and explore the activity. She sat at the table with the children, asking a few questions, and supplying extra paint or paper when needed. Throughout choice time Julia moved around the room. She made sure that each child came to the apple art area, they were all required to participate. I wondered, "What's the goal/purpose of the apple painting?" (S. Guyon, field observation notes, October 30, 2018) and made a note to ask Julia about it in our follow up conversation. 
She sat with them when they first arrived and took a few notes. The children were able to leave when they wanted, Julia did not ask them to continue or do more.

Throughout choice time the children were active and focused. Four children played with the teacher aide at the Lego table. Four other children became deeply involved with the hospital area, co-constructing a dramatic story involving the birth of many children at the same time. A few children asked for playdoh, another child asked for a floor puzzle. Each time the children were given what they had asked. Julia moved about the room during this time. A few times children needed reminders about the room rules, but they were rarely told 'no'. Instead they were encouraged to think of a different way to accomplish their task. The children seemed well aware of the rules and parameters set in the classroom. They reminded each other to follow the rules, especially the one limiting the dramatic play area to four children and helped each other find other find solutions or alternatives.

At the end of choice time the children were given a five-minute warning and then asked to clean up. The clean-up process went very smoothly. Everyone participated and finished their tasks then moved to the cubbies to get their coats. When the children went outside, I took an opportunity to write a quick reflection about my morning in Julia's classroom. The notes I had recorded while in the classroom replicate the structure of the day and any small aspect that stood out to me. These aspects included routines, snippets of conversations, antidotal notes on interactions between Julia and others, environmental notes, and things that I was wondering about and wanted to remember to ask Julia in our follow up conversation. The reflection I wrote during our break was to record my overall 
thoughts, considerations, and interpretations about the ways in which I saw Julia work and the ways in which I thought I saw the influence of being required to use Teaching Strategies GOLD® in the classroom. While I waited, lunch arrived, and the assistant teacher set up the lunch tables.

The children returned to the classroom after coming in, visiting the bathroom, and washing their hands. They found their name tags and sat in their chairs. Julia sat at one table and the assistant teacher at the other. The children waited until everyone was sitting before they started serving themselves food. Traditional United States table manners were encouraged but not enforced during this time. The conversation at each table was casual, the children talked about the food, what they did outside, and other parts of their day. As they ate, one of the children noticed the seeds from the watermelon. He showed the seeds to Julia and remarked how the seeds were different than the ones they found in the apples earlier that day. Julia replied that she thought the child was right, the seed were different then got up to bring a few apple seeds to the table for the children to explore.

As the children finished their lunches, Julia moved back to the circle area for a movement circle. The children danced to five different songs then sang a good-bye song. Each child was asked to put on their coat and line up. We walked together back to the entryway and Julia checked each child out to their parent.

Julia and I walked back to the classroom. She shared her classroom with another teacher that has an afternoon class. Julia picked up the room and helped the other teacher set up for the new class of children. We then moved out into the hallway to talk about her day. 


\section{Reflective conversation.}

We began the conversation with me asking Julia just to tell me about her day. She stated that she felt that the day was "really chill" having the lower numbers brought the normal level of energy down in the classroom. Julia told me that having me observe, even though the "stakes were low" had made her realize that she thought about what she was doing in the room a little more than usual. She continued to talk about the lower numbers and the way in which that changed the dynamics of the classroom:

I don't even know if it would be different [if all the children were there today], it just takes a little longer. Like the bathroom transitions, we spend so much time just going down the hall and going to the bathroom. If we had a bathroom in the class, we would just have so much more time for everything.

I asked Julia to expand on this and she told me that she would set up her day

completely differently. She stated that she would have centers out at the beginning of the day that the children could explore independently then they could talk about it at circle time and revisit the areas during free choice time but with the way things are now, she would have to interrupt the children's explorations too much. She commented that because her classroom had to work around the schedules of the upper classes that she does not have much flexibility in the schedule of the day for the children.

I mentioned that even with the limited free choice time, it seemed as if the children were able to get into really deep explorations and talked a little bit about what I saw going on in the dramatic play center. In addition, I told Julia how I had noticed the children were very aware of the classroom expectations and that they often encouraged each other to stay within the boundaries of these expectations. Julia smiled when I gave 
the example of a child that supported two other children who wanted to play in an already full area by finding a timer for them and setting it up, Julia replied:

Yes, I love seeing that. My big thing is to model everything, I am constantly talking out loud about what I am doing and why I am doing it. At the beginning of the year you are really showing them how to be part of the classroom and it is amazing how they just pick up on it just watching and listening to me.

I expanded on this idea and told Julia how it seemed as if the children had a lot of ownership in the classroom. I mentioned how she told the children a few times that they were the experts in the classroom and needed to help their new teacher learn the rules and routines. I was curious then about the apple art project as it was the only activity the children were required to do and the one in which the children seemed most disengaged. I asked Julia to tell me about the purpose of doing the apple project.

Julia mentioned that the apple art was just part of an overall exploration. She stated that she wanted to do a counting and color activity the next day so, "I can see where they are with that" for upcoming conferences. She explained that in a different time or place she would have the apple art set out and not explained so that the children could just come as they wanted and explore the apples and paint in their own way. "But because of all the things required here, I can't do it that way." I asked Julia if by the requirements she meant Teaching Strategies GOLD®. Julia told me that part of it was because of Teaching Strategies GOLD® but part of it is also because of the overall structure of the day. "I feel like everything has to be rushed. I don't have time to let everyone to come up to the provocation on their own. I need it to be now." I understood what Julia meant. 
Julia had recently accepted a new position as a supervisor through a different agency. Part of her decision around leaving the classroom was for the additional income, another aspect was the locations of the centers she will be supporting. A third aspect of her decision to move into this new position is that she wanted to be a positive influence on other early childhood educators. She had been thinking about this a lot:

So much of my knowledge is just from being in the classroom. I don't feel like there has been a lot of that in [my education], there's no 'how do you make this work' with the procedures of the day. I just feel like I have learned that all with my experiences in the classroom and I want to be able to help new teachers navigate their way.

I ended my conversation with Julia and gathered up my things. Julia said good-bye to me and moved on into the room, greeting the children of the afternoon class as she made her way to her desk to continue and finalize her Teaching Strategies GOLD® checkpoints.

\section{Final interview conversation.}

Using the process I described earlier in this chapter to sort through the areas in which I saw the consistencies and inconsistencies between what I had understood to be Julia's true self as an early childhood educator and what she was doing in the classroom, I outlined our final interview conversation together (Appendix L). At Julia's suggestion, we met at a tea shop in her neighborhood on a Sunday morning. The tea shop was quiet, and she was comfortable speaking in this setting. After catching up and discussing her upcoming trip to Italy for the Reggio Emilia Study Abroad program, we began our final interview conversation together, which was recorded on my personal device.

I began our conversation by sharing with Julia the idea I had built of how she saw herself as an early childhood educator. Over the course of our conversations, Julia and I 
had discussed and fine-tuned this image. I explained the process I had used for preparing for our final interview conversation.

The questions I had designed for our final interview conversation together were to examine the places I which I had seen consistency and inconsistency with the image I had developed of Julia throughout our interactions together. The image I had developed of Julia was a well-educated, well-experienced individual who was thoughtful and intentional in her work with young children. I also saw a strong sense that Julia considered herself an advocate for children's learning and experiences, and the right for teacher autonomy. I shared this image with Julia, and she was in agreement with this assessment of her true self as an early childhood educator.

For the majority of our conversations and interactions, Julia exemplified this image. There were only a few instances, all during Julia's observation, that I did not see the way she interacted with the children as being consistent with the image she represented as an early childhood educator. I shared my reflections of the times I saw consistency and inconsistency with this image with Julia.

The times I noticed consistency between the image I had of Julia and what she did in the classroom were the times that she was not focused on the routine of the day or recording learning objectives. It was in these times that Julia seemed engaged in what the children were doing and saying. These were the moments that she seemed happy. This was mostly during transition times, at the morning circle, and at mealtimes. I also saw consistency through the ways Julia supported the children's independence and autonomy in the classroom. 
The times Julia's interactions seemed inconsistent with the image I had of her as an early childhood educator, she seemed distant or distracted. These were times that she was following a routine or plan. Throughout our conversations Julia lamented the lack of time she had during the day to get into deep, organic learning, with the children. Because of this lack of time, Julia felt it was necessary to implement structured curriculum, based on obtaining documentation associated with learning objectives, in order for her to meet the expectations set by the agency she worked at through the Teaching Strategies GOLD® system. These moments, most specifically the apple art project, seemed like a chore for Julia. Her lack of enthusiasm in these moments and the children's lack of enthusiasm were apparent.

Although at first Julia did not seem bothered about and agreed with these areas of inconsistency, she wanted to revisit my recollections of the apple project several times during our final conversation. She reflected:

I don't even remember what I did that day. I don't think I was really into it. It is so interesting because I feel so comfortable in all those moments where you just kind of run with it and it's organic. Doing something just to get a checkpoint is frustrating to me and I don't feel I need it. I feel as if I can plan and be intentional without Creative Curriculum® or Teaching Strategies GOLD®. But then when I need to get information for a certain checkpoint that I don't have then I feel like I have to do these really specific things.

Since I last saw Julia, she had moved to a different agency and a different position. Julia was now a supervisor at a federal and state funded early childhood education program in the Pacific Northwest. I was curious about how mentoring teachers, rather than working with students had affected her thoughts about Teaching Strategies GOLD®. Julia had been reflecting about this as well: 
It's been interesting now in coaching teachers because I feel like I have a lot of teachers that are inexperienced. They don't have the training or the education. There are so many new staff and so many teaching assistants and aides that are stepping up to be the teacher and they have no background [in early childhood education]. I see how the objectives in Teaching Strategies GOLD® could be a way to help them learn how to be intentional about planning.

Julia expanded on her experiences in her new position. The agency is

experiencing what Julia referred to as to as a staffing crisis. Rooms that usually have a teacher, assistant teacher, and a teaching aide, are surviving with just two aides running the classroom. Support and mentoring staff such as herself are being pulled to cover understaffed classrooms and are unable to get into the classrooms of the teachers assigned to them. She said that morale is low, and that classroom staff is doing what they can to get by and not getting the support they need. She told of an experience she had when she was able to visit one of her assigned classrooms:

It's such a mess. This teacher, she gave me a stack of 'documentation' and it was just worksheets, it didn't tell me anything. I asked her if she could tell me more about them, what she observed. She's an aide, stepping up to be a teacher. She doesn't know. She is just trying to fill in the objectives. The worksheets were just dots that children follow along to write letters and numbers. She doesn't understand that this paper doesn't tell me a story, that it's not engaging for the children. It's just something they did. So now I am thinking about how to use all those Teaching Strategies GOLD® and Creative Curriculum ${ }^{\circledR}$ tools as a way to train teachers or facilitate their learning as a teacher. I think it is interesting how TS GOLD® can be helpful when you are just learning but then become something like 'UGH!' when you know what you are doing.

I reminded Julia of her comment during our second conversation, that she saw some use in Teaching Strategies GOLD ${ }^{\circledR}$ but she also felt that a "chain store style of education" was kind of weird. Julia laughed that I remembered that quote so well. She admitted that she still believes it, then talked about the wide variety of schools, teaching, 
and learning that all fall under the category of a preschool, "It's all just so differently regulated, there is such an array of experiences. Being a preschool teacher can mean so many different things." I agreed with her observation and asked her if she thought that is why structured teaching and assessment formats like Teaching Strategies GOLD® seem so appealing to early childhood programs. Julia commented that the paperwork and other structures that take the focus away from the children is the big issue. She stated that even when she interviews someone that she thinks will be a great teacher she knows that the candidate will get burnt out by all the rules, restrictions, and paperwork and eventually leave.

Our conversation slowed down, and as Julia glanced at her phone and I felt as if she was ready to wrap up our conversation. I asked Julia if there was anything else she would like to tell me, our final interview question together:

As more of a teacher teacher, I am seeing all these things now. I am not necessarily sure if TS GOLD® is helping. I mean it is though, it is helping the teacher help the students by learning what certain things are educational and how to tease out those learning opportunities from play. It should be about meaningful learning.

Julia stood up and we said good-bye. As I walked out the door with her, I was curious about this conversation on its own and in the context of our interactions together. I continued to think about it on my drive home and was anxious to revisit her story in its entirety.

\section{Julia - Sorting out the puzzle pieces and final reflection.}

I used Clandinin and Connelly's three commonplaces of narrative inquiry to sort out the pieces of the larger narrative being told by Julia. After interpreting each 
interaction, I pulled out the commonplaces outlined by Clandinin, (2007, 2013), and Clandinin and Connelly (2000) three-dimensional narrative inquiry space as detailed in chapter three; the temporal, the societal, and place. For Julia I used turquoise post-it notes, attaching them to three $2 \times 4$ foot pieces of foam board, each representing one of the commonplaces. When I revisited Julia's commonplace post it notes, I found two conflicting themes. As an experienced early childhood educator, she found using Teaching Strategies GOLD® to be degrading and a waste of time, however, she saw value in Teaching Strategies GOLD® as a tool for new teachers who did not know what to look for when it came to young children's learning. To demonstrate the two themes best, I begin with the sociality commonplace.

The sociality commonplace has two subareas, the personal and the social. The personal subarea of the sociality commonplace are the internal influences, including the emotions, moral responses, and aesthetic reactions to the situation. Julia has a deep belief that learning should be meaningful. She has faith in letting children experiment, tinker, and follow their curiosity and is confident that learning "is as much about the process as it is about what is being learned." These ideas are the core to her principles and personal theories, they influence every decision and interaction she has with and about children. Being required to attach children's learning processes to preconceived learning objectives feels insincere to Julia, like it is taking something away from the child's experience. For Julia it is removing the magic of learning.

The social subarea of the sociality commonplace represents the outer influences, including the social, cultural and institutional things that shape the decisions you make 
and the way you think about things. Through the social side of the sociality commonplace Julia is influenced by aspects that conflict deeply with her personal beliefs. From our first interaction, Julia spoke about the perception of early childhood educators in the United States and her feelings of how there is a lack of respect for their knowledge, expertise, education, and specialization, resulting in low pay and inadequate compensation for teachers who work with young children. Julia also mentioned how the field of early childhood education is differently regulated than elementary or secondary levels stating, "Being a preschool teacher can mean so many different things." She is uncomfortable with the increasing focus on readiness and skills in early childhood education and expressed frustration and the intensifying pressure of the expectations from administrators, parents and agency structures. Julia mentioned in our first interview conversation that because of these pressures, having a system like Teaching Strategies GOLD® gave her a sense of authority when it came to talking with parents. In her new position as a supervisor, Julia saw an additional value in using Teaching Strategies GOLD ${ }^{\circledR}$ as a way to help "train" the new and/or inexperienced teachers she oversees. She stated that she sees now how Teaching Strategies GOLD® could help her teach her staff "what certain things are educational, and how to tease out those learning opportunities from play." However, it is more than just the sociality influences that are persuading Julia in this way, it is also the agency for which she works.

Clandinin (2007, 2013) and Clandinin and Connelly’s (2000) commonplace of place represents the actual physical setting and how the different strategies and structures of where Julia works affects how she responds to different experiences. Although Julia 
changed agencies and positions during our time together, she worked under the same federal and state funded early childhood education program and the actual physical settings in which she worked were very similar. As a teacher, Julia worked in a classroom set in an elementary school with children who attended for 3.5 hours per day. Parts of her day, such as when they could use the playground, were set by the school in order to work around the schedule of the older students. Other parts of her day, such as when and where to have mealtimes, were set by the agency that employed her. The agency also had certain requirements that Julia had to implement into each day including an opening and closing circle time, and free choice or work time. Additionally, Julia was required to complete four Teaching Strategies GOLD® checkpoints per year (the final one being over the summer), and strongly encouraged to have at least two observations for each child in each learning objective per checkpoint period. Julia expressed her frustration with the ways the constraints placed on her classroom by the agency and the program limited the children's opportunities:

In 3.5 hours we are having two meals, recess and a circle, so it's maybe 30 minutes of work time. You have so many things going on that it's not like there's really any time to see that organic learning.

Each of these structures affected how Julia implemented curriculum and experiences in her classroom.

As a supervisor, Julia's staff is under many of these same constraints, although some of her classes have children who attend school for 8 hours a day instead of 3.5. The 8 hour a day classes have an additional required outdoor time, snack, rest period, and circle time during each day. The educators are still required to have the same amount of 
documentation as the 3.5 hour a day classes. Julia had been excited at the prospect of being able to help mentor teachers in her new position, yet the experience has not been everything she anticipated. The agency that Julia works for is in a staffing crisis leading to a lower number of educators in a room and/or having inexperienced educators running classrooms. Support staff like Julia are unable to observe, support, and mentor the educators because they are covering classrooms themselves. Julia and the educators do not have the time to reflect and think deeply about what the children are doing, and the classroom staff is struggling:

It's such a mess. This teacher, she gave me a stack of 'documentation' and it was just worksheets, it didn't tell me anything. I asked her if she could tell me more about them, what she observed. She's an aide, stepping up to be a teacher. She doesn't know. She is just trying to fill in the objectives.

Julia doesn't have the time to mentor and coach her staff about responsive teaching and intentional curriculum. They are in survival mode and Julia is just thankful when everyone shows up.

This circumstance has changed Julia's thoughts about using Teaching Strategies GOLD ${ }^{\circledR}$, "Now I am thinking about how to use all those Teaching Strategies GOLD ${ }^{\circledR}$ and Creative Curriculum ${ }^{\circledR}$ tools as a way to train teachers or facilitate their learning as a teacher." Yet she still doesn't buy in to the system and concluded this thought by adding "I think it is interesting how TS GOLD® can be helpful when you are just learning but then become something like 'UGH!' when you know what you are doing." At her new position Julia is not thinking about how to help her staff develop into early childhood education professionals, she is only focused on how to support them to get it all done in ways that are developmentally appropriate. 
The final commonplace is the temporal, or the way Julia's past experiences are influencing how she is responding in the present moment and thinking about the future. Julia's transitioning thoughts about Teaching Strategies GOLD ${ }^{\circledR}$ during our interactions was interesting. As an educator she was strongly against using the objectives and dimensions found in Teaching Strategies GOLD® to plan her interactions with the children claiming that she could see children's learning without having to dissect it into learning objectives. Although she also admitted that the language and structure of Teaching Strategies GOLD® would have been helpful in giving her some authority when working with difficult parents.

Julia's conflicting experiences as a teacher have influenced her thoughts as supervisor, she can see ways in which using Teaching Strategies GOLD® can help her support new or inexperienced early childhood educators to become more intentional and thoughtful about their work with young children:

It's been interesting now in coaching teachers because I feel like I have a lot of teachers that are inexperienced. They don't have the training or the education. There are so many new staff and so many teaching assistants and aides that are stepping up to be the teacher and they have no background [in early childhood education]. I see how the objectives in Teaching Strategies GOLD® could be a way to help them learn how to be intentional about planning.

However, Julia does not see it as the end-all-be-all of early childhood education. Instead she sees it as a necessary step to move the staff in a direction away from checklists and ditto sheets towards using more developmentally appropriate practices. She doesn't think Teaching Strategies GOLD ${ }^{\circledR}$ is the best way, but in her current situation, she doesn't see that she has an alternative. 
During our conversations together Julia was constantly rethinking and returning to earlier questions or ways in which she responded to my questions. She is in an ongoing conflict with herself regarding her personal beliefs and theories about the different ways in which children learn and the reality of the circumstances of the early childhood educators and the early childhood education programs where she has worked. Over the course of our interactions together, it seemed to me that Julia was becoming increasingly frustrated with what she felt was right as an early childhood education professional and what she was required to do in the field of publicly funded early childhood education. This back and forth contention with Teaching Strategies GOLD® was a reoccurring part of my conversations with each of the participants, but before I connect the pieces together to show the larger narrative reflected in each of their stories, I share Sasha's story.

\section{Sasha's Story.}

I met Sasha late on a fall afternoon. She greeted me with a big smile and firm handshake. She is confident, and I told her how much I appreciated her participation in this study. She told me that she is excited to do it and we move to a quiet place to begin our discussion. When I first spoke with Sasha over the phone, she was with a different early childhood education program than where she was working when we met.

Sasha loves working with young children. She began to realize this in high school as she coached 5-7 year olds in tennis. After high school she entered college with the ambition of becoming a child psychologist. However, Sasha found the work depressing and left school. 
When she moved to the city where she lives now, Sasha started working at the local athletic club running a summer camp. At the end of the summer when the position was over, she started at an inclusive early childhood education program that serves a 60/40 blend of typically developing children and children with special rights as an assistant teacher. She stated, "It just fit and felt so right." Sasha worked her way up to a teaching position and stayed at that program for four years.

I asked Sasha about what she liked best about being an early childhood educator and she shared a story of helping a young girl learn to walk. On reflecting about it, Sasha said:

I really love working with kids with special needs and seeing progress. When you have been working with them on something for so long, it's been tough, and then it clicks for them and there's that moment. Even with typical developing kids, everybody has those things that they are struggling at. There are those moments when it clicks, and you are so excited for them and you just think, 'You worked so hard and I knew you could do it'!

Sasha has recently returned to school and is in her second year of earning a degree in early childhood education. Her constructivist beliefs about children's learning come mostly from her experiences in working with children. For Sasha, "Being a constructivist means following what the kids are into and really understanding, or really practicing that learning happens while they are playing." Following this practice is extremely important for Sasha and she described how it looked in her classroom with a reflection:

We had this phone that was broken so we decided to pop it open and look inside. They were super into that and they had all these questions about this phone. They said, 'I don't have a phone like that, this is a phone?' and I had never had a phone like that either, it was a rotary phone. We decided to bring in a bunch of phones and do a study about phones. Many of the kids said they had their own phones that didn't make calls. Several of them brought their phones in. They were all 
different and we could pop them all open and look inside. It was very cool because they were so interested in it and had such great insights while we were doing it and it all started with something familiar in our classroom that we could look at another way.

Allowing children the time and freedom to play and discover is extremely important to

Sasha and she finds ways in which to bring it into her everyday practice:

When I got to be a lead teacher at my last program, I went to a training and learned that it takes 45 minutes for children to get into good, deep sociodramatic play. I realized that our morning routine wasn't allowing for that. We moved our circle time to later into the day. [By making this adjustment] we were able to see them get really engaged. They also did so much better at circle time. We ended up extending their free play time, having it go from 7-10:30. At 10:30 they were actually ready to sit down and have circle time. It worked better, and I didn't have to interrupt them. Sometimes my voice can lessen. If I am not interrupting them they are working things out on their own.

When reflecting about what she struggles with as an early childhood educator, Sasha brought up two different points. She said, "Sometimes [I struggle with] just remembering that the little things are the child's whole life." She spoke about the importance of stepping back and realizing that even when the situation doesn't seem like such a big deal to her, it is a big deal to the child. "They don't have the real-world problems we do, but in that moment, they have a reason to be upset, this is their realworld problem. You have to honor that." These thoughts coincide with her respect for giving children time and space to play, work, and explore.

Sasha mentioned a second point of struggle as an early childhood educator, the outside pressures and priorities that came from the program administrators of the last place she worked. She told me that when she changed her morning circle time to better support the children in her classroom, she received a lot of push-back. The program 
administrators wanted Sasha to hold an earlier circle time to be consistent with the other preschool classrooms. She reflected:

I understood that it did bring a sense of community, and it was a time to acknowledge everyone. But they were also doing that on their own, going from place to place, interacting with everybody. They were doing it in a way that worked best for them. If it works best for them, it works best for me as a teacher.

Most of Sasha's work in using Teaching Strategies GOLD $®$ coincides with working with Creative Curriculum ${ }^{\circledR}$ According to The Creative Curriculum ${ }^{\circledR}$ for Preschool Tour Guide:

The Creative Curriculum ${ }^{\circledR}$ focuses on meeting the needs of individual children while honoring and respecting the role that teachers play in making learning engaging and meaningful for every child. All components of The Creative Curriculum ${ }^{\circledR}$ for Preschool were designed to fit together to create a seamless day of teaching and help teachers build an engaging and effective program. The Foundation offers insight into the most current research and best practices for early childhood education. The Daily Resources, including Teaching Guides, Intentional Teaching Cards ${ }^{\mathrm{TM}}$, Mighty Minutes ${ }^{\circledR}$, and Book Discussion Cards ${ }^{\mathrm{TM}}$, help teachers organize and manage their days intentionally and effectively. The curriculum components also include built-in support for all learners, with specific sections of guidance for working with English- and dual-language learners, advanced learners, and children with disabilities. (p. 17)

Sasha has mixed feelings about Teaching Strategies GOLD®. She reflected back to the phone exploration instigated by the children in her classroom:

It was very child led, TS GOLD® does allow for us to look at stuff like that and look at the objectives and the dimensions, but at that moment, I wasn't thinking about the objectives and dimensions. I don't want to in those moments because I want to be engaged with them. I also don't to label everything they are saying to me. I want to enjoy it, and enjoy them, and enjoy their excitement. Yes, you can still do that and record a video, but I feel like you have to step out if you are going to be taking a note or taking a video of something that is happening spontaneously. 
Sasha does implement some of the curriculum tools and supports supplied by The Creative Curriculum ${ }^{\circledR}$ for Preschool as intentional explorations in which to document children's skills for the Teaching Strategies GOLD® assessment system. During one such exploration, using the tree study from Creative Curriculum ${ }^{\circledR}$, the children became drawn to the pictures of bees:

[The children] were super excited about bees. They all started making bee hives out of materials we had in our classroom. Their conversation was very in-depth. They had me Google different pictures of bees, why some were orange and others bright yellow, and what's the difference. I was trying to take notes through the whole thing but still be engaged, yet not label what they were doing. It was really tough to document who said what, while at the same time stay present in what they were doing.

I asked Sasha about her new job and the program she will be at starting the next day. Sasha told me that the classroom is part of the city's Preschool Promise program. This program offers high-quality, affordable preschool to 3- and 4-year-old children living in the city (Seattle Public Schools, 2017). In addition, the public school system utilizes Teaching Strategies GOLD® developmental assessments to track student progress and outcomes (Seattle Public Schools, 2017). The city’s Preschool Promise program has a sliding tuition scale based on family size and household income.

Sasha mentioned that her new classroom will have a higher ratio of children than her previous classroom. She has heard from her co-teacher that it can be very difficult recording documentation for twenty children. Sasha foresees that they will be using the Creative Curriculum ${ }^{\circledR}$ Intentional Teaching Cards $^{\mathrm{TM}}$ often to supplement the documentation. Since this is a new classroom and the first classroom in the center funded 
by the municipal Preschool Promise program, Teaching Strategies GOLD® is new to most of the teachers at the program.

After our meeting, Sasha was going to a professional development session as part of her orientation for her new position. I asked Sasha if she knew what sort of professional development she would be doing but she was not sure. I also asked Sasha if she has received any professional development specifically on Teaching Strategies GOLD®. Sasha informed me that she had received a two-day professional development on the Creative Curriculum ${ }^{\circledR}$ and Teaching Strategies GOLD® at her last center.

Because the classroom that Sasha will be working in is part of the municipal Preschool Promise program, Sasha and her co-teacher will be provided with two hours of planning time each day. The school day runs from 9 to 3. Before school care is available, for an additional cost, from 7 to 9, and after care is also available for an additional cost from 3 to 6 . Sasha believed that her planning time will be split, one hour in the morning that will be dedicated to planning and one hour in the afternoon dedicated to updating Teaching Strategies GOLD®.

This structured planning time was one of the aspects that made Sasha apply for the position, she stated, "It is if someone said, 'If you want me to do all this, this is how it has to be to get it all done'. At [my last center] they were supposed to do it like this, but the director took the two hours of planning each day out of the contract with the city." She mentioned that the teachers at her last center are expected to be entering observations anytime they have free time (such as nap time) and have two hours per week set aside to 'level out' all of their observations. 
I asked Sasha to tell me more about her experiences with using Teaching Strategies GOLD®, what does she struggle with and what does she like about it. Sasha explained that she has used Creative Curriculum ${ }^{\circledR}$ to focus the information needed in Teaching Strategies GOLD® and stated:

I'm not in love with Creative Curriculum ${ }^{\circledR}$ but it does help when I have to label what the kids are doing. I use the app a lot and I take documentation when I have very low numbers of kids. I know I am supposed to be taking documentation all day long, but it is easier for me to do it when there are lower numbers. I also take it when we are using the instructional teaching cards, and the moments that stand out to me during the day. The app locks you out constantly and there have been times that I wanted to take documentation, but I just gave up because the app kicked me out. It can also take forever to upload or sometimes it will upload what you are doing three or four times and some of those uploads include your documentation while others don't so you have to go back through all of it to clean it up.

Sasha spoke about some of the benefits of the Teaching Strategies GOLD\& assessment system. She stated that it can be helpful to see the objectives and dimensions and to be able to put a name on what she sees every day. Sasha also said she likes that it helps her show parents what the children are doing in the classroom:

I like that it sounds fancy and it sounds like you know all this big stuff. I think parents just assume that we play all day and if I am able to give them the objectives and the dimensions it gives us a reason to play all day. It helps them to understand it more.

Sasha reflected back to the program she has just left. She told me that she felt that the program was moving into a space of more and more structured requirements. “They're really going by the book. There is a strong push that we do things how TS GOLD® wants us to do them.” Sasha felt that by not allowing the children to stay in play, or whatever they were engaged in, in order to follow a regimented schedule didn't 
fit with her beliefs about what is best in supporting young children learn. She mentioned that many of the teachers were struggling with the implementation of Teaching Strategies GOLD® and attributed the increasing lack of freedom as one of the reasons she left the program. I inquired to why Sasha thought there was such a push to use Teaching Strategies GOLD® this way. Sasha said:

When you have been out of the classroom for a while, you kind of forget what it is like to be in the classroom. When [the administrators] have never had to use it the way they want the teachers to use it, it can be tough. It's tough to tell them that it is hard or that it takes you out of what you should ${ }^{6}$ be doing in the classroom.

Sasha's sentiments felt like a good place to end our first interview conversation and begin the write up and following reflection. We said good-bye and she headed into her center as I made my way back to my hotel.

\section{Reflection and follow up conversation.}

Sasha is full of joy. She loves working with children. When first joining the study, she was working at a different center but informed her new program about this research study and asked to be able to continue to participate in this research. With Sasha I connected to how she sees children learn, the way that she sees children make connections and the value of giving children time. These are primary reasons she changed programs. I would say that her feelings about Teaching Strategies GOLD® float around. She isn't wild about the structure, but she sees value in the authenticity Teaching Strategies GOLD® brings when speaking with paraprofessionals and parents.

\footnotetext{
${ }^{6}$ Emphasis in original recording
} 
I was curious about what sort of professional development in Teaching Strategies GOLD® Sasha received when she started at her new position. The children had been back in school for about two weeks when Sasha started, and I wondered if her orientation would be abbreviated because of her late start. Sasha mentioned in our conversation that Teaching Strategies GOLD® was new to the center and I was interested to learn if other classrooms besides her are using Teaching Strategies GOLD® as an assessment system.

One thing I found curious in my conversation with Sasha was that she mentioned she could foresee herself using the Creative Curriculum ${ }^{\circledR}$ Intentional Teaching Cards ${ }^{\mathrm{TM}}$ to supplement some of the documentation she would need because her classroom had a higher ratio than what she had before. To me this seemed to clash a little bit with the other ways Sasha had described her work with Teaching Strategies GOLD®. I was also curious if the associate teachers who work during the morning and late afternoon hours contribute any observations to Teaching Strategies GOLD® or if the children are only assessed during the 'school' hours.

Sasha and I had our follow up conversation in early November. I called her from my phone on a preset time and date. I was home alone in my office. I used the speaker phone option and recorded our conversation using my personal recorder.

I began our conversation by reminding Sasha that the purpose for this follow up phone call was to make sure I was representing Sasha accurately and giving her the opportunity to clarify or add to our previous conversation. I read Sasha the reflection I had wrote about our conversation and she was pleased that it was an accurate reflection of her feelings and interactions with Teaching Strategies GOLD®. 
From our earlier conversation I was curious about what sort of professional development Sasha had received when starting at her new school. The classroom that Sasha was going to be working in was the first municipally funded preschool classroom in that program. Part of the stipulation of the funds were to use the Teaching Strategies GOLD® assessment system. Sasha did not receive any additional professional development on Teaching Strategies GOLD® when she began in this program. In fact, the program has not previously used Teaching Strategies GOLD® and Sasha believed she and her co-teacher (who has also used Teaching Strategies GOLD® in her previous job) know "quite a bit more than any of the other teachers here" about the system. This includes the two associate teachers who work with the children in Sasha's classroom during early and after care. All of the documentation recorded is done by Sasha and her co-teacher.

Because of these limited hours, Sasha admitted that, as predicted, they use a lot of the Intentional Teaching Cards ${ }^{\mathrm{TM}}$ provided by Creative Curriculum ${ }^{\circledR}$ to supplement getting the documentation:

Right now, as we are coming up on checkpoints, we are realizing it's really hard to take documentation for eighteen children. We know that we are doing everything. We know that we are covering all of the objectives and dimensions, but it is just really tough to have those moments with each child. Just like those good teaching moments that I had with a smaller group of kids has been drastically cut down. Whereas I could take like two or three super detailed notes before and had lots of little personal notes, a lot of the good teaching moments are just gone.

She continued to tell me that they try to have a small group time a few days a week. In the small group time Sasha and her co-teacher rotate a few children at a time to join in a structured activity. The activity is usually from the Creative Curriculum ${ }^{\circledR}$ Intentional 
Teaching Cards ${ }^{\mathrm{TM}}$ and has specified directions, questions, objectives, and dimensions. Sasha commented that "everybody's going to have the same documentation" but at least it will fill in a place in which they are lacking documentation on their reports. As she reflected on this, she commented on how she feels like by having so many objectives in Teaching Strategies GOLD® programs that teachers are almost forced to use Creative Curriculum ${ }^{\circledR}$ just to get the documentation needed.

When Sasha and I had met earlier we were both encouraged about the amount of planning time that her new program would allow each week. I asked Sasha whether or not it was actually given to her. She laughed and said yes and that it was really nice. I asked how she and her co-teacher used this time. Sasha informed me that they usually work for an hour together in the morning, talking about the children, looking at the reports, planning activities to fill in where they need documentation, and collecting materials. The second hour of their time is used individually to update documentation into the Teaching Strategies GOLD® system.

I was very interested in seeing Sasha in the classroom. The way she had described how she was working at this new program seems different than how she described her work before. I was curious to see how she was finding the balance that she described so well in our first conversation into her early childhood classroom.

\section{Observation with Sasha.}

It was a clear and cold day when I arrived at Sasha's school around 7:45. As I approached the school, families were arriving for the day. It was the day after Veterans' Day and children greeted each other excitedly by calling out and giving hugs. Sasha had 
instructed me to text her when I arrived, and she would meet me up at the front of the school. I walked into the school and looked for the office, knowing that I would probably need to sign in. The office was locked so I stood and waited. Sasha came from around the corner and led me to a small office tucked behind what looked like a work room. The school was an older elementary school. Sasha explained to me that the community outgrew the school about ten years ago. A new school was built a few blocks away and this one was being rented out to two different preschool programs. This explained the lack of front office staff.

Sasha's classroom was part of the municipal Preschool Promise program. The program she worked for also had differently funded preschool classrooms including full tuition classrooms. The 'official' preschool day runs from 9 AM to 3 PM, before and after care were available at an additional cost. She provided me with their typical schedule of the day (Figure 23):

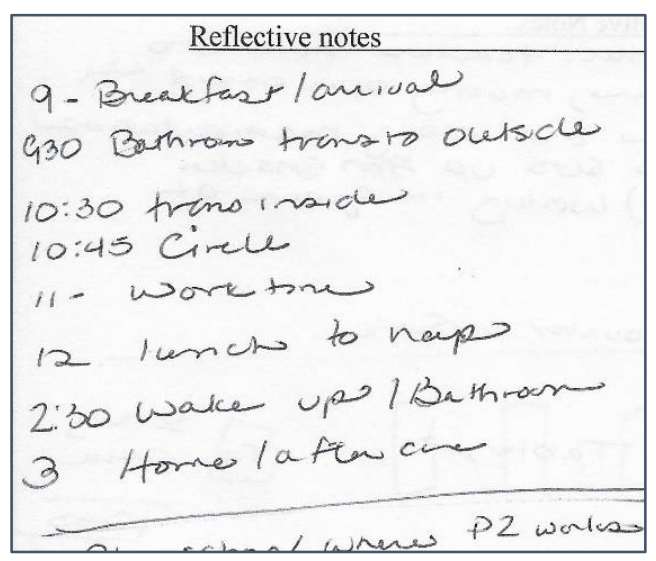

Figure 23: Sasha's daily schedule.

Sasha usually arrived around 7:45 each morning. She worked on entering documentation until her co-teacher arrived at 8:15. Sasha and her co-teacher usually 
spend the next half hour finalizing their plans for the day. Their checkpoints for Teaching Strategies GOLD® were due at the end of the week I was visiting and they spent their morning planning time talking about how many children they have left to complete, and the different ways in which they rate children in the areas of Science, Art, and Social Studies this early in the year. Both Sasha and her co-teacher admitted that they enter some documentation at home, asserting that they can complete the process much more quickly at home where there are not as many distractions and that they would rather spend their time at school interacting and planning for the children.

At 8:45 we made our way to the classroom. The morning care providers had brought the children who were there early into the room and the children were busy playing. The room was large with defined areas (Figure 24). Children were playing in groups of two or three around the room. The morning care providers checked in with Sasha and her co-teacher, then said good-bye to the children.

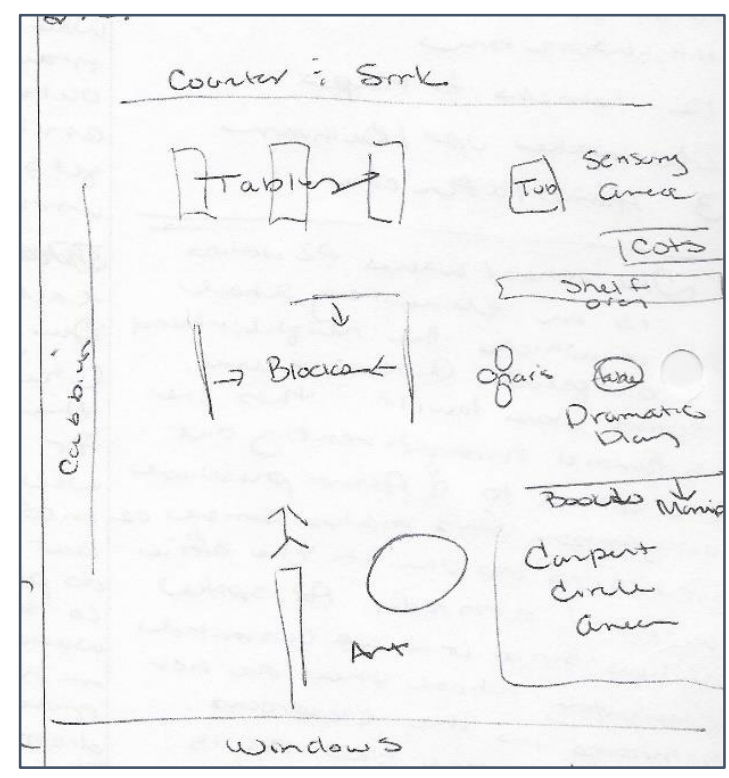

Figure 24: Diagram of Sasha's classroom. 
Sasha moved into the room, greeted children and sat where she could see and interact with the children working with manipulatives in the circle area, the block area, and the dramatic play area. Three children were building with straws and connectors. They were working independently, and each wanted to share their creations with Sasha. Sasha listened to the children and repeated back what they have said. A child moved close to Sasha and held up his creation saying, "I made a ball." Sasha looked at the child's face as he spoke, then looked at the creation, "You made a ball? Look at how you made this! You took something straight and made it curvy." She pointed out the way the straws are bending slightly inward. The child looked at the straws and nodded his head. Sasha said, "You are changing these into something I've never seen before." The child's smile grew, and he hurriedly moved back to add to his creation.

More children were arriving. Sasha called out hellos from where she was while her co-teacher set up morning snack and carried on short greetings with parents and children. A child ran over to Sasha and greeted her with a hug. She commented that he has been gone four days asked to hear about what he has been doing. He filled her in on his brother being sick and his weekend adventures. Sasha listened intently, reframed his comments, and asked for more information.

Morning snack was ready and Sasha's co-teacher called out a general invite to the class. Sasha moved around the room, inviting children individually. Her co-teacher did the same. Some children expressed that they are not hungry, and Sasha and her co-teacher were sure to offer the opportunity to have snack a few times to these children before snack was over. In the building area three boys had been working collaboratively 
building a large structure. Sasha moved to invite them to snack but instead started with asking about their structure. They explained that it is a fortress and showed her the different areas. She remarked that she noticed when they turned the gate, another area near the top of the building moved too. She encouraged them to move the gate again and asked, "Did you notice that too?" They had not but quickly moved into a discussion about what they could do with this new information and/or how they can fix it. Sasha listened intently, and repeated part of what they were saying to clarify the plans. She pulled out her phone, took a few photos, and entered some text. I was surprised to see Sasha use her personal phone to record documentation and made a note to ask her about it, "Does P use her phone to upload doc using the app or just for the photo?" (S. Guyon, field observation notes, November 13,2018$)$. The children came up with an idea they all agreed with and began to make changes. Sasha reminded them that morning snack time is almost over and told them what they were having. One of the children left to wash his hands while the others continued to build.

In the dramatic play area, a child told Sasha what he has been cooking. He talked very fast and was naming multiple ingredients and processes he used. Sasha listened and asked questions then said, "That recipe sounds so good! Do you want a clipboard so you can write it down and remake it later?" The child was excited at this prospect and agreed. Sasha reminded the child where to find the clipboards, paper, and pens. He gathered these materials and returned to Sasha then asked, "Can you help me?" Sasha said sure and the boy sat down on the floor and started to set up his paper. Sasha said, "Let me go and get you a recipe book." She moved to the dramatic play area and grabbed a recipe book. 
Sasha brought the recipe book back to the boy and showed the boy how the recipe book can help him know how to write the recipe. Sasha sat on the floor next to the boy and pointed out that he should list the ingredients first. The boy told her what is in the soup and Sasha coached him as he wrote out each ingredient (40 cups of lava) and the rest of the recipe. During this process emotions were escalating in the block area. Sasha stayed engaged with the boy writing the recipe while keeping an eye and ear on the block area.

The block building children became frustrated with each other. One walked to Sasha to tell her what is going on while the other went to Sasha's co-teacher. Both teachers listened to what is being said to them, asked questions, and gave suggestions for the children. The suggestions were very similar, and the children returned to the block area to renegotiate. The boy who was writing the recipe asked Sasha if he has spelled something correctly and she turned her attention to the boy after quickly glancing at her co-teacher. Sasha's co-teacher saw Sasha engaged and moved to the block area to check in. The co-teacher stood near and listened to what the children were doing then, seemingly satisfied the children have worked it out on their own, moved back to the snack area to oversee the children bussing their dishes.

Sasha's co-teacher let the children know that she was taking out the snack cart and she would be turning on the clean-up song soon. Sasha continued to work with the boy writing the recipe and asked if she could take a picture of it. He agreed, and she took a photo with her phone then entered some text.

Sasha and her co-teacher started to move around the room letting the children know that it is just about time to clean up. All 18 children were at school that day. The 
block builders wanted to save their creation and asked Sasha's co-teacher to let everyone know. Sasha's co-teacher made an announcement to the room that the building will not be put away. She made everyone understand they are to leave it where it is. A few children brought other small projects to her that they wanted to save, and Sasha's coteacher suggested that maybe they should put them on a shelf near the block area. She put on a clean-up song and the children moved around the room, bobbing their heads to the beat, and putting things away. The children seemed to know this routine well and moved throughout the room. The song led them naturally to the circle area where they danced freely to the end of the clean-up song and then danced to a more structured good morning song.

As Sasha's co-teacher led circle, Sasha finished cleaning up the room then sat in circle with the children. Sasha and her co-teacher showed the children how they learned different ways of animal breathing and ask for children to give suggestions too. They tried out each of the examples given by the children.

Next the children gave a check in of how they are feeling by giving a thumbs up, thumbs down, or in-between signal. Children were asked if they wanted to share why they are feeling the way they were and were responded with, "Thanks, that is good to know." The circle ended with the children being called individually to select what job they wanted to do for the day and then moving with Sasha to put on their coats to go outside.

The teachers walked the children to the restroom where they went to the bathroom and washed their hands. They then moved to the outside area to play. The outside area 
included a large blacktop area, grassy lawn, and some playground structures. The children were not allowed to play on the playground structures as they were installed when the school hosted children in grades K-6 and are not licensed for children that are preschool aged. Sasha informed me that this doesn't seem to bother the children at all. The children played mostly on the blacktop area, running and playing a zombie-chase game, pushing dead leaves with hula hoops, and shooting baskets. Sasha and her coteacher took their breaks during this time and set up centers in the classroom. They played and talked with the children when invited. I took this time to step aside and write a reflection about the morning.

When we were back in the classroom the children had a very short circle time to hear what centers had been set up and to move into the room to play. Five children left the room to join other children in the program for a creative movement time. During the free choice time the children moved around the room. Sasha sat at a table with connecting blocks and two children. The children were building with the blocks and discussing the letters and numbers that were printed on the side. Sasha listened to the children and built on their observations. One of the children found an A and said that it is one of the letters in his name. Sasha said that he is right and asked what other letters are in his name. I was curious about this interaction and made a note to ask Sasha about it in our follow up conversation, "Was the P asking the questions because she needed the observation? Would she have done that anyway?" (S. Guyon, field observation notes, November 13, 2018). They worked together to find the letters and connect them to spell the child's name. 
Sasha moved around the room visiting each area and spending about 10-15 minutes with each group of children. She asked questions, commented on their ideas, and expressed surprise when the children tried out something new. Her comments and questions inspired the children to think and respond. Most of her questions began with 'Did you think...', 'were you surprised...', 'what do you think will happen...', 'how do you think...'. The children considered her ideas and questions, sometimes trying something new, other times solidifying their thoughts and reasonings for their decisions.

Around 11:15 AM the children who went to the creative movement class returned. The rest of the children had begun to clean up the room and were transiting to the circle area. Circle was led by Sasha's co-teacher as Sasha and a few of the children set up mats for nap and the tables for lunch. The children sat with their teachers at lunch and talked about their weekends. After lunch they moved to their mats to rest or read books. The lights were turned out at about noon and Sasha moved around the room to help a few children get settled. After about 20 minutes, we left the room together and made our way back to her office to talk.

\section{Reflective conversation.}

My reflective conversation with Sasha began the same way I started my reflective conversation with Julia, by simply asking her to tell me about her day. Sasha stated that the day wasn't too bad, having the five children leave for creative movement made it easier for her to have meaningful interactions with the children who stayed on the room during free choice time. She mentioned that normally she would have more children to 
visit in more areas but with the 5 children at creative movement she was able to spend a lot of time in each area.

I was curious about the letter conversation she had at the table with the children using the connecting blocks and asked her if she had planned on talking about letters or if it just happened. Sasha replied:

I just saw an opportunity to add letters and counting. It was set up just to build. [One child at the table] can get super into working with letters but he likes to do them in his own space and on his own time. Since he mentioned the letter first, I thought maybe we could build on that and he was super into it. I just thought, 'let's do it' and he really enjoyed it. It never would have worked if I had initiated it first.

She said that as soon as he was done, he was done, and she felt good about the experience for both of them.

I mentioned that it felt like Sasha and her co-teacher had a lot of autonomy in the classroom and that translated into the children having a lot of autonomy as well. Sasha said that at first they were given a schedule to follow and that they had to advocate to their program to change it to something that worked best for the children in their classroom although it still wasn't perfect all the time. Sasha stated:

There are some rough days. The schedule didn't impact us too much today but there are some days that we have eight different people coming in. Nobody knows our classroom, we are kind of separate from the rest of the program, which in some ways is nice because we get to do whatever we want. At first people would just show up to give us our breaks and we wouldn't really know them, and the children wouldn't know them, and it would be the worst possible moment of the day. We had to push back about that and say that we really needed our breaks between certain times every single day and that the people had to know our children. 
Sasha continued to tell me that the program followed through and it made everything much better. She said that the program has been very supportive and let Sasha and her coteacher change the children's scheduled outdoor time to be early in the morning rather than later, elaborating that the children needed the time to move in a big space before they were ready to settle down and focus in circle time or in the room.

Throughout the day I saw Sasha and her co-teacher pull out their phones to take photographs or enter text. I was curious if they were using their phones to take observations for Teaching Strategies GOLD®. Sasha said that they both use the Teaching Strategies GOLD® app on their phones. She mentioned that in the past she has had difficulties with the app but now it works very well for her. She said it is easier and faster than trying to keep post-it notes and enter the information later and that the children are so used to seeing phones in adults' hands that taking a quick photo while they are in the moment doesn't seem to faze them.

We talked more about the children's autonomy in the room, how I saw them work through problems and know to come to Sasha or her co-teacher if they could not work it out on their own. I commented to Sasha that it was interesting to see the way she and her co-teacher worked. They both have a deep respect and care for the children. Sasha was much more one on one and spoke with the children individually or quietly whereas her co-teacher seemed much more 'big picture' and tended to talk to the children as a group. Sasha laughed at this observation and congratulated me on the insight. She told me that she was so excited when her co-teacher called her to ask her to apply for the position. They had worked together before and "it was such a good fit, such a great balance 
between us." Even with the different styles, they both interact with joy and respect to the classroom.

I thanked Sasha for her time and let her know that I would hopefully be seeing her again in December for our final meeting together. Sasha told me that she has really enjoyed the process and is so excited to see what it is going to be. We said good-bye and I showed myself out of the building.

\section{Final interview conversation.}

At Sasha's suggestion, we met on a Friday afternoon in January at a coffee shop a few miles from her school. It was quiet and comfortable. We began our conversation by catching up and Sasha telling me about her classroom adventures that week which included taking the children on a city bus to the YMCA for swimming lessons. We then began our final interview together.

As I had done with Julia, I had outlined my final interview conversation with Sasha using the process I described earlier in this chapter to sort through the areas in which I saw the consistencies and inconsistencies between what I had understood to be Sasha's true self as an early childhood educator and what she was doing in the classroom (Appendix L). Over the course of our conversations, Sasha and I had discussed and finetuned this image. I began our final interview conversation, recorded by my personal device, by sharing this image with Sasha.

The image I had developed of Sasha as an early childhood educator was one who is confident in her knowledge of children and has a deep respect, love, and joy of children. I also saw ways in which Sasha used her confidence in her knowledge about 
children as a platform to advocate for the children in her classroom. I saw this in the experiences she described in her last center and in the ways that she interacted with the children in her current classroom. Sasha is a teacher-researcher. She not only does research with children, she does research about the children she is working with. She is interested in more than if a child can do a skill, she is someone who is curious about each child and what each child was thinking.

Sasha was pleased with this interpretation, she had not heard the term teacherresearcher before but identified with the idea. After discussing being a teacher-researcher, Sasha said, "That is who I try to be. I am so thankful that you saw that because I felt like I don't get to do as much here with more children and less hours with them, but you saw it, so thank you." I shared with Sasha ways in which I saw consistency with this image throughout the day of her observation:

Your deep joy, respect, and love for children came through in the ways I saw you interact with them. You listened intently, asked questions, made observations that built on what they had told you, and took your time with them. You were truly present. I saw this most strongly when you were talking with the three boys who had built the fortress in the block area. You moved into the area to remind the children to have morning snack but then spent almost 10 minutes in conversation with them about what they had created. During this time, as with other times in the room that you were in conversation with children, you did not seem worried about the time or other things going on around you. It was the same as you worked with the child writing the lava soup recipe and when you were working with the children with the letter and number blocks at the table.

Sasha laughed at my reflection about the boys building and told me that they had just started a Creative Curriculum ${ }^{\circledR}$ unit on buildings because of that group of children in her classroom. 
I shared with Sasha that I did not recall seeing any inconsistencies from this image that I had formulated about her. The day I observed was not a day that they had a structured small group time built around the Creative Curriculum® Intentional Teaching Cards $^{\text {TM }}$, as Sasha had described in our earlier conversation. I shared with Sasha that after revisiting her story, and my notes of her interactions, I wanted to spend another day in the room with her. I found myself wondering how she would respond to the children during these pre-formatted interactions, and what she would do if the children's explorations, questions, and curiosities broke away from what was on the cards. Sasha laughed and apologized but I assured her that it was a good thing that she didn't alter her day because I was there. Sasha told me that she tries not to let Teaching Strategies GOLD® affect what she does in the classroom, she does however like that it has helped enrich her conversations with the children explaining:

Sometimes it's nice because I can tell a child, 'Oh wow, you are really using your hands and fingers to mold that clay'. Before I probably would have said something like 'Wow you are squishing that clay really hard'.

She feels that by using this language she is giving the children the opportunity to think more purposefully about what they are doing with the clay.

I asked Sasha what else she would like to share with me in regard to Teaching Strategies GOLD®. "The documentation is tedious; the checkpoints are tedious. I wish it was all less tedious." This comment sparked a conversation about the frequency of the checkpoints each year and I asked Sasha if she thought having less checkpoints per year would be helpful. Sasha said that this was a consideration by the agency that employs her, "I think that would be better because you would have more real documentation, you 
wouldn't be rushing every three months just to fill in the holes." She also wishes that you could see the progression of a child's development over the course of the checkpoint rather than just at the end:

For this first [conference] we had this one child that just progressed over the checkpoint time period so much. It was visible to anyone who came into our room. It would have been nice to be able to show the parents that but it's way different than what happens in Teaching Strategies GOLD®.

I asked Sasha to expand on this comment and she spoke about the way in which Teaching Strategies GOLD® breaks apart each learning domain into so many objectives and then each objective into so many dimensions that it is hard to see the larger story of the child. She finishes this thought by saying:

In general, I don't like that kids have to prove that they are learning because you can tell that they are if you just pay attention. They are going to take what is relevant to them and then they are going to keep expanding on that and that is all that really matters.

This brings our final interview conversation to a natural close. We talk briefly about when I should be finished with my interpretations and the final dissertation. She is excited to read it and learn about the experiences of the other participants in the study and makes me promise to send her a copy. We walk to the door together and hug good-bye, Sasha is greeted by a friend that has come to take her out for happy hour and I climb back into my car for the drive home.

\section{Sasha - Sorting out the puzzle pieces and final reflection.}

As with Julia, I used Clandinin and Connelly's three commonplaces of narrative inquiry to sort out the pieces of the larger narrative being told by Sasha. After interpreting each interaction, I pulled out the commonplaces outlined by Clandinin, (2007, 2013), 
and Clandinin and Connelly (2000) three-dimensional narrative inquiry space and detailed in chapter three; the temporal, the societal, and place. For Sasha I used red post-it notes, attaching them to three $2 \times 4$ foot pieces of foam board, each representing one of the commonplaces. Sasha's story had one strong theme. Throughout our interactions, she found some value in using Teaching Strategies GOLD® but overall, she could take it or leave it and it tried not to let it influence what she did in the classroom or her personal beliefs about children and their learning. To demonstrate this theme, I begin with the sociality commonplace

The sociality commonplace has two subareas, the personal and the social. The personal subarea of the sociality commonplace are the internal influences, including the emotions, moral responses, and aesthetic reactions to the situation. Sasha finds joy in her work with young children. This joy is fueled by her curiosity to understand the children she works with, to know what they are thinking, and how they have come to those conclusions. "There are those moments when it clicks, and you are so excited for them and you just think, 'You worked so hard and I knew you could do it'!" That progression of learning is important to her and she finds the dismemberment of children's learning experiences into unconnected learning objectives frustrating, conflicting with her belief about how children learn best.

The social subarea of the sociality commonplace represents the outer influences, including the social, cultural, and institutional things that shape the decisions you make and the way you think about things. Sasha spoke often about the outside influences that are being pushed into early childhood classrooms. In our first interview conversation 
together, Sasha spoke of how she saw early childhood programs becoming more structured due to outside influences. She sees that these influences are often valued over the opinions of educators that actually work with young children. She connected these thoughts to the overall structure of the United States public school system and the idea that educators need to prove that children are learning.

In Sasha's situation, the idea that educators need to prove that children are learning connects well to the commonplace of place. The commonplace of place represents the actual physical setting and how the different strategies and structures of where Sasha works affects how she responds to different experiences. Sasha's place of practice has a lot of influence on her use of Teaching Strategies GOLD®. She spoke about how what she and her co-teacher do in the classroom changes the closer they get to checkpoints.

Right now, as we are coming up on checkpoints, we are realizing it's really hard to take documentation for eighteen children. We know that we are doing everything. We know that we are covering all of the objectives and dimensions, but it is just really tough to have those moments with each child.

Funding for the program where Sasha works is directly associated with using the Teaching Strategies GOLD® system. In our final interview conversation Sasha and I talked about her recent parent-teacher conferences. I asked her if she had remembered to have her parents sign the conference form, something I often failed to do myself. Sasha replied, "Oh yeah, that's where (agency name) gets their money from is hitting the checkpoints on time and getting the signatures at the conferences." I find this direct association between funding and signed Teaching Strategies GOLD® parent conference forms unnerving. 
However, the influence of having funding connected to Teaching Strategies GOLD® checkpoints and conferences has had some positive effects. First is the ample amount of planning time provided for Sasha and her co-teacher to complete checkpoints, two hours per day. However, Sasha and her co-teacher admitted that they prefer instead to use this time to prep for the day in the morning and reflect about the day in the afternoon and do most of their entering of Teaching Strategies GOLD® documentation at home.

Second is the ways in which Sasha and her co-teacher have been able to push back against certain structures and schedules implemented by the program in order to support the needs of the children in the classroom. Their classroom is a pilot classroom within a larger program that has a variety of differently funded classrooms including full tuition classrooms. Sasha's class is the first municipally Preschool Promise funded classroom in the program and this position has given them some authority in areas they would not have had otherwise:

At first people would just show up to give us our breaks and we wouldn't really know them, and the children wouldn't know them, and it would be the worst possible moment of the day. We had to push back about that and say that we really needed our breaks between certain times every single day and that the people had to know our children.

They have also been able to exert more control around the overall daily schedule in their classroom, changing their outdoor time to meet the needs of the children.

A third benefit is that the agency is considering reducing the number of checkpoints per year based on early childhood educators' feedback who are working in the city's Preschool Promise program. Sasha thinks this will put less pressure on Sasha 
and her co-teacher to fill in missing documentation with structured curriculum experiences that do not connect to the children's interests or learning.

The final commonplace is the temporal commonplace. The temporal commonplace represents the way Sasha's past experiences are influencing how she is responding in the present moment and thinking about the future. Sasha is a reflective practitioner. During our interactions together she mentioned several areas in which she felt Teaching Strategies GOLD® was helpful in her work with children and families. The area that this was most prevalent was through the authority that the language of Teaching Strategies GOLD® gave her as an early childhood educator:

I like that it sounds fancy and it sounds like you know all this big stuff. I think parents just assume that we play all day and if I am able to give them the objectives and the dimensions it gives us a reason to play all day. It helps them to understand it more.

She has pulled the aspects of Teaching Strategies GOLD® that support her perception of children and how children learn into her daily practice without letting the system take over what she does in the classroom. She has also paid attention to how the language that she uses with the children pulled from the Teaching Strategies GOLD® learning objectives, affects the children's thinking about what they are doing.

Sometimes it's nice because I can tell a child, 'Oh wow, you are really using your hands and fingers to mold that clay.' Before I probably would have said something like 'Wow you are squishing that clay really hard.'

She can find value in the process but finds the overall system tedious and time consuming. 
These thoughts were consistent in each of my interactions with Sasha. From the beginning Sasha expressed how she had thought about Teaching Strategies GOLD® critically, finding the good and the bad within the system. Whereas with Julia this was a conflict, for Sasha it was a process. But before I connect the pieces of Sasha and Julia's puzzles to show the larger narratives reflected in each of their stories in the interpretation and findings section of this chapter, I share Cynthia's story.

\section{Cynthia's Story}

Cynthia has been working in early childhood education since high school. She started working part-time in a preschool program just a few blocks from where she is currently employed. When she graduated high school, she took a full-time assistant teacher position. As she stayed, she moved into a teacher position. When she was ready to move on, she contacted her mentor who she had worked for in the past and asked if she would recommend a place. She was recommended to the early childhood education program where she is working currently. At that time, there was only a toddler teacher position available. Cynthia took it because she liked the program. Eventually a position in a preschool classroom opened and she transitioned into that age group. She has been at this program for 15 years and in the field of early childhood education for almost 20 years.

The program where Cynthia works is an inclusive early childhood program that strives for a 60/40 split of children developing typically and children with special rights. It was started in the early 1960s by a group of mothers who were denied public schooling for their children who had been diagnosed with disabilities. Since its creation, the 
program where Cynthia works has expanded its services to support children and adults with special rights in a variety of ways including job training and placement, birth to three therapy, continuing education, and other areas. The program has two early childhood education centers. I asked how the early childhood education centers fit in the larger matrix now. Cynthia confessed that there was often a lack of communication between 'corporate' and the teachers. She told me that this year, the corporation had decided to change one of the preschool classrooms to a state funded classroom that receives funding from the state to work with children with special rights. Changing the dynamics of that preschool classroom changed the dynamics of Cynthia's classroom and over half of the children in her room are under the age of three, a reality that Cynthia did not know could be a possibility before starting the school year.

Cynthia loves working with children, she particularly loves working with children age three to six. When I asked her about moving from a toddler room to a preschool room she replied, "I just knew that preschool was always my thing." Cynthia told me that seeing children being able to connect experiences is what she loves most about teaching. She shared a story that happened that morning with me:

Yesterday, one of the children was looking in the tree on our playground and he noticed there was a nest in the tree. He told me about the nest, and I asked him who he thought might live there. The child said he thought maybe a hummingbird, or a crow might live in that nest. Then this morning there was a hummingbird outside of our classroom window. I pointed it out to the child and asked him if he thought that was the one that lived in the nest. He looked at me and had this bright-eyed connection. Those moments are really enjoyable.

Cynthia smiled as she told me this story. 
Cynthia has been working on her associate's degree in early childhood education on and off since she started working in the field. She said she is about twenty credits short and that the majority of the credits she needs are in general education. She has completed all her early childhood credits and said that she doesn't feel very motivated to finish but knows that she should. She has found it difficult to navigate through the community college system and is frustrated with the difficulties of having to "test and place in" despite the fact that the program where she works has brought in people from the college to help employees move forward in obtaining their degree.

Cynthia described her role as a constructivist early childhood educator as noticing where children's strengths and struggles are and finding ways in which to partner with children to support their development. "That's what I love about working with children with special needs. It promotes different ways of thinking within the group. We don't have to do everything the same way." She recalled another recent story in her room:

We were doing a word activity and the kids were at different levels of proficiency [in their letter recognition skills]. Some of the children can write some letters, and other children can recognize and name their letters. One child was just tracing the letters with his finger while I said the name of the letter to him. The other children were watching and learning with us. Not just learning letters but learning about him through my interactions with him.

Seeing the children connect with each other through different experiences is important to Cynthia. She feels that the most important area of development for children age 3-6 is their social/emotional development:

I feel really passionate about supporting the children's social/emotional development. Being aware of how others feel, and promoting empathy is important to me. I want them to have positive feelings, good self-esteem, and confidence in social situations. Those are the things you need as an adult. 
She commented that she feels like there is a more pressure recently to focus on rote skills, academics, and getting children ready for kindergarten.

When reflecting about what she struggles with as an early childhood educator, Cynthia took a deep breath and let out a long sigh. She talked about the lack of communication from the larger corporation, and the frustration she feels sometimes when "change just gets dropped on top of me." She connected the frustration of not having a say or even being aware of changes until they have already happened into her thoughts about Teaching Strategies GOLD®, "I like innovation and change and staying with the times, it's what is smart and how the world functions, so you need to get on board. It is how I feel about TSG, I just have to get on board to keep up." I asked Cynthia to explain further.

Cynthia told me that the center that she works at had been using a paper version of Teaching Strategies GOLD® for years. "We would do tallying on the forms. It was from the old Creative Curriculum ${ }^{\circledR}$ and we just kept photocopying the forms." I wondered if they had used paper portfolios as a means of communicating with parents and making the children's learning visible. Cynthia explained:

We would do the paper version and then think about the child, looking at the objective and remember an incident that I saw the child meet that objective, then scoring them accordingly. Then I would carry that information over to the conference form to share with the family.

Because of this paper version, Cynthia had some basic knowledge about Teaching Strategies GOLD® before the program switched to using the computer version a year ago. She recalled a two-day professional development that she attended on Teaching 
Strategies GOLD® quite a few years ago. Cynthia stated that she had found that professional development useful, but the system was now almost completely different.

Cynthia has recently attended additional professional development sessions using Teaching Strategies GOLD® on-line assessment system:

We did a couple during in-service days with the books and the teaching cards. At that point I was too green, so they were way too advanced for me. They were like 'Look! You can get this YouTube and hook it to your objective and you can hook it to your lesson plan and dadadadadada...' And I didn't even know how to make my lesson plan on the computer at that point.

At the program where Cynthia works, they have created a position for a Teaching Strategies GOLD®/Creative Curriculum ${ }^{\circledR}$ support person who has worked in a preschool classroom using the on-line version of Teaching Strategies GOLD® for a year. Cynthia explained that she appreciates this person very much. The support person attends their planning meetings each week, is available to answer questions, helps coach teachers to learn how to use the Teaching Strategies GOLD® system, helps teachers learn how to pull, read, and utilize the reports that can be found in the Teaching Strategies GOLD® system, and makes sure that teachers are staying on track with entering observations.

The support person is scheduled to meet with Cynthia and her co-teacher for a half hour each week during their two hours of allotted planning time. Cynthia described the format for their planning time:

Currently we get one to two hours a week of planning. One hour is usually your time to do your lesson plans, pull out your teaching cards and maybe gather the books you will need for your read alouds and other materials. Then the second hour that we are just starting to get into is dedicated to putting in more TSG documentation, making sure you are doing your reports. We just started the Interrater Reliability [certification process]. 
The Interrater Reliability certification is "An online certification process that gives you the opportunity to evaluate sample child portfolios and compare your ratings with those of Teaching Strategies’ master raters” (Teaching Strategies ${ }^{\circledR}$ How-To Guide for Teachers, p. 1). Cynthia has found the Interrater Reliability certification process "extremely defeating" and admitted that she failed many of the certification tests on her first try. She commented:

I struggled at the Interrater Reliability but that just shows me that I'm not using the tool right. I'm working on it, but I find it extremely defeating. You know, you are scoring them, and you think you are scoring them well and then you take that, and you just think all of your documentation must be wrong. The computer version is much faster, you have to be quicker on your thought processes, you have to be like 'Score, score, score!' and I always feel the pressure, I have so much to do and I am trying to get it done quickly and then I think that sometimes doesn't create the best work.

Cynthia stated that part of her frustration comes from the fact that her 26-year old coteacher passed all the Interrater Reliability tests the first time and received his certificate in one week.

At the program where Cynthia works, there are four checkpoints per year. A minimum of one piece of documentation is required for each objective per child per checkpoint period although conferences are only required three times a year. Cynthia shared her learning curve of gathering documentation over the past year, explaining that having multiple pieces of documentation is helpful when creating the conference forms and that sometimes group observations can lack depth. Beyond her one hour of planning time dedicated to entering documentation into the Teaching Strategies GOLD® system each week, teachers are expected to be entering documentation throughout each day during their 'free time' when the number of children in their classroom is low or nap 
times. I asked Cynthia if there were any limitations on how many objectives she can attach to a single observation. Cynthia said there isn't a limit. When entering documentation Cynthia will attach it to as many objectives as she thinks can connect. When completing this step, she reviews the objectives she chose and disconnects any objectives that her documentation doesn't align with the examples provided by Teaching Strategies GOLD®.

Teaching Strategies GOLD® has an app in which teachers can log into their account and enter documentation for children on a mobile device. Cynthia had mixed feelings about the app and said that she liked the app but if she did not have time to enter the anecdotal note and level the observation then it was "pointless because I can't fix it later." She admitted that she was more successful using the app when she had fewer children but now she mostly uses the i-Pad supplied by the center to take photos, writing a quick anecdotal note on paper to add to the Teaching Strategies GOLD® system later.

Cynthia spoke often about reading the reports that she could pull from the Teaching Strategies GOLD® system and "filling in the holes." I asked Cynthia to expand on this. Cynthia said that each week either she, her co-teacher, or the Teaching Strategies GOLD®/Creative Curriculum $®$ support person will run a report that shows all the children in the classroom and how many pieces of documentation she has connected to each child in each objective, (the Documentation Status Report detailed in Chapter 2):

We tend to look at the report and see where we have holes. If I see we need math then we will pull an Intentional Teaching Cards ${ }^{\mathrm{TM}}$ for math and add it to the lesson plan. I also look at the [Snapshot Report] to see where there are holes, or where we are behind. On that report I can click on the objective and it will give me a slew of Intentional Teaching Cards ${ }^{\mathrm{TM}}$ to use. 
I inquired to how similar this was to the way she would plan if she was not required to use Teaching Strategies GOLD®. Cynthia reflected on the different aspects of Teaching Strategies GOLD® and Creative Curriculum ${ }^{\circledR}$ :

I think it is similar to how I would teach if I wasn't using TS GOLD $®$ because it's noticing something that is needed then finding ways to work on it. It is similar, but it is really hard because I am not a computer person. It's super user friendly but there are points of it that are so frustrating. The Intentional Teaching Cards ${ }^{\mathrm{TM}}$ are like activities I used to do but it's different. All the things I used to do are in TS GOLD ${ }^{\circledR}$, it's all just so sanitized or less fluid in the way that I would do it, but I have to do it that way because it is already on our plan. It's pressure sometimes, where I feel like I don't have enough time in the day to get everything done. Yet everything I am being asked to do were things that I was already doing, it's just that I feel like I have to follow these guidelines.

Throughout our conversation Cynthia spoke about feeling under pressure several times. I asked her whether she felt that the pressure was something coming from herself or from the administration.

I feel that it's my self-pressure. I think the tool is valuable because it is so interpreter friendly. I feel the pressure comes from myself [to do everything]. It's important because Teaching Strategies GOLD ${ }^{\circledR}$ and Creative Curriculum ${ }^{\circledR}$ shows you it is important. It's just a lot. It's tricky, but I think doable. But I think too we just want to $b e^{7}$ sometimes. It's just the pressure of 'We've got to get this done, and we've got to get that done'. It's my self-pressure, it's definitely my selfpressure because the administration is very fluid.

She continued to explain that although the administration at her program wants her to meet the criteria and follow the Intentional Teaching Cards $^{\mathrm{TM}}$, they are supportive when it is a busy day in the classroom and she cannot get everything on her lesson plan completed.

\footnotetext{
${ }^{7}$ Emphasis on "be" is in the recording
} 
As Cynthia continued to reflect, she became emotional and needed a moment. We sat together quietly as she collected herself. After a few moments, Cynthia took a shaky breath and said:

I don't feel that it is negative, but the pressure of doing it the way they want me to do it versus how I have always done it. It's like you're really good at your job for 20 years and really confident and then now I feel as if I don't know anything and I've never taught children and I'm a total failure. But not all of the time, just some of the time. That's the thing I have struggled with. I took all my ECE classes years ago, none of that was on the computer. It was all about active listening and being present. That is still in Teaching Strategies GOLD® but [the way it is implemented] contradicts what I learned. At the same time, this is what is required by my job now, so I respect that.

Cynthia smiled at me and told me that the teachers at her program had an on-going joke anytime the administrators said that "we selected this curriculum for their school.", the teachers look at each other and think about how none of them really had a choice.

I asked Cynthia how she found Teaching Strategies GOLD® helpful. She found my use of the word 'helpful' interesting. "I find it is a requirement that I need to meet. I don't find it very helpful. It is something I am required to do.” However, as she continued to consider my question, Cynthia could find some ways that Teaching Strategies GOLD® has been a support to her. She appreciates the way she is able to correlate the information she puts into the system, how she can make the conference forms and include her lesson plan. "It's helpful and not helpful. It does give me a fuller picture of development overall by having it be a requirement that I have an observation in all of those objectives and dimensions." To help Cynthia make sure she gets all of her documentation, she has created her own forms to document children's experiences during small group time. She selects an objective that she needs to meet then finds an activity in the Teaching 
Strategies GOLD® that meets that objective. The form Cynthia has created has a place where she can write the objectives she is looking for, list the children's names, and write what she is seeing:

I like it because the objectives and dimensions are correlated with my observations on the date for the activity and it's all right there, you just have to enter it and it doesn't have to be a group observation. I can be thoughtful about leveling each child based on their interaction with the teaching card and the objective and dimensions.

She reflected again on her feelings of being under pressure. Cynthia does not feel that this pressure comes from the administration,

They tell us to make it what it is for yourself, try it one time, see how it feels or don't do that one. Just make sure you are meeting the criteria, you are meeting the objectives and dimensions so that you have evidence-based practice to show the parents at the conference.

I asked Cynthia if there was anything else she wanted to share with me. Cynthia gave me her final thoughts:

I think it's just the pressure because it goes back to that overall feeling that you are really good at what you do but now it's like you have been punched in the gut and you don't know a damn thing. I think I am emotional about failing the Interrater Reliability tests. Other teachers have failed it too but no one's really talking about it. The tool overall seems to be working successfully, it's just the lack of time of being able to put in your observations. Everyone's very cool about it, where it's like 'Get it done, we'll help you get it done'. It's not like I don't feel like I have support, I am just really hard on myself. With failing the Interrater Reliability test, I think I don't know what I am doing in documenting, writing down the right stuff. It's like with the boy and the hummingbird. I struggle with moments that the child demonstrated a skill, but it doesn't fit [in the objective] because TS GOLD® requires it a certain way. He recognized and recalled, but I can't use that example in the objective even though it is perfect. 
Our interview ends, and we said good-bye as Cynthia walked me to the door. My conversation with Cynthia gave me a lot to think about and I found myself thankful for my long drive home.

\section{Reflection and follow up conversation.}

Cynthia loves working with children. Throughout our conversation she shared stories and reflections about her experiences with children. During those recollections Cynthia became more relaxed, smiling and laughing at the memories.

Cynthia has been working with children for 20 years, 15 of those at her current place of practice. The center is like a home to her. It is where she has developed her sense of self as an early childhood educator. In addition, the center is where Cynthia met her husband, who was also a preschool teacher. Her sister has worked there as well as her brother-in-law. It is where her own daughter attends school.

When it comes to Teaching Strategies GOLD®, Cynthia is struggling. She claimed throughout the conversation that the pressure being put on her to implement Teaching Strategies GOLD® and Creative Curriculum ${ }^{\circledR}$ is internal, but in revisiting our conversation, it seems to me as if the source of her self-pressure is coming from the expectations from the program administrators. Cynthia seems to be receiving constant mixed messages from the program administrators. In our conversation, Cynthia spoke about her Teaching Strategies GOLD® support person who tells her 'it's flexible' and can be used 'in her own way'. She also talked about receiving messages from this same support person informing her that she has noticed Cynthia didn't put in any observations during the week. When I had my follow up phone call conversation with Cynthia and we 
discussed whether or not she agreed that she received mixed messages from her administrators, she disagreed and stated, “I don't think it's mixed messages. It's more like it's flexible, do it your way but also you better get it done." I was glad that I gave Cynthia the opportunity to clarify this with me.

Cynthia agrees that an external layer of pressure is coming from the Teaching Strategies GOLD® system itself through the Interrater Reliability tests and the narrow scope of examples for each objective. During our follow up conversation Cynthia was happy to tell me that she had now passed all but two of the Interrater Reliability tests. She has since taken the tests in these areas a third time, "The third time I was really stressed out about having to opt out of my own child's conferences. I find that when I am stressed then try to do the Interrater Reliability, I fail it." She said that at this point she found it humorous that the administration would not or could not find her time out of the classroom to meet with her child's teachers but now they were going to have to find time for her out of the classroom to take the Interrater Reliability tests for a fourth time.

Cynthia admitted she does not like technology, and that she has struggled with "getting it all done" and "doing it the way Teaching Strategies GOLD® says to do it." She is overwhelmed and puts the blame on herself for these feelings. The pressure of implementing and using Teaching Strategies GOLD®, the Intentional Curriculum cards, and the perceived validity of obtaining Interrater Reliability certification is making Cynthia question her worth and beliefs as an early childhood educator. She is frustrated by how what she has learned through her courses in early childhood education, and her 
20 years of experience as an early childhood educator working in an inclusive classroom contrasts with what she feels she is being asked to do with Teaching Strategies GOLD®.

In revisiting our conversation, I hear how defeated she feels. I hear the ways in which she questions herself and gives in to the system just because it is part of a larger system that she perceives to have authority in the field. I notice the ways in which her work with children is changing. In the beginning of our conversation, Cynthia shares an experience doing a small group word activity with the children. When she spoke about the importance of that activity, she reflected about a boy who needed to do the activity differently than his peers. Cynthia said, "The other children were watching and learning with us, Not just learning letters, but learning about him through my interactions with him." She follows this thought with multiple references to the importance of social/emotional development with preschool age children. Yet near the end of the conversation Cynthia is telling me about the form she uses to record her documentation during small groups, when describing this process, her comment "I can level each child based on their interaction with the teaching card and the objective and dimension." starkly contrasts what she has said earlier. In the first reflection the interaction is between the group as a community. In the second reflection the interaction is with the curriculum.

In our follow up conversation, Cynthia seemed to be struggling less with the technological side of Teaching Strategies GOLD®. When we speak, she has been focusing on finalizing the checkpoints to prepare for parent/teacher conferences. She told me that her checkpoints are due in a few weeks and that "We have been printing out a report and using that for planning, trying to get the holes filled before we can finalize our 
checkpoints." She sees this as a task to accomplish and told me that she feels as if she is doing really good embedded curriculum but not documenting everything. I asked Cynthia why she wasn't documenting everything, she replied;

It's like the documentation process takes away from my activities. Then I feel frustrated because I don't have enough for my checkpoints. Sometimes I just do on-the-spot activities just like 'Here! Show me this!'. As I get closer to my checkpoints, I start doing more group documentation to try and knock out one or two objectives for a group of kids. The documentations is just basic, you know, this child can do A.B.C. I don't know if that type of documentation is important to parents.

Since Cynthia is a parent at the center, as well as a teacher, I asked her what she would want to hear about her child during a parent/teacher conference. Cynthia told me that she would just want to know that her child is happy at school, that she is well cared for and that her teachers know her. She said her daughter is starting to get finicky about food and would want to talk about what her daughter is eating, if she is getting enough protein, and she would want to talk about changing her child's diaper more often, so her daughter doesn't have as many diaper rashes. Since both Cynthia and her husband have been early childhood educators, she does not worry about her child's development and feels that they have a good idea of what to watch.

As we continued our conversation, Cynthia told me that the implementation of Teaching Strategies GOLD® was one of the reasons that her husband left the center and changed careers, and stated,

He was so opposed to it. He didn't agree with it, it wasn't what he did with children. I get it, I tend to have days where it feels like I am doing data entry all of the time. I have two planning sessions a week, one on Tuesday and one on Thursday. Which is great, I need that time, but it really breaks up my week. I can't walk to the park with my kids. I'm not comfortable enough with Teaching 
Strategies GOLD® to fully implement what I used to implement, I am still trying to get a handle on Teaching Strategies GOLD®. I really need and appreciate the time to get it done for these criteria but it's like I so hate sitting and doing data entry when I could be playing with my kids.

Throughout both of our conversations, Cynthia has focused on the ways that utilizing Teaching Strategies GOLD® in the classroom has distanced her from her interactions with the children. It will be interesting to see how this looks in the classroom.

\section{Observation with Cynthia.}

I arrived at Cynthia's school on a foggy, cold November morning. I rang a doorbell to be let in and signed in with the front desk. It was 7:45AM and already the center was busy. The front receptionist showed me to Cynthia's classroom. I said hello to Cynthia and she showed me where to put my things. There were four children in the classroom, two sitting at a table exploring playdoh and scissors, a third saying good-bye to her parent, and a fourth child was 'skateboarding' on the carpet using a flat block. He introduced himself to me and I introduced myself back. He showed me his skateboarding game and we talked about different boards you can ride. The carpet moved a little and the boy got very excited calling out to Cynthia that the carpet moved like a wave. He told her that he must be surfing now and changed his hand motions on the block. I moved around the room and find Cynthia's schedule for the day (Figure 25). 


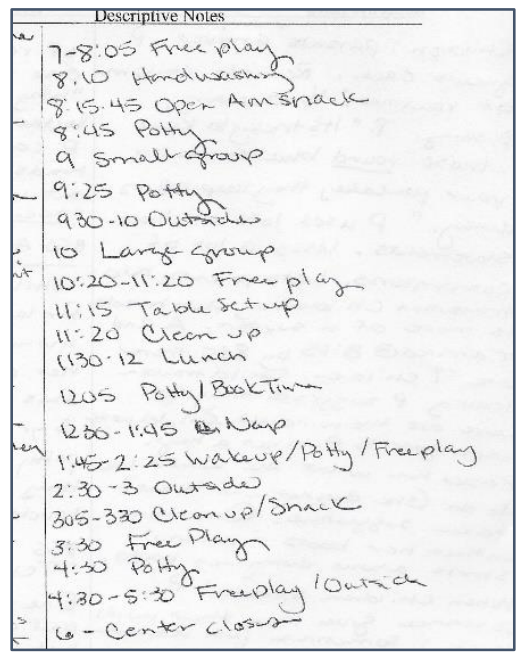

Figure 25: Cynthia's daily schedule.

While I wrote down the schedule for the day, more children arrived. Cynthia greeted each parent and child and let them settle into the classroom in their own way. A second child joined the first on the carpet. Instead of surfing, he was building with blocks. The first child 'surfed' into the second child's building. They argued a little bit. Cynthia stayed where she was setting up snack but kept an eye on the boys. The first one picked up his block and walked over to Cynthia. He complained that the second child is building in the middle of his ocean. Cynthia walked over with the boy to the carpet. She had the first boy explain his frustration. The second boy claimed he wanted to build. Cynthia asked, "How do you think we can make it work for both of you to use the carpet in these ways?" Through a little negotiation they decided the second boy can build closer to the wall. Both boys were happy about this and the first boy (who is much taller) hugged the second boy, who pushed him away. Cynthia reminded the first boy, "Remember, you are a lot bigger than him. You need to ask him if you can hug him." The boys compared sizes and found this very funny. Cynthia smiled at them and let them 
know she was going to go finish putting snack out. The boys began a new game comparing their heights to different parts of the room.

Snack was ready, and Cynthia moved around the room to invite children to wash their hands. The two boys moved to the sink. The sink was at an adult sized counter and there was a moveable stair placed in front of it so the children can reach the water. The shorter of the two boys washed first, climbing to the second stair then standing to wash his hands. The first boy watched. When it is his turn, he climbed the stairs to the same stair as the other boy. He had to lean down to reach the water. He sat on his knees to wash his hands. Cynthia was standing near, in the doorway of the bathroom so she could keep an eye on a child using the toilet and the classroom. The boy looked at Cynthia and smiled, she said. "That's a new way to do that, very interesting." She asked the boy if he is washing his hands this way because he is so tall. He replied yes and laughed. She nodded and laughed too.

A second teacher arrived in the classroom. There were now seven children. Cynthia sat at the snack table and listened to the children compare the pancakes with the waffles. The second teacher moved near the art area where three girls were gathering. Cynthia watched what was going on in the room, greeted parents and children, reminded them to wash their hands and other routines, tracked what the children at the table are eating, marked children in on the sign in sheet, and stayed in the conversation with the children at the table. She continued to let the parents support the children as they transition in, suggesting to a child to go to the window to wave good-bye to her parent 
when the parent seems to be struggling to leave. The child did and after she watched her parent leave, she returned to Cynthia to get a hug.

The children moved around the room. Cynthia invited each one to snack and the children decided if they wanted to eat or do something else. As children finished their snack, they let her know then put their dishes away. At 8:45 AM Cynthia reminded the few remaining children at the table that snack would be finishing soon. She started to put away the serving dishes.

A few minutes later, Cynthia reminded the children that it will be time to clean up in just five minutes. She discovered three girls who had been pulling stickers out of one of the girl's backpacks and sticking them on each other. Cynthia asked them to put away the stickers and the youngest girl began to cry. Cynthia talked to the girl, but she cried louder. Cynthia asked the girl if she needed a moment to feel better and the girl nodded then sat on a pillow in the book area.

Cynthia continued to move around the room encouraging the children to clean up so they could start circle. Many of the children showed Cynthia what they had been doing. Cynthia listened to each one, either giving the information back to them or asking a question. She did not seem rushed and engaged with each child. She asked the crying girl if she was feeling better and would like to come to circle, the girl told her no. Cynthia rubbed her back and told her just to come over when she is ready. The children were starting to move the carpet where they have circle. Cynthia sang that they will be singing the Good Morning song soon. The children giggled at her. She sat down in the circle area and brought out a tone apple. The apple was passed around the circle and each child held 
it while their name was sung. Cynthia's co-teacher arrived just after nine and the other teacher left. The crying girl made her way to Cynthia still crying. Cynthia asked the girl if she wanted to join circle, the girl stood continuing to cry. Cynthia's co-teacher asked the girl if she needed to go back to the pillow. The girl cried more, and Cynthia asked, "Did you want to hold the apple while we sing to you?" The girl nodded and Cynthia handed her the apple. They sang hello to her and the girl handed the apple back to Cynthia. She stopped crying. Cynthia asked if she needed a hug and the girl hugged her then sat in her lap. Cynthia let her stay there.

In the circle time, Cynthia held up the tone apple and a real apple. She asked the children to compare the two. This was so similar to what Julia had done during her circle time that I wondered, "Is this class also doing the [Creative Curriculum $\left.{ }^{\circledR}\right]$ apply study? What led to this?" (S. Guyon, observation field notes, November 14, 2018). She encouraged them to make their observations and comments. She built off the observation from one of the children that the real apple grew on a tree, and explained that the next day, Jessica, one of the people who make their meals, was going to come and talk with them about food that grows on trees. She told the children that they should think of what questions they might want to ask Jessica. The children called out ideas. Cynthia wrote each idea down on a large piece of paper, first naming the child and then repeating the question. She showed the children what she had recorded so far, stating the child's name and their question. She asked children who have not offered any information if they have a question to add to the list. Some of them did, some of them did not. She hung the paper 
with the questions on the wall and told the children that they should keep thinking about it and she would add more questions later.

Cynthia brought the iPad to the circle. She told the children she wanted them to think of a letter. I was confused about this switch and made a note to ask Cynthia why she had two such different circle activities, "Why did C. decide to do the letter activity? Is there an interest in letters?" (S. Guyon, observation field notes, November 13, 2018). The children started to call out letters and Cynthia named one child and the letter he called out. She asked the children how they can make the letter and what sound the letter makes, often glancing at the iPad. The children called out ideas and Cynthia repeated the instructions while creating the letter on the carpet with tape. She invited the child who chose the letter to walk along it before moving onto the next child. There were 13 children at school that day and when she had completed about half the letters, Cynthia had her co-teacher work with some of the children. Once the children become engaged, Cynthia stopped looking back at the iPad. The children called out things they noticed about the letters, the $\mathrm{C}$ is curvy, the $\mathrm{O}$ never stops, the $\mathrm{W}$ and $\mathrm{M}$ look like each other depending on where you are standing. Cynthia commented on each of these observations, "You are right! The $\mathrm{W}$ and the $\mathrm{M}$ do look alike." Her co-teacher encouraged the children to say the sound of the letter and remember how it felt to walk on it.

As the children continued to walk on the letters, Cynthia and her co-teacher had them start using the restroom and getting their coats on to go outside. A different teacher than the one from earlier that morning came into the room to give Cynthia her break. When the children went outside, I stayed in and looked around the room, and to write a 
reflection about the morning. It was 9:20. It took about 15 minutes for the children to use the restroom, get their coats, and go outside.

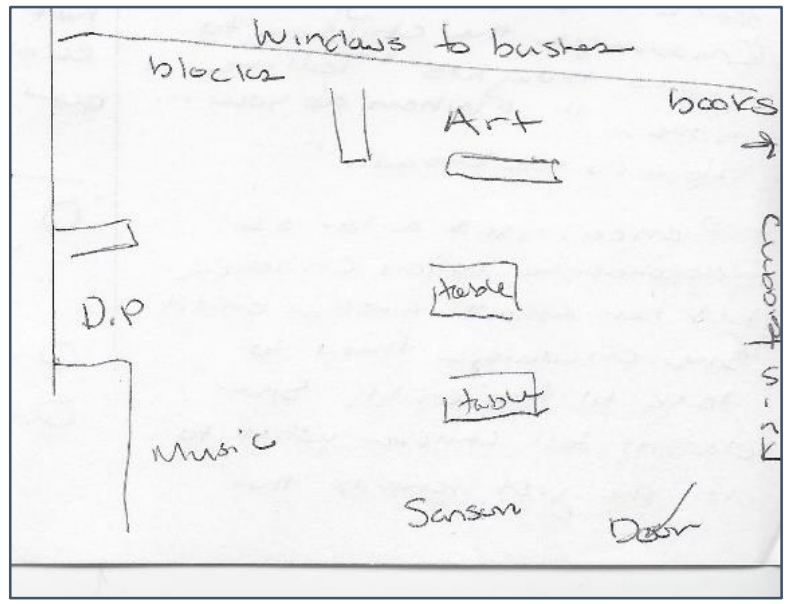

Figure 26: Diagram of Cynthia's classroom.

The room was not large but not small (Figure 26). Cynthia's class has children age 2.5 to 5 so she is at a lower ratio (1:7) than she has been in past years when her youngest child was 3 (1:10). The windows look out towards the street but are full of bushes. Even though the day was cold and foggy, several humming birds have visited the flowers on the bushes while I was in the room. Around the room were different tools to support Teaching Strategies GOLD® and Creative Curriculum ${ }^{\circledR}$. On top of the cubbies was a binder containing the Creative Curriculum ${ }^{\circledR}$ Tree study. It was open to the page about foods that come from trees and was been marked with a post-it note that says "You are here." There were also several rings around the room holding small laminated cards. Each card showed one of the learning objectives found in Teaching Strategies GOLD® and the dimensions found under that objective. I looked at the team schedule posted on the wall and noticed that Cynthia was scheduled to do 45 minutes of Teaching Strategies 
GOLD® work time the day before. Her co-teacher was scheduled to have 45 minutes of Teaching Strategies GOLD® work time that day from 9:45-10:30 AM.

The children came back in at 10:05 AM. They removed their coats and shoes, washed their hands, and go to the circle area. Cynthia told the children they had Spanish language class next and chatted with them as they transitioned over. She brought down the question chart from earlier and revisited it with the children. She looked around the circle and asked, "What else do we want to know?" A few of the children had additional things they are curious about. Cynthia asked children who haven't given any suggestions if they would like to add anything. One did, two did not. Cynthia was relaxed, laying on the floor, chatting with the children, and dictating what she is writing. Her co-teacher kept glancing at the clock and then at the door.

The Spanish language teacher arrived at 10:20 AM. Cynthia moved out of the circle and he moved in. While the children were engaged with the Spanish language teacher, Cynthia grabbed the iPad and sat at one of the tables. I wondered, "What would C. be doing differently at this time if she wasn't required to work on Teaching Strategies GOLD®?" (S. Guyon, observation field notes, November 14, 2018). Her co-teacher stayed in circle and helped the children stay focused on the books and songs that are being sung in Spanish. The lesson ended at 10:45 and the children said good-bye and transitioned to free play. Cynthia stayed on the iPad. The co-teacher looked at the schedule and remarked that he was supposed to have 'Gold time' that day. Cynthia laughed and apologized and asked if he would like her to find coverage to do it now. Her co-teacher replied that he is almost done and not to worry about it. He went on his break. 
Cynthia stayed working on the iPad. The other teacher in the classroom who had arrived to give her co-teacher his break, sat in the art area with a group of four children who were decorating paper towel rolls. One girl brought letter cards to the table where Cynthia was sitting and tried to engage her. The girl talked to Cynthia and asked her questions. Cynthia glanced up and gave the child short answers then continued to work on the iPad. The child continued to ask questions and hold up cards. After 10 minutes Cynthia closed the iPad and engaged fully with the child. She looked around the room while she played the letter game with the girl at the table.

Lunch arrived, and the children cleaned up the room. While the co-teacher set up the tables, Cynthia had the children set out their mats for nap. The children took the mat Cynthia handed to them, moved to the area where they sleep, set the mat down, and went to their cubbies to get their blankets and whatever else they have brought to help them sleep. As they finished with their mats, they washed their hands and sat at the table for lunch. There were two lunch tables, one teacher sat at each. They encouraged the children to try the foods and discussed what they like and have a long discussion about who has what type of milk and why.

After they are finished eating, the children scraped and stacked their dishes, visited the restroom, and washed their hands. They then sat on their mats with books until the lights were turned out around 12:15 PM. Cynthia took her lunch break at 12:30 PM and I slipped out of the classroom for my lunch as well, and to reflect about the second half of the morning. 
I returned at 1:30 PM. A few children had started to wake up and were laying quietly on their mats. Cynthia returned right after me and had a quick conversation with her co-teacher. Her co-teacher left for lunch. A few minutes later four children were awake on their mats and a second teacher joined the classroom. Cynthia started to open the curtains furthest away from the children, letting some natural light in the room. She moved around the room letting children who were awake know they could get off their mat but they needed to stay quiet while friends still slept. She stopped at one child and said, "I noticed you were very quiet! Thank you!” The child loudly whispered, "I was quiet as a stone." The children were aware of what they could and could not do. They were quiet and silly. Two of the children played a word/letter guessing game with Cynthia. Suddenly Cynthia looked at me and said, "I totally forgot I should be taking observations for the next checkpoint." She glanced around the room and found a small pouch. She tossed it diagonally across her body while saying, "Here's my satchel, now I am ready to go." and moved back to the children. As she worked with the girls, Cynthia took notes of their conversation. Two girls got into a skirmish in the art area. One was taller than the other. Cynthia moved over and asked the tall girl (who was holding a paper towel roll over her head) if she can hold the object while they worked out a solution. The girl started to tell Cynthia what was happening. Cynthia encouraged her to talk with her friend instead. They both stated their cases and then come up with a solution. Cynthia handed the child back the paper towel roll and the children rushed to the art table to implement their plan. 
Throughout this hour the children were engaged in different activities. As more children woke up Cynthia moved around the room and greeted each of them. One child asked to have paint at the easel and two other children asked for a dance party. She said yes to all of it but let the dance party children know had to wait until the children sleeping in the dance area woke up. She got the paint for the other girl and handed it to her saying, "Do you need anything else? Are these all the colors you need?" More children woke up and the children were able to dance. They were careful with their bodies and needed few reminders to be safe. Everyone was relaxed and having fun. "The children seem aware of what they can do. Everyone moves at their own pace." (S. Guyon, observation field notes, November 13, 2018). Soon there were only four children on their mats and Cynthia did not rush them to get up.

Instead Cynthia sat on the floor near them and they talked. She glanced at the clock and remarked that they are running late. She told the dancers they can have one last song and then everyone needed to get ready to go outside. The song began, and she encouraged the last children on their mats to put their nap things away and go to the bathroom. Soon most of the children not dancing had their coats on but the song continued to play. Cynthia laughed and said, "Wow this is a long song." She let the children finish their dance before having them get their coats. During this time her coteacher returned from lunch and he and the other teacher escorted the children outside while Cynthia and I stay back to talk about the day. 


\section{Reflective conversation.}

As I did with the first two participants, I began asking Cynthia what she thought about the day and recorded our conversation on my personal device. Cynthia said she had felt that the children were a little more on edge than usual and believed it might be because of the long weekend and upcoming short week. She said it was mostly was a typical day.

I asked her about her circle activities, was that the way she usually would have run circle or was she trying to get a specific observation? Cynthia told me that they have been following the Creative Curriculum ${ }^{\circledR}$ Tree study and that they were at the point of the study that they talk about the types of food that grow on trees. I asked if all the preschool classrooms were doing the tree study. Cynthia replied that each room picks what study they want to do. She told me that she and her co-teacher chose this study because she had done it at the end of last year and she wanted to see how revisiting the study would be with the children that returned to her class. "My little guys are really into cars and construction, so we will probably do the [Creative Curriculum ${ }^{\circledR}$ ] Road study next." She commented that she will implement the studies that reflect the children's interest this year. I told her that it seemed as if the children enjoyed the letter activity during circle. Cynthia laughed and said that she loves the Walking the Letter activity and that is something she used to do before they started using Creative Curriculum ${ }^{\circledR}$. She stated that the children have been really into letters lately, so she wanted to add an activity that was specifically for them. 
Cynthia mentioned that because they have just completed a checkpoint and are working on conference sheets, she had kind of forgotten that she needs to be taking notes for the next checkpoint period. "I was watching all those things and not worrying about writing them down because I know I already have it for my conferences, but it completely slipped my mind I could be getting this info for the next checkpoint." I replied that I had noticed on the schedule that she was scheduled for work time yesterday and her co-teacher was scheduled for it today, and asked if that was something they were actually able to do.

Cynthia explained to me that they now have two hours per week of planning time that she gets to work with her co-teacher. This time is for looking at the Teaching Strategies GOLD® reports, noticing where they are missing documentation, pulling Intentional Teaching Cards ${ }^{\mathrm{TM}}$, and making the lesson plan for the week. On top of that, the front desk schedules about 30-45 minutes a week for each of them to have work time dedicated solely to Teaching Strategies GOLD® and entering observations. She said that there are many times that the Teaching Strategies GOLD ${ }^{\circledR}$ work time doesn't work out, either from having too many staff members out or the children needing extra support in the classroom. She said that today, during the Spanish language class, it worked great for her to be able to sit back and work on her conference forms, even though it was technically her co-teacher's time.

I asked Cynthia what she would have been doing during that time if she wasn't working on conference forms, if they were not using Teaching Strategies GOLD® or 
Creative Curriculum ${ }^{\circledR}$. Cynthia quickly answered that she would have been setting out an art provocation:

Like 100\% I would be setting up something for art. My kids just don't get art projects anymore. We did one recently, but it was just to get something up in the hallway. It was totally teacher directed. I made a tree using tape and had them sponge paint around it to notice the negative space. The whole time they were like 'Ugh! My hands are dirty!' and I was thinking 'They think painting is getting dirty? Oh, we are so far behind on this!' I miss art.

She brought up that she thinks some of the more intense reactions of a child in her class is due to the fact that she doesn't have art as readily available as she used to. "She's such a sweet girl but she has some real anger going on. Being able to just lose herself painting is really helpful to her, I wish I could figure out how to make it more accessible on top of everything else." Cynthia talked about trying to get in the question of the day and the Mighty Minutes ${ }^{\circledR}$ activities while they are waiting. She laughed and told me she had a Mighty Minutes ${ }^{\circledR}$ activity planned before going outside this afternoon, but the last dance party song went on for so long.

I chuckled too and remark how much I appreciated how she followed through with the song and that group of children even though it put her off her time schedule. I mentioned that following through with what she said she was going to do with children was something I saw her do all day long. Cynthia replied:

Yes, I feel like that builds attachment and bond. How are they going to listen to anything you say of you don't follow through? It's about trust. Trust that I am going to do what I say and trust that you are going to do what you say too.

I commented that I could see that trust and a respect between her and the children in the classroom stating that in addition, or perhaps because of the respectful and trusting relationship between Cynthia and the children, it seemed as if the children had so much 
ownership and autonomy in the room. I remarked, "I never heard you tell them no, you just asked them to think of an alternative way to accomplish what they were doing." Cynthia commented that this was something she had worked on for years and stated that she had a professor who asked her to track how many times she said no or don't in one day on a piece of tape in her arm. She admitted she was horrified to see all those slash marks and from there has worked hard to reinforce the boundaries in the classroom in a positive way. She stated that she always tries to expect the best from the children in the classroom.

I told Cynthia how I noticed that I saw her helping children to expect the best from each other in the ways she was always having them listen to each other and work out their differences. I reflected, "So many times they were able to work it out on their own. The children know their words are important because you show them their important by the way you listen to them all day." Not only was Cynthia listening to the children's words, she was consistently having them rethink their ideas by repeating back what they were telling her or by asking them to explain it further. Cynthia explained me that it was important to instill from the beginning that this is the children's classroom. She started this by having the children make the rules at the beginning of the year, "Those rules are theirs." and how she sees the children go back to the rules (which are written with pictures and hung on the wall) and talk about how they are following them.

Cynthia and I continued to talk about the day and I told her that the one thing that surprised me, that contrasted sharply from our initial conversation, is that during that interview she seemed so stressed about time yet in the classroom she never seemed 
stressed about time. She never hurried the children and always took time to listen and wait for them to finish their thought or what they were doing. She laughed and said, "Well the end of that dance party I was just like oh my god we were supposed to be outside five minutes ago!" I remarked that she may have thought it, but she didn't emulate this in her actions and all I saw her do all was glance at the clock and remark that the class was running late. She did not rush the children and even continued to play with a child who was slowly getting off his mat. She laughed and said, "Well the thing is, they don't really care about my schedule they're going to go and do what they need and be happy, and that is what is really important to me." Cynthia's class returned from outside and our conversation ends. I thanked Cynthia and her co-teacher for letting me spend the day with them then thanked the children and say good-bye.

\section{Final interview conversation.}

Using the process, I described earlier in this chapter to sort through the areas in which I saw the consistencies and inconsistencies between what I had understood to be Cynthia's true self as an early childhood educator and what she was doing in the classroom, I outlined my final interview conversation with Cynthia (Appendix M).

I met with Cynthia on a Friday morning at her place of practice in a private room. I turned on my personal recording device and we talked about her conferences and the recent changes in her classroom for about twenty minutes before starting our official final interview conversation. I explained the process I had used for preparing for our final interview conversation and how the questions I had designed for our final interview conversation together were to examine the places I which I had seen consistency and 
inconsistency with the image I had developed of Cynthia throughout our interactions together. I began by sharing with Cynthia the idea I had built about how she saw herself as an early childhood educator.

I confessed to Cynthia that out of the three participants, she was the most complex. Cynthia laughed out loud at this and said "That's very Libra of me! Very high highs and very low lows." I explained that I had developed two conflicting images. The first was the image of Cynthia as an early childhood educator was as someone who had a deep love and respect for children and was confident in their beliefs about how children learn and the importance of supporting children's social and emotional development.

The second imaged I described to Cynthia was an image of Cynthia as an early childhood educator was in the context of Teaching Strategies GOLD® and Creative Curriculum ${ }^{\circledR}$. In this image I didn’t see that confidence. She seemed defeated, almost trapped within her circumstances, and highly conflicted with her beliefs about early childhood education and the pressure to conform to the parameters being put on her through the implementation of Teaching Strategies GOLD®. Cynthia affirmed that I had captured her very well.

I explained to Cynthia that I wasn't sure who I was going to see when I entered her classroom but was glad to see what I considered her true self:

The first person is who I saw that day, the confident person who really knows child development and loves children. I mean, I have never seen a teacher show so much respect for children the way you did. It was just amazing to watch. I really didn't expect that. I kind of expected, because you were always talking about time and having to get it all done, I kind of expected you to be stressed and rushing the children but you were really your true self. 
Cynthia thanked me and laughed, recalling a particularly long dance song that she needed to end to get the children outside:

That SONG! I'm glad I appeared calm because in my head I was just like 'OMG don't freak out, don't freak out'. We were so late! I was really trying hard not to let them know I was freaking out, but I was literally losing it mentally on the inside.

I laughed too and told her I had no idea that she was freaking out on the inside. I recalled to Cynthia that when I asked her about it later that day, she told me that even though she was feeling stressed she knew that the children were going to do what makes them happy and that is what was important to her.

We continued to talk about the different areas where I saw this consistency to the first image. I told her about the interactions I saw between her and the children, how much she was engaged and encouraging deeper thought. She listened attentively and purposefully. I reminded Cynthia of the interaction she had with the child at circle time and how she just seemed to know that the child wanted a turn with the tonal apple. I stated, "You have this kind of aura about you with the children, where you really seem to understand them and partner with them." Cynthia agreed:

I have always had this kind of awareness. When I look at a kid there is an immediate something. I call it that I can see their soul. I just seem to know them, and they seem to know me. It is partially just knowing the development, but I think there is a lot of just natural nuances. I have always been around children and taken care of children and building on that with education and understanding of brain development helped, but I have always had that emotional connection with children.

I find this aspect about Cynthia's work invaluable and often an overlooked essence about early childhood educators. I address this idea further in my interpretation of Cynthia in the final paragraphs of Cynthia's story. 
Cynthia and I continued our conversation and I brought up the two times that I felt that Cynthia was inconsistent with the image I had of her as an early childhood educator. The first was during the large group letter activity and the end of the morning circle time. I recalled the situation to Cynthia and how once the children became comfortable with the activity, she set aside the i-Pad and the interactions became less generic. The second was when Cynthia had been working on the i-Pad to finish up a checkpoint and a child was trying to engage her in a conversation, she would stop and answer the child's questions but did not extend the conversation further.

Cynthia was not surprised that in both instances she was using the i-Pad or that there was a generic-ness to the beginning of the letter activity. She commented to me that she had done a similar letter activity in the past and her center's encouragement for the teachers to make Teaching Strategies GOLD® their own was one thing she has liked about it but still struggled with:

Most of the things in [Teaching Strategies GOLD® and Creative Curriculum $®$ ] I have done my own way before, so it's not like I am unfamiliar with it. It is just tweaking it a bit to fit the criteria which is irritating because it takes away from the natural flow of their learning and our interactions with each other.

This thought led Cynthia to a further reflection about Teaching Strategies GOLD®. She told me that she thinks of Teaching Strategies GOLD® as a "constant monkey on my back" and she was never going to be doing enough:

I'm never going to document enough, I'm never going to have the right pieces of documentation, I'll never have [the objectives and dimensions] all memorized. It's just so much work. I mean I literally sit at the computer and think about if I had wanted to work in data entry, I would have gone into data entry and got an office job. It is always unbalanced. Sometimes I do [an observation] that is 
targeted just for a certain objective or dimension, but we have so many in that area I can't use it.

Cynthia tells me that she has been working on using the language in Teaching Strategies GOLD® when taking notes in the classroom to add into the system later. She said she is hoping that by using the Teaching Strategies GOLD® language she will find it easier to rate the children on the rating scale within the objectives and dimensions.

I think the big challenge is the spectrum in the objectives and dimensions. You know a child can manage his feelings, but all those little steps make it difficult for me to level. I know he can 'attend and engage' but now I have to figure out how it fits into the language of the system.

As we started to move into Cynthia's lunch break, I wanted to be respectful of her time and asked if there was anything else she wanted to share with me about Teaching Strategies GOLD®. Cynthia smiled, and said:

I hate it. I hate it. I, I can't say I love it. I hate it and I hate it but I think it helps give parents a picture of what happens in the room. From having my own parent perspective, it helps me to know what they do with my kid nine hours a day. I feel like that really validates it for the parents because we have the ability to share and all that. It has created a relationship with parents but at the same time I have a great relationship with my parents from talking to them face to face. I have this constant swing of both ways where it is helpful but not helpful. It doesn't work around the natural flow of the school year and returning to work after the holidays and how for the first three weeks you are just trying to get everyone back on track then here it is four weeks later, and I haven't even touched the i-Pad or entered any documentation. Now I am feeling pressured again. It just never ends.

On that note, I thank Cynthia for her time, and her constant honesty throughout our interactions together. She thanks me too and tells me that she has enjoyed our interactions. She says it has been nice for her to talk about her experiences and frustrations with Teaching Strategies GOLD ${ }^{\circledR}$ with someone who doesn't keep trying to justify the system and process. She walks me to the door, and we say good-bye. 


\section{Cynthia - Sorting out the puzzle pieces and final reflection.}

As with Julia and Sasha, I pulled out the commonplaces outlined by Clandinin, (2007, 2013), and Clandinin and Connelly (2000) three-dimensional narrative inquiry space and detailed in chapter three; the temporal, the societal, and place. For Cynthia I used yellow post-it notes, attaching them to three $2 \times 4$ foot pieces of foam board, each representing one of the commonplaces. Cynthia's story had three strong and intertwined themes. First, was her love and respect for children. Second, was her connection to the center she has worked at for fifteen years. Third, was her feelings about being required to use Teaching Strategies GOLD®. To demonstrate these three intertwined themes, I begin with the sociality common place.

The sociality commonplace has two subareas, the personal and the social. The personal subarea of the sociality commonplace are the internal influences, including the emotions, moral responses, and aesthetic reactions to the situation. Where Cynthia finds most value in her job is through supporting children's confidence, self-esteem, and overall social emotional development. In our first interview conversation Cynthia said:

I feel really passionate about supporting the children's social/emotional development. Being aware of how others feel, and promoting empathy is important to me. I want them to have positive feelings, good self-esteem, and confidence in social situations. Those are the things you need as an adult.

I saw this in her interactions with children and the ways in which she supports children to connect their learning experiences. She values multiple areas of intelligence and different ways of thinking, it is one of the aspects of working in an inclusive preschool that strives for 60/40 ratio of children developing typically and children with special rights that appeals to her most. Working with young children is her passion. For the first time in her 
career, Cynthia finds herself questioning her abilities as an early childhood educator. The reason for this questioning can be found in the social subarea of the sociality commonplace.

The social subarea of the sociality commonplace represents the outer influences, including the social, cultural and institutional things that shape the decisions you make and the way you think about things. Cynthia is aware of the pressures that the larger United States society puts on early childhood education and children. She spoke in our first interview about understanding that a reason the administration at her center chose to use Teaching Strategies GOLD® and Creative Curriculum ${ }^{\circledR}$ was to be able to secure public funding for their preschool. Because of these outside pressures, the perceived value of Teaching Strategies GOLD® often challenged Cynthia's self-worth as an early childhood educator as she learned to work within the Teaching Strategies GOLD® structure. Cynthia found the Interrater Reliability certification testing, especially defeating and stated:

I struggled at the Interrater Reliability but that just shows me that I'm not using the tool right. I'm working on it, but I find it extremely defeating. You know, you are scoring them, and you think you are scoring them well and then you take that, and you just think all of your documentation must be wrong. The computer version is much faster, you have to be quicker on your thought processes, you have to be like 'Score, score, score!' and I always feel the pressure, I have so much to do and I am trying to get it done quickly and then I think that sometimes doesn't create the best work.

The focus on the importance of passing the Interrater Reliability tests and failing left her feeling defeated and questioning the work she had been doing with children for years. 
Cynthia put a huge amount of pressure on herself. I saw this pressure over and over in our interactions. During our first conversation interview she broke down in tears over her frustration in trying to do everything right. Although she did not always agree with what needed to be implemented to get her objectives and "fill the holes" in her reports to level the children, she said "It's important because Teaching Strategies GOLD® and Creative Curriculum® shows you it's important.” In her classroom she had multiple supports for taking documentation for Teaching Strategies GOLD® including laminated learning objective cards, a Creative Curriculum® study notebook, and structured curriculum plans specifically aligned with objectives. In our final conversation interview she described the ways in which she was fine-tuning how she took observations so that she could fit the documentation into the Teaching Strategies GOLD® structure more easily:

Most of the things in [Teaching Strategies GOLD® and Creative Curriculum $®$ ] I have done my own way before, so it's not like I am unfamiliar with it. It is just tweaking it a bit to fit the criteria which is irritating because it takes away from the natural flow of their learning and our interactions with each other.

Cynthia had also been changing the words she was using to record children's experiences to help her remember which objective or dimension she was thinking about when recording information about a child:

I think the big challenge of the objectives and dimensions is the spectrum. You know a child can manage his feelings but it's all the little steps with the examples that are helpful but not helpful that I find I have trouble leveling. I know it's 'Attends and Engages' now I have to figure out how it fits the language of the system. I am trying to use the language of the system to make my documentation connect better and to benefit me so its not so debilitating to find the level [on the spectrum]. 
She is frustrated with ways she is constantly having to manipulate what she is doing or how she is documenting the children's experiences to fit into the structured language of the Teaching Strategies GOLD® system but she does it because she knows it is a requirement of her job.

In our final interview conversation together, Cynthia and I also spoke about the natural nuances of just understanding children, Cynthia spoke about always having an awareness about children. She joked that she called it being able to see their soul, "I just seem to know them, and they seem to know me. It is partially just knowing the development, but I think there is a lot of just natural nuances." I found this aspect about Cynthia's work invaluable and often an overlooked essence about early childhood educators. For some reason, understanding children, having an instinct for knowing children is not seen as a part of being and early childhood professional in the larger United States society, yet in other professions skills that enhance that profession are valued.

I have mentioned that Cynthia's themes are intertwined, and the tightest knots are between the commonplaces of personal sociality and place. The place commonplace represents the actual physical setting and how the different strategies and structures of where Cynthia works affects how she responds to different experiences. Much of Cynthia's considerations of her personal and professional self are tied to her place of practice. She has been at the same center for fifteen years, she met her husband there, her daughter attends there, it is where she honed her skills as an early childhood education professional. She does not want to leave. It is no wonder then that being required to use a 
system that contrasts so harshly with her beliefs about children and children's learning has left Cynthia often feeling defeated:

I think it's just the pressure because it goes back to that overall feeling that you are really good at what you do but now it's like you have been punched in the gut and you don't know a damn thing. I think I am emotional about failing the Interrater Reliability tests. Other teachers have failed it too but no one's really talking about it. The tool overall seems to be working successfully, it's just the lack of time of being able to put in your observations. Everyone's very cool about it, where it's like 'Get it done, we'll help you get it done'. It's not like I don't feel like I have support, I am just really hard on myself. With failing the Interrater Reliability test, I think I don't know what I am doing in documenting, writing down the right stuff. It's like with the boy and the hummingbird. I struggle with moments that the child demonstrated a skill, but it doesn't fit [in the objective] because TS GOLD® requires it a certain way. He recognized and recalled, but I can't use that example in the objective even though it is perfect.

Cynthia is not alone in this frustration. In our first conversation interview, she commented on the contention from the educators when the administrators used the generalization that 'we' decided to implement Teaching Strategies GOLD $®$, she said, "WE teachers didn't get a say." She often spoke about how using Teaching Strategies GOLD® was a requirement of her job and she seemed aware that her value as a professional at the center was being connected to her ability to meet the expectations set by the center for Teaching Strategies GOLD®.

Cynthia's center has provided her with many different supports to help the teachers complete the Teaching Strategies GOLD® expectations. These include structured documentation time for the teachers to leave the classroom, dedicated planning time to pull Intentional Teaching Cards ${ }^{\mathrm{TM}}$ to plan for learning experiences that meet certain objectives, and a new position of a Teaching Strategies ${ }^{\circledR}$ support person on staff. 
Yet many of these areas of support, such as the dedicated documentation time outside of the classroom and the Intentional Teaching Cards ${ }^{\mathrm{TM}}$ actually increased Cynthia's frustration by further limiting what she could do with the children in her classroom:

I have two planning sessions a week, one on Tuesday and one on Thursday. Which is great, I need that time, but it really breaks up my week. I can't walk to the park with my kids. I'm not comfortable enough with Teaching Strategies GOLD® to fully implement what I used to implement, I am still trying to get a handle on Teaching Strategies GOLD®. I really need and appreciate the time to get it done for these criteria but it's like I so hate sitting and doing data entry when I could be playing with my kids.

The decision to implement Teaching Strategies GOLD® was a deciding factor in her husband leaving the center and the field of early childhood education completely. Cynthia doesn't want to leave the center she is at so she knows in order to stay on she will have to "get on board" with Teaching Strategies GOLD ${ }^{\circledR}$ to stay.

The final commonplace is the temporal commonplace. The temporal commonplace represents the way Cynthia's past experiences are influencing how she is responding in the present moment and thinking about the future. To use her own words, Cynthia is in a "constant swing" of finding Teaching Strategies GOLD® helpful and not helpful. She struggles with the ways in which what she is being asked to do is different than how she learned to work with children, what she has always done and learned in her early childhood education courses. She feels the Teaching Strategies GOLD® system doesn't take in account the natural flow and eb that comes in working in a classroom with children.

I think of Cynthia's description of being in a "constant swing" about Teaching Strategies GOLD® a little differently than she described it. Cynthia said that she was in a 
constant swing between whether Teaching Strategies GOLD® was helpful or not helpful. I see instead that Cynthia is a constant swing of resisting placing value on Teaching Strategies GOLD® and being worn down to a place of acceptance. One feeds her beliefs about children and her self-worth as a professional, and the other secures her employment. Whereas Julia was in a conflict in regard to her thoughts about Teaching Strategies GOLD® and Sasha was going through a process, Cynthia was in a constant swing between what she had to do and what she felt was right. There were similar patterns within each of these different relationships with Teaching Strategies GOLD®, and in the next section I will begin to connect the assembled puzzle pieces of Julia's, Sasha's and Cynthia's stories into a larger narrative.

\section{Interpretation of Findings: Fitting the Puzzle Pieces Together}

My experiences using Teaching Strategies GOLD® helped to frame the boarder of my research puzzle, and in conducting this research I found many similarities to my experiences and the experiences of the participants. As part of my research and interpretation process, I organized the participants' experiences using Clandinin (2007, 2013) and Clandinin and Connelly's (2000) three commonplaces of the narrative inquiry space. I viewed the commonplaces as a way to assemble the puzzle pieces with similar patterns in order to see the bigger picture.

After examining each of the participants' commonplaces separately, I connected the pieces of their individual stories, starting first with the commonplace of sociality before moving on to the commonplaces of place and temporality. As I worked through each commonplace, I reflected on the initial wonderings I had about the experiences of 
self-identified constructivist early childhood educators required to use the Teaching Strategies GOLD® assessment system to build the larger narrative.

\section{The sociality commonplace.}

The sociality commonplace has two subareas, the personal and the social. The personal subarea of the sociality commonplace are the internal influences, including the emotions, moral responses, and aesthetic reactions to the situation. All three of the participants shared that they loved working with young children. Each of them described their work similarly, Julia reported, "It was just my thing." (J., personal communication, August 16, 2018), Cynthia said, "It was my passion.” (C., personal communication, September 19, 2018), and Sasha stated, "It just fit and felt so right." (S., personal communication, September 18, 2018). This made me think about my own love of working with young children and how when in dialogue with children, it hardly felt like 'work' at all. Additionally, all three of the participants had similar understandings of how children learn. They each held constructivist beliefs about learning and saw learning happening all the time. All the participants valued children's right to be the engineer of their own learning, to follow their curiosities, and learn through making connections with others and past learning experiences.

The social subarea of the sociality commonplace represents the outer influences, including the social, cultural and institutional narratives that shape the decisions you make and the way you think about things. The outside influence that affected the participants the most was the lack of respect that the larger United States society holds for early childhood educators. The participants all felt an intensifying pressure for early 
childhood programs to meet expectations and structures set by outside influences. They also all commented that early childhood educators rarely had a say in the policies and procedures that were being pushed into their practice and programs. As I noted in chapter two, the conflicting attitudes regarding the value of positive early childhood education experiences and the devaluing of early childhood educators has created a social and cultural nature that leaves early childhood educators on the outside of the circle of policy creation for early childhood education programs (Ayers, 1989; Parnell, 2010). It is a precarious attitude that insinuates a perception that early childhood educators are "unworthy of serious attention" (Ayers, 1989, p. 3) and that those who create education policy know how children learn better than those who work with young children on a daily basis. Sasha reflected about this idea when I asked her why she felt there was such a push from administrators at her old program to use Teaching Strategies GOLD® and Creative Curriculum ${ }^{\circledR}$ in the program and classrooms:

When you have been out of the classroom for a while, you kind of forget what it is like to be in the classroom. When [the administrators] have never had to use it the way they want the teachers to use it, it can be tough. It's tough to tell them that it is hard or that it takes you out of what you should be doing in the classroom. (S., personal communication, September 18, 2018).

Cynthia, who was the most experienced early childhood educator for this study, struggled with the push from her administrators to use Teaching Strategies GOLD®:

I don't feel that it is negative, but the pressure of doing it the way they want me to do it versus how I have always done it. It's like you're really good at your job for 20 years and really confident and then now I feel as if I don't know anything and I've never taught children and I'm a total failure. But not all of the time, just some of the time. That's the thing I have struggled with. I took all my ECE classes years ago, none of that was on the computer. It was all about active listening and being present. That is still in Teaching Strategies GOLD® but [the way it is 
implemented] contradicts what I learned. At the same time, this is what is required by my job now, so I respect that. (C., personal communication, September 19, 2018)

Cynthia has been at her program for over 15 years, she is considered a mentor within the program and often asked to take on new educators as co-teachers yet her voice in speaking out against the pervasiveness of using Teaching Strategies GOLD ${ }^{\circledR}$ and Creative Curriculum ${ }^{\circledR}$ was seemly unheard. Further, she often commented on how making sure she was "filling in the holes" (C., personal communication, September 19, 2019) on the Teaching Strategies GOLD® Documentation Status and Snapshot reports were a large influence on her lesson plans and how she spent her planning time. Cynthia even had a 'coach' at her center to help her with implementing Teaching Strategies GOLD®.

Even though each of the participants held a level of frustration and resentment towards being required to work within the Teaching Strategies GOLD® assessment system, they also each acknowledged that using the system gave them a sense of authority, mostly with parents, that they would not have had otherwise. Julia reflected on how the benefit a structure like the one that Teaching Strategies GOLD® provides could have supported her interactions with difficult parents stating, "It would have been helpful to me if I could use the language of that kind of system to explain what we were doing." (J., personal communication, August 16, 2018). Sasha commented on how she liked that Teaching Strategies GOLD® helped her to show parents what the children were doing in the classroom:

I like that it sounds fancy and it sounds like you know all this big stuff. I think parents just assume that we play all day and if I am able to give them the 
objectives and the dimensions it gives us a reason to play all day, it helps them to understand it more. (S., personal communication, September 18, 2018).

Two of the three participants made direct connections to the use of Teaching Strategies GOLD® and public funding received by the program at which they worked.

The experiences of the early childhood educators that participated in the study strongly reflected my own experiences of being required to use Teaching Strategies GOLD®. In my experiences my already muffled voice, and the muffled voices of the children, were being even further silenced by an increased pressure to focus on the result of the child's experiences rather than the lived experience itself. Each of the participants expressed this same ordeal in different ways. Julia felt the increasing focus on readiness and academics took away the magic of children learning, Sasha felt the dismemberment of children's learning experiences into unconnected objectives conflicted with her beliefs, and Cynthia believed that focusing on implementing activities just to fill in a hole on her documentation report, took away from the children's natural learning experiences.

Looking at the experiences of the participants through the sociality commonplace made me realize that I was not alone in my frustration in being required to use Teaching Strategies GOLD® and the powerlessness I felt in the classroom, program, and in the creation of early childhood education policy. The powerlessness the participants felt varied throughout the research process and was tied closely with the program each participant worked. In the next section, I take a closer look at the commonplace of place and the ways in which the participants' relationship and role within their place of practice affected their work in using Teaching Strategies GOLD®. 


\section{The place commonplace.}

The place commonplace represents the actual physical setting and how the different strategies and structures of where the participants work affects their response to different experiences. In my own experiences as an early childhood educator required to use Teaching Strategies GOLD®, I had wondered if some of my struggles in using Teaching Strategies GOLD® in a way that reflected my beliefs of how children learn came from the very small amount of time available to successfully use the information my teammates and I put into the system. The place commonplace played a significant role in the ways in which the participants responded to using Teaching Strategies GOLD® and each was quite different.

Cynthia's experience was most like my own in regard to the amount of time she spends with children and the time available for her to enter documentation and complete the other requirements set for her around Teaching Strategies GOLD®:

It's like the documentation process takes away from my activities. Then I feel frustrated because I don't have enough for my checkpoints. Sometimes I just do on-the-spot activities just like 'Here! Show me this!'. As I get closer to my checkpoints, I start doing more group documentation to try and knock out one or two objectives for a group of kids. The documentations is just basic, you know, this child can do A.B.C. I don't know if that type of documentation is important to parents. (C., personal communication, November 6, 2018).

Cynthia's response to Teaching Strategies GOLD® was very adverse from the beginning and did not soften as she became more familiar with the system:

I'm never going to document enough, I'm never going to have the right pieces of documentation, I'll never have [the objectives and dimensions] all memorized. It's just so much work. I mean I literally sit at the computer and think about if I had wanted to work in data entry, I would have gone into data entry and got an office job. (C., personal communication, January 18, 2019). 
Cynthia loves where she works and cannot imagine leaving, and often stated that she had to "get on board" because it was a "requirement of my job now" (C., personal communication, September 19, 2018). For Cynthia, Teaching Strategies GOLD® took her away from the valuable moments and experiences she could have been having with the children in her classroom.

Julia had the most time for work outside of being with children, about three hours per day. Julia also had numerous other requirements and responsibilities to fill during that time. In regard for time, Julia's biggest frustration was not the time it took to enter documentation into the system, but the lack of time she spent with the children in free exploration due to the structures and schedules she was required to meet in her program:

In 3.5 hours, we are having two meals, recess and a circle, so it's maybe 30 minutes of work time. You have so many things going on that it's not like there's really any time to see that organic learning. (J., personal communication, October 26, 2018).

Julia felt that the limited amount of time to see the children become deeply engaged in learning forced her to use the Teaching Strategies GOLD® and Creative Curriculum ${ }^{\circledR}$ tools to know what the children could do.

Between our initial screening phone conversation and the first interview conversation, Sasha changed workplaces. Part of her decision was based on the restrictions she was feeling from her former place of practice commenting. "They're really going by the book. There is a strong push that we do things how TS GOLD® wants us to do them." (S., personal communication, September 18, 2018). The agency that Sasha moved to and worked for during our interactions together had funding that was tied directly to signed Teaching Strategies GOLD® Parent Conference Forms, however the 
agency was in the second year of implementation and interested in finding ways to make the process beneficial to educators. In her new workplace, Sasha had the most balanced amount of time set aside for planning and working with children. She was with the children for 6 hours a day, with an hour before and an hour after to plan and work on Teaching Strategies GOLD®. Interestingly, Sasha spent most of her planning and work time prepping for the day in the morning and reflecting about the day in the afternoon, choosing to complete her Teaching Strategies GOLD® requirements at home.

Additionally, out of the three participants, Sasha had the most autonomy at her place of practice and was able to advocate to set structures around her daily schedule that benefited the children in the classroom most. She described the ways in which she and her co-teacher had advocated for her children:

There are some rough days. The schedule didn't impact us too much today but there are some days that we have eight different people coming in. Nobody knows our classroom, we are kind of separate from the rest of the program, which in some ways is nice because we get to do whatever we want. At first people would just show up to give us our breaks and we wouldn't really know them, and the children wouldn't know them, and it would be the worst possible moment of the day. We had to push back about that and say that we really needed our breaks between certain times every single day and that the people had to know our children. (S., personal communication, November 13, 2018).

In our final conversation together, Sasha told me that, based on the feedback the agency that Sasha worked for was getting from teachers, they were considering limiting the number of Teaching Strategies GOLD® checkpoints to two each year instead of the four recommended by assessment system.

It was interesting in this study to see how the dynamics of power and autonomy changed the ways in which the participants worked with Teaching Strategies GOLD®. 
Cynthia felt she had no power or say over how and if to use Teaching Strategies GOLD® in her classroom. She implemented it as she was told to do and then worked around it. Julia also felt restrictions around using Teaching Strategies GOLD® but implemented it as little as she could. When Julia needed to use a Creative Curriculum ${ }^{\circledR}$ activity in order to gain information connected to a specific set of Teaching Strategies GOLD® learning objectives, she did it resentfully. Out of the three, Sasha had the most power and autonomy in how she used Teaching Strategies GOLD® and in what happened in her classroom. This gave Sasha the freedom to find ways in which Teaching Strategies GOLD® supported her work with children rather than guiding it.

\section{The temporal commonplace.}

The temporal commonplace represents the way the participants' past experiences influence how they respond in the present moment and how they think about the future. All the participants' responses to working with Teaching Strategies GOLD® at the beginning of the study were similar. Each of them was an experienced early childhood educator and had experience in documenting young children's learning without using a structured system. Each of the participants felt the Teaching Strategies GOLD® assessment system was unnecessary, sterile, and a waste of time. Julia and Sasha saw how the system could give them a sense of authority when speaking about young children's learning and development with parents, and Julia could see some value in it for new or inexperienced early childhood educators, but Cynthia saw very little value in it at all. 
Before beginning this study, I had wondered what the impact of being required to use Teaching Strategies GOLD® had on the early childhood educators' perception of themselves. This was most apparent in our conversations around the Interrater Reliability certification testing that each of the participants were required to complete and pass. Sasha had taken her Interrater Reliability certification tests the previous year and had passed; she was not required to retake the tests by her new center. Both Cynthia and Julia took the Interrater Reliability tests this year. Julia failed the Social/Emotional and the Physical tests several times. She found this confusing and felt the process was degrading. Cynthia struggled with the Interrater Reliability testing the most, failing each several times:

I struggled at the Interrater Reliability but that just shows me that I'm not using the tool right. I'm working on it, but I find it extremely defeating. You know, you are scoring them, and you think you are scoring them well and then you take that, and you just think all of your documentation must be wrong. The computer version is much faster, you have to be quicker on your thought processes, you have to be like 'Score, score, score!' and I always feel the pressure, I have so much to do and I am trying to get it done quickly and then I think that sometimes doesn't create the best work. (C., personal communication, September 19, 2018).

Failing the Interrater Reliability tests completely defeated Cynthia and affected her perception of herself as an early childhood educator. Coupled with the increasing pressures to incorporate Teaching Strategies GOLD® into her daily routine, failing the Interrater Reliability tests left Cynthia feeling overwhelmed:

I think it's just the pressure because it goes back to that overall feeling that you are really good at what you do but now it's like you have been punched in the gut and you don't know a damn thing. I think I am emotional about failing the Interrater Reliability tests. Other teachers have failed it too but no one's really talking about it. (C., personal communication, September 19, 2019). 
Julia also struggled with failing the social/emotional and physical parts of the Interrater Reliability tests and how the requirement to pass the tests changed the work she did with the children:

I feel like I really know my stuff. I have two degrees in education, but I was not succeeding in [the tests]. My co-teacher failed every single category the first time she took it. We spent our entire week trying to pass the tests. Then deadlines (for checkpoints) came down and we had to turn in everything. I was just like 'Oh yeah, I am doing everything based around this system and the checkpoints', that business is running my class right now. That feels really weird, it is just the opposite of what I want to be doing, especially at the beginning of the year. (J., personal communication, October 26. 2018).

When learning about Cynthia's and Julia's experiences with taking the Interrater Reliability testing, I wondered about the significance of the requirement to pass the tests. I wondered if Cynthia's and Julia's struggles with passing the Interrater Reliability tests and an effect on how they were viewed as a professional by their supervisors or if it was just a part of meeting the requirements set by the Teaching Strategies GOLD® system.

As the study and their lives progressed, and the participants worked their way through a checkpoint period from the beginning of the school year to the first set of conferences, their thoughts about Teaching Strategies GOLD® progressed as well. Julia's relationship to Teaching Strategies GOLD® was the most conflicted. As she moved from the position of an early childhood educator in the classroom to a position where she supervised and supported early childhood educators, she was still strongly conflicted around, in her words, “a chain store style of education" (J., personal communication, October 26, 2018) but felt it was better than what she was seeing happening in classrooms: 
It's been interesting now in coaching teachers because I feel like I have a lot of teachers that are inexperienced. They don't have the training or the education. There are so many new staff and so many teaching assistants and aides that are stepping up to be the teacher and they have no background [in early childhood education]. I see how the objectives in Teaching Strategies GOLD® could be a way to help them learn how to be intentional about planning. (J., personal communication, February 3, 2019).

In her experiences as an early childhood educator, Julia did not feel it was necessary to use Teaching Strategies GOLD® as long as she was able to have enough time with the students and the students were able to get large sections of time to get into a deep level of learning. Moving into the role of supervisor, Julia had hoped to elevate the work of the early childhood educators she supervised with her own experiences. She did not expect to have so many inexperienced staff members and sees using Teaching Strategies GOLD® as a necessary step to move the staff in a direction away from checklists and ditto sheets towards using more developmentally appropriate practices. Julia doesn't think Teaching Strategies GOLD® is the best way, but in her current situation, she doesn't see that she has an alternative.

Sasha had the most autonomy in her practice and how she used Teaching Strategies GOLD® and that autonomy helped her learn how to make the system work for her:

I'm not in love with Creative Curriculum ${ }^{\circledR}$ but it does help when I have to label what the kids are doing. I use the app a lot and I take documentation when I have very low numbers of kids. I know I am supposed to be taking documentation all day long, but it is easier for me to do it when there are lower numbers. I also take it when we are using the instructional teaching cards, and the moments that stand out to me during the day. (S., personal communication, September 18, 2018). 
Sasha admitted that she tended to do more structured curriculum based on specific learning objectives closer to the checkpoint deadlines and that she found the whole thing rather tedious:

Right now, as we are coming up on checkpoints, we are realizing it's really hard to take documentation for eighteen children. We know that we are doing everything. We know that we are covering all of the objectives and dimensions, but it is just really tough to have those moments with each child. (S., personal communication, October 29, 2018).

She commented that she didn't really care for the system one way or the other, so she tried not to let it influence what she was doing in the classroom.

Cynthia has learned to integrate working with the Teaching Strategies GOLD® and Creative Curriculum ${ }^{\circledR}$ systems:

Most of the things in [Teaching Strategies GOLD® and Creative Curriculum $\left.{ }^{\circledR}\right]$ I have done my own way before, so it's not like I am unfamiliar with it. It is just tweaking it a bit to fit the criteria which is irritating because it takes away from the natural flow of their learning and our interactions with each other. (C., personal communication, January 18, 2019).

She does what she is supposed to do and experiences different levels of resentment towards Teaching Strategies GOLD® throughout the process. Cynthia's past experiences to the center where she works are deeply ingrained into her personal and professional self, and she chooses to figure out how to make Teaching Strategies GOLD® ${ }^{\circledR}$ work rather than leave the program.

It is clear that each of the commonplaces had a significant bearing on the participants' experiences with working with the Teaching Strategies GOLD® assessment system. As the features associated with each commonplace became more apparent, I began to see connections to many of the concerns I addressed through chapter two's 
literature review, such as the restructuring of the field of early childhood education, the redefinition of what it means to be a professional in the field, and the larger consequences that come when the work that early childhood educators are required to do does not connect with the work they love and find valuable. In the next section I highlight a few areas of significance before showing the bigger picture of the assembled puzzle in chapter five.

\section{Reflections}

Throughout this research process I was continually drawn back to the work, as described in chapter two, of Apple (2009), Christakis, (2016), and Parnell (2010). Apple wrote about the restructuring of the field of education, referring to the de-skilling of the act of teaching, and how the intensification of educators' work that is not with students, is now becoming "misrecognized as a symbol of professionalism" (p. 206). This restructuring is creating an atmosphere in which early childhood educators are forced to either give in to a system that does not follow their passion or get out of the field completely (Apple, 2009; Christakis, 2015; Parnell, 2010).

\section{Give in or get out.}

The environment where early childhood educators are obliged to either 'give in' or 'get out', was prevalent throughout the research process. Cynthia felt she needed to conform with the requirements of her center and was conforming to practices that did not show her beliefs about how children learn nor feed her passion about working with young children. In our first interaction I asked Cynthia if she found Teaching Strategies 
GOLD® helpful in the work that she does, Cynthia replied, (C., personal communication, September 19, 2018).

As Sasha reported, she got out, leaving a center that no longer reflected the work she wanted to do in order to find a place where she could work with young children without compromising her beliefs. Julia first got out by leaving the role of an early childhood educator in the classroom to take on the role of a supervisor where she hoped she could have more control over policy and practice. Once in this position, Julia felt forced to give in when faced with multiple inexperienced and/or undereducated staff members by yielding to the overall structure of the Teaching Strategies GOLD® assessment system and the ways in which Creative Curriculum ${ }^{\circledR}$ feeds the system as a starting place to help her educators develop into what is deemed as professionals. Julia's feelings were still mixed, and she stated in our last interview, "I think it is interesting how TS GOLD® can be helpful when you are just learning but then become something like 'UGH!' when you know what you are doing." (J., personal communication, February 3, 2019). She felt given the current state of the program where she works, she has no other alternative.

\section{The disconnection between Teaching Strategies GOLD® and the work the} participants' found valuable.

Another area of significance in this research was that the participants did not use the information in Teaching Strategies GOLD® beyond 'filling in the holes' needed for the Teaching Strategies GOLD® reports. The information they were entering into the system did not affect or enhance the ways they supported the children's learning and 
development. Reports were created to find the learning objectives in which the participants were missing documentation and curriculum was implemented in order to fill in the missing pieces. Julia stated:

Doing something just to get a checkpoint is frustrating to me and I don't feel I need it. I feel as if I can plan and be intentional without Creative Curriculum ${ }^{\circledR}$ or Teaching Strategies GOLD®. But then when I need to get information for a certain checkpoint that I don't have then I feel like I have to do these really specific things. (J., personal communication, October 26, 2018)

Sasha also found herself focusing on the objectives rather than the children's interest when checkpoints deadlines were close and told me about planning small group time that was specifically implemented to meet a checkpoint criterion. She understood that it was generic claiming that "everybody's going to have the same documentation" but at least it will fill in a place in which they are lacking documentation on their reports. (S., personal communication, October 29, 2018). Once the learning objective had been completed to the parameters set by the center, no additional documentation was connected to that learning objective.

This did not mean that the children stopped growing in that area or that the participants stopped being aware of the children's growth. How the participants thought about the children was disconnected to the work they were adding into the Teaching Strategies GOLD® system. Cynthia commented on this after her observation when I recalled the children's conversation at morning snack during her observation stating, "I was watching all those things and not worrying about writing them down because I know I already have it for my conferences, but it completely slipped my mind I could be getting this info for the next checkpoint." (C., personal communication, November 14, 2018). 
The system was a requirement of their jobs that was separate from the what the participants considered as their work with the children.

\section{Ways in which the participants found Teaching Strategies GOLD® helpful.}

However, the participants did all appreciate the parent conference forms provided by Teaching Strategies GOLD®. Using the language of the system helped the participants to show the value of what the children were already doing in the classroom. It is important to note, however, that these connections were made through the conversations the participants had with the parents, not the preconceived, generic learning objectives found in Teaching Strategies GOLD®. Cynthia commented on this during our final meeting:

From having my own parent perspective, it helps me to know what they do with my kid nine hours a day. I feel like that really validates it for the parents because we have the ability to share and all that. It has created a relationship with parents but at the same time I have a great relationship with my parents from talking to them face to face.(C., personal communication, January 18, 2019).

Each of the participants, no matter how much they liked or disliked using the Teaching Strategies GOLD® assessment system, found that having the forms and language from the system gave them a sense of authority when working with parents. Through the eyes of the parents Teaching Strategies GOLD® helped them to be defined as a professional in their field, even though this definition that was outside of their control and outside of their beliefs.

\section{Summary}

The purpose of this research study was to collect and understand the experiences of self-identified constructivist early childhood educators required by their place of 
practice to use the Teaching Strategies GOLD® assessment system. When I was in the initial planning stages of this research process, I decided to open the study to three participants. By keeping the participants to three, I was able to obtain a level of camaraderie with each of the participants. Our conversations together were relaxed and open. The participants were honest in their reflections and comfortable in correcting or clarifying my interpretations if they did not fully agree with them. In our interactions together we laughed, expressed frustration, reflected, and even cried a little. Because of my experiences as an early childhood educator working with Teaching Strategies GOLD®, and my sincere intention to understand the participants' experiences, I was able to offer a level of empathy and understanding that the participants were not receiving elsewhere.

The three areas of significance that I highlighted in the previous section; the give in or get out atmosphere of education, the disconnection between what educators are required to do to what they find valuable, and the definition of professionalism in the field of early childhood education that is being created through conforming to policy and structures, were not surprising to me and connected strongly to the literature I reviewed when preparing to do this research. Each of these areas alone is a weighty issue and complied together they exhibit a pathway that is leading the field of early childhood education into a situation that is counteractive to the benefit of children.

In completing the research and analysis section of my dissertation, I find myself concerned about this pathway. It was apparent throughout the research and interpretation process that the implementation of Teaching Strategies GOLD® and Creative 
Curriculum ${ }^{\circledR}$ into early childhood programs was having a forceful effect on how the educators worked in their classrooms. Furthermore, the programs' focus of what was considered important work for the participants was shifting away from what the educators were doing in the classroom and towards completing their Teaching Strategies GOLD® requirements on time. These two aspects combined were changing not only the purpose of early childhood education but also creating a definition of an early childhood professional that is defined by an educators' ability to conform to a system and practices in which they do not believe.

An additional question to ask is what is the purpose of Teaching Strategies GOLD®? If educators who are forced to use it see it only as a requirement of their job and do not use the information in the system in their work with children, why are we asking them to do it at all? In the next chapter, I revisit why I began this research as well as taking a closer look at each of these concerns, drawing connections between the participants' experiences to the larger issues found in United States' early childhood education programs, practices, and policies today. 


\section{Chapter Five: Discussions and Conclusions}

Research has shown connections between positive early childhood experiences and life-long learning success (Bergen \& Woodin, 2017; Duncan, Dowsett, Classens, Magnuson, Jutson, Klebanoy, \& Sexton, 2007; Logue 2007; Shonkoff \& Phillips, 2000;

Schweinhart \& Weilart, 1997; among others). Such research has brought state and federal funding to early childhood programs like never before. However, as I detailed in chapter one through an examination of the Oregon Preschool Promise along with other educational policy programs, with funding comes the requirement to use measurement systems such as Teaching Strategies GOLD®.

Teaching Strategies GOLD® is an on-line assessment system used nationwide and in multiple types of programs to rate young children's learning and development. In chapter two, I shared some of the published research around Teaching Strategies GOLD®. The majority of these publications, which are centered around one large research study, demonstrated that when early childhood educators used Teaching Strategies GOLD®, children were rated the same regardless of the type of early childhood program, the demographics of the children, or the location of the program (Kim, Lambert, \& Berts, 2013a, 2013b; Lambert, Kim, \& Burts, 2014, 2015). Lacking in the research was the experiences of the educators who use Teaching Strategies GOLD® and how it affected the way they worked with children and their perception of themselves as professionals. I believed that understanding the experiences of educators using Teaching Strategies GOLD® would provide a more comprehensive perception of the 
effects of using the system in early childhood education programs than relying on quantitative data alone.

The purpose of my research was to collect and understand the experiences of selfidentified constructivist early childhood educators required to work with the preformatted, portfolio style assessment system Teaching Strategies GOLD®. In my experience as a self-identified constructivist early childhood educator required to use the Teaching Strategies GOLD® assessment system, I had long struggled with the way in which the assessment system categorized children's learning into pre-established, generic learning objectives. I had consoled myself by the knowledge that when meeting with parents and guardians about their child, I could represent their child's learning and growth in a genuine way based on my interactions, experiences, and the relationship I had with the child. However, as I continued to implement this strategy, I could not help but notice that even with my best intentions, my ability to holistically describe the child's learning became lost within the myriad of learning objectives, categories, and reports found within the Teaching Strategies GOLD® system.

When I set off on this research journey, I had my own ideas and opinions about Teaching Strategies GOLD®, but I wanted to learn about other early childhood educators' experiences in different programs who were required to use this system. I was not surprised to discover that many of the experiences of the participants in this study were similar to my own. As I assembled my research interpretation puzzle, the shapes and patterns of the participants' experiences blended well with mine and with each other's and a larger picture began to develop. Many parts of this image stood out boldly 
and quickly called for my attention. Other parts were more subtle but permeated the bolder parts so fastidiously that they indicated conditions outside of this research study that are difficult to ignore.

\section{Synthesis of Findings}

There were three areas in which I was drawn to learn about when I began my research. First, I was curious to learn how working with Teaching Strategies GOLD® affected the ways in which the participants worked with children. I was also curious about how the requirements around using Teaching Strategies GOLD® affected the participants' perception of themselves as professionals. Further, I wondered if there were ways in which the participants were using Teaching Strategies GOLD® so that it supported the work they did. I expand on each of these areas in the next sections.

Table 1

Synthesis of Findings

\begin{tabular}{|c|c|c|c|}
\hline $\begin{array}{l}\text { The participants' work } \\
\text { with children and what } \\
\text { they deemed as valuable. }\end{array}$ & $\begin{array}{l}\text { How working with } \\
\text { Teaching Strategies } \\
\text { GOLD® affected the } \\
\text { ways in which the } \\
\text { participants worked } \\
\text { with children. }\end{array}$ & $\begin{array}{l}\text { The affects that using } \\
\text { Teaching Strategies } \\
\text { GOLD® had on the } \\
\text { participants" sense of } \\
\text { their professional } \\
\text { selves. }\end{array}$ & $\begin{array}{l}\text { The ways in which } \\
\text { Teaching Strategies } \\
\text { GOLD® supported the } \\
\text { work of the participants. }\end{array}$ \\
\hline $\begin{array}{l}\text { I realized that } \\
\text { [preschool] was just my } \\
\text { happy place and I loved } \\
\text { it. }\end{array}$ & $\begin{array}{l}\text { "[Teaching Strategies } \\
\text { GOLD®] contradicts } \\
\text { what I was taught (in } \\
\text { my early childhood } \\
\text { education courses) but } \\
\text { at the same time this is } \\
\text { what's required by my } \\
\text { job." }\end{array}$ & $\begin{array}{l}\text { "It kind of is telling } \\
\text { teachers what they } \\
\text { should be looking for } \\
\text { and that's all that } \\
\text { matters. That can really } \\
\text { narrow your view." }\end{array}$ & $\begin{array}{l}\text { "I don't need that kind } \\
\text { of system to do that. It is } \\
\text { just helpful sometimes } \\
\text { and can be an } \\
\text { authority." }\end{array}$ \\
\hline
\end{tabular}


It just fit and felt so right.

I just knew that preschool was always my thing.
I feel really passionate about supporting the children's social/emotional development. Being aware of how others feel, and promoting empathy is important to me. I want them to have positive feelings, good self-esteem, and confidence in social situations. Those are the things you need as an adult.
"I try not to let it affect what I do. I don't really care for it one way or the other, so I don't want it to influence what I'm doing."

I don't have time to let everyone to come up to the provocation on their own and see what happens. I need it to be now.

If I wasn't doing TSG, I would have been setting up an art exploration for the kids. Maybe it would have been openended, maybe it would have been teacherdirected. I miss art. It's just not in my day.
Doing something just to get a checkpoint is frustrating to me and I don't feel I need it. I feel as if I can plan and be intentional without Creative

Curriculum ${ }^{\circledR}$ or

Teaching Strategies

GOLD®. But then when I need to get information for a certain checkpoint that I don't have then I feel like I have to do these really specific things.

Now I am thinking about how to use all those Teaching Strategies GOLD® and Creative Curriculum $®$ tools as a way to train teachers or facilitate their learning as a teacher. I think it is interesting how TS GOLD® can be helpful when you are just learning but then become something like 'UGH!' when you know what you are doing.

I struggled at the Interrater Reliability but that just shows me that I'm not using the tool right. I'm working on it, but I find it extremely defeating. You know, you are scoring them, and you think you are scoring them well and then you take that, and you just think all of your documentation must be wrong.
Sometimes it's nice because I can tell a child, 'Oh wow, you are really using your hands and fingers to mold that clay'. Before I probably would have said something like 'Wow you are squishing that clay really hard'. 
When you have been working with them on something for so long, it's been tough, and then it clicks for them and there's that moment. Everybody has those things that they are struggling at. There are those moments when it clicks, and you are so excited for them and you just think, 'You worked so hard and I knew you could do it!'

There's this sense of wonder that everyone talks about and that's so real at the preschool age. Having a social/emotional foundation and focus is very important. That is how you set a lot of students up for success in academics, because that is what academics is when you are four. You have to trust the process and the rest will happen.
I have sat on so many interviews since I started this position and the really great ones, I just think, 'Oh my gosh, I want you, but you don't want to be here.' They have masters' degrees and all this experience, and I just think, 'This is amazing, but you are going to get burnt out on all the paperwork.'

"It's really tough to have those good teaching moments where I could work with just two or three children and really focus on what they are doing."

We are supposed to [create our lesson plans to fit the objectives]. Honestly, I don't do that because I feel like it is a waste of time.
With failing the Interrater Reliability test, I think I don't know what I am doing in documenting, writing down the right stuff.

"That is where [the center's] money comes from, hitting the checkpoints on time and getting the signatures that you did your parent-teacher conferences."

I feel like I really know my stuff. I have two degrees in education, but I was not succeeding in [the tests]. My coteacher failed every single category the first time she took it. We spent our entire week trying to pass the tests. 


\section{The participants work with children and what they deemed as valuable.}

Each of the participants self-identified as constructivist minded early childhood educators. The first question I asked the participants when beginning this research study was why they chose to work in early childhood education. Each of the participants' replies were closely associated with how much they enjoyed working with children. When I dug more deeply into their responses, I learned that their love of working with children was strongly connected to how they saw their professional selves. Supporting the children's social and emotional growth was a key aspect of the participants' work, and each considered this work as instrumental in a child's lifelong learning success. Additionally, each of the participants identified themselves as constructivist minded early childhood educators and believed learning happened through a series of meaning making and connections. The participants believed that listening to children and encouraging them to be curious, to ask questions, to explore, and to test theories was essential to the children building confidence in themselves and in developing a love of learning.

I was curious about how working with Teaching Strategies GOLD® affected the ways in which the participants worked with children. In doing this research, I discovered that the participants felt that the work they did to meet the requirements around using Teaching Strategies GOLD ${ }^{\circledR}$ was separate from the 'real work' they found valuable with young children. However, as checkpoint dates became closer, these two aspects of their work began to blend as each of the participants implemented structured learning experiences for the children that were focused on completing areas of their Teaching Strategies GOLD® reports. In the next section, I take a closer examination at the ways in 
which the participants' requirements around Teaching Strategies GOLD® effected the interactions they had with the children in their classrooms.

How working with Teaching Strategies GOLD® affected the ways in which the participants worked with children.

As I outlined in chapter two, there are 38 learning objectives found in the Teaching Strategies GOLD® system containing over 75 subcategories for children age 3 years and older. Each of the programs that participated in my research study had a set requirement of having four checkpoint sessions per year, which was about once every 1315 weeks, although the fourth checkpoint period was either extremely short or set over the summer. All three of the participants' classrooms contained 18 children. This meant even if the participants were connecting three of the subcategories to each piece of documentation, the participants and their co-teachers would need to submit about 450 pieces of documentation for each checkpoint period.

Although the time allotted for the participants to be with children and the time allotted for the participants to work on Teaching Strategies GOLD® varied greatly, time was a significant issue when it came to their work with Teaching Strategies GOLD®. Julia worked in a half day classroom, children arrived at 8:30 and left at noon. The rest of the day, about three hours each day, was dedicated for meetings, supporting the afternoon teacher if needed, working on her Teaching Strategies GOLD® and completing other tasks and reports required by the program. During the time the children were at school with Julia, they ate two meals, visited the restroom twice, had two circle times, and went outside for about 40 minutes. Julia felt the shorter day limited the time in which she could 
let the children explore freely and the built-in structure of her day set by her program limited how much autonomy she could allow the children. Julia wanted more open-ended time with the children and less time focusing on other work.

Cynthia had the most amount of time with children, but the least amount of time set aside to work on Teaching Strategies GOLD®. In her program, Cynthia was allotted two hours per week to plan for children's learning experiences and work on her Teaching Strategies GOLD® documentation and reports. If she needed additional time, Cynthia was expected to work on Teaching Strategies GOLD® during 'slow' times in the classroom such as nap time or when the number of children present was low. During Cynthia's observation, I noticed that she had sat away from the children and worked on her Teaching Strategies GOLD® while the Spanish language teacher was in the room.

Cynthia could not see getting out of her Teaching Strategies GOLD® responsibilities and tried to get them done as quickly as possible. She tried different approaches for meeting her Teaching Strategies GOLD® requirements but admitted that it wasn't always the best work. Cynthia wanted less Teaching Strategies GOLD® requirements overall.

Sasha's schedule was the most balanced in regard to time. Sasha was allotted two hours a day to work on Teaching Strategies GOLD ${ }^{\circledR}$ and plan for the children's learning experiences. One hour was in the morning, and the second hour was at the end of the day. Sasha was with the children from 9:00 AM to 3:00 PM each day. However, even with this balanced amount of time, Sasha struggled to record documentation in each of the 75 subcategories for each of the 18 children in her classroom for each checkpoint period. 
Although the balance of time available and/or required to work with Teaching Strategies GOLD® varied between the participants, the result was the same. Each of the participants saw their work with Teaching Strategies GOLD® as a task to accomplish and disconnected to what they considered to be the real work they did with children. Each wanted more open-ended time to work with the children. Sasha wanted to have authentic interactions with the children and tried to keep her responsibilities around Teaching Strategies GOLD® out of the classroom. The participants' thoughts and emotions were noticeable in my observations in their classrooms. Each of the participants seemed most at ease most as what they considered as their true professional selves when they were interacting with children and not focused on learning objectives and Teaching Strategies GOLD®.

Regardless of how they felt about Teaching Strategies GOLD® it was an expectation of each of the participants' employment to complete the checkpoints. Meeting these expectations consumed much of the participants' time, and the part of their professional development and support in the programs had become centered around helping educators complete their Teaching Strategies GOLD® reports. Time was built into the day for educators to be away from children to work on Teaching Strategies GOLD® giving them less opportunities to see learning happening organically. As checkpoint dates loomed, planning for the children's learning experiences became focused on implementing activities around what the educators needed to get their Teaching Strategies GOLD® reports complete, creating a cycle of task that took them away from the work that they loved (Figure 27). 

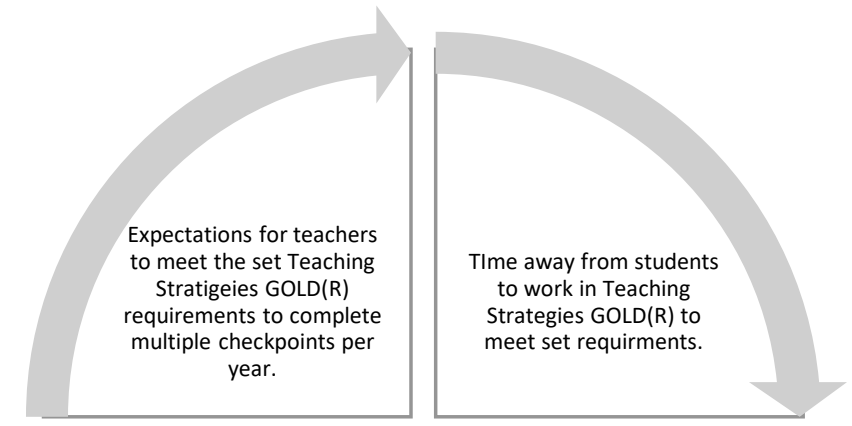

Educators implemented structured curriculum focused on learning objectives in order to complete Teaching Stragegies GOLD $(R)$ reports.

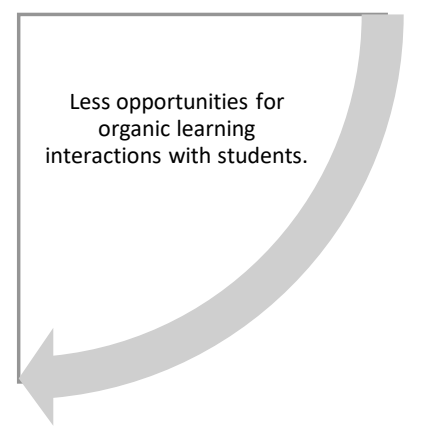

Figure 27: Cycle for completing Teaching Strategies GOLD ${ }^{\circledR}$.

These activities were implemented to meet the requirements of Teaching Strategies

GOLD ${ }^{\circledR}$, not to support the children's social/emotional growth, help the children build on a skill, increase their knowledge about a concept, follow the children's interest, and so on, aspects that the participants felt were valuable to their work as professionals and supported the children in their classrooms.

Each of the participants were required to use the Teaching Strategies GOLD® Family Conference forms and offer a conference with each child's family for two of the four checkpoint sessions. Completing the reports held different levels of justification for the participants. For Sasha, handing in signed copies of the Teaching Strategies GOLD® Family Conference forms was directly associated with the program receiving funding, Cynthia used the iPad to show parents her Teaching Strategies GOLD® documentation and photos during the conference but still printed the reports. For all three of the 
participants, completing the reports and using the data for family conference forms was a requirement of their employment.

The participants' requirements and experiences around Teaching Strategies GOLD® connected to the work of Apple (2009). Apple wrote about the implementation of structures in education and how often with new policies and requirements the intensification in the educator's workload outside of time spent with students increases. The workload became overwhelming to educators, leading them to conforming to practices and policies in which they did not believe. This was apparent not only in the ways in which the participants in my research study shifted the work they did with the children to complete their Teaching Strategies GOLD® reports, it was also apparent in the ways that the demands complete the Teaching Strategies GOLD® checkpoint reports had an effect on how they saw themselves as early childhood professionals.

For the participants, having the abilities and experience to support children in to be confident and enthusiastic learners was what defined them as early childhood education professionals. This definition of professionalism in early childhood education differed from how they felt others viewed what it meant to be an early childhood education professional in the midst of United States early childhood education policy creation. Conflicting attitudes regarding the value of positive early childhood education experiences and the devaluing of early childhood educators has created a space that leaves early childhood educators on the outside of the circle of policy creation for early childhood education programs (Ayers, 1989; Parnell, 2010). It is a precarious attitude that insinuates a perception that early childhood educators are "unworthy of serious 
attention" (Ayers, 1989, p. 3) and that those who create education policy know how children learn better than those who work with young children on a daily basis.

During our interactions together, each of the participants spoke about how this perception affected their work. Sasha mentioned that there is often a disconnect between what program administrators want done in the classroom and what educators understand is best for children. Cynthia discussed how there is also often a lack of communication between the corporation that heads the program where she works and the educators that work in the classroom.

The participants were aware of the contrast between how they considered themselves as professionals and how the greater society did not necessarily view them this way, but it did not seem to affect their perceptions of themselves. This was not, however, always the case when it came to the ways in which working with Teaching Strategies GOLD® affected their perceptions of themselves as early childhood education professionals.

The effects of Teaching Strategies GOLD ${ }^{\circledR}$ on the participants' perception of their professional self.

In the previous section, regarding the effects using Teaching Strategies GOLD® had on the way the participants worked with children, I demonstrated how entering documentation and completing the requirements for the Teaching Strategies GOLD® checkpoints absorbed much of the participants' time. Furthermore, I defined how each of the programs for which the participants worked had scheduled time for the participants to work on completing their Teaching Strategies GOLD® requirements away from the 
children. Additionally, I was curious about how being required to use Teaching Strategies GOLD® effected the participants' perception of their professional self.

For Cynthia and Julia, professional development provided by the programs where they worked centered around Teaching Strategies GOLD® with an emphasis of connecting the learning objectives to their planning, and tools to complete the Teaching Strategies GOLD® checkpoints and reports. This contributed to a shift in the professional development within the programs. The program where Julia worked as an early childhood educator set an expectation of using Teaching Strategies GOLD® to create lesson plans and support the educators' professional development.

Julia expressed concern about placing such importance on Teaching Strategies GOLD $®$ in her program. She stated, "It kind of is telling teachers what they should be looking for and that's all that matters. That can really narrow your view." (J., personal communication, August 16, 2018). Julia said that there is an expectation at her program to use the learning objectives in Teaching Strategies GOLD® to create lesson plans but it wasn't something she tended to do. When Julia became a supervisor at a similar program, she began to see how using the Creative Curriculum ${ }^{\circledR}$ along with the Teaching Strategies GOLD® learning objectives might be helpful in supporting new or inexperienced early childhood educators to learn how to see children's learning happening.

Cynthia also was encouraged to use the Teaching Strategies GOLD® learning objectives in her lesson plan. During the program's in-service days, at the beginning of the year, Cynthia attended professional development sessions around using Teaching Strategies GOLD®. Additionally, at the program where Cynthia works, they have created 
a position for a Teaching Strategies GOLD®/Creative Curriculum ${ }^{\circledR}$ support person who has worked in a preschool classroom using the on-line version of Teaching Strategies GOLD® for a year. Cynthia explained that she appreciates this person very much. The support person attends their planning meetings each week, is available to answer questions, helps coach teachers to learn how to use the Teaching Strategies GOLD® system, helps teachers learn how to pull, read, and utilize the reports that can be found in the Teaching Strategies GOLD® system, and makes sure that teachers are staying on track with entering observations.

The program where Sasha worked was different. Sasha's classroom was the first within the program to be part of the local municipally funded early childhood education programs and the first to be using Teaching Strategies GOLD®. She and her co-teacher had used Teaching Strategies GOLD® at a previous program and were considered the experts at it. The professional development around Teaching Strategies GOLD® where Sasha worked was just to let her know what the requirements were to continue to receive funding for her classroom.

I was not surprised about Julia's and Cynthia's experiences of having professional development provided by the programs be centered around how to use Teaching Strategies GOLD®. These experiences were similar to my own. Additionally, as I shared in chapter two, at the 2016 NAEYC National Conference I attended a session titled, "Helping teachers implement curriculum with fidelity by individualizing professional development and mentoring” (NAEYC, 2016, p. 87) led by Clarissa Martinez, Content Development Associate for Teaching Strategies GOLD®, and Breeyn Mack, Content and 
Community Manager at Teaching Strategies GOLD®. This session addressed the doctrine of how supervisors and mentor teachers can determine to what degree teachers were implementing curriculum the way the developer intended and how accurately and consistently teachers are delivering content (C. Martinez, personal communication, November 3, 2016). It also included coaching strategies in which supervisors and mentor teachers could support teachers to see what 'right' looks like and define the gaps in implementing curriculum with fidelity as objectivity (B. Mack, personal communication, November 3. 2016). According to Mack, these gaps could be addressed through professional development, professional learning opportunities, staff development, and individualized instruction for teachers.

When professional development and educational opportunities are focused on conforming to the policies and implementation procedures of PFPSA systems and boxed curriculum sets and standardized assessments, such as Teaching Strategies GOLD® and the Creative Curriculum ${ }^{\circledR}$, early childhood educators lose out on the opportunities to develop teaching ingenuity and professional development in areas in which they would like to gain new insight or support (Parnell, 2010). Instead they are forced to follow along, increasing the image that the early childhood educator is not good enough, smart enough, intuitive enough, or professional enough to understand how to work with young children. This perceived powerlessness is enough to dampen the spirits of many early childhood educators, leaving them overwhelmed by the intensification of work that does not follow their passion (Apple, 2009; Christakis, 2016; Parnell, 2010). 
One area in which the participants' professional development became focused on conforming to policies and the implementation of procedures was the Interrater Reliability Certification process. The Interrater Reliability Certification process is "An online certification process that gives you the opportunity to evaluate sample child portfolios and compare your ratings with those of Teaching Strategies' master raters" (Teaching Strategies® How-To Guide for Teachers, p. 1). All the participants were required by their place of practice to pass the Teaching Strategies GOLD® Interrater Reliability Certification process. The Interrater Reliability Certification process was designed to coach educators on how to analyze the work they were seeing the children do to fit within the Teaching Strategies GOLD® system. Although Teaching Strategies GOLD ${ }^{\circledR}$ states that the Interrater Reliability Certification process is "not designed to train you, or evaluate you as a teacher" educators need to agree $80 \%$ of the time with the "master ratings in each area of development and learning" in order to earn certification in each of the categories (Teaching Strategies GOLD® How to Guide for Teachers, 2018, p. 59).

The Interrater Reliability Certification process held different levels of weight for each of the participants. Cynthia admitted that she failed many of the certification tests on her first try. While struggling to pass the Interrater Reliability tests, Cynthia began to doubt the work she had been doing with children for almost twenty years.

Julia was also required to take and pass the Interrater Reliability certification process and struggled with two of the categories. She found it confusing that she failed the social/emotional test four times. Julia commented that she was looking at the 
examples provided by Teaching Strategies GOLD® in the testing and they were similar to what she would enter into the system, but she was not able to pass. Julia had learned that many of the teachers had not passed the tests the year before.

Cynthia also had commented that many of the teachers at her center were struggling with the Interrater Reliability certification, but no one was really talking about it. For Cynthia, failing the tests made her question how she was documenting the work she did with children. She continued to struggle with the certification process throughout our time together.

Sasha was the only participant not effected by the Interrater Reliability certification process. As examined in the data, Sasha had passed the tests the year before, and the center she was working at did not require her to re-do the testing. For Sasha, completing the tests was just another task to be completed.

\section{The ways in which Teaching Strategies GOLD® supported the work of the}

\section{participants.}

When beginning this research study, I was curious if there were ways in which Teaching Strategies GOLD® was helpful in the work that the participants were doing with young children. The responses of the participants varied greatly in this aspect of my research. Yet, as I sorted through our conversations together, I could see patterns in which using Teaching Strategies GOLD® was or could be helpful for early childhood educators.

The first of the areas in which Teaching Strategies GOLD® was helpful to the participants was connected to the perception of professionalism. As I detailed in chapter 
two, and further explored with the participants in chapter four, the definition of what it means to be an early childhood education professional can differ broadly between those who work in the classroom, those who create policy in the field, and those who are not connected, or very loosely connected to the field at all. Each of the participants expressed that using Teaching Strategies GOLD® gave them a sense of authority when working with parents.

Julia spoke about how using the reports in Teaching Strategies GOLD® validated what she knows about the child when speaking with parents. Sasha commented about how she is able to use the Teaching Strategies GOLD® reports to advocate for children having the right to play. Cynthia found the perception of authority that Teaching Strategies GOLD® provided helpful in the ways in which she could connect her documentation to the Parent Conference forms.

Sasha found that the language in Teaching Strategies GOLD® enhanced the way she worked with children, she spoke of how she was using the language in the Teaching Strategies GOLD® learning objectives to expand on her reflections with the children:

Sometimes it's nice because I can tell a child, 'Oh wow, you are really using your hands and fingers to mold that clay'. Before I probably would have said something like 'Wow you are squishing that clay really hard'. (S., personal communication, January 18, 2019)

She believed that by using this language she is giving the children the opportunity to think more purposefully about what they are doing.

As a supervisor overseeing many inexperienced and new early childhood educators in her program, Julia felt that there were ways in which using Teaching Strategies GOLD® and the Creative Curriculum ${ }^{\circledR}$ could help her staff to better 
understand the ways in which young children learn. Julia could find value in using Teaching Strategies GOLD® but still did not believe in using an assessment to plan for children's learning and explorations. However, at the time she felt she really did not have any other option.

As an experienced early childhood educator, Cynthia found it difficult to recognize Teaching Strategies GOLD® as being helpful. She struggled with the ways in which the system classified children's learning experiences and with manipulating her observations and documentation to fit within the language of the system. However, she did appreciate having the Parent Conference form easily accessible during her conferences on the i-Pad and being able to enter the goals for the children with the parents during her conferences.

\section{Connecting the Puzzle Pieces}

There were two main areas that stood out as I worked with the participants to assemble my research puzzle. The larger areas that dominated the puzzle space were the time needed to complete Teaching Strategies GOLD® and the perception of the early childhood education professional. Each of these areas were equally important in my findings and each manipulated and altered the other as time away to work on Teaching Strategies GOLD® changed the amount and length of open-ended time the participants could spend with children.

For the participants, their image of being an early childhood professional was directly connected to the time they spent with children and supporting children's development and growth. Their view of their professional self was connected deeply to 
their respect for the children and the relationships that blossomed within the classroom. They each believed deeply in supporting children's social and emotional growth and following the interests of the children to develop curriculum and explorations.

The participants' image of themselves as early childhood professionals collided with the perception of the early childhood education professional commonly held in the United States and being supported by the way the Teaching Strategies GOLD® was used in their programs. As I stated in chapter two, in the United States, it is commonly believed that the educator is seen as a giver of knowledge (Apple 2009; Eisner, 1985; Freire, 2003; Parnell, 2010). This perception has influenced United States educational policy for decades. Yet, even as the public educational policies that have been implemented into United States schools place the educator in the role as a giver of knowledge, they also demonstrate a belief that educators need to be told what knowledge to bestow and how to bestow that knowledge to students (Apple, 2009; Eisner, 1985; Freire, 2003; Hess \& McShane, 2013; Kohn, 2000). Eisner (1985) outlines this process as the belief from policy creators of school being a place where common goals must be stated, much like a business. He suggests that the tasks of politicians and administrators is to define and articulate those goals, breaking them down into units and creating procedures to help teachers achieve the goals. To make sure teachers follow these procedures, monitoring systems, such as standardized testing, need to be implemented. This process of controlling the curriculum and how it is implemented not only controls teachers, but also controls the children in their classrooms. 
The process in which children and educators are controlled through policy and required procedure as described by Eisner (1985) is demonstrated in how the perception of the early childhood educators as professionals became redefined in the programs where they worked by Teaching Strategies GOLD®. The recommendations of Teaching Strategies GOLD® to complete four assessment checkpoints a year, which each of the programs followed, altered the way time was distributed for each of the participants. Time entering documentation into the system became a priority within the programs, often replacing or blending into the time they spent with children. The focus on the Teaching Strategies GOLD® learning objectives altered how the participants worked with the children in their classroom. Each of the participants confessed to implementing structured curriculum to meet Teaching Strategies GOLD® criteria when checkpoint dates were nearing:

Deadlines came down and I am doing everything based around the [Teaching Strategies GOLD®] system and the checkpoints, that business is ruling my class right now. It is why I am doing all these activities and that feels really weird, especially at the beginning of the year because it is the opposite of what I want to be doing. (J. personal communication, October 29. 2018)

As I get closer to my checkpoints, I start doing group documentation to try and knock out 21B for five of my primaries. I just do the activity and then it's something, I can say [in the parent conference] 'yeah your kid can do ABC' but is this documentation valuable to parents? I don't know. (C. personal communication, November 6, 2018)

Because of the policy to have documentation connected to each of the learning objective subcategories, making sure the reports were complete became more important than the documentation itself. 
Connecting the larger areas of my research puzzle were two complex yet compelling aspects. I describe these aspects as complex, because although technically they were not within the original scope of my research puzzle, they came into conversations with each of the participants. I describe them as compelling because each could have had an influence on the participant's responses to Teaching Strategies GOLD®. The first of these aspects included the extensive array of early childhood programs. Each of the programs that participated in this study were vastly different from the others, yet were similar in how the programs followed recommendations set by Teaching Strategies GOLD®. Additionally, each of the programs were at least partially funded in connection to the completion of the Teaching Strategies GOLD® reports through city, state, and/or federal funding. This meant that the participants within the programs did not have a choice of whether or not they wanted or needed to use Teaching Strategies GOLD® and connecting the system to funding gave it an ample amount of power over the ways in which the system has been used within the program.

The second aspect was the different levels of experience and education held by early childhood educators. Each of the participants in my research study were required to have had a minimum of five years of experience working with young children. According to Katz (1972), early childhood educators working five or more years in the field are at a place where they begin to look for more meaningful insight about what it means to be an early childhood educator, their philosophical roots, and are ready to seek out the opportunities for more diverse professional development. This level of security in themselves as early childhood professionals affected the ways in which they perceived 
using Teaching Strategies GOLD® and each touched on how they could understand that using the Teaching Strategies GOLD® and Creative Curriculum® systems would be helpful for new or inexperienced early childhood educators. It would be beneficial to explore the effects that being required to use Teaching Strategies GOLD® would have with new or inexperienced early childhood educators.

Originally created as a system to assess where young children may need additional support, the way in which Teaching Strategies GOLD® is being implemented into early childhood programs is now dictating how and what early childhood educators should be doing in the classroom. The effects of this mandate risk excluding culturally responsive practices, emergent curricular experiences, and creative and innovative teaching and learning. This finding is comparable to the findings discovered by Shultz (2015) that I explored in chapter two. Shultz suggests that when using a PFPSA system, early childhood educators' interpretations of observations are often altered during the process of data collection and analysis to fit within the set learning areas, objectives, categories, and subcategories outlined by the system. Schultz researched the use of two different PFPSA systems, Early Excellence and Learning Stories. Conducted in 18 kindergarten groups over a period of 15 working days each, Shultz also examined "the idea of the homogeneity of the 'learning child' and the related assumption that the learning child is always observed and documented in the same way" (p. 210).

After analyzing over 800 pages of data Shultz concluded that "the documented object - the children's learning - is subject to a continuous transformative reworking in a contextually bound and situationally produced interplay of documents, actors, and 
practices" (p. 216). Or in other words, as the documentation is transferred from the original recording by the early childhood educator to the final categorization within the assessment system, it is changed and transformed to fit within that system until it is not an accurate reflection of the child's learning "but of the child within the context of the institution" (p. 215). Additionally, the structures of Teaching Strategies GOLD® seem to be implying to early childhood educators that there is a generically defined image of a what a well-developed child should be and how that child should behave.

The way Teaching Strategies GOLD® is being implemented into early childhood programs is leading us down a pathway that strays dangerously close to a system in which children's learning experiences are directly connected to the assessment. As Sasha described, "It feels like it almost forces you to use the curriculum. If you don't then you are going to be lacking in a lot of the (checkpoint) areas." (S., personal communication, November 6, 2018). When curriculum and learning experiences are focused on reducing a child's learning process to a series of checkpoints and learning objectives to obtain, we move the focus away from the process of the learning to looking only on the 'next step' to achieve (Feeney, 2016; Shultz, 2015). We lose the opportunity to support children's critical thinking and problem-solving skills in our efforts to move them along to the next level of achievement.

\section{Rethinking a Reductionist View of Assessment in Early Childhood Education}

When I completed the research collection and interpretation process, I found myself at a fork in the road towards multiple pathways. Seeing the ways in which the implementation of Teaching Strategies GOLD® was keeping the participants away from 
the work they loved and was changing the work they did in the classroom was incredibly discouraging. Knowing from my research that the Teaching Strategies GOLD® system was just another version of the dominant educational discourses that quantitative, rubric style checklists in education are the most reliable way to demonstrate learning accountability through measurement, frustrated me. However, I could not reject the conversations I had with the participants about the ways in which Teaching Strategies GOLD® might help new or inexperienced teachers see how children learn through play. I wondered how, if the system was implemented differently, it could be used as a tool to support teachers. Yet in the end, I found myself thinking about the children I had met in each of the classrooms while conducting my research, as well as the many children that had been in my own classrooms in the past, and how any version of using Teaching Strategies GOLD® diminished their stories and silenced their voices.

The pitfalls of using Teaching Strategies GOLD® have been clearly demonstrated in this inquiry, most notably that it reduces the process of children's learning into generic steps of progression. I now push outside the boarders of my research puzzle, to look beyond the idea that a reductionist view of children's learning should carry more weight than one that amplifies and celebrates the process of children's learning (Figure 28). Around the world, we are seeing approaches to early childhood education that amplify children's voices and celebrates their learning journeys. Three of these approaches are the Te Whāriki framework being used in Aortearoa/New Zealand (Carr 2005; Fleet, 2006; Ministry of Education, 2017), the Angi Play approach coming out if the Zhejiang Province in China (Coffino and Bailey, 2019), and the Reggio Emilia approach inspired 
by the municipally funded infant/toddler centers and pre-primary schools of Reggio

Emilia, Italy (Edwards, Gandini, \& Forman, 2012). Each of these approaches to early childhood education encompasses a desire to empower children by giving them opportunities to take a leading role in their learning journeys and by having children be active participants in the process of curriculum development and documentation.

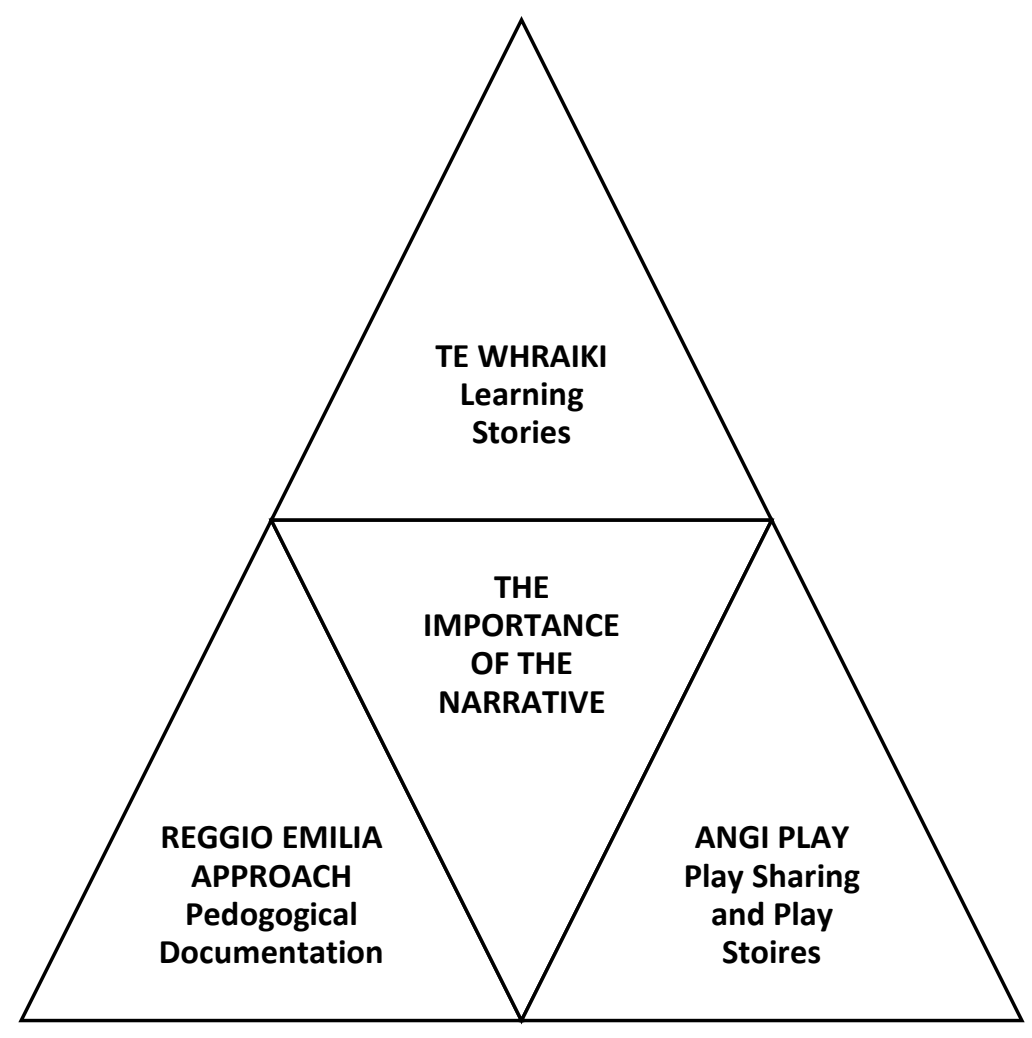

Figure 28: The importance of the narrative.

It would take an additional dissertation, or three, to fully describe these early childhood education approaches. Instead of going into deep detail, I briefly highlight some of the values, found within each of the approaches that connect with the participants' beliefs about how children learn. In the next few paragraphs I focus specifically on how educators practicing each approach support children's social and emotional growth, listen and encourage children's critical thinking skills, and support 
children as they develop a love for learning. Additionally, I will demonstrate how each approach empowers children as participants in the creation and documentation of their learning journeys and further paths of inquiry.

The Te Whāriki framework was developed in New Zealand with the intention of creating guidelines for early childhood education practice that was both inclusive and empowering (Ministry of Education, 2017). It is based in a belief that "each child is on a unique journey" and "comes into our world eager to learn and into a family, whānau or áiga that have high hopes for them" (p. 6) The Te Whāriki framework has an obligation for protecting the indigenous Māori culture and language. There are four main principals in the Te Whāriki framework, these include empowerment, holistic development, family and community, and relationships. Each of these principals supports children's social and emotional development within the community and the school, safeguarding that Māori children can revel in education as Māori.

Assessment in the Te Whāriki framework is formative and focuses on "creating a shared picture of each child in order to be able to plan for further learning experiences" (Fleet, 2006). This is done by creating shared places of dialog through Learning Stories. Carr, (2005) describes Learning Stories stating, "Learning Stories are framed around learning dispositions-in-action of the kind that make up learning and narratives and makes sense to teachers and families: taking an interest, being involved, persisting with difficulty, expressing ideas and feelings, and taking responsibilities” (p. 47). Learning Stories can be written by the child, teacher, or family. In Learning Stories, one learning experience may be interpreted many different ways. Each interpretation is given value 
and "contributes to the construction of a shared picture of the learning that occurs" (Fleet, 2006, p. 84) leading to possible future areas of inquiry. Sharing Learning Stories gives children, teachers, and families the opportunity to learn through listening to and recognizing other's perspectives, thinking critically about their own experiences, and foster meaningful connections through people, places, and things. It can inspire and support a love of learning and investigation. Learning Stories "widen the community of learners that is constructing self-making narratives" (Carr, 2005, p. 47) and give children and families encouragement to engage in assessment through the writing and telling of their stories.

The Angi Play approach is an early childhood education philosophy and approach that has been created to allow for the ideal conditions for children's play. With a commitment to understand the true meaning of play, the creator Cheng Xuequin and her colleagues, reflected on their own memories of play, interviewed parents and grandparents about their memories of play, and documented the children in their classrooms at play (Coffino and Bailey, 2019). In Angi Play preschools, children engage in "True Play" meaning play "that comes from the child" (p. 6). The role of the teacher is to be an observer and a "student of the children's masterful play" (p. 6). In testing this approach, teachers gave children the opportunity to determine risks, negotiate conflict, and follow their own path of inquiry, which led to the teachers noticing the children's ability to solve complicated problems, demonstrate compassion, and show empathy. Angi Play teachers capture children's play through video and photos. They practice a "hands down, mouths shut, ears and eyes open" method of allowing children to 
be the leaders of their own play and interest (Coffino and Bailey, 2019, p. 6). At the end of each day, children and teachers typically gather together in their classroom to share the videos and photos of the children through Play Sharing. Play Sharing includes giving the children the opportunity to talk about what they were doing and why they were doing it. Children also create daily Play Stories in which they draw pictures of their play and then either write or dictate the story to their teacher. The Play Stories are collected to create a deeply detailed record of the child's learning, development, and inquiry. The children's development in numeracy, early writing, language, and inventive spelling skills become apparent through the collection of the Play Stories. Initially extremely objecting the "risks, dirt, and lack of explicit academic instruction" of the Angi Play school, parents were "shocked to see the developmental milestones met and exceeded by their children in play" in comparison to the nationally sanctioned standards (p. 8). Parents became strong supporters of the Angi Play approach once they observed the approach in action and saw how the process of initiating, experimenting, remembering, reflecting, questioning, commenting, and documenting their play helped children learn from their experiences.

In the municipally funded preprimary schools and infant and toddler centers of Reggio Emilia, Italy, children are considered full citizens of the community. The role of the early childhood educator is not as one who bestows knowledge, but a partner in learning (Cadwell, 1997, 2002; Edwards, 2012; Gandini, 2012; Rinaldi, 2012). Teachers listen with full attentiveness to children (Edwards, 2012). Conversations happen between children, educators, parents, and the community through the process and with the support of pedagogical documentation (Cadwell, 1997, 2002; Forman \& Fyfe, 
2012; Parnell, 2011a; Rinaldi, 2001a, 2001b, 2012). Pedagogical documentation is the process of creating, revisiting, reflecting and making meaning of experiences with children as an ongoing process of learning (Cadwell, 1997, 2002; Forman \& Fyfe, 2012; Fleet et al., 2006; Rinaldi, 2001a, 2001b, 2012; Rintakorpi \& Reunamo, 2016). Through pedagogical documentation, children are encouraged to question, wonder, and experiment, working with each other, early childhood educators, parents, and other community members to develop their own theories about life and the world around them.

Each of these approaches have similar values to those held by the participants in my research study, and each requires a level of connection and commitment to children that the participants demonstrated throughout our time together. It is a level of commitment that goes beyond completing checklists and implementing generic curriculum. With commitment comes huge benefits. For educators, it offers the opportunities to learn more about the children in their care as well as grow a better understanding for how children learn. For children this commitment offers opportunities for autonomy in learning, to build confidence in themselves as investigators, and to see themselves as problem solvers. For everyone this commitment offers the opportunity to be seen, to be heard, and to be valued.

The importance of being seen, heard, and valued cannot be understated, and is apparent through the process of this research study and the use of narrative inquiry. When designing this study, I could have easily created a survey and blasted it out to multiple agencies and educators then crunched anonymous data into colorful charts, and that could 
prove important and a different kind of research and set of questions than what surfaced here.

Instead, for my research study, it was important to me to find a way to amplify the voices of the participants, early childhood educators required to use Teaching Strategies GOLD®, and share their experiences. The methodology cycle I used in this study paralleled pedagogical documentation through a process for understanding and being understood. Each time I met with the participants I had a deeper understanding of their experiences than I did before. Each of our interactions together gave them the opportunity to be seen, heard, and valued. However, it was the relationships that we built through narrative inquiry that created a level of trust in which the participants were comfortable at sharing their experiences and showed the true implications that implementing the Teaching Strategies GOLD® assessment system has on educators and children.

\section{Final Thoughts and Future Research Interests}

Through the process of conducting this research study, I had the opportunity to walk alongside three incredible early childhood education professionals as they negotiated their way through the requirement of using the Teaching Strategies GOLD® assessment system. Along the way, each expressed joy, frustration, and courage in the work they do with children and the seemingly powerlessness that their positions hold. There were times that I feared two of them would become so defeated by the requirements of their job outside of the work that they loved that they would leave the system entirely, yet they continued to persevere. 
Throughout my conversations with the participants, each of them mentioned how they could see ways in which Teaching Strategies GOLD® could be helpful for early childhood educators that are new to the field or have little education in the area of young children. Each of the participants in my research study had worked in the field for a minimum of five years, none of the participants were new to the field. I wonder how and if the results may have differed if the participants included new or inexperienced early childhood educators. One area for future research would be to replicate this study but with participants that are new to the field and compare the results between the two.

Additionally, as I demonstrated throughout this chapter, my research has exposed concerns associated with implementing the Teaching Strategies GOLD® assessment system into early childhood education programs. Many of these concerns are a consequence of the system itself, yet each of these concerns connect to larger issues of the perception of the early childhood education professional and the power dynamics of the creation of United States' early childhood policy creation.

These larger issues are outside of the context of this research study, but I find myself inspired to research ways in which we can support the future and development of early childhood education professionals in Oregon. I wonder how we can create mentoring structures within early childhood education programs in which each classroom team consisted of early childhood educators at different levels of experience and/or education, each working in partnerships with local higher education programs in their professional development. I wonder too, how we can elevate the perception of early 
childhood educators and value the work they do with children each day, giving them voice in the creation of early childhood education policy.

The purpose of this research was to explore the experiences of self-identified constructivist early childhood educators who were required to use Teaching Strategies GOLD®. In this study I have amplified the voices of my participants and have demonstrated the commitment and knowledge that each of them hold to their field. Further, as their voices become more prominent, I hope they are shown the recognition they deserve as professionals and given the power to shape and change the field of early childhood education for the better. I am deeply grateful for their time, laughter, tears, and honesty. I leave this research study inspired and encouraged, knowing that they were just three among the many amazing early childhood educators out there. 


\section{References:}

Alvesson, M., \& Sköldberg, K. (2017). Reflexive methodology: New vistas for qualitative research. Sage. doi: 10.1111/j.1365-2648.2001.0435d.x.

Apple, M.W. (2009) Controlling the work of educators. In Flinders, D. J., \& Thornton, S. (Eds.), The curriculum studies reader (pp.199-210). New York, New York. Routledge.

Ayers, W. (1989). The good preschool teacher: Six teachers reflect on their lives. New York, NY: Teachers College Press.

Bassok, D., Latham, S., \& Rorem, A. (2016). Is Kindergarten the New First Grade?. AERA Open, 2(1), doi: 10.1177/2332858415616358.

Bergen, D., \& Woodin, M. (2017). Brain Research and Childhood Education: Implications for Educators, Parents, and Society. New York, New York: Routledge.

Bodrova, E., \& Leong, D. J. (2005). Uniquely preschool. Educational Leadership, 63(1), 44.

Bodrova, E. (2008). Make-believe play versus academic skills: A Vygotskian approach to today's dilemma of early childhood education. European Early Childhood Education Research Journal, 16(3), 357-369. doi: 10.1080/13502930802291777.

Bodrova, E., Germeroth, C., \& Leong, D. J. (2013). Play and self-regulation: Lessons from Vygotsky. American Journal of Play, 6(1), 111. 
Brown, D. T. (2016). Here's the biggest flaw with common core. The Education Digest, $82(3), 55$.

Burr, V. (2015). Social constructionism. New York, New York: Routledge.

Cadwell, L. B. (1997). Bringing Reggio Emilia home: An innovative approach to early childhood education. Teachers College Press.

Cadwell, L. B. (2002). Bringing learning to life: The Reggio approach to early childhood education (Vol. 86). Teachers College Press.

Cagliarri, P. (2015, March). Promoting the rights and potentials of children. In the North American Reggio Emilia Study Tour. Reggio Emilia, Italy.

Carr, M. (2005). The Leading Edge of Learning: Recognizing Children's Self-Making Narratives. European Early Childhood Education Research Journal,13(2), 41-50.

Chaillé, C. (2008). Constructivism across the curriculum in early childhood classrooms: Big ideas as inspiration. Allyn \& Bacon.

Christakis, E. (2016) The importance of being little: What preschoolers really need from grownups. Penguin Random House LLC. New York, New York.

Clandinin, D. J. (Ed.). (2007). Handbook of narrative inquiry: Mapping a methodology. Sage Publications.

Clandinin, J. (2013). Engaging in narrative inquiry. New York, NY: Taylor \& Francis.

Clandinin, J. Connelly, M. (2000). Narrative Inquiry: Experience and Story in Qualitative Research. San Francisco, CA: Jossy-Bass.

Coffino, J., \& Bailey, C. (2019). The Anji Play ecology of early learning. Childhood Education, 95(1), 3-9. 
ECE EXPERIENCES WORKING WITH TEACHING STRATEGIES GOLD ${ }^{\circledR}$

Coles, R. (1989). The call of stories: Teaching and the moral imagination. Houghton Mifflin Harcourt.

Creswell, J. W. (2008). Educational research: Planning, conducting and evaluating quantitative and qualitative research. Pearson Education. Upper Saddle River, New Jersey.

Creswell, J. W. (2014). Research design: Qualitative, quantitative, and mixed methods approaches $4^{\text {th }}$ Edition. Sage publications.

Cross, C. T. (2014). The Reagan years: The bully pulpit and loosening strings. In Political Education: Setting the Course for State and Federal Policy (Second). New York, New York: Teachers College Press.

Dahlberg, G. (2012). Pedagogical documentation: A practice of negotiation and democracy. In C. Edwards, L, Gandini, and G. Forman (Eds.), The Hundred Languages of Children, the Reggio Emilia Experience in Transformation, Third Edition (pp. 225-231). Santa Barbara, CA: Praeger.

Dahlberg, G., Moss, P., \& Pence, A. R. (1999). Beyond quality in early childhood education and care: Postmodern perspectives. Psychology Press.

Dee, T. S., \& Jacob, B. (2011). The impact of No Child Left Behind on student achievement. http://doi.org/10.1002/pam.20586.

Delrio, G. (2012). Our responsibility toward young children and toward their community. In C. Edwards, L, Gandini, and G. Forman (Eds.), The hundred languages of children, the Reggio Emilia experience in transformation, Third Edition (pp. 8188). Santa Barbara, CA: Praeger. 
DeVries, R. (1997). Piaget's social theory. Educational Researcher, 26(2), 4-17.

DeVries, R. (2000). Vygotsky, Piaget, and education: A reciprocal assimilation of theories and educational practices. New ideas in Psychology, 18(2), 187-213. doi: 10.1016/S0732-118X(00)00008-8.

DeVries, R. (2004). Why the child's construction of relationships is fundamentally important to constructivist educators. Prospects, 34(4), 411-422. doi: $10.1007 / \mathrm{s} 11125-005-2713-6$.

DeVries, R., Zan, B., Hildebrandt, C., Edmiaston, R., \& Sales, C. (2002). Developing constructivist early childhood curriculum: Practical principles and activities. Early childhood education series. Teachers College Press, PO Box 20, Williston, VT 05495-0020.

Dewey, J. (1938). Experience and education. New York.

Duncan, G. J., Dowsett, C. J., Claessens, A., Magnuson, K., Huston, A. C., Klebanov, P., ... \& Sexton, H. (2007). School readiness and later achievement. Developmental psychology, 43(6), 1428.

Edwards, C. (2012). Educator and learner, partner and guide: The role of the educator. In C. Edwards, L, Gandini, and G. Forman (Eds.), The hundred languages of children, the Reggio Emilia experience in transformation, Third Edition (pp. 147172). Santa Barbara, CA: Praeger.

Egan, K., \& McEwan, H. (Eds.). (1995). Narrative in teaching, learning, and research. Teachers College Press. Mishler, E.G. (1986). Research Interviewing. President and Fellows of Harvard College. 
Eisner, E. W. (1985). The educational imagination (p. 176). New York: Macmillan.

Etherington, K. (2013). Narrative approaches to case studies. Last accessed, 30.

Fact Sheet President Obama's Plan for Early Education for all Americans. (n.d.).

Retrieved: October 14, 2015, from https://www.whitehouse.gov/the-pressoffice/2013/02/13/fact-sheet-president-obama-s-plan-early-education-allamericans.

Feeney, S. (2016). DEY: Straight talk about kindergarten readiness assessment. Retrieved from: https://deyproject.org/2016/03/17/dey-releases-straight-talkabout-kindergarten-readiness-assessment/.

Fleet, A., Patterson, C., \& Robertson, J. (2006). Insights: Behind early childhood pedagogical documentation. Castle Hill, New South Wales. Pademelon.

Forman, G. E., \& Hill, F. (1984). Constructive play: Applying Piaget in the preschool. Addison Wesley.

Forman, G., Fyfe, B. (2012). Negotiated learning through design, documentation, and discourse. In C. Edwards, L, Gandini, and G. Forman (Eds.), The hundred languages of children, the Reggio Emilia experience in transformation, third edition (pp. 247-271). Santa Barbara, CA: Praeger.

Forman, G. (2005). The project approach in Reggio Emilia. In C. Fosnot (Ed.), Constructivism: theory, perspectives, and practice, second edition (pp. 212-221). Educators College Press.

Fosnot, C. T. (2005). Constructivism: Theory, perspectives, and practice. Educators College Press. 
Freire, P. (2003). Pedagogy of the oppressed. New York, NY: Continuum.

Fyfe, B. (2012). The relationship between documentation and assessment. In C. Edwards, L, Gandini, and G. Forman (Eds.), The hundred languages of children, the Reggio Emilia experience in transformation, third edition (pp. 273-291). Santa Barbara, CA: Praeger.

Gandini, L. (1993). Fundamentals of the Reggio Emilia approach to early childhood education. Young Children, 49(1), 4-8.

Gandini, L. (2001). Two Reflections About Documentation. In L. Gandini, \& C. P. Edwards, (Eds.), Bambini: The Italian approach to infant/toddler care (pp.124145). Teachers College Press.

Gandini, L. (2012). History, Ideas, and Basic Principles: An Interview with Loris Malaguzzi. In C. Edwards, L, Gandini, and G. Forman (Eds.), The Hundred Languages of Children, the Reggio Emilia Experience in Transformation, Third Edition (pp. 27-71). Santa Barbara, CA: Praeger.

Geertz, Clifford. (1995). Disciplines. (anthropology). Raritan: A Quarterly Review,14(3), 65.

Gilbert, C. (2014). A call for subterfuge: Shielding the ELA classroom from the restrictive sway of the Common Core. English Journal, 104(2), 27.

Gilbert, J. L. (2001). Getting Help from Erikson, Piaget, and Vygotsky: Developing Infant Toddler Curriculum. The Annual Meeting of The Association for Childhood Education International Conference and Exhibition. Toronto, Canada.

Gilligan, C. (1982). In a different voice. Harvard University Press. 
Giudici, C., Rinaldi, C., \& Krechevsky, M. (2001). Making learning visible: Children as individual and group learners. Cambridge, MA: Project Zero, Harvard Graduate School of Education.

Glesne, C. (2016). Becoming qualitative researchers: An introduction. Pearson Education. New York, New York.

Goldhaber, J. (2001). Two Reflections About Documentation. In L. Gandini, \& C. P. Edwards, (Eds.), Bambini: The Italian approach to infant/toddler care (pp.124145). Teachers College Press.

Goldstein, J., \& Flake, J. K. (2015). Towards a framework for the validation of early childhood assessment systems. Educational Assessment, Evaluation and Accountability, 28(3), 273-293.

Greene, M. (1978). Landscapes of learning.

Guba, E. G., \& Lincoln, Y. S. (2005). Paradigmatic Controversies. Contradictions, and.

Hess, F. M., McShane, M. Q. (2013). Common Core in the real world. Phi Delta Kappan, 95(3), 61-66.

Hursh, D. (2007). Assessing No Child Left Behind and the rise of neoliberal education policies. American educational research journal, 44(3), 493-518.

Jennings, L. E., \& Graham, A. P. (1996). Postmodern perspectives and action research: reflecting on the possibilities.

Josselson, R. (2006). Narrative research and the challenge of accumulating knowledge. Narrative inquiry, 16(1), 3-10. 
Kamii, C. (1991). Toward autonomy: The importance of critical thinking and choice making. School Psychology Review.

Kanno, Y. (1997). Researcher-Participant Relationship in Narrative Inquiry.

Katz, L. G. (1972). Developmental stages of preschool educators. The Elementary School Journal, 73(1), 50-54.

Katz, L. G. (2000). Curriculum disputes in early childhood education. DOCUMENT RESUME, 3.

Kim, D. H., Lambert, R. G., \& Burts, D. C. (2013a). Evidence of the validity of Teaching Strategies GOLD® assessment tool for English language learners and children with disabilities. Early Education \& Development, 24(4), 574-595.

Kim, D. H., Lambert, R. G., \& Burts, D. C. (2013b). Validating a developmental scale for young children using the Rasch model: applicability of the teaching strategies GOLD assessment system. Journal of applied measurement, 15(4), 405-421.

Kohn, A. (2000). The case against standardized testing: Raising the scores, ruining the schools. Heinemann Portsmouth, NH.

Krathwohl, D. R. (2009). Methods of educational and social science research: An integrated approach. Longman/Addison Wesley Longman.

Lambert, R. G., Kim, D. H., \& Burts, D. C. (2014). Using educator ratings to track the growth and development of young children using the Teaching Strategies GOLD® assessment system. Journal of Psychoeducational Assessment, 32(1), 27-39. 
Lambert, R. G., Kim, D. H., \& Burts, D. C. (2015). The measurement properties of the Teaching Strategies GOLD® assessment system. Early Childhood Research Quarterly, 33, 49-63.

Leong, D. J., \& Bodrova, E. (2006). Developing self-regulation: The Vygotskian view. Academic Exchange Quarterly, 10(4), 33-38.

Leong, D. J., \& Bodrova, E. (2012). Assessing and scaffolding: Make-believe play. YC Young Children, 67(1), 28.

Logue, M. E. (2007). Early childhood learning standards: Tools for promoting social and academic success in kindergarten. Children \& Schools, 29(1), 35-43.

MacDonald, M. (2007). Toward formative assessment: The use of pedagogical documentation in elementary classrooms. Early Childhood Research Quarterly, 22(2), 232-242.

Mack, B. (2016. November). Helping teachers implement curriculum with fidelity by individualizing professional development and mentoring. NAEYC National Conference, Los Angeles, CA.

Margini, D. (2015, March). Opening Conversation. In The North American Reggio Emilia Study Tour. Reggio Emilia, Italy.

Martinez, C. (2016. November). Helping teachers implement curriculum with fidelity by individualizing professional development and mentoring. NAEYC National Conference, Los Angeles, CA.

Maxwell, J. A. (2012). Qualitative research design: An interactive approach: An interactive approach. Sage. 
McClelland, M., \& Squires, J. (2012). Kindergarten Assessment Summary Report.

McMullen, C., \& Braithwaite, I. (2013). Narrative inquiry and the study of collaborative branding activity. Electronic Journal of Business Research Methods, 11(2), 92.

Mealman, C. A., \& Lawrence, R. L. (2002). Reflective Synergy: A Research Model for Collaborative Inquiry.

Mishler, Elliot G. "The analysis of interview-narratives." (1986).

Mooney, C. (2000). Theories of Childhood, An Introduction to Dewey, Montessori, Erickson, Piaget and Vygotsky. St Paul, Minnesota: Redleaf Press.

Moran, M. J. (2007). Collaborative action research and project work: Promising practices for developing collaborative inquiry among early childhood preservice teachers. Teaching and Teacher Education, 23(4), 418-431.

Morrison, G. S. (2007). Early Childhood Education Today. Upper Saddle River, NJ: Pearson Education.

National Association for the Education of Young Children. (2002). Early Learning Standards Position Statement. Washington, DC: Author.

National Association for the Education of Young Children. (2016). 2016 Annual Conference Program. Washington, DC: Author.

New Zealand Ministry of Education. (2018). Te Whāriki Online. Retrieved from: https://tewhariki.tki.org.nz/.

Noddings, N. (1985). Fidelity in teaching, teacher education, and research for teaching. Harvard educational review, 56(4), 496-511. 
Oregon Department of Education. (2011) Early Childhood and Family Investment Transition Team. (2011). The Early Childhood Family Investment Transition Report. Multnomah County, Oregon.

Oregon Department of Education. (2015a) 581-022-0102 Definitions. January 2015. Retrieved from: http://www.ode.state.or.us/superintendent/priorities/instructionaltime-attachment---draft-oar-581-022-0102---january-22-2015.pdf.

Oregon Department of Education. (2015b) Kindergarten Content and Assessment Advisory Committee Outcomes, 2015, February 15. Retrieved from: http://www.ode.state.or.us/gradelevel/pre_k/ka_advisory_committee_outcomes_f eb15.

Oregon Department of Education. (2015c). [PowerPoint Slides]. Kindergarten Assessment Training 2015-16. Retrieved from: http://www.ode.state.or.us.search/page/?id-2477.

Oregon Department of Education. (2016) Preschool Promise Legislative Report, 2016, January. Retrieved from: https://olis.leg.state.or.us/liz/2015I1/Downloads/CommitteeMeetingDocument/82 278.

Oregon Department of Education. (2017) Oregon's Early Learning and Kindergarten Guidelines, 2017. Retrieved from: http://www.oregon.gov/ode/students-andfamily/FullDayK/Documents/ODE_EarlyLearningStandards_final.pdf.

Parnell, W. (2010). Image of the teacher in educational leadership. International Journal of Educational Leadership Preparation. 
Parnell, W. (2011a). Experiences of teacher reflection: Reggio inspired practices in the studio. Journal of Early Childhood Research, 10(2), 117-133.

Parnell, W. (2011b). Teacher Collaboration Experiences: Finding the Extraordinary in the Everyday Moments. Early Childhood Research \& Practice, 13(2), n2.

Parnell, W., Iorio, J. (2018). Vivid Life and Learning: Rendering thorough Illustrations Rather Than Chopping Human Stories to Bits. In W. Parnell \& J. Iorio (Eds.), Meaning Making in Early Childhood Research: Pedagogies and the Personal. Springer. Retrieved from: https://www.routledge.com/Meaning-Making-in-EarlyChildhood-Research-Pedagogies-and-the-Personal/Iorio-ParnellYelland/p/book/9781138238527.

Peters, L., Ortiz, K., \& Swadener, B.B. (2015). Something Isn't Right, In J. M. Iorio \& W. Parnell (Eds.), Rethinking Readiness in Early childhood education; Implications for Policy and Practice. New York, New York: Palgrave Macmillan.

Piaget, J. (1954) The Construction of Reality in the Child. (Trans M Cook). Basic Books, Inc.

Piaget, J. (1977). The development of thought: Equilibration of cognitive structures. (Trans A. Rosin). Viking.

Piaget, J. (1979). Piaget on Piaget: the epistemology of Jean Piaget. Yale Broadcast \& Media Center. Retrieved from: https://www.youtube.com/watch?v=0XwjIruMI94. 
Pitre, N. Y., Kushner, K. E., Raine, K. D., \& Hegadoren, K. M. (2013). Critical feminist narrative inquiry: Advancing knowledge through double-hermeneutic narrative analysis. Advances in Nursing Science, 36(2), 118-132.

Pitre, N. Y., \& Kushner, K. E. (2015). Theoretical triangulation as an extension of feminist intersectionality in qualitative family research. Journal of Family Theory \& Review, 7(3), 284-298.

Poglitsch, M., \& Ryan, Kathleen O. (2008). Preschoolers series: Preschoolers (overview) (Education in video). Chicago: Learning Seed.

Preschool Teacher.org (2016). Oregon Preschool Teacher Salaries. Retrieved from: http://www.preschoolteacher.org/oregon/oregon-salary.

Rinaldi, C. (2001a). Two Reflections About Documentation. In L. Gandini, \& C. P. Edwards, (Eds.), Bambini: The Italian approach to infant/toddler care (pp.124145). Teachers College Press.

Rinaldi, C. (2001b). Documentation as Assessment: What is the Relationship? In C. Giudici, C. Rinaldi, \& M. Krechevsky (Eds.) (2001). Making learning visible: Children as individual and group learners. Cambridge, MA: Project Zero, Harvard Graduate School of Education.

Rinaldi, C. (2006). In dialogue with Reggio Emilia: Listening, researching and learning. Psychology Press.

Rinaldi, C. (2012). Pedagogy of Listening: The listening perspective from Reggio Emilia. In C. Edwards, L, Gandini, and G. Forman (Eds.), The Hundred Languages of 
Children, the Reggio Emilia Experience in Transformation, Third Edition (pp. 187-211). Santa Barbara, CA: Praeger.

Rinaldi, C., \& Gardner, H. (2001). Making Learning Visible. Reggio Children, Reggio Emilia.

Rintakorpi, K. (2016). Documenting with early childhood education teachers: pedagogical documentation as a tool for developing early childhood pedagogy and practises. Early Years, 1-14.

Rintakorpi, K., \& Reunamo, J. (2016). Pedagogical documentation and its relation to everyday activities in early years. Early Child Development and Care, 1-12.

Schulz, R., Schroeder, D., \& Brody, C. M. (1997). Collaborative narrative inquiry: Fidelity and the ethics of caring in teacher research. International Journal of Qualitative Studies in Education, 10(4), 473-485.

Schultz, M. (2015) The Documentation of Children's Learning in Early childhood education. Children \& Society, 29 (3), pp. 209-218.

Schweinhart, L. J., \& Weikart, D. P. (1997). The High/Scope preschool curriculum comparison study through age 23. Early childhood research quarterly, 12(2), $117-143$

Seattle Preschool Program. (2017). Program Overview. Retrieved from: https://www.seattleschools.org/cms/One.aspx ?portalId=627\&pageId=33649617. Seattle Preschool Program. (2017). Our Philosophy. Retrieved from: https://www.seattleschools.org/departments/early_learning/preschool/seattle_pres chool_program/our_philosophy. 
Shonkoff, J. P., \& Phillips, D. A. (2000). From neurons to neighborhoods: The science of early childhood development. National Academy Press, 2101 Constitution Avenue, NW, Lockbox 285, Washington, DC 20055.

Singer, D. G.; Revenson. T. A. (1997). The Piaget Primer, How a Child Thinks, Revised Addition. New York, NY: International Universities Press, Inc.

Souto-Manning, M. (2014). Critical narrative analysis: the interplay of critical discourse and narrative analyses. International Journal of Qualitative Studies in Education, 27(2), 159-180.

Spector-Mersel, G. (2011). Mechanisms of selection in claiming narrative identities: A model for interpreting narratives. Qualitative Inquiry, 17(2), 172-185.

State of the Union Address, 2013. (n.d.). Retrieved October 14, 2015, from https://www.whitehouse.gov/the-press-office/2013/02/12/remarks-president-stateunion-address.

Strozzi, P. (2015, March). Messages for the Planet. In the North American Reggio Emilia Study Tour. Reggio Emilia, Italy.

Teaching Strategies, LLC (2000) Teaching Strategies GOLD $(R)$ Basic Online. (n.d.) Retrieved January, 22, 2017, from: https://www2.teachingstrategies.com/myaccount/pd_modules.cfm?userCourseID $=44662$.

Teaching Strategies, LLC. (2010). Research-Foundation: Teaching Strategies GOLD® Assessment System. Washington DC. 
Teaching Strategies LLC. (2012). Teaching Strategies GOLD® Online: Time-Saving Features. Washington DC.

Teaching Strategies, LLC. (2013). GOLD® Online Guide for Administrators. Washington DC.

Teaching Strategies, LLC. (2014) - Teaching Strategies GOLD® Touring Guide. Washington DC.

Teaching Strategies LLC. (2015a). Teaching Strategies GOLD® Reports. Washington DC.

Teaching Strategies LLC (2015b). GOLDplus ${ }^{\mathrm{TM}}$ Touring Guide. Washington, DC.

Teaching Strategies, LLC. (2016). Help: Entering Checkpoint Levels on a Progression Screen. Washington DC.

Teaching Strategies, LLC. (2017a) Teaching Strategies GOLD® Head Start. Retrieved from: https://teachingstrategies.com/markets/head-start/.

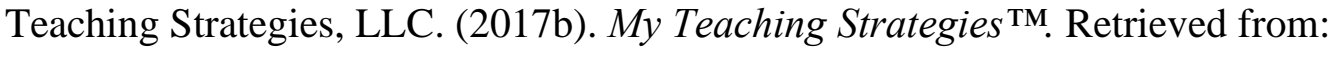
https://teachingstrategies.com/goldplus/.

Teaching Strategies, LLC. (2018). How-to Guide for Teachers. Retrieved from: https://teachingstrategies.com/wpcontent/uploads/2017/05/MyTeachingStrategies-How-To-Guide-for-Teachers.pdf.

Thornton, L., \& Brunton, P. (2015). Understanding the Reggio approach: Early years education in practice. New York, New York: Routledge, Taylor \& Francis Group.

Vannest, K. J., Mahadevan, L., Mason, B. A., \& Temple-Harvey, K. K. (2009). Educator and Administrator Perceptions of the Impact of No Child Left Behind on Special 
Populations. Remedial and Special Education, 30(3), 148-159.

http://doi.org/10.1177/0741932508315378.

Vecchi, V. (2010). Art and creativity in Reggio Emilia: Exploring the role and potential of ateliers in early childhood education. New York, New York: Routledge.

Vygotsky, L. (1962). Thought and Language. Cambridge, Massachusetts: The Massachusetts Institute of Technology.

Vygotsky, L. S. (1978). Mind and society: The development of higher mental processes. Cambridge, Massachusetts: Harvard University Press.

Wang, L., Beckett, G. H., \& Brown, L. (2006). Controversies of standardized assessment in school accountability reform: A critical synthesis of multidisciplinary research evidence. Applied Measurement in Education, 19(4), 305-328.

Wells, K. (2011). Narrative inquiry. Oxford University Press, USA.

Wilterdink, N. A. (2002). The sociogenesis of postmodernism. European Journal of Sociology/Archives Européennes de Sociologie, 43(2), 190-216.

Wolk, S. (2007). Why go to school?. Phi Delta Kappan, 88(9), 648-658.

Zeeman, L., Poggenpoel, M., Myburgh, C. P. H., \& Van der Linde, N. (2002). An introduction to a postmodern approach to educational research: Discourse analysis. Education, 123(1), 96-103. 


\section{Appendix A: Introduction Email}

Participant Recruitment E-mail:

Dear XXXXX,

My name is Sally Guyon and I am an Education Doctorate student at Portland State University in Portland, Oregon. I received your name from Dr. XXXX that you may be interested in participating in my dissertation research. The purpose of this dissertation is to collect and understand the experiences of self-identified constructivist early childhood educators who are required by their place of practice to work with the preformatted, portfolio style assessment system Teaching Strategies GOLD®. Or in other words, to give the early childhood educators who are required to use Teaching Strategies GOLD® an opportunity to tell their stories about their experiences in using this system, a chance for their voices to be heard. If you would like to share your story too, please e-mail me back with a phone number and convenient time to call. I look forward to hearing from you.

Sally Guyon

skguyon@pdx.edu

503.764 .8747 


\section{Appendix B: Participant Screening Questions}

\section{Participant Recruitment Screening Questions:}

1. Are you currently working with children between the ages of 0-72 months?

2. Have you worked in the field of early childhood education for five or more years?

3. Do you believe that children are able to construct knowledge through interactions with objects and others?

4. Have you seen children construct knowledge through interactions with objects and others in your classroom?

5. Do you identify as a constructivist early childhood educator?

6. Are you required by your program/school/place of practice to use the Teaching Strategies GOLD® on-line assessment system?

7. Have you been using Teaching Strategies GOLD® for a year or more?

8. Would the researcher be allowed to observe you in your place of practice for a day? (There would be no photography, and the center/program would only be named in the most generic of terms such as "a large corporate early childhood education program located in the Pacific Northwest")

9. In this study the participants are asked to be co-researchers. By joining research study, you will be asked to share your experiences as a self-identified constructivist early childhood educator required by their place of practice to use the Teaching Strategies GOLD® assessment system with me, reflect on your work with young children, and revisit the stories you share with me. Is this something you are willing to do?

10. Participants in this study will be asked to meet with me in person six times between the months of January and May 2018. Twice will be for narrative interviews which will last for about 60 minutes each. Once will be for a field observation in your classroom, and three times will be for reflective conversations for about 45 minutes each. These meetings may need to take place in the evening or on weekends. Are you willing to commit to this amount of time? 


\section{Appendix C: Congratulations Email}

\section{Congratulations Email}

Dear [Participant],

Thank you for your interest in joining my research study! I am pleased to let you know that you will be one of the three participants! Attached please find a consent form and contact information sheet. Please complete both forms and email them back to me at your earliest convenience. If you have any questions, please contact me.

Kind Regards,

Sally Guyon

skguyon@pdx.edu

(503) 764-8747 


\section{Appendix D: Participant Consent Form}

\section{$\underline{\text { Participant Consent Form }}$}

\section{$\underline{\text { Sarah Guyon }}$}

Exploring Experiences of Self- Identified Constructivist Early Childhood Educators who are required to use the Teaching Strategies GOLD® assessment system.

Title of Study:

The purpose of this study is to explore the experiences of self-identified constructivist early childhood educators required their place of practice to work with the preformatted, portfolio style assessment system, Teaching Strategies GOLD®.

\section{Researcher:}

Sarah (Sally) Guyon

503.764.8747

skguyon@pdx.edu

\section{Background:}

You are being invited to take part in a research study! Before you decide to participate in this study, it is important that you understand why the research is being done and what it will involve. Please take time to read the following information carefully and ask the researcher if there is anything that is not clear to you.

The purpose of this study is to explore the experiences of self-identified constructivist early childhood educators required by their place of practice to work with the preformatted, portfolio style assessment system, Teaching Strategies GOLD®.

\section{Study Procedure:}

Research will be conducted over six to eight months. Participants will be asked to participate in two narrative interview conversations and three reflective conversations with the researcher. The participant will also be observed by the researcher one day in the participant's place of practice.

Each interview conversation will take approximately 60 minutes. Participants will be encouraged to reflect on the conversation and make notes of any subjects or areas that they would like to continue in the next conversation. A reflective conversation will take place approximately two weeks later. The reflective conversation is an opportunity for 
the researcher to share and discuss with the participant about what the researcher saw, heard and connected to during the narrative interview and for the participant to share their reflections as well.

The field observation will take place at the participant's place of practice and the participant's convenience. The purpose of the field observations will be to deepen the researcher's understanding of the participant. A reflective conversation will take place after the field observation. The purpose of the reflective conversation will to give the participant the opportunity to reflect on the day and share those reflections with the researcher.

A second narrative interview will take place about six to eight weeks after the field observation and will last about 60 minutes. The second interview will be an opportunity for the participants to share additional stories about their work an expand in ideas shared before. It will also be an opportunity for the researcher and the participant to share any new feelings, thoughts, or opinions that have surfaced while doing this research.

\section{Benefits:}

The benefit of this project for the individual participants of this study would grow professionally having the opportunity to discuss and reflect about their experiences of working with the Teaching Strategies GOLD system and their work with young children.

\section{Confidentiality, How is participant's (your) privacy protected:}

For the purpose of this research project, your interview will be confidential unless you give permission for the use of your identity. Every effort will be made by the researcher to preserve your confidentiality including the following:

- Assigning code names and numbers to all participating individuals that will be used on all researcher notes and documents

- Notes, audio, transcriptions, transcribed notes, and any other identifying participant information will be kept in a locked file cabinet in the personal possession of the researcher. When no longer necessary, all materials will be destroyed. Collages will be returned to you if desired.

- Information from this research study will be used solely for the purpose of this study and any publications that may result from this study. Any final publications will remain confidential unless you have agreed to waive confidentiality.

- You have the opportunity to obtain a transcribed copy of their interview and photos of their collage. Please tell the researcher if a copy of the interview and photos of the collage are desired. 
To protect the privacy of the participants in this study the participants will have the option of using pseudonyms as identifiers during the focus group conversation. Program identifiers will not be used during focus group, data analysis, or the dissertation accept in generic terms. Any group correspondence will be sent blind.

All narrative interview conversations and reflective conversations will be audio recorded. The recordings will be stored in two places; the researcher's personal laptop, and on an external hard drive. Electronic copies of written transcripts will also be secured on the researcher's personal laptop and on an external hard drive.

Voluntary Participation:

Your participation in this study is voluntary. It is up to you to decide whether or not to take part in this study. If you do decide to take part in this study, please sign this consent form. You are still free to withdraw at any time and without giving a reason. You are free to not answer any question or questions if you choose. Your decision whether or not to participate in this study will not affect the relationship you have with the researcher.

\section{Consent:}

By signing this consent form, I confirm that I have read and understood the information and have had the opportunity to ask questions. I understand that my participation is voluntary and that I am free to withdraw at any time, without giving a reason and without cost. I understand that I will be given a copy of this consent form. I voluntarily agree to take part in this study.

Participant's Signature Date

Researcher's Signature Date 


\section{Appendix E: Participant Contact Sheet}

$\underline{\text { Participant Contact Information Sheet: }}$

Name:

Preferred phone number:

$\underline{\text { Preferred e-mail address: }}$

Preferred method of contact (email, phone call, text, or other):

Best time to reach you:

Place of practice (where you work):

Hours you work:

Best time(s) to meet: 


\section{Appendix F: Program Site Permission Form}

\section{$\underline{\text { Program Site Permission Form }}$}

Dear Program Administrator,

My name is Sally Guyon and I am an Education Doctorate student at Portland State

University in Portland, Oregon. XXXXX, an early childhood educator in your program, has elected to take part in my dissertation research study. The purpose of this study is to explore the experiences of self-identified constructivist early childhood educators required by their place of practice to work with the preformatted, portfolio style assessment system, Teaching Strategies GOLD®.

As part of the research process, a field observation will take place during late February and early March 2018 at the participant's place of practice and the participant's convenience. An exact date and time will be coordinated through the participant, the program administrator, and the researcher.

The purpose of the field observation will be to deepen the researcher's understanding of the participant by observing the ways in which the participant works with children and the ways in which they may or may not incorporate strategies and knowledge gained from Teaching Strategies GOLD into their work. A reflective conversation will take place after the field observation. The purpose of the reflective conversation will to give the participant the opportunity to reflect on the day and share those reflections with the researcher.

The field observation will be conducted in two-hour 'chunks', taking 45 minutes between each chunk to reflect and write a retelling of what the researcher observed during the observation time. During the field observation, the researcher will take notes regarding the physical environment and the interactions between the participant and other individuals in the classroom. These notes will be recorded in the researcher's personal research notebook. No photographs will be taken, and any audio recordings will be with the permission of the participant and for the researcher's reflection only. All information will remain strictly confidential.

To protect the privacy of the participants in this study the participants will have the option of using pseudonyms as identifiers during the focus group conversation. Program identifiers will not be used accept in generic terms. 
Interaction with the children will be minimized, however, you should be aware that the researcher is a mandated reporter by Oregon law and confidentiality is not protected if the researcher is legally required to make a report on an incident involving a child.

If you have any questions, please contact me. By signing this consent form, you are confirming that you have read and understood the information provided and give permission for the researcher to observe [participant's name] for the purposes as indicated above.

(Administrator's Signature and Printed Name)

(Date) 


\section{Appendix G: First Interview Questions}

First Interview Conversation: (approximately 60 minutes)

The first narrative interview conversation will begin by reviewing the IRB, addressing any questions the participant may have about the research procedures, and having the participant and the researcher each sign two copies of the IRB and consent form.

Next the researcher will ask the participant a series of questions to expand on the screening phone call questions. These questions may include:

- Please tell me the story of how you became an early childhood educator.

○ How long have you been in the field?

○ What sort of programs have you worked for?

- What age(s) of children have you worked with?

- What do you like best about this profession?

- What do you struggle with the most in this profession?

- What is your educational background?

- In our phone conversation you told me that you self-identify as a constructivist early childhood educator, what does that mean to you?

○ How did you become to believe this?

- Tell me a story of when have you seen these beliefs in practice.

$\circ$ What are your reflections about this story?

- Please tell me about where you work currently.

o What type of program is it?

- How long have you worked there?

○ What age children do you work with?

$\circ$ How is the program structured?

○ When do the children transition to new classrooms and/or teachers?

- In our phone conversation you said that the program where you work requires you to use Teaching Strategies GOLD®, how long has this program used Teaching Strategies GOLD®?

○ How did the implementation with Teaching Strategies GOLD® come about?

$\circ$ What sort of training or support did you receive when the system was first implemented or when you started?

- What sort of additional training or support have you received?

- How often is additional training or support offered? Is it required or optional?

- How many checkpoint dates does your program do each year?

- What requirements has the program where you work set around Teaching Strategies GOLD® and checkpoint dates?

○ What sort of time/scheduling structures have been created for you to use Teaching Strategies GOLD®? 
- Please tell me about your history with Teaching Strategies GOLD®.

- How do you use the system when working with the children in your care?

○ What do you find helpful or supportive?

- What do you struggle with?

- How would an administrator at your program describe the ways in which the teachers use Teaching Strategies GOLD® at your program?

$\circ$ Why do you think there is this difference?

- What else would you like to share with me? 


\section{Appendix H: Observation Form}

$\underline{\text { Sample Observation Form for Field Observations }}$

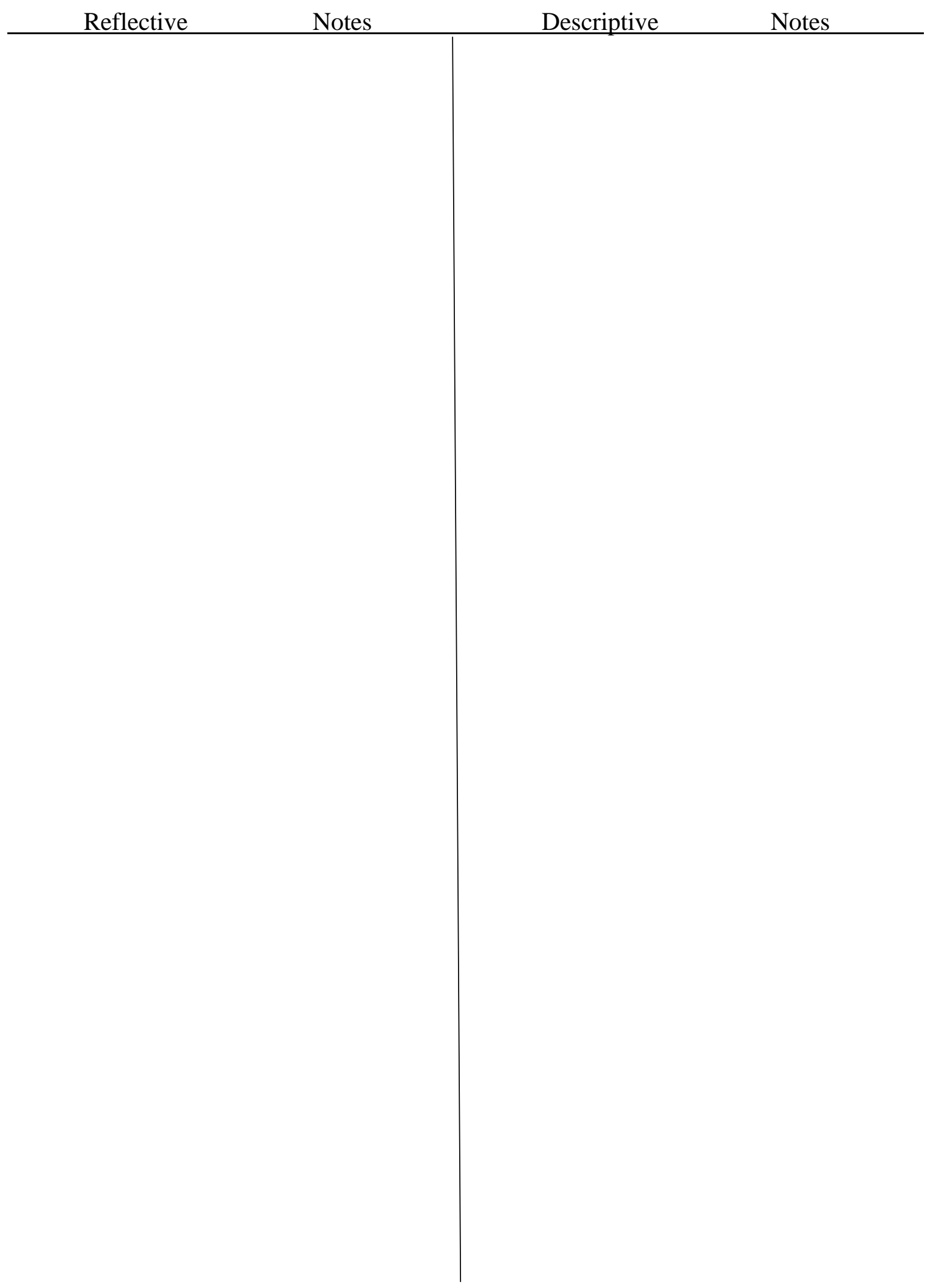




\section{Appendix I: Sample Second Interview Questions}

$\underline{\text { Second Interview Conversation (approximately } 60 \text { minutes) }}$

The purpose of the second narrative interview will be for the participant to have an opportunity to share additional stories about their work and expand on ideas that they shared before. It will also be an opportunity for us to share any new opinions, feelings, or thoughts that have surfaced while doing this research.

The researcher will begin the conversation by informally reviewing the notes form the earlier interactions; the first interview and reflective conversation, and the field observation and reflective conversation. The researcher will mention the snippets that seemed important to the participant and ask the participant to elaborate on, or correct the researcher's interpretation. Possible conversation prompts may include:

- These were some of the areas of consistency that I noticed in our initial interview, the field observation, and the follow up reflective conversations about your work....

- Does this seem to be an authentic portrayal of your professional self?

- What is different or the same to how you have always viewed yourself as an early childhood educator?

○ What does this interpretation make you wonder?

- These were some of the areas that did not seem consistent between our initial interview, the filed observation, and the follow up reflective conversations about your work....

- What is surprising to you?

○ Would you agree or disagree, why/why not?

○ Why do think there is this inconsistency?

- What are your thoughts about the ways you use Teaching Strategies GOLD®?

○ Do you see any effect that the required use of Teaching Strategies GOLD® has had on the way you look at children's learning and development? Please explain

- Is this similar or different than what you thought before participating in this research study?

- What does it make you wonder about? 
- What else would you like to tell me? 


\section{Appendix J: Data Coding}

$\underline{\text { Note Abbreviations for data interpretation }}$

Temporal Commonplace:

Tps Temporal, past

Tpr Temporal, present

Tfc Temporal, future considerations

Sociality Commonplace:

Ssi Sociality, social, institutional

Ssc Sociality, social, cultural

Ssf Sociality, social, familial

Spn Sociality, personal, inward

Spo Sociality, personal, outward

$\underline{\text { Place Commonplace }}$

PL Place 


\section{Appendix K: Julia's Final Prompts}

Julia's final interview conversation prompts:

During our conversations together, I had built an idea of how you see yourself as an early childhood educator. This image was built from how you described your experiences, your education, and your beliefs about how children learn. The image I have is of a well-educated, well-experienced individual who was thoughtful and intentional in her work with young children. I also see a strong sense of yourself as an advocate for children's learning and experiences, and the right for teacher autonomy. This is the image of you I carried into your classroom for your observation.

1. Some of the areas that I saw consistency with this image were how you worked with the children during transitions. I know from our conversations that during transition times you were expected to implement the "Mighty Minutes" from Creative Curriculum ${ }^{\circledR}$ but that you were opposed to those times being artificial. Instead during those times I saw genuine interactions with the children intertwined with necessary management of the time. I also saw a consistency during mealtimes. During these times the children led the conversation and the exchanges around the table were respectful and engaging. You also did not force conversation during these times and the quietness was comfortable. A third time I saw consistency was during your circle time. I find circle time fascinating in itself as I feel as if it is a time that teachers feel as if they should have the control. During your circle time you had a definite plan and followed through with it, however you were comfortable with letting the children sit or lay down however they wanted, and although you encouraged them to raise their 
hands, if they shouted out responses instead of waiting to be called on you still listened intently to their answer and recorded it along with the others. The final area I saw consistency between my image of you as an early childhood educator and what you did in the classroom was the autonomy and independence the children displayed in the classroom. There was a strong feeling of partnership and respect between you and the children.

a. Does my image of you as an early childhood educator seem to be an authentic portrayal of your professional self?

b. What is different or the same to how you view yourself as an early childhood education professional?

c. What does this interpretation make you wonder?

2. The times that what I saw during the observation were inconsistent with my image of you as an early childhood educator were times in which you were confined with what you were doing because you needed to follow the schedule, routine, or plan. This was most evident during the apple art project. Throughout the day you were having meaningful conversations with the children. During the apple art project you asked and answered questions and supplied them with additional materials, but you didn't get into that sort of deeper thought or conversation with them. You seemed disengaged, or unenthusiastic with the activity and the children in turn seemed disengaged and unenthusiastic. I don't believe any of them stayed for more than a few moments.

a. Is this observation surprising to you? 
b. Why or why not?

c. What does this interpretation make you wonder?

3. Based on this conversation and your experiences, what are some of your thoughts about the ways in which you used Teaching Strategies GOLD® in the classroom?

a. Do you see any effect that the required use of Teaching Strategies GOLD® has had an effect on the way you look at children's learning and development? Please expand.

b. Is this similar or different than what your thoughts were before participating in this research study?

c. What does it make you wonder about?

4. What else would you like to tell me? 


\section{Appendix L: Sasha's Final Prompts}

Sasha's final interview conversation prompts:

During our conversations together, I had built an idea of how you see yourself as an early childhood educator. The image was built from how you described your experiences, your education, and your beliefs about how children learn. The image I have is of a teacher who is confident in her knowledge of children and has a deep respect, love, and joy of children. I also see ways in which you use your confidence in your knowledge about children as a platform in which you advocate for the children in your classroom. I saw this in the experiences you described in your last center. There is a term, the "teacher-researcher" that gets tossed around and misunderstood a lot. Being a teacherresearcher not only means doing research with children, it means doing research about the children in your classroom. You are interested in more than if a child can do a skill, you are someone who was curious about each child and what each child was thinking. This is the image of you I carried into your classroom for your observation.

1. I saw consistency between this image and what you did in the classroom throughout the day. Your deep joy, respect, and love for children came through in the ways I saw you interact with them. You listened intently, asked questions, made observations that built on what they had told you, and took your time with them. You were truly present. I saw this most strongly when you were talking with the three boys who had built the fortress in the block area. You moved into the area to remind the children to have morning snack but then spent almost 10 minutes in conversation with them about what they had created. During this time, as with other times in the room that 
you were in conversation with children, you did not seem worried about the time or other things going on around you. It was the same as you worked with the child writing the lava soup recipe and when you were working with the children with the letter and number blocks at the table.

a. Does my image of you as an early childhood educator seem to be an authentic portrayal of your professional self?

b. What is different or the same to how you view yourself as an early childhood professional?

c. What does this interpretation make you wonder?

2. I didn't really see times in which you were inconsistent with my image of you as an early childhood educator and I wondered about this a lot. During the day that I observed with you, you did not have a structured group time planned using one of the Creative Curriculum ${ }^{\circledR}$ Intentional Teaching cards. I found myself wondering how she would respond to the children during these pre-formatted interactions, and what she would do if the children's explorations, questions, and curiosities broke away from what was on the cards. I also wondered about the different ways that you and your coteacher interact with the children. She has this sort of bigger picture, structure of the day, large group focus whereas yours is much more individualized and in the moment. The styles compliment each other so well because since she is focused on the bigger picture, you can focus on the in the moment and because you are focused on the individual, she has the opportunity to look at the day or class as a whole.

a. Is this observation surprising to you? 
b. Why or why not?

c. What does this interpretation make you wonder?

3. Based on this conversation and your experiences, what are some of your thoughts about the ways in which you used Teaching Strategies GOLD® in the classroom?

a. Do you see any effect that the required use of Teaching Strategies GOLD® has had an effect on the way you look at children's learning and development? Please expand.

b. Is this similar or different than what your thoughts were before participating in this research study?

c. What does it make you wonder about?

4. What else would you like to tell me? 


\section{Appendix M: Cynthia's Final Prompts}

Cynthia's final interview conversation prompts:

During our conversations together, I had built an idea of how you see yourself as an early childhood educator. This image was built from how you described your experiences, your education, and your beliefs abut how children learn. You were especially intriguing to me because from our conversations I had developed two conflicting images. The first was the image of you as an early childhood educator was as someone who had a deep love and respect for children. You were confident in your beliefs about how children learn and the importance of supporting children's social and emotional development.

The second was an image of you as an early childhood educator was in the context of Teaching Strategies GOLD ${ }^{\circledR}$ and Creative Curriculum ${ }^{\circledR}$. In this image I didn’t see that confidence. You seemed defeated, almost trapped within your circumstances, and highly conflicted with your beliefs about early childhood education and the pressure to conform to the parameters being put on you through the implementation of Teaching Strategies GOLD®. It was these two images of you that I carried with me into your classroom for your observation.

After being in your classroom, and watching you with the children in your care, the first image is who I saw that day. I expected you to be stressed. I anticipated a day filled with rushing the children from one activity to the next. Yet I found that you are able to be your true self as an early childhood educator in your classroom and it was that image that I held when planning for this final interview conversation. 
1. Some of the areas that I saw consistency with this image were almost every single interaction you had with the children. You were deeply engaged and listening to what they were telling you. You confirmed what you thought they were saying, asked questions, and helped the children build on their thoughts and ideas. You saw them make connections and encouraged them in their thoughts. You were extremely caring. You hugged children when they wanted hugs, sat next to them and supported them through transitions, and helped them identify their feelings. This was most apparent when the one child moved the quiet space before circle. You told her to take her time and when she joined circle and wanted to participate in the way the other children had, you let her, even though you had just moved on from there. You promoted an atmosphere of respect, confidence, dignity, and ownership in the classroom. To me this center seems like your home, and the classroom seemed like the children's home as well.

a. Does my image of you as an early childhood educator seem to be an authentic portrayal of your professional self?

b. What is different or the same to how you view yourself as an early childhood education professional?

c. What does this interpretation make you wonder?

2. The times that what I saw during the observation were inconsistent with my image of you as an early childhood educator were times in which you were using the i-Pad. When you first began the letter activity during circle time, you were focused on the iPad and your interactions with the children were brief. As the children became 
engaged with the activity, you abandoned the i-Pad and your interactions became more genuine and deeper. The other moment was at the end of the children's Spanish language class when the children transitioned into free choice time. You had been using the i-Pad to work on Teaching Strategies GOLD® during the Spanish language class and stayed on the i-Pad as you finished a conference form for about 10 minutes during free choice time. One child tried to engage with you repeatedly during these 10 minutes and although you responded to the child and answered her questions, it wasn't until she had put the i-Pad away you she truly engaged with the child.

a. Is this observation surprising to you?

b. Why or why not?

c. What does this interpretation make you wonder?

3. Based on this conversation and your experiences, what are some of your thoughts about the ways in which you used Teaching Strategies GOLD® in the classroom?

a. Do you see any effect that the required use of Teaching Strategies GOLD® has had an effect on the way you look at children's learning and development? Please expand.

b. Is this similar or different than what your thoughts were before participating in this research study?

c. What does it make you wonder about?

4. What else would you like to tell me? 